UNIVERSIDAD PERUANA DE CIENCIAS APLICADAS

Facultad de Ingeniería

Escuela de Ingeniería de Sistemas y Computación

Carrera de Ingeniería de Sistemas de Información

\title{
MODELO DE MEJORAS DE E-SERVICIOS MUNICIPALES
}

\author{
TESIS \\ PARA OPTAR POR EL TÍTULO DE INGENIERO DE SITEMAS DE \\ INFORMACIÓN
}

AUTORES

García Girón, Allison Janisse (0000-0001-8397-0552)

Hinostroza Lozada, Raphel Xavier (0000-0003-3946-2854)

ASESOR DE TESIS

Velásquez Nuñez, Ángel Augustll (0000-0003-4702-2576)

Lima, Setiembre 2018 
Esta tesis esta dedicada a nuestras familias, cuyo apoyo se mantuvo incondicional durante nuestra vida universitaria y crecimiento profesional.

Gracias por todo. 


\section{Resumen Ejecutivo}

El gobierno electrónico es la implementación de las tecnologías de información y comunicación en los ámbitos gubernamentales con el fin de incrementar la eficiencia y efícacia de las funciones públicas de un país, contribuir con la transparencia e integridad de las administraciones públicas, y favorecer la relación entre el gobierno y los ciudadanos. Existen cinco fases, las cuales no son necesariamente consecutivas, pero contribuyen a mejorar la eficiencia y transparencia de las instituciones que implementen el gobierno electrónico. Estas fases son: Presencia, Interacción, Transacción, Transformación y Participación Democrática.

La Secretaría de Gobierno Digital, SeGDi, es el órgano rector del Sistema Nacional de Informática en el Perú. Es el encargado de formular y proponer políticas, normas, planes, lineamientos y estrategias en el ámbito informático y de Gobierno Electrónico. Pese a la existencia de un órgano rector de Gobierno Electrónico, no existe una guía de implementación para el mismo.

Este modelo de nombre Modelo de Mejoras de E-Servicios Municipales propone una guía de implementación del gobierno electrónico en municipalidades en base a servicios electrónicos, los servicios que las municipalidades ofrecen, pero de una manera digital y más rápida. Estos servicios electrónicos o e-servicios se encuentran alineados a las leyes peruanas con una serie de consideraciones tomadas en cuenta y con un diseño de implementación basada en la arquitectura empresarial TOGAF.

Palabras claves: e-servicios municipales, e-servicios, municipalidad, TOGAF. 


\begin{abstract}
E-government is the solution of information and communication technologies in public enterprises to increase the efficiency and effectiveness of the functions of the United Nations, collaborates with transparency and the conditions of public administrations, the government and the citizens. There are five phases, which are not necessarily consecutive, but do contribute to improving the efficiency and transparency of the institutions that implement e-government. These phases are: Presence, Interaction, Transaction, Transformation and Democratic Participation.
\end{abstract}

The Secretariat of Digital Government, SeGDi, is the governing body of the National Computer System in Peru. He is responsible for formulating and proposing policies, standards, plans, guidelines and strategies in the field of information technology and Electronic Government. There is no implementation guide for it.

This model named Model of Improvements of Municipal E-Services offers a guide of implementation of the electronic government in municipalities based on electronic services, the services that the municipalities offer, but in a digital and faster way. These electronic services or e-services are aligned to the Peruvian lines with a series of textbooks taken into account and with design of a solution in the TOGAF business architecture.

Key words: municipal e-services, e-services, municipality, TOGAF 


\section{Tabla de Contenido}

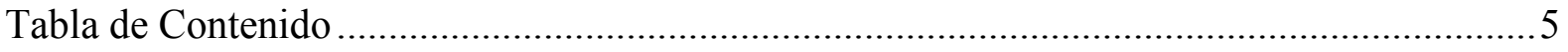

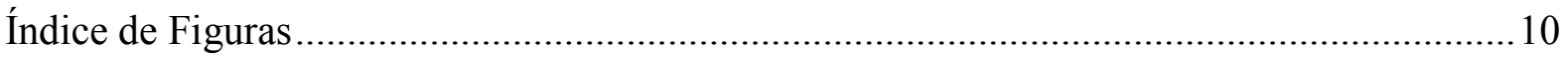

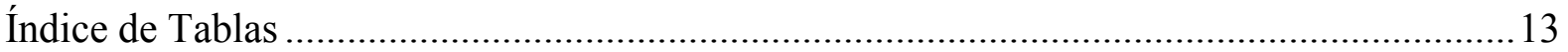

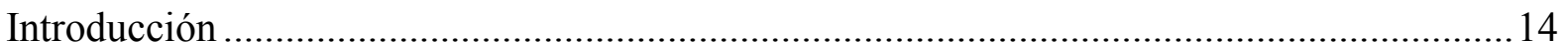

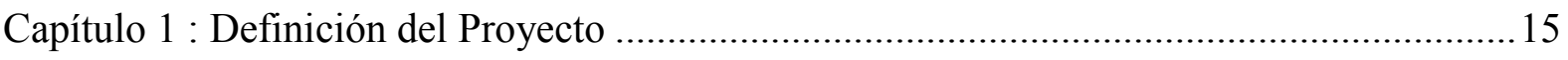

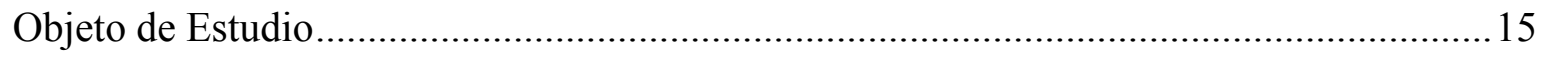

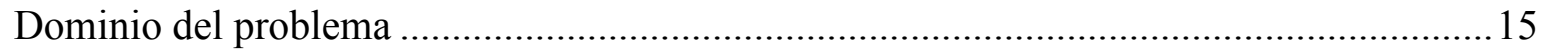

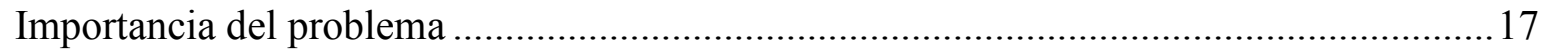

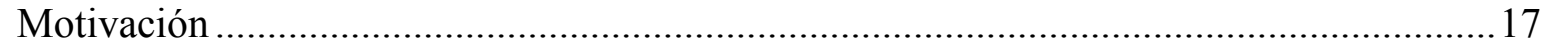

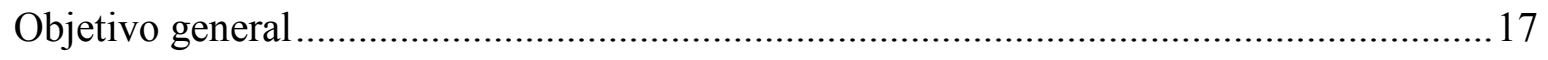

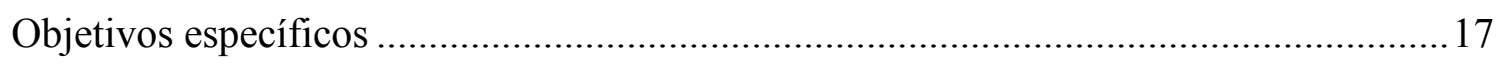

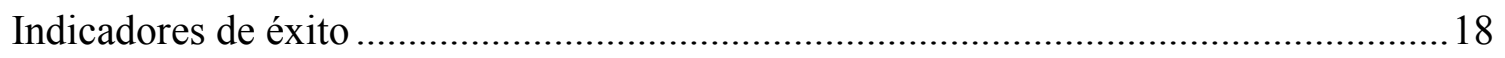

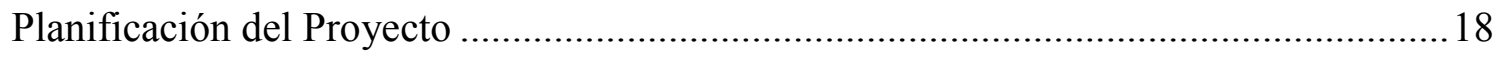

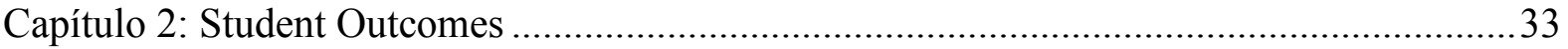

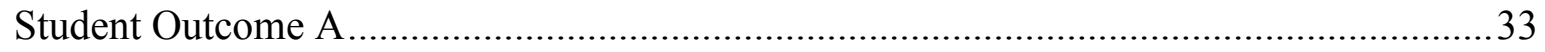

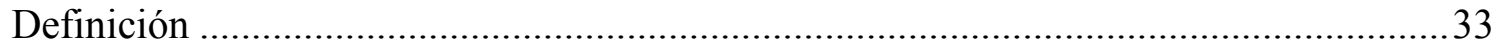

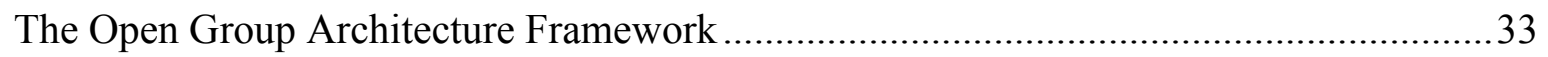

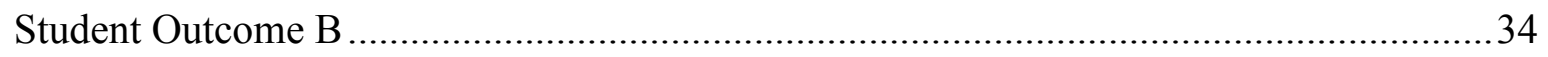

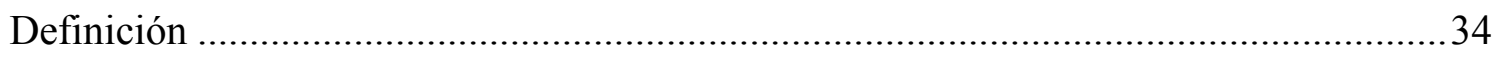

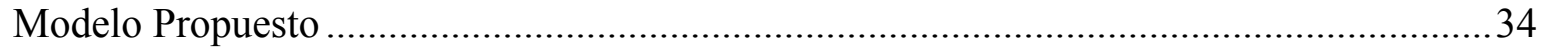

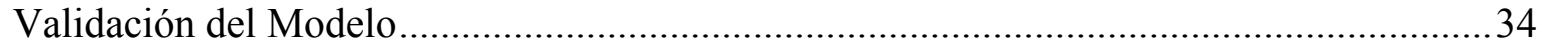

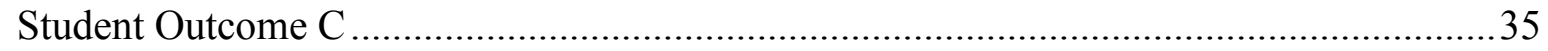

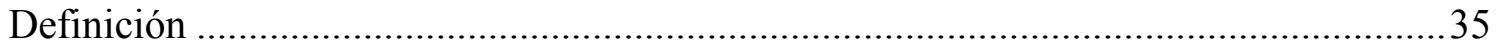

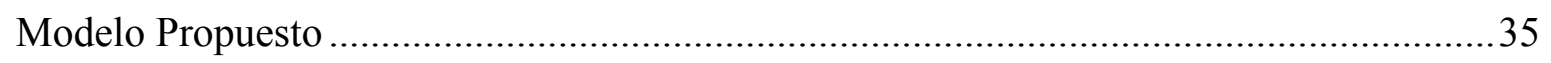

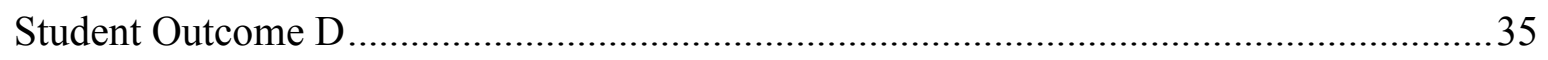

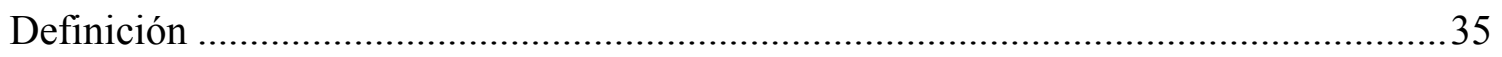

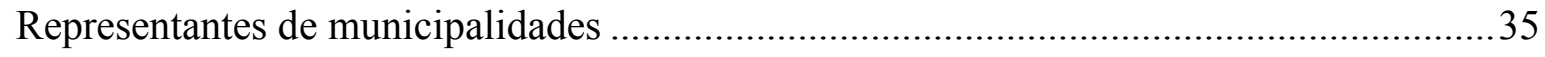

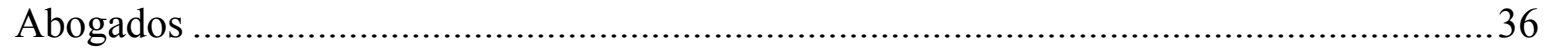

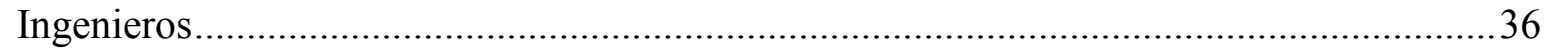




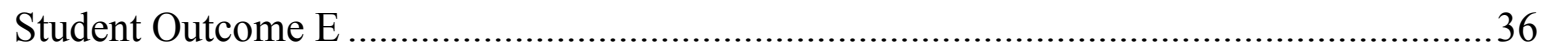

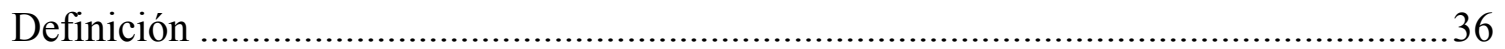

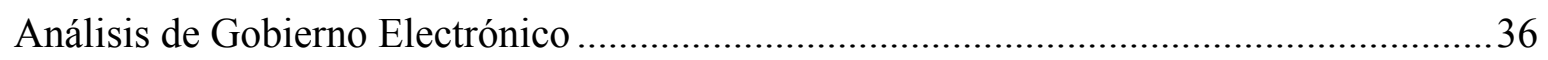

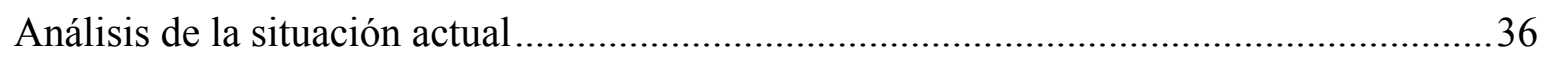

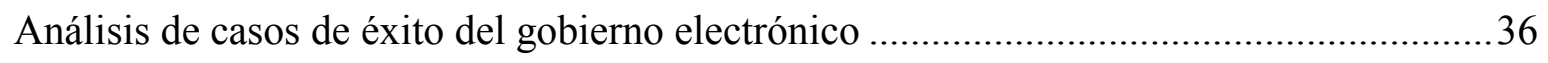

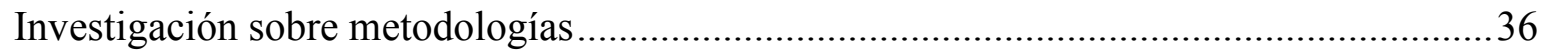

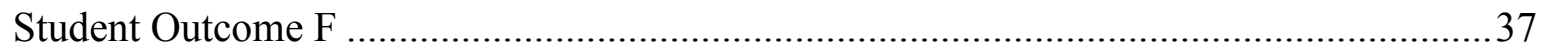

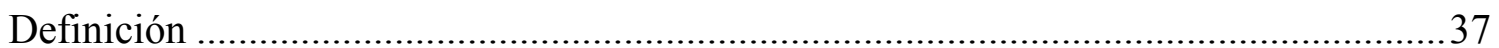

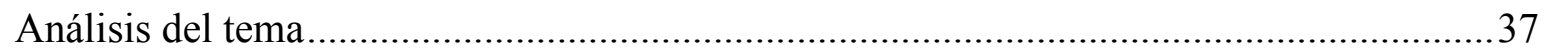

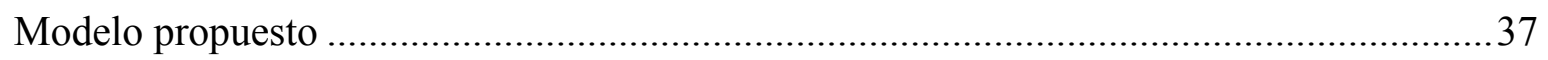

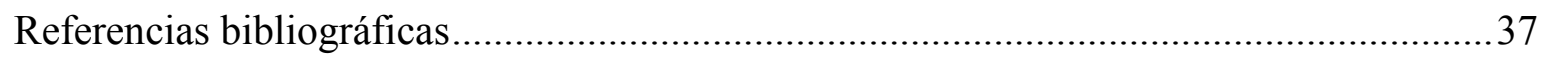

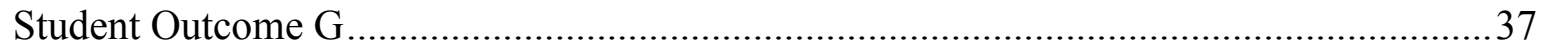

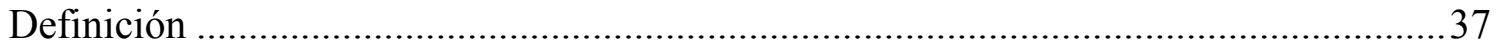

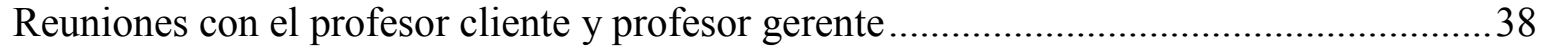

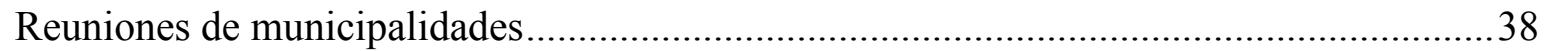

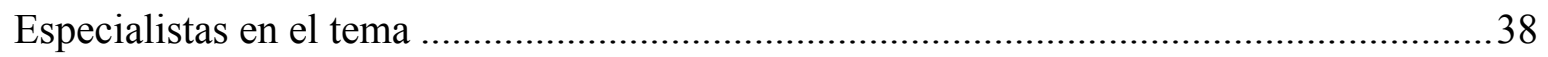

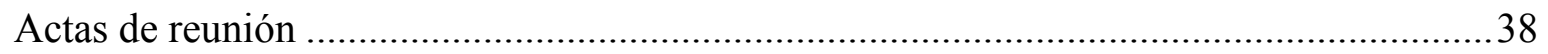

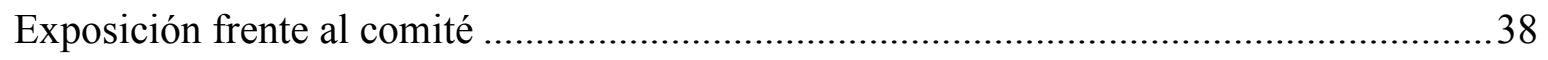

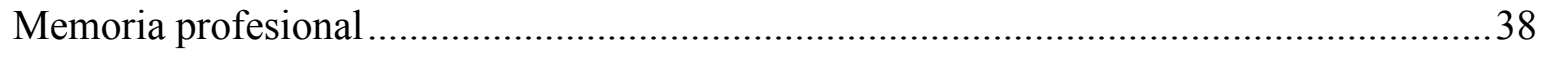

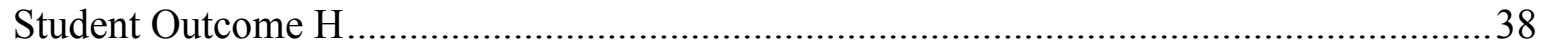

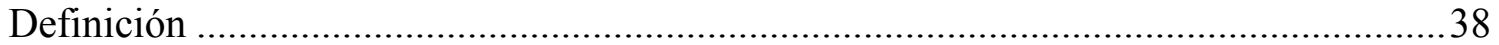

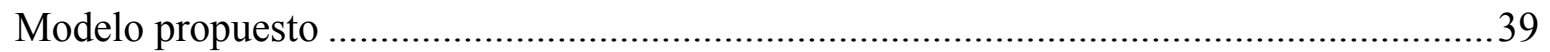

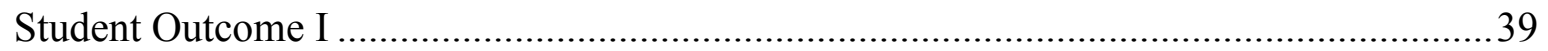

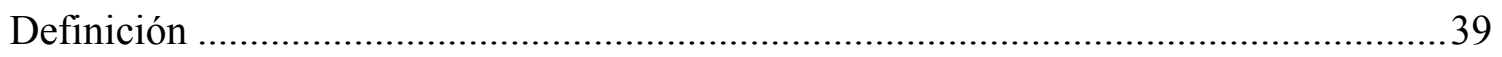

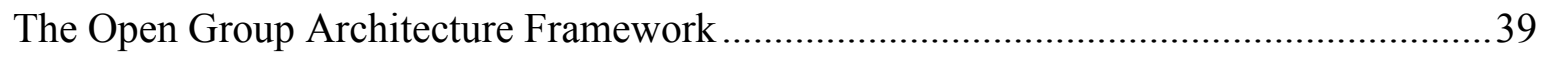

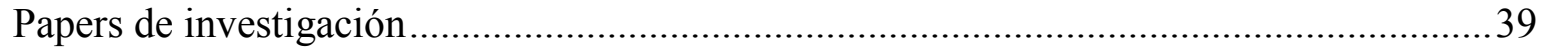

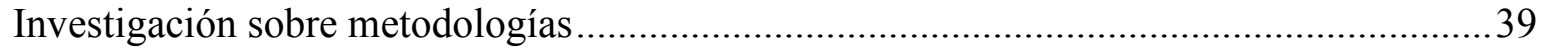

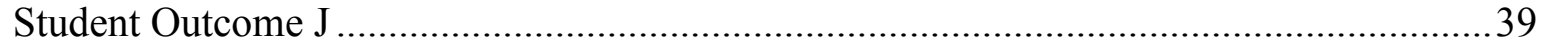

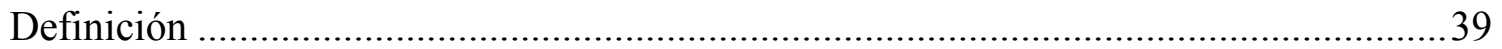

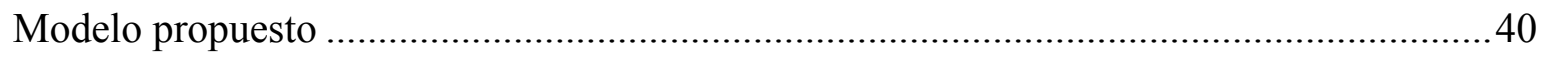

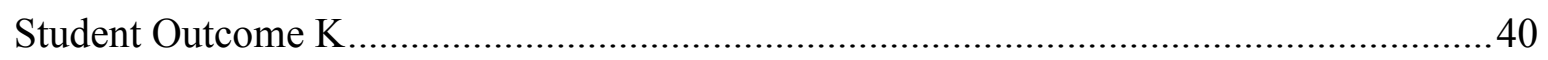

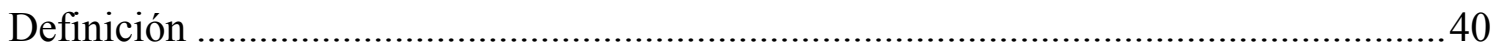

The Open Group Architecture Framework ............................................................. 40

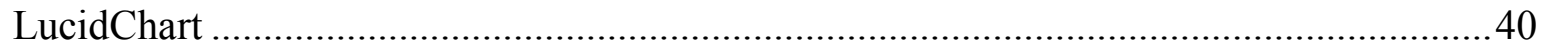




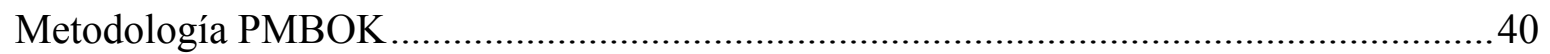

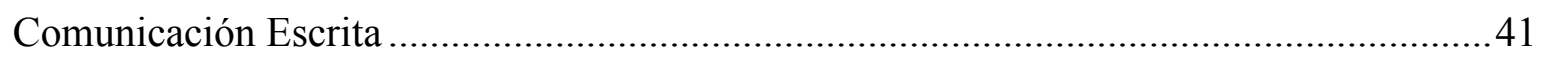

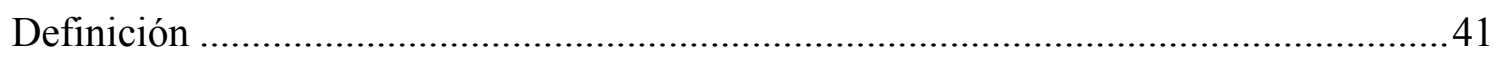

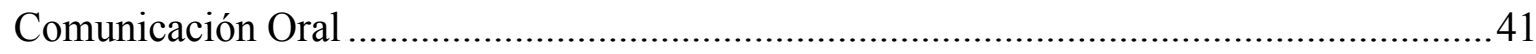

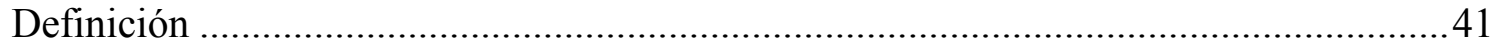

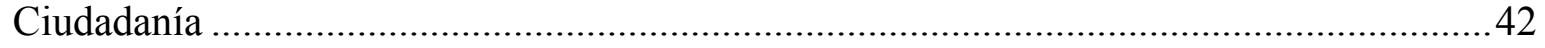

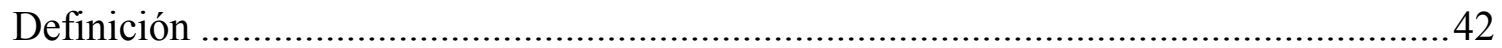

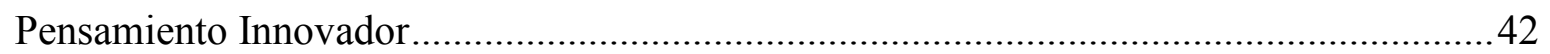

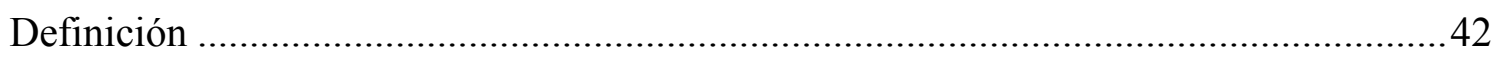

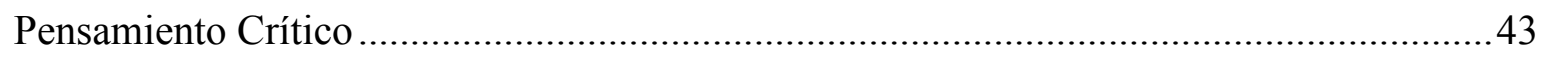

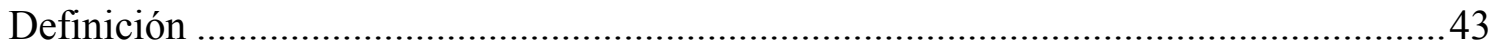

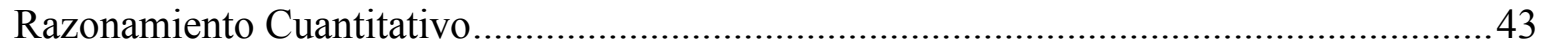

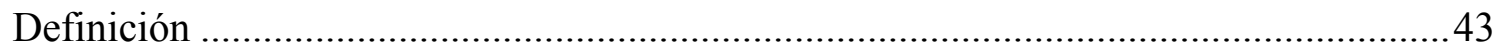

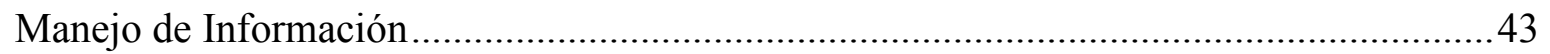

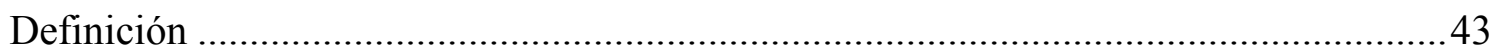

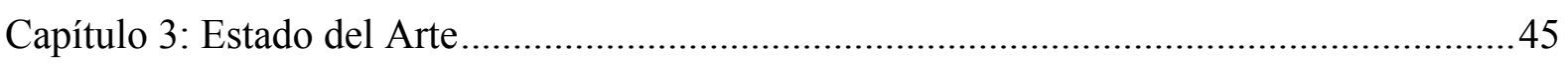

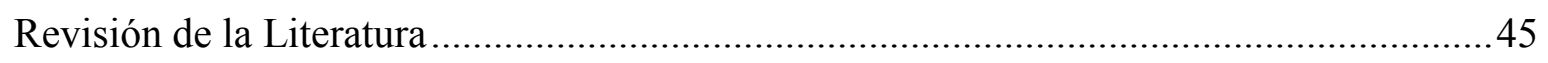

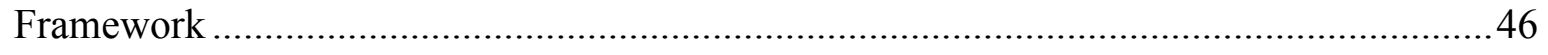

Un marco de implementación para E-Government 2.0 ................................................46

Diseño y validación del marco de cultura de seguridad de la información .....................49

Mapa ontológico de la arquitectura orientada a servicios para servicios de administración

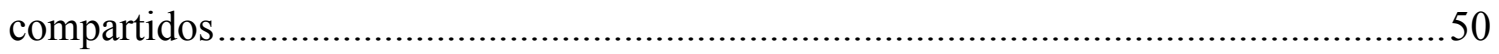

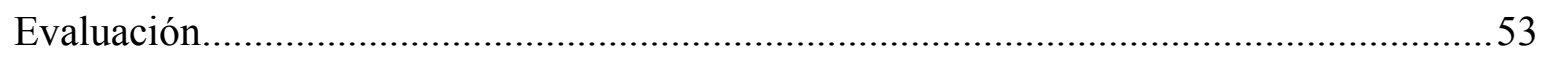

Participación de los ciudadanos en los sitios de Facebook de los gobiernos locales. Un análisis empírico: El impacto de los diferentes tipos de medios y contenidos en Europa Occidental .53

Sistema de recomendación de desarrollos de aplicaciones : una encuesta ......................57

Facilidad de uso y la credibilidad de los sitios web de gobierno electrónico 61

La adminoistración electrónica en las ciudades de la sociedad del conocimiento. Una investigación empírica de los sitios web gubernamentales de Smart Cities ....................65

Modelo para la Calidad de los Servicios en Línea del Gobierno Local...........................69

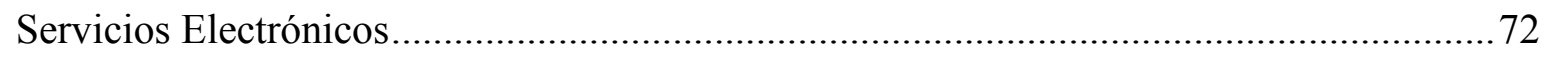


Investigando Discrepancias entre E-Services: Implementación o No - Iso 9001: Perspectivas de los Clientes en el Ejemplo de los Servicios Electrónicos en Cataluña

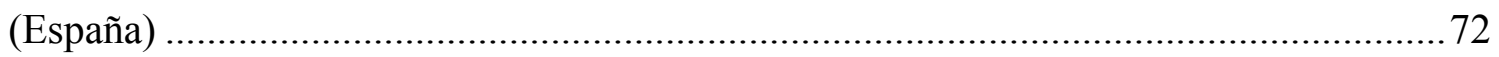

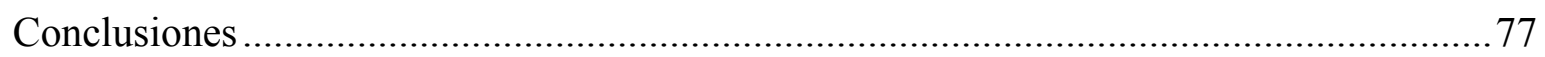

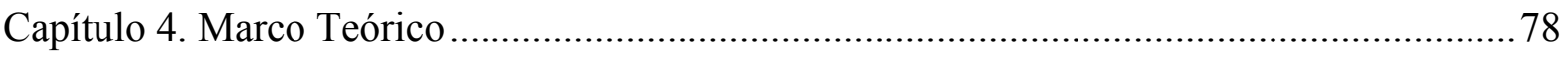

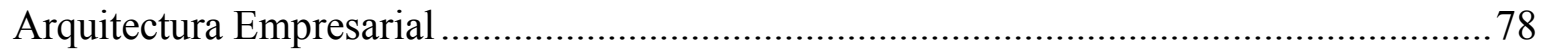

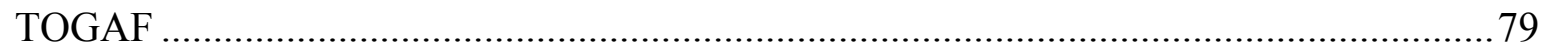

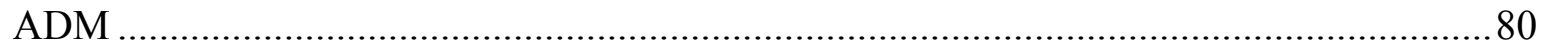

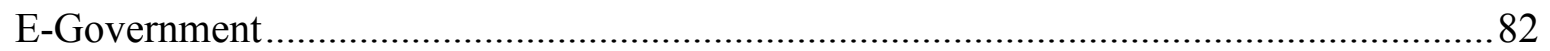

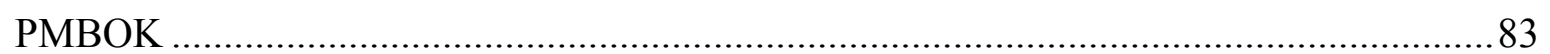

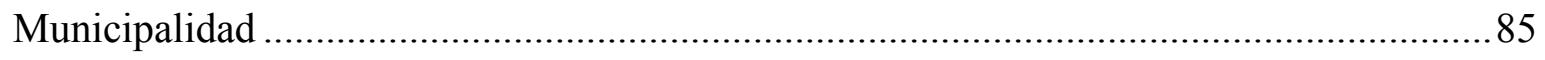

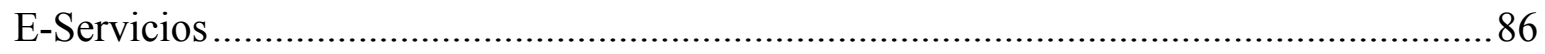

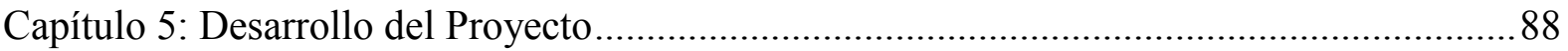

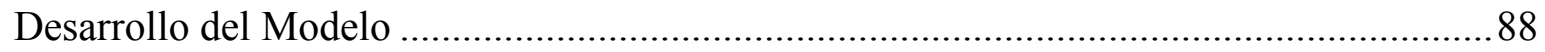

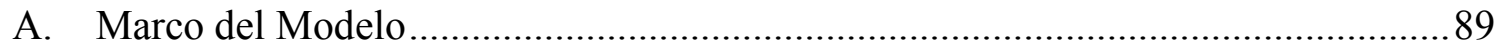

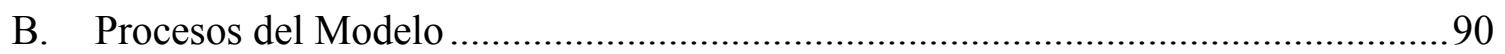

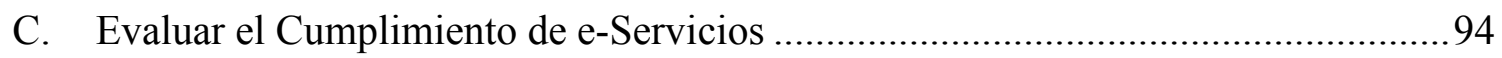

Recomendaciones para Implementación de e-Servicios ...............................................97

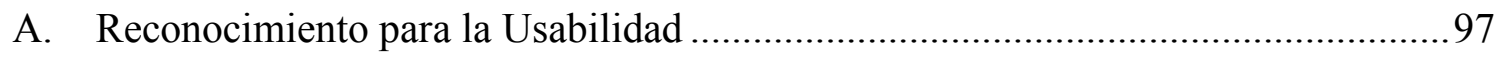

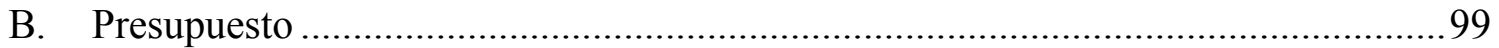

C. Restricciones Organizacionales - Leyes para Municipalidades y de Gobierno

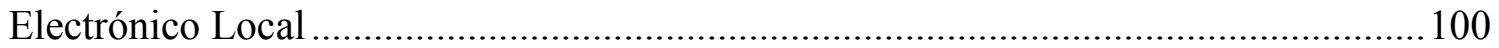

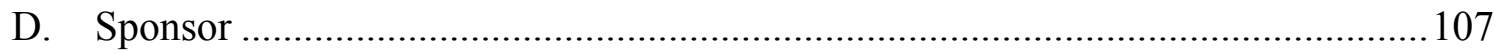

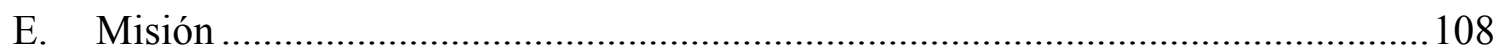

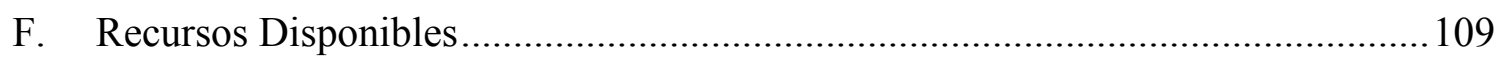

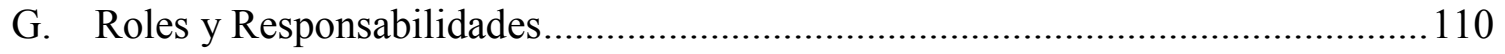

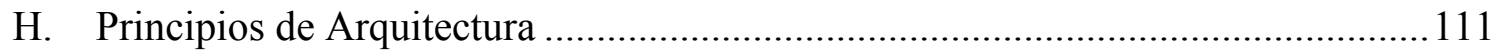

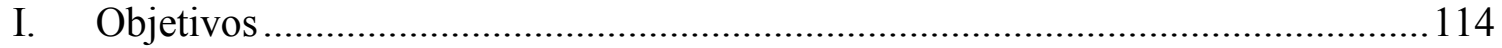

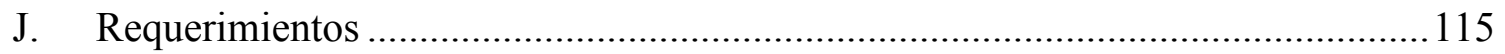

K. Modelamiento de Procesos .................................................................................... 116

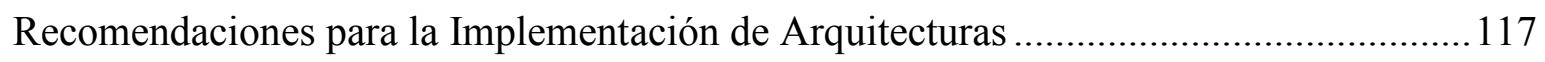

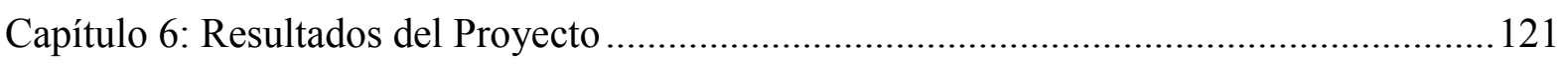

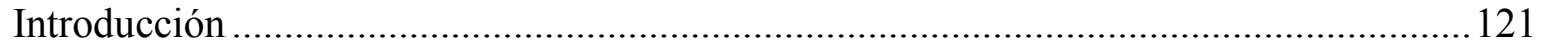

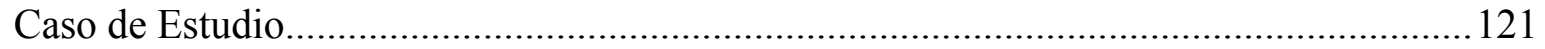




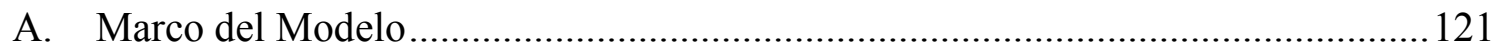

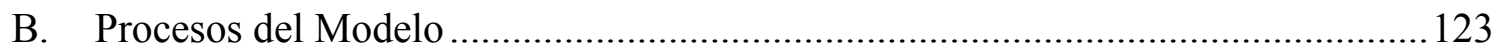

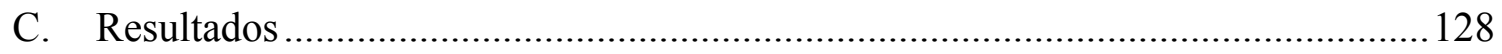

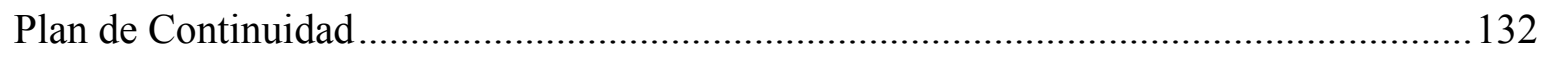

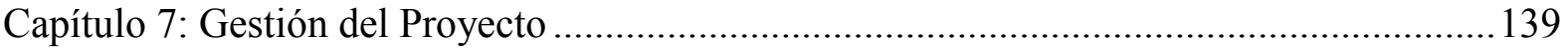

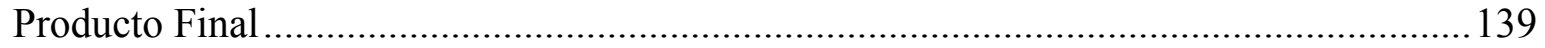

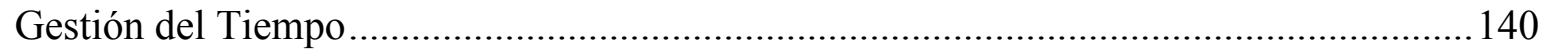

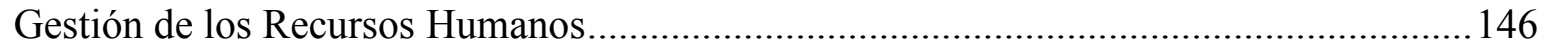

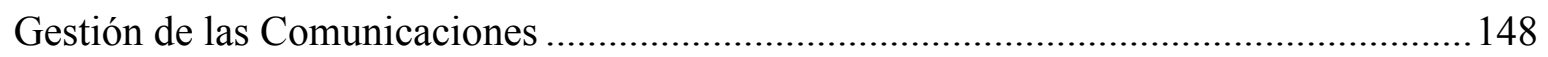

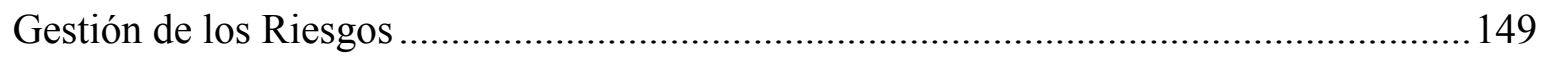

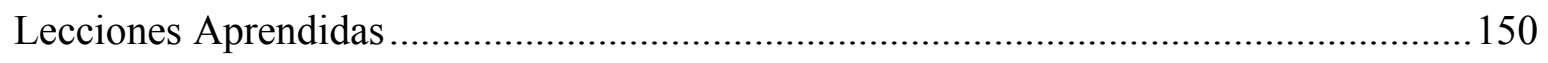

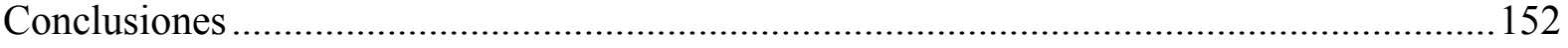

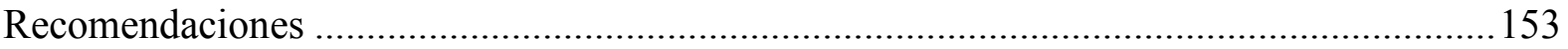

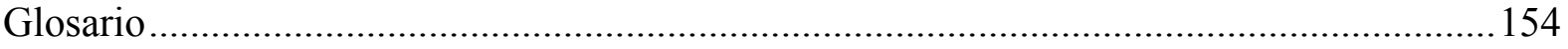

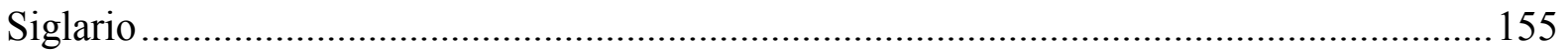

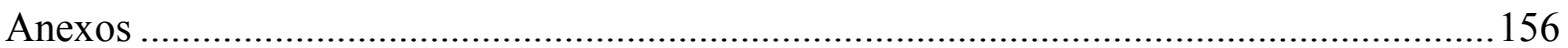

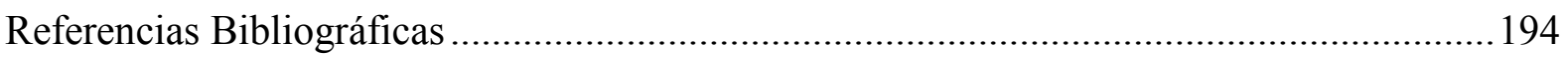




\section{Índice de Figuras}

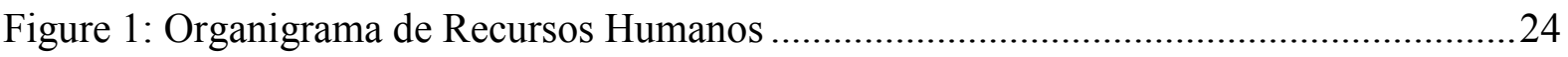

Figure 2: Matriz de Riesgos - Identificación..........................................................................

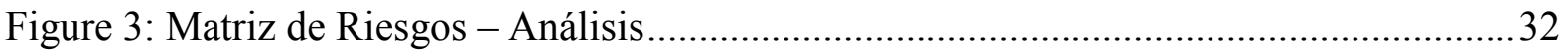

Figure 4: Matriz de Riesgos - Estrategia de Respuesta.............................................................32

Figure 5: Visión general del marco propuesto para el gobierno electrónico 2.0 .....................46

Figure 6: Comparación de proyectos de gobierno electrónico con marco de e-Gobierno 2.0.48

Figure 7: Marco de cultura de seguridad de la información .................................................49

Figure 8: Vista ontológica primaria de SOA para SSM ....................................................51

Figure 9: El papel de Facebook en la comunicación G2C y C2G …....................................54

Figure 10: Métricas de Facebook para la participación de los interesados..............................55

Figure 11: Utilización de Facebook en gobiernos locales .....................................................56

Figure 12: Porcentaje de publicaciones por tipo de contenido y estilo de administración pública .57

Figure 13: Resumen de técnicas de recomendación en cada dominio de aplicación...............61

Figure 14: Tareas asignadas a los usuarios antes de llenar el cuestionario ............................62

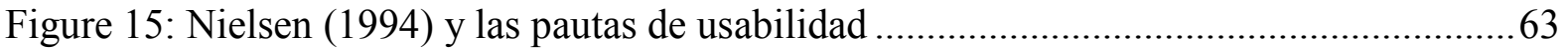

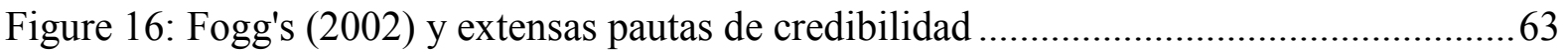

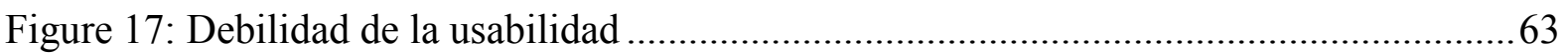

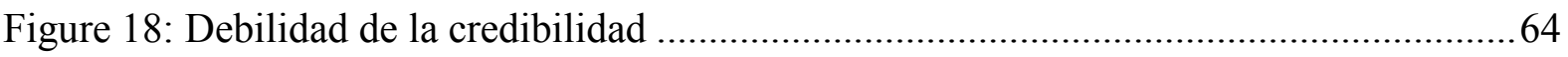

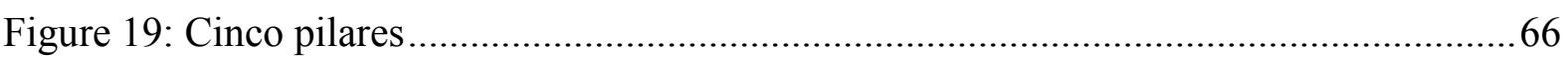

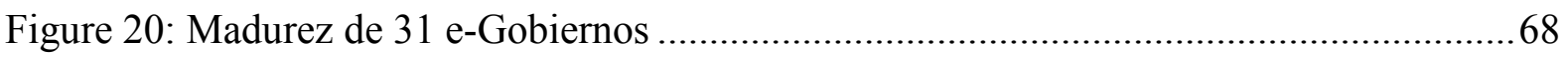

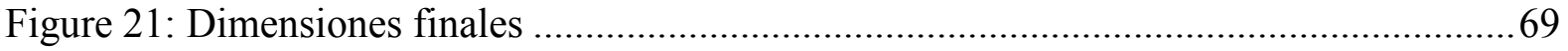

Figure 22: Hoja de trabajo de evaluación para los servicios en línea del gobierno local ........71

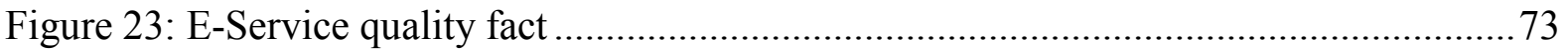

Figure 24: Perceived value, loyalty intention and e-satisfaction factors ...............................74

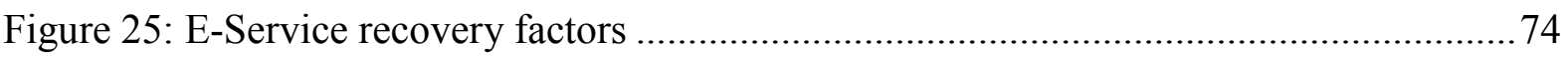

Figure 26: Características demográficas y perfil de los encuestados por bancos ....................76

Figure 27: Análisis de ANOVA y valor Eta por categoría ISO ..........................................76

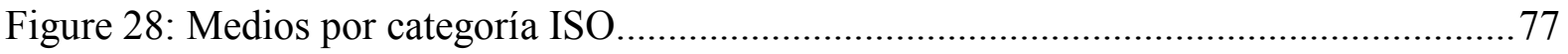

Figure 29: Componentes de la Arquitectura Empresarial..................................................... 79 
Figure 30: Fases del ADM.

Figure 31: Secuencia de ejecución del modelo. .88

Figure 32: Entrada y salida del Sub Proceso de Análisis y Diseño del negocio......................92

Figure 33: Entrada y salidas del Sub Proceso Análisis y Diseño de Datos ............................92

Figure 34: Entradas y salidas del Sub Proceso de Aplicaciones...........................................93

Figure 35: Entradas y salidas del Sub Proceso de Análisis y Diseño de Infraestructura .........93

Figure 36: Componentes del Índice de Gobierno Electrónico Municipal ...............................94

Figure 37: Fases de Gobierno Electrónico Municipal propuestas por Esteves.......................95

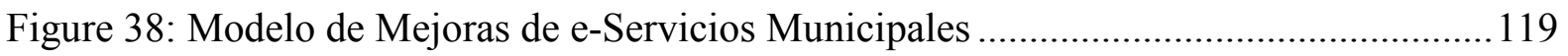

Figure 39: Gráfico Modelo de Mejoras de e-Servicios Municipales ..................................... 120

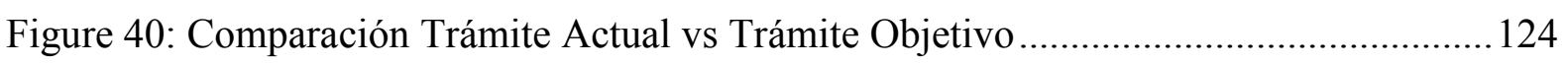

Figure 41: Extracto de Diagrama de Base de Datos .......................................................... 125

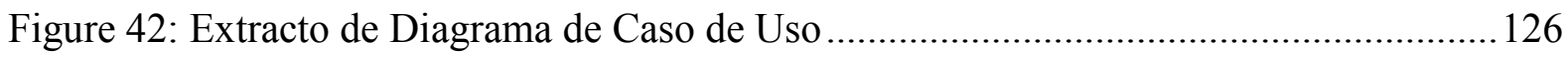

Figure 43: Resultado de Reducción de Carga Procesal del Trámite de Licencia de

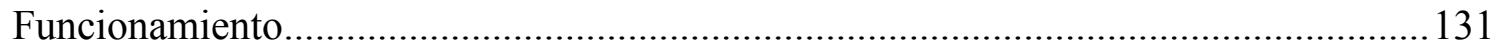

Figure 44: Resultado de Juicio de Expertos Municipales en Tecnología ................................ 132

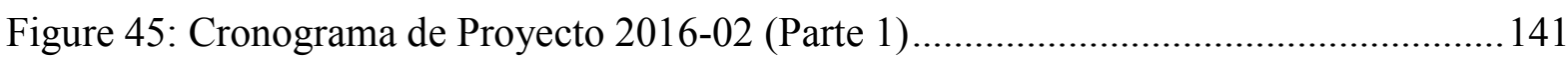

Figure 46: Cronograma de Proyecto 2016-02 (Parte 2) ...................................................... 142

Figure 47: Cronograma de Proyecto 2017-02 (Parte 1) ........................................................ 143

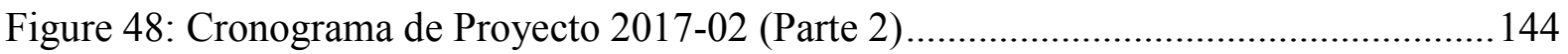

Figure 49: Cronograma de Proyecto 2017-02 (Parte 3) ....................................................... 145

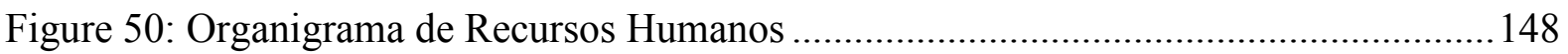

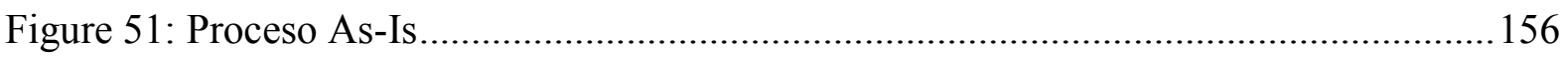

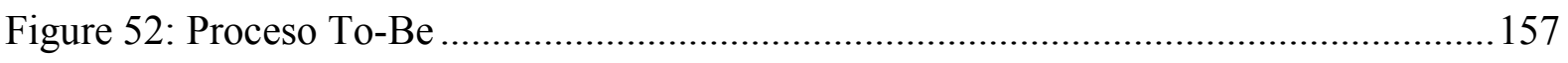

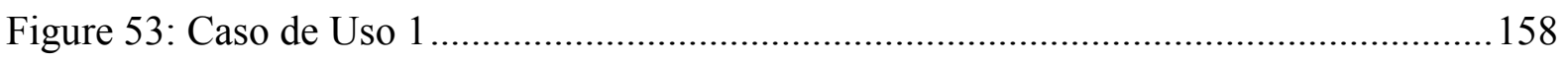

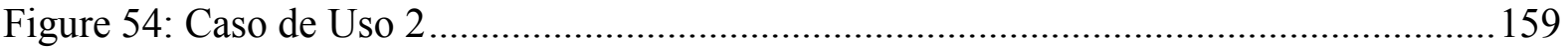

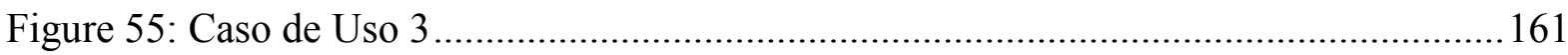

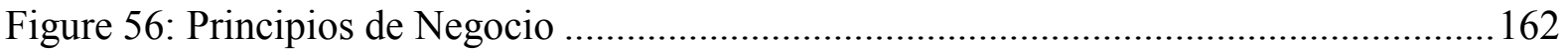

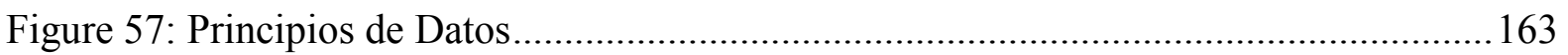

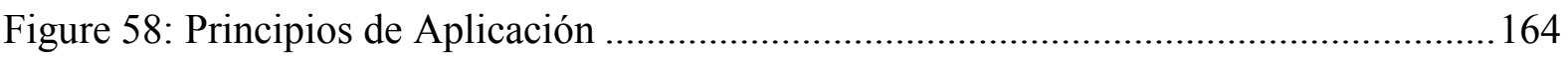

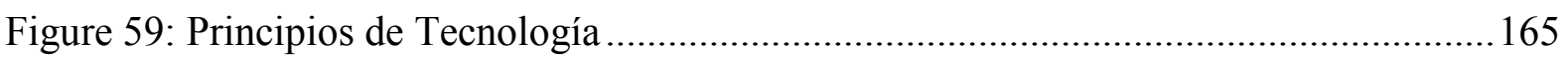

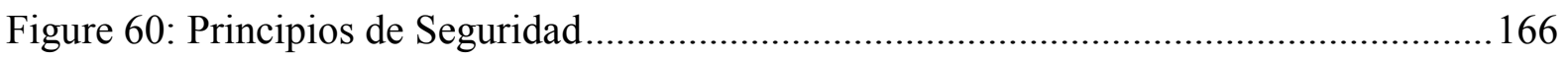

Figure 61: Misión Municipalidad de Miraflores............................................................... 167

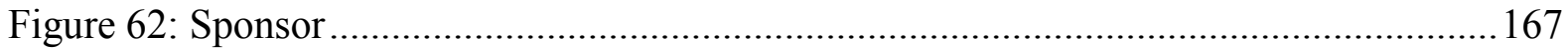




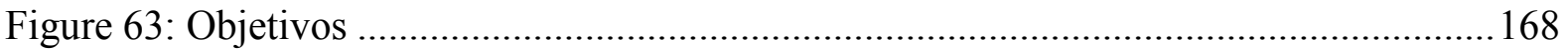

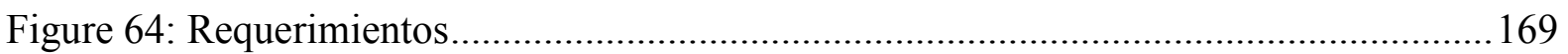

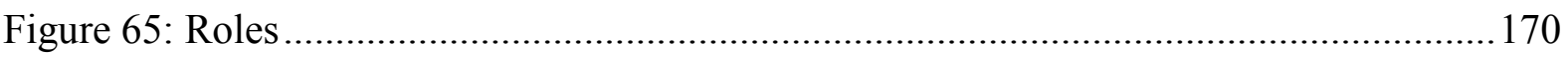

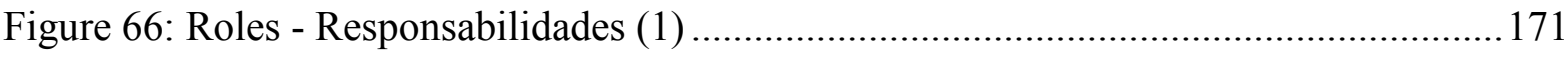

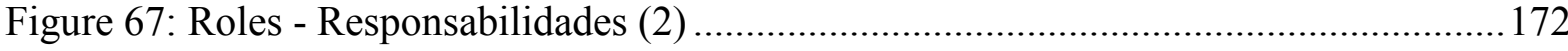

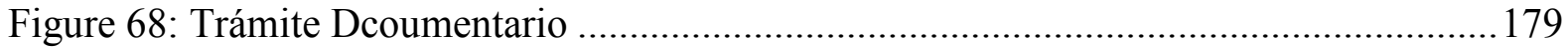

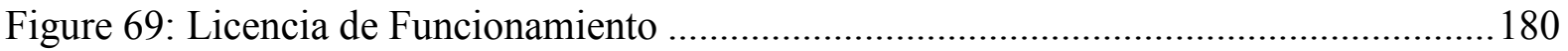

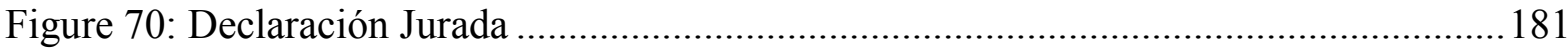

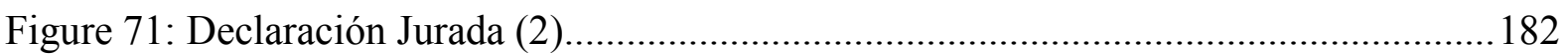

Figure 72: Solicitud de Declaración Jurada .................................................................... 183

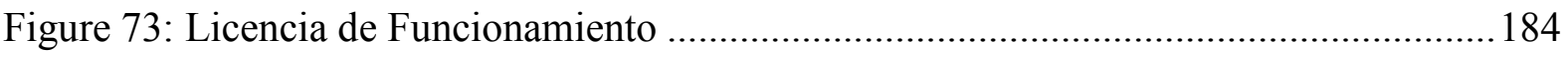

Figure 74: Licencia de Funcionamiento (2).................................................................... 185

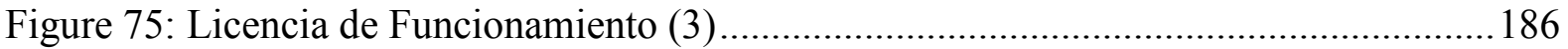

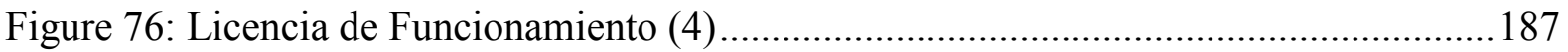

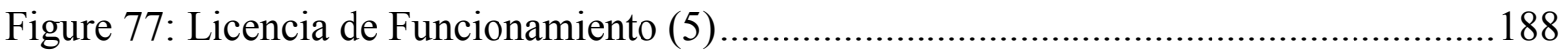

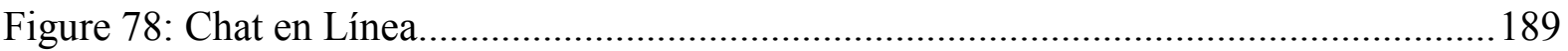

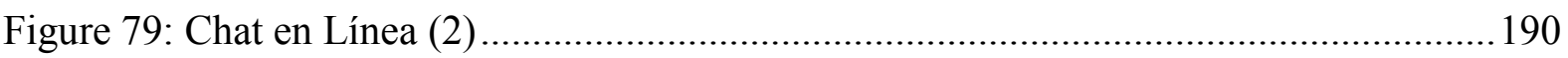

Figure 80: Firma de Certificado .................................................................................... 191

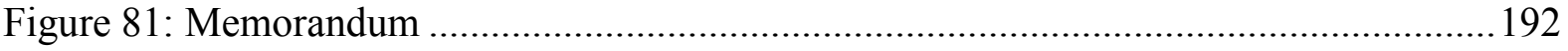

Figure 82: Elaborar Documento.................................................................................. 193 


\section{Índice de Tablas}

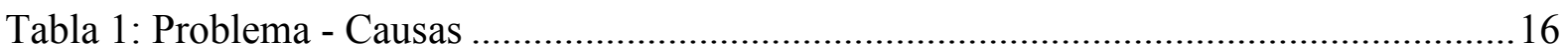

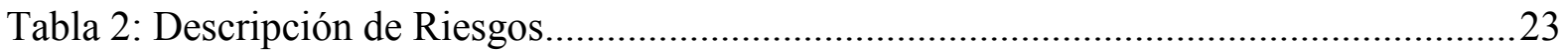

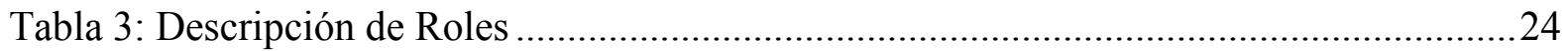

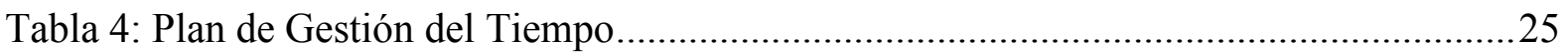

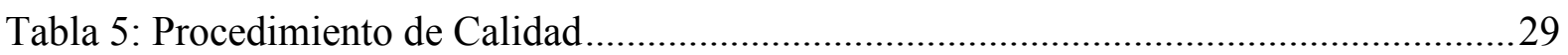

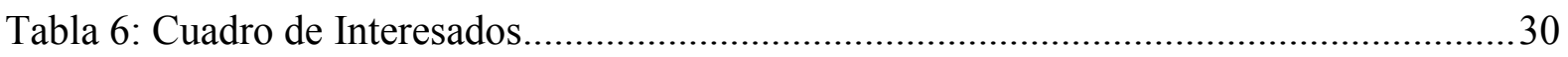

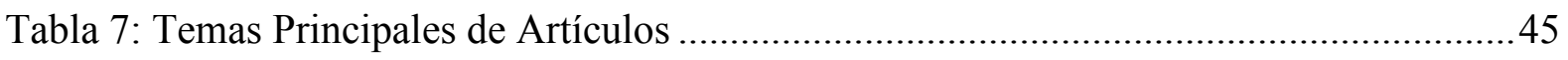

Tabla 8: Tipos de Arquitectura soportados por TOGAF …................................................ 79

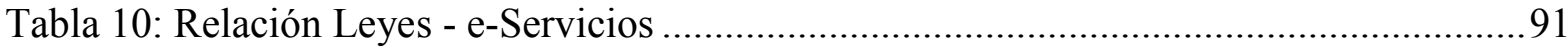

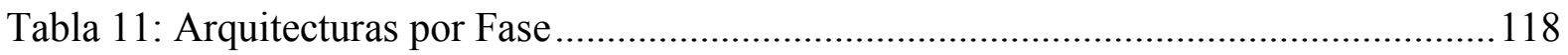

Tabla 12: Funcionalidades y e-Servicios que serán utilizados en el e-Trámite de Licencia de

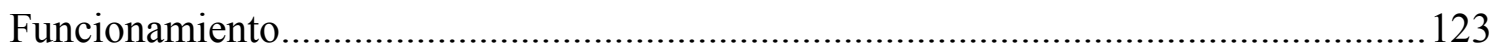

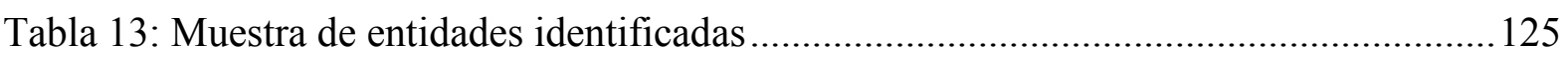

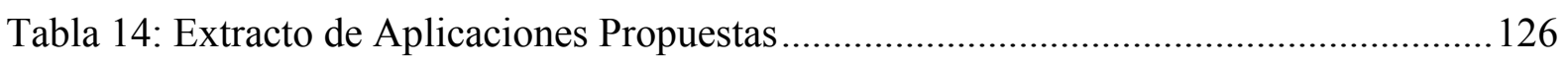

Tabla 15: Interacción del e-Trámite con las Otras Aplicaciones ............................................127

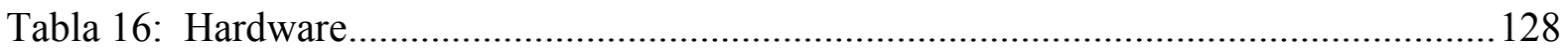

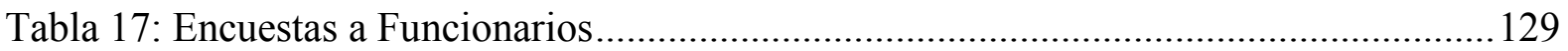

Tabla 18: Preguntas de Encuestas a Ciudadanos .................................................................. 129

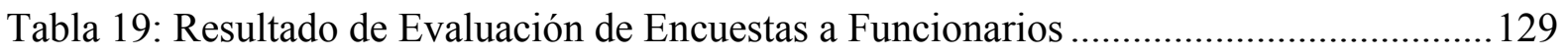

Tabla 20: Resultado de Evaluación de Encuestas a Ciudadanos .......................................... 130

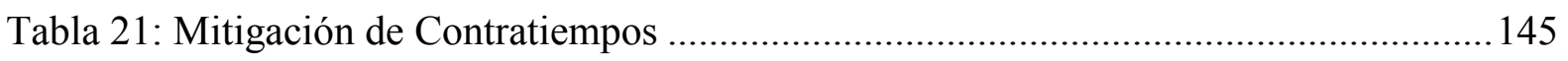

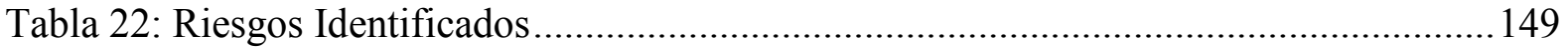




\section{Introducción}

Este proyecto nace como mejora de los servicios electrónicos en una municipalidad y brinda una propuesta de implementación de gobierno electrónico en la misma, ya que estas entidades públicas manejan muchos documentos en físico, lo cual dificulta las labores de auditoría y propician la corrupción. Adicionalmente, otra de las dificultades que se encuentran son los servicios lentos y sus sistemas no interconectados, y con esto, la posibilidad de no contar con información en tiempo real.

Para la definición clara de este proyecto, se abordan los siete siguientes capítulos:

El capítulo 1 describe el proyecto y su posicionamiento. Se detalla el problema, objetivo general, objetivos específicos, alcance, impacto y riesgos del proyecto.

En el capítulo 2 se detallan los student outcomes de la carrera de ingeniería de sistemas de información desarrollados a lo largo del proyecto.

En el capítulo 3 se define y explica el estado del arte de las tecnologías utilizadas en el proyecto.

En el capítulo 4 se define el marco teórico del proyecto, es decir conceptos básicos y fundamentales que aportan un mayor entendimiento.

En el capítulo 5 se detalla el desarrollo del proyecto, las metodologías utilizadas a lo largo del proyecto, especificando las tareas y actividades que deben ser realizadas.

En el capítulo 6 se explica el producto final y los resultados obtenidos en base a los indicadores previamente definidos, la puesta en producción y opiniones de usuarios finales.

En el capítulo 7 se da a conocer la gestión del proyecto luego de realizado el proyecto, este se realiza bajo la metodología PMBOK. Se detalla el tiempo empleado con la planificación y la gestión para la realización del proyecto. 


\section{Capítulo 1 : Definición del Proyecto}

En este capítulo se describe la problemática de la municipalidad sobre la cual se basa el proyecto, así como el objetivo general y los objetivos específicos que se desea alcanzar para su resolución. Se definen los documentos para la planificación del proyecto según PMBOK que son Plan de Gestión de Alcance, Plan de Gestión de Comunicaciones, Plan de Gestión de Riesgos, Plan de Gestión de Recursos Humanos, Plan de Gestión del Tiempo y Gestión de la Calidad.

\section{Objeto de Estudio}

La Organización de las Naciones Unidas para la Educación, la Ciencia y la Cultura, UNESCO por sus siglas en inglés, se encuentra desarrollando un proyecto con el fin de promover el uso de las Tecnologías de Información en municipalidades en Latinoamérica, África y el Caribe. Una parte de estos proyectos se encuentra dirigida hacia la implementación del gobierno electrónico, el cual la organización lo define como el uso de las tecnologías de información y comunicación en el sector público; de modo que, mejore el servicio brindado. Esto, con el fin de propiciar la participación del ciudadano en la toma de decisiones en las instituciones.

Un problema importante que se observa en las municipalidades peruanas es el manejo de grandes cantidades de documentos en físico, los cuales llegan a ser almacenados en depósitos. Sus sistemas no se encuentran interconectados, por lo que no cuentan con información centralizada ni integrada y la dificultada en la disponibilidad de información en tiempo real. Es por esto por lo que, se tiene como objeto de estudio, el desarrollo de un modelo de mejoras de servicios electrónicos municipales, el cual está basado en buenas prácticas del gobierno electrónico y por la selección de artefactos del ADM.

\section{Dominio del problema}

Existe una creciente intervención de las tecnologías en muchos aspectos de la vida diaria como es el uso del internet. En el Perú, existen empresas y entidades, tanto privadas como del Estado, que no desarrollan estas tecnologías en los servicios que ofrecen, siendo lentos, de mala calidad e ineficientes. 
Las municipalidades, entidades del Estado, brindan una serie de servicios a los ciudadanos y a otras empresas, presentan diversos problemas como:

- Información descentralizada

- Sistemas no interconectados, lo que no permite contar con información en tiempo real

- Documentos en físico, teniendo una cantidad enorme de documentos que son guardados en depósitos

- Procesos manuales

A estos se suma la exigencia de mostrar sus procesos de una manera transparente.

Para los problemas mencionados anteriormente se busca implementar una solución donde que aproveche los avances en tecnologías de información y comunicación que permita mejorar los procesos de la municipalidad, la calidad, eficiencia y eficacia de estos, aumentar la disponibilidad y acceso a los servicios; y permitir una interacción electrónica con los ciudadanos y otras empresas en tiempo real.

Para esta problemática, el presente proyecto propone un modelo de mejoras de los servicios electrónicos que puede brindar una municipalidad. Este modelo se basa en buenas prácticas del gobierno electrónico y analiza artefactos del ADM de las fases A, B, C y D.

Tabla 1: Problema - Causas

\begin{tabular}{|c|c|}
\hline Problema & Causas \\
\hline $\begin{array}{l}\text { Creciente necesidad de mejorar } \\
\text { la rapidez, eficacia y eficiencia } \\
\text { en los servicios ofrecidos por } \\
\text { una municipalidad con ayuda de } \\
\text { las tecnologías }\end{array}$ & $\begin{array}{l}\text { - Las áreas de la municipalidad no se encuentran } \\
\text { interconectados. } \\
\text { - No cuentan con información integrada. } \\
\text { - Cuentan con sistemas que no están interconectados. } \\
\text { - Manejan muchos documentos físicos. } \\
\text { - Los servicios que brindan son de manera manual. } \\
\text { - Creciente demanda de transparencia de los procesos } \\
\text { gubernamentales por parte de la ciudadanía. }\end{array}$ \\
\hline
\end{tabular}

Fuente: Elaboración Propia 


\section{Importancia del problema}

La UNESCO, United Nations Educational, Scientific and Culture Organization por sus siglas en inglés, se encuentra desarrollando un proyecto con el fin de promover el uso de las Tecnologías de Información en municipalidades de Latinoamérica, África y el Caribe.

Las municipalidades peruanas son entidades o gobiernos locales que se encargan de brindar servicios públicos a los vecinos de un distrito y el desarrollo integral del mismo. Estas entidades del Estado cuentan con procesos establecidos, los cuales son extensos y lentos; y una cantidad enorme de papeles, llegando a ser almacenados en grandes depósitos.

\section{Motivación}

La principal motivación del proyecto es con respecto a un plan bicentenario establecido por el Estado, el cual tiene como objetivo mejorar la rapidez, eficacia y eficiencia de los servicios ofrecidos con ayuda de las tecnologías, apuntando a alcanzar los objetivos propuestos por el gobierno central con dicho plan.

Es por esto que, analizando los procesos de las municipalidades peruanas, las soluciones existentes con respecto a la tecnología y el análisis de artículos que la apoyen, se llegó a la conclusión de la utilización del Gobierno Electrónico aporta en la mejora de las procesos, la eficiencia y eficacia de los mismos, reduce la utilización de papel, incluye las tecnologías en la administración de los gobiernos locales y disminuye la corrupción en estos.

\section{Objetivo general}

Implementar un modelo de mejoras de e-servicios municipales basado en buenas prácticas del gobierno electrónico analizados por la selección de artefactos del ADM de TOGAF.

\section{Objetivos específicos}

OE1: Analizar el contexto global y las buenas prácticas de e-Government para aterrizarlo en el contexto de la municipalidad de Villa María del Triunfo.

OE2: Diseñar el esquema de e-Government aplicado a las fases del framework Togaf.

OE3: Validar el esquema de e-Government mediante juicio de expertos.

OE4: Proponer un plan de continuidad que permita la mejora de e-servicios municipales. 


\section{Indicadores de éxito}

1. Para OE1:

1. IE01: Análisis de casos de éxito sobre la implementación de Gobierno Electrónico en el mundo y de su estado actual en el Perú.

2. Para OE2:

1. IE02: Entregables basado en TOGAF de las fases Preliminar, Requerimientos, A, B, C y D, aprobados por el cliente profesor.

2. IE03: Aprobación del esquema propuesto por parte del profesor cliente.

3. Para OE3:

1. IE04: Validación del esquema propuesto por parte del cliente.

4. Para OE4:

1. IE05: Aprobación de la cartera de proyectos.

\section{Planificación del Proyecto}

Es necesario contar con una estrategia que permita gestionar el proyecto a realizar de manera eficiente. En esta ocasión elaboramos los documentos de gestión que brinda el PMBOK.

\section{Plan de Gestión Alcance}

El alcance del proyecto abarca el desarrollo de un modelo de mejoras de e-servicios municipales, las cuales se encuentran basadas en buenas prácticas del gobierno electrónico, y son analizadas por la selección de artefactos del ADM de TOGAF. Para llevar a cabo el proyecto debemos contemplar los siguientes puntos:

- Análisis del contexto global y buenas prácticas de e-Government.

- Diseñar un esquema de e-Government donde se aplique las fases A, B, C y D de TOGAF

- Realizar los entregables propuestos por la metodología PMBOK.

- Demostrar la viabilidad del proyecto a través de una evaluación financiera.

- Validar el modelo vía juicio de expertos.

- Proponer un plan de continuidad que permita la mejora de e-servicios municipales.

Para el presente proyecto estará fuera del alcance lo siguiente: 
- El esquema de e-Government no abarcará las fases E, F, G y H de TOGAF.

- No se implementará el esquema propuesto de E-Government.

El alcance del proyecto abarca lo siguiente:

La primera fase, inicio del proyecto, está compuesta básicamente por el siguiente entregable:

- Project Charter

La segunda fase, planificación del proyecto, cuenta con los entregables propios para la gestión del proyecto, tales como:

- Cronograma

- Descripción de Roles y Responsabilidades

- Diccionario EDT

- Matriz de Comunicaciones

- Matriz de Riesgos

- Matriz de Trazabilidad de Requerimientos

- Matriz RAM

- Plan de Gestión de Alcance

- Plan de Gestión de Calidad

- Plan de Gestión de Comunicaciones

- Plan de Gestión de Riesgos

- Plan de Gestión de RRHH

- Plan de Gestión del Cronograma

- Registro de Interesados 
La tercera fase, análisis y diseño del proyecto, se encuentra por los entregables correspondientes al estudio y esquema del proyecto, tales como:

- Documento Estado Perú

- Documento Gobierno Electrónico

- Documento Casos Gobierno Electrónico

- Entregable Sponsor

- Entregable Requerimientos

- Entregable Recursos Disponibles

- Entregable Objetivos

- Entregable Catálogo de Principios

- Entregable Misión

- Recomendación para Fase de Presencia

- Fase Presencia - Ubicación de aplicaciones y usuarios

- Fase Presencia - Matriz de interacción de aplicaciones

- Fase Presencia - Catálogo de Entidades

- Fase Presencia - Catálogo de Aplicaciones

- Fase Presencia - Case de Uso Información Municipal

- Fase Presencia - Matriz de Tecnología 1

- Fase Presencia - Diagrama de Red

- Fase Presencia - Catálogo de Portafolio de Tecnología

- Fase Información Urbana - Ubicación de aplicaciones y usuarios

- Fase Información Urbana - Matriz de Interacción de Aplicaciones 
- Fase Información Urbana - Catálogo de Entidades

- Fase Información Urbana - Catálogo de Aplicaciones

- Fase Información Urbana - Caso de Uso Información Municipal

- Fase Información Urbana - Matriz de Tecnología

- Fase Información Urbana - Diagrama de Red

- Fase Información Urbana -Catálogo de Portafolio de Tecnología

- Fase Interacción - Ubicación de aplicaciones y usuarios

- Fase Interacción - Matriz de Interacción de Aplicaciones

- Fase Interacción - Catálogo de Entidades

- Fase Interacción - Catálogo de Aplicaciones

- Fase Interacción - Caso de Uso Información Municipal

- Fase Interacción - Caso de Uso Contacto con el Ciudadano

- Fase Interacción - Matriz de Tecnología

- Fase Interacción - Diagrama de Red

- Fase Interacción - Catálogo de Portafolio de Tecnología

- Fase Transacción - Ubicación de aplicaciones y usuarios

- Fase Transacción - Matriz de Sistemas y Funciones

- Fase Transacción - Matriz de Interacción de Aplicaciones

- Fase Transacción - Matriz de Datos y Funciones de Negocio

- Fase Transacción - Catálogo de Entidades

- Fase Transacción - Catálogo de Aplicaciones 
- Fase Transacción - Caso de Uso Trámite Municipal

- Fase Transacción - Caso de Uso Información Municipal

- Fase Transacción - Caso de Uso Contacto con el Ciudadano

- Fase Transacción - Matriz de Tecnología

- Fase Transacción - Diagrama de Red

- Fase Transacción - Catálogo de Portafolio de Tecnología

- Fase e-Democracia - Ubicación de aplicaciones y usuarios

- $\quad$ Fase e-Democracia - Matriz de Sistemas y Funciones

- Fase e-Democracia - Matriz de Interacción de Aplicaciones

- Fase e-Democracia - Matriz de Datos y Funciones de Negocio

- Fase e-Democracia - Catálogo de Entidades

- Fase e-Democracia - Catálogo de Aplicaciones

- Fase e-Democracia - Caso de Uso Trámite Municipal

- Fase e-Democracia - Caso de Uso Información Municipal

- Fase e-Democracia - Caso de Uso Contacto con el Ciudadano

- Fase e-Democracia - Matriz de Tecnología

- Fase e-Democracia - Diagrama de Red

- Fase e-Democracia - Catálogo de Portafolio de Tecnología

La cuarta fase, cierre del proyecto, se encuentra compuesto por los entregables correspondientes a la culminación del proyecto.

- Modelo Final de la Propuesta

- Estabilidad Financiera 
- Memoria Final del Proyecto

- Paper de Investigación

- Poster

- Acta de cierre (Capacitación y Conformidad)

- Lecciones aprendidas

\section{Plan de Gestión de Riesgos}

Se lista los riesgos que pueden impedir el desarrollo y culminación del proyecto. Para cada uno de los riesgos, se propone una estrategia de mitigación.

Tabla 2: Descripción de Riesgos

\begin{tabular}{|c|c|c|c|c|}
\hline \# & Riesgo & Probabilidad & Impacto & Estrategia de mitigación \\
\hline 1 & $\begin{array}{l}\text { El cliente no define } \\
\text { correctamente los requisitos del } \\
\text { proyecto. Esto puede causar } \\
\text { demoras en el levantamiento de } \\
\text { información. }\end{array}$ & Baja & Muy Alto & $\begin{array}{l}\text { Informar al cliente sobre los } \\
\text { problemas encontrados y } \\
\text { definir los requisitos con él. }\end{array}$ \\
\hline 2 & $\begin{array}{l}\text { Poca disponibilidad de tiempo } \\
\text { del cliente debido a sus } \\
\text { funciones municipales. }\end{array}$ & Alta & Muy Alto & $\begin{array}{l}\text { Realizar con cronograma de } \\
\text { reuniones con el cliente. }\end{array}$ \\
\hline 3 & $\begin{array}{l}\text { Abandono del proyecto por parte } \\
\text { de un integrante del equipo. }\end{array}$ & Baja & Muy Alto & $\begin{array}{l}\text { Mantener una comunicación } \\
\text { constante entre los } \\
\text { participantes del equipo }\end{array}$ \\
\hline 4 & $\begin{array}{l}\text { Cambios en el alcance del } \\
\text { proyecto propuestos por el } \\
\text { comité o por el cliente. }\end{array}$ & Baja & Muy Alto & $\begin{array}{l}\text { Gestionar adecuadamente la } \\
\text { holgura del proyecto. }\end{array}$ \\
\hline 5 & $\begin{array}{l}\text { No cumplir con las expectativas } \\
\text { del cliente }\end{array}$ & Medio & Muy Alto & $\begin{array}{l}\text { Realizar encuestas de } \\
\text { satisfacción al cliente de } \\
\text { manera periódica. }\end{array}$ \\
\hline 6 & $\begin{array}{l}\text { Inadecuado seguimiento y } \\
\text { control hacia los recursos. }\end{array}$ & Bajo & Alto & $\begin{array}{l}\text { Realizar reuniones de } \\
\text { seguimiento. }\end{array}$ \\
\hline
\end{tabular}




\begin{tabular}{|c|l|c|c|c|}
\hline$\#$ & \multicolumn{1}{|c|}{ Riesgo } & Probabilidad & Impacto & \multicolumn{1}{|c|}{ Estrategia de mitigación } \\
\hline 7 & $\begin{array}{l}\text { Cambio de cliente luego de } \\
\text { haber iniciado el proyecto. }\end{array}$ & Muy Bajo & Muy Alto & $\begin{array}{l}\text { Realizar análisis procesos } \\
\text { estándares en las } \\
\text { municipalidades. }\end{array}$ \\
\hline 8 & $\begin{array}{l}\text { No contar con el documento de } \\
\text { presentación por parte de la } \\
\text { universidad por lo que } \\
\begin{array}{l}\text { imposibilita que la } \\
\text { municipalidad no brinde la } \\
\text { información. }\end{array}\end{array}$ & Bajo & Muy Alto & $\begin{array}{l}\text { Solicitar el documento de } \\
\text { presentación algún } \\
\text { miembro del comité de } \\
\text { proyecto. }\end{array}$ \\
\hline
\end{tabular}

Fuente : Elaboración Propia

\section{Plan de Gestión de Recursos Humanos}

Se detalla el organigrama del proyecto.

Figure 1: Organigrama de Recursos Humanos

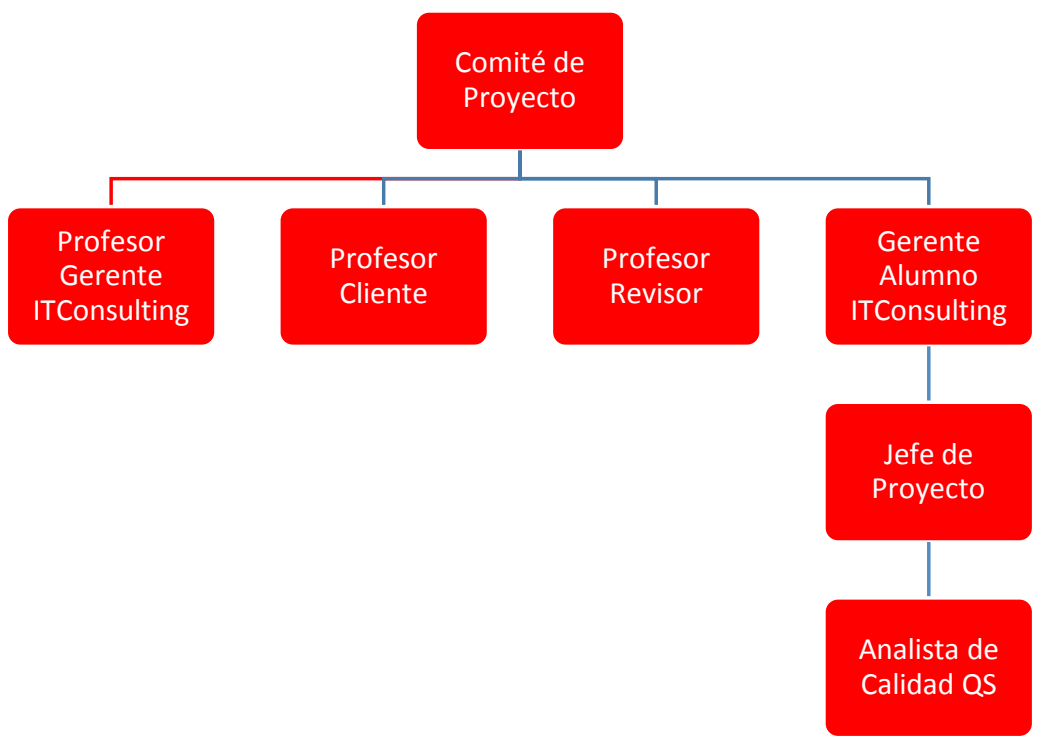

Fuente : Elaboración Propia

A continuación, se definen los roles y las responsabilidades dentro del proyecto.

Tabla 3: Descripción de Roles

\begin{tabular}{|c|c|c|}
\hline \multicolumn{1}{|c|}{ Rol } & \multicolumn{1}{|c|}{ Miembro } & \multicolumn{1}{c|}{ Responsabilidades } \\
\hline Jefe de Proyecto & Allison García & $\begin{array}{l}\text { Gestionar el proyecto, de acuerdo con los objetivos y al } \\
\text { cronograma establecido. }\end{array}$ \\
& & $-\quad$\begin{tabular}{l} 
Identificar los riesgos del proyecto. \\
\hline
\end{tabular}
\end{tabular}




\begin{tabular}{|c|c|c|}
\hline & & $\begin{array}{l}\text { - Desarrollar las funciones necesarias para llevar a cabo del } \\
\text { proyecto. }\end{array}$ \\
\hline Jefe de Proyecto & Raphael Hinostroza & $\begin{array}{l}\text { - Gestionar el proyecto, de acuerdo con los objetivos y al } \\
\text { cronograma establecido. } \\
\text { - Identificar los riesgos del proyecto. } \\
\text { Desarrollar las funciones necesarias para llevar a cabo del } \\
\text { proyecto. }\end{array}$ \\
\hline $\begin{array}{l}\text { Gerente Profesor IT- } \\
\text { Consulting }\end{array}$ & Ángel Velásquez & $\begin{array}{l}\text { - Controlar y monitorear las actividades programadas del } \\
\text { proyecto. }\end{array}$ \\
\hline $\begin{array}{l}\text { Gerente Alumno IT- } \\
\text { Consulting }\end{array}$ & Eduardo Ulloa & $\begin{array}{l}\text { - Apoyo en el monitoreo y control de las actividades del } \\
\text { proyecto. } \\
\text { - Gestionar los recursos necesarios para el proyecto. }\end{array}$ \\
\hline Profesor Cliente & Edgar Díaz & $\begin{array}{l}\text { - Orientar a los jefes de proyecto. } \\
\text { - } \quad \text { Solicitar los requerimientos para el desarrollo del proyecto. }\end{array}$ \\
\hline Profesor Revisor & Jorge Sánchez Castro & $\begin{array}{l}\text { - Validar y certificar que este documento se encuentre } \\
\text { alineada a la tesis desarrollada. }\end{array}$ \\
\hline Analista de Calidad QS & Analista QS & - Revisar entregables. \\
\hline
\end{tabular}

Fuente : Elaboración Propia

\section{Plan de Gestión del Tiempo}

Se detalla las fases, hitos y entregables del proyecto.

Tabla 4: Plan de Gestión del Tiempo

\begin{tabular}{|c|c|c|c|c|}
\hline $\begin{array}{l}\text { Fase del } \\
\text { Proyecto }\end{array}$ & Hito del proyecto & $\begin{array}{c}\text { Fecha } \\
\text { Estimada }\end{array}$ & Entregables incluidos & Prioridad \\
\hline Iniciación & $\begin{array}{l}\text { Aprobación del Project } \\
\text { Charter por parte del } \\
\text { Comité de Proyecto }\end{array}$ & Semana 3 & Project Charter & Alta \\
\hline \multirow{6}{*}{ Planificación } & \multirow{6}{*}{$\begin{array}{c}\text { Aprobación de la } \\
\text { planificación del proyecto } \\
\text { por parte del Comité de } \\
\text { Proyecto }\end{array}$} & Semana 4 & Cronograma & Alta \\
\hline & & Semana 5 & $\begin{array}{c}\text { Descripción de Roles y } \\
\text { Responsabilidades }\end{array}$ & Alta \\
\hline & & Semana 5 & Diccionario EDT & Alta \\
\hline & & Semana 5 & Matriz de Comunicaciones & Alta \\
\hline & & Semana 5 & Matriz de Riesgos & Alta \\
\hline & & Semana 6 & $\begin{array}{l}\text { Matriz de Trazabilidad de } \\
\text { Requerimientos }\end{array}$ & Alta \\
\hline
\end{tabular}




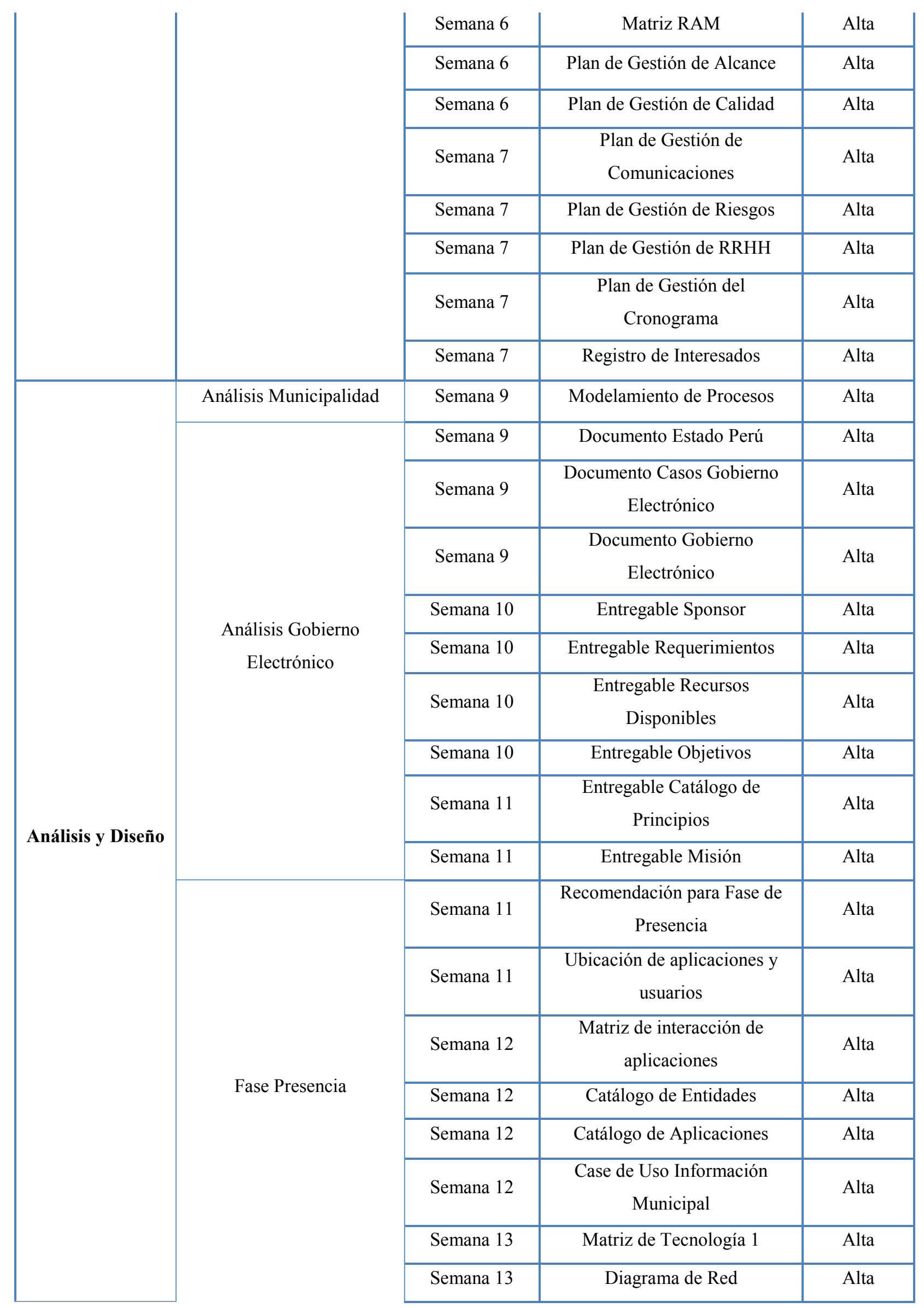




\begin{tabular}{|c|c|c|c|}
\hline & Semana 13 & $\begin{array}{c}\text { Catálogo de Portafolio de } \\
\text { Tecnología }\end{array}$ & Alta \\
\hline \multirow{8}{*}{ Fase Información Urbana } & Semana 14 & $\begin{array}{c}\text { Ubicación de aplicaciones y } \\
\text { usuarios }\end{array}$ & Alta \\
\hline & Semana 14 & $\begin{array}{l}\text { Matriz de Interacción de } \\
\text { Aplicaciones }\end{array}$ & Alta \\
\hline & Semana 14 & Catálogo de Entidades & Alta \\
\hline & Semana 14 & Catálogo de Aplicaciones & Alta \\
\hline & Semana 15 & $\begin{array}{c}\text { Caso de Uso Información } \\
\text { Municipal }\end{array}$ & Alta \\
\hline & Semana 15 & Matriz de Tecnología & Alta \\
\hline & Semana 15 & Diagrama de Red & Alta \\
\hline & Semana 15 & $\begin{array}{c}\text { Catálogo de Portafolio de } \\
\text { Tecnología }\end{array}$ & Alta \\
\hline \multirow{9}{*}{ Fase Interacción } & Semana 17 & $\begin{array}{c}\text { Ubicación de aplicaciones y } \\
\text { usuarios }\end{array}$ & Alta \\
\hline & Semana 17 & $\begin{array}{c}\text { Matriz de Interacción de } \\
\text { Aplicaciones }\end{array}$ & Alta \\
\hline & Semana 17 & Catálogo de Entidades & Alta \\
\hline & Semana 17 & Catálogo de Aplicaciones & Alta \\
\hline & Semana 18 & $\begin{array}{c}\text { Caso de Uso Información } \\
\text { Municipal }\end{array}$ & Alta \\
\hline & Semana 18 & $\begin{array}{c}\text { Caso de Uso Contacto con el } \\
\text { Ciudadano }\end{array}$ & Alta \\
\hline & Semana 18 & Matriz de Tecnología & Alta \\
\hline & Semana 18 & Diagrama de Red & Alta \\
\hline & Semana 19 & $\begin{array}{c}\text { Catálogo de Portafolio de } \\
\text { Tecnología }\end{array}$ & Alta \\
\hline \multirow{6}{*}{ Fase Transacción } & Semana 19 & $\begin{array}{c}\text { Ubicación de aplicaciones y } \\
\text { usuarios }\end{array}$ & Alta \\
\hline & Semana 19 & Matriz de Sistemas y Funciones & Alta \\
\hline & Semana 19 & $\begin{array}{c}\text { Matriz de Interacción de } \\
\text { Aplicaciones }\end{array}$ & Alta \\
\hline & Semana 20 & $\begin{array}{l}\text { Matriz de Datos y Funciones de } \\
\text { Negocio }\end{array}$ & Alta \\
\hline & Semana 20 & Catálogo de Entidades & Alta \\
\hline & Semana 20 & Catálogo de Aplicaciones & Alta \\
\hline
\end{tabular}




\begin{tabular}{|c|c|c|c|c|}
\hline & & Semana 20 & $\begin{array}{c}\text { Caso de Uso Trámite } \\
\text { Municipal }\end{array}$ & Alta \\
\hline & & Semana 21 & $\begin{array}{c}\text { Caso de Uso Información } \\
\text { Municipal }\end{array}$ & Alta \\
\hline & & Semana 21 & $\begin{array}{c}\text { Caso de Uso Contacto con el } \\
\text { Ciudadano }\end{array}$ & Alta \\
\hline & & Semana 21 & Matriz de Tecnología & Alta \\
\hline & & Semana 21 & Diagrama de Red & Alta \\
\hline & & Semana 22 & $\begin{array}{c}\text { Catálogo de Portafolio de } \\
\text { Tecnología }\end{array}$ & Alta \\
\hline & \multirow{12}{*}{ Fase e-Democracia } & Semana 22 & $\begin{array}{c}\text { Ubicación de aplicaciones y } \\
\text { usuarios }\end{array}$ & Alta \\
\hline & & Semana 22 & Matriz de Sistemas y Funciones & Alta \\
\hline & & Semana 22 & $\begin{array}{c}\text { Matriz de Interacción de } \\
\text { Aplicaciones }\end{array}$ & Alta \\
\hline & & Semana 23 & $\begin{array}{l}\text { Matriz de Datos y Funciones de } \\
\text { Negocio }\end{array}$ & Alta \\
\hline & & Semana 23 & Catálogo de Entidades & Alta \\
\hline & & Semana 23 & Catálogo de Aplicaciones & Alta \\
\hline & & Semana 23 & $\begin{array}{c}\text { Caso de Uso Trámite } \\
\text { Municipal }\end{array}$ & Alta \\
\hline & & Semana 24 & $\begin{array}{c}\text { Caso de Uso Información } \\
\text { Municipal }\end{array}$ & Alta \\
\hline & & Semana 24 & $\begin{array}{c}\text { Caso de Uso Contacto con el } \\
\text { Ciudadano }\end{array}$ & Alta \\
\hline & & Semana 24 & Matriz de Tecnología & Alta \\
\hline & & Semana 24 & Diagrama de Red & Alta \\
\hline & & Semana 24 & $\begin{array}{c}\text { Catálogo de Portafolio de } \\
\text { Tecnología }\end{array}$ & Alta \\
\hline \multirow{7}{*}{ Cierre } & \multirow{7}{*}{$\begin{array}{l}\text { Aprobación de los } \\
\text { entregables finales por } \\
\text { parte del Comité de } \\
\text { Proyecto }\end{array}$} & Semana 27 & Modelo Final de la Propuesta & Alta \\
\hline & & Semana 28 & Estabilidad Financiera & Alta \\
\hline & & Semana 29 & Memoria Final de la Propuesta & Alta \\
\hline & & Semana 29 & Paper de Investigación & Alta \\
\hline & & Semana 30 & Póster & Alta \\
\hline & & Semana 30 & $\begin{array}{c}\text { Acta Cierre (Capacitación y } \\
\text { Conformidad) }\end{array}$ & Alta \\
\hline & & Semana 31 & Lecciones Aprendidas & Alta \\
\hline
\end{tabular}




\section{Plan de Gestión de Calidad}

Se detalla el procedimiento a seguir para asegurar la calidad del proyecto.

Tabla 5: Procedimiento de Calidad

$1 \quad$ Procedimiento para la Planificación de la Calidad

Establecer indicadores para la realización de los entregables.

Establecer fechas en el cronograma para la revisión de la calidad de los entregables.

2 Procedimiento para Aseguramiento de la Calidad

Realizar el seguimiento de la entrega de los entregables en la fecha establecida en el cronograma para la revisión de la calidad de los mismos.

Verificar la utilización de recursos de QS para el aseguramiento de la calidad de los entregables.

Poner en marcha los planes de contingencia y mitigación en caso el proyecto lo requiera.

Evaluar el impacto en la calidad en caso exista algún cambio en el proyecto.

\section{Procedimiento para el Control de la Calidad}

El control de calidad se realizará con la revisión de los entregables por parte del analista QS. Estas revisiones serán enviadas junto con una matriz de observaciones.

En caso exista algún cambio o corrección, se volverá a revisar.

En caso exista algún error, se procederá a identificar las causas del mismo y aplicar la corrección correspondiente.

$4 \quad$ Procedimiento para Mejora Continua

Cada entregable debe participar en ciclo de mejora continua PHVA.

Fuente : Elaboración Propia

\section{Plan de Gestión de Comunicaciones}

Todas las reuniones deben seguir las siguientes pautas:

- En caso de tener un nuevo miembro en cada reunión, se hará la respectiva presentación de este ante los asistentes.

- Se manejará una agenda para cada reunión de acuerdo a los temas de interés a tratarse, así como también las tareas pendientes de reuniones anteriores. Para este caso, se debe tener en cuenta el entregable a realizar según el diccionario EDT.

- Cada punto de la agenda contará con un nivel de prioridad a ser tratado.

- Se cuenta con un horario específico para cada reunión, sin embargo, será necesario confirmar/recordar la reunión vía correo electrónico un día antes como máximo.

- En caso se deba postergar una reunión, se deberá justificar y además acordar el nuevo día de esta. 
- Al finalizar cada reunión se deberá recopilar lo tratado, resaltando los acuerdos para posteriormente elaborar el acta de reunión.

- Todas las actas de reunión deberán ser firmadas por el jefe de proyecto, profesor gerente IT-Consulting, o profesor cliente, respectivamente.

Toda la remisión de correos electrónicos debe seguir las siguientes pautas:

- Cada correo electrónico debe ser redactado de una manera formal.

- Todo correo electrónico al cliente debe ser copiado a todo el equipo de proyecto; en especial a gerente, jefe, asistente de proyecto

- Los correos electrónicos entre el gerente de la empresa y el cliente, deberá ser enviado por el jefe de proyecto para establecer un estándar en la conexión.

- En caso de envíos de solicitud de servicios a empresas externas, se debe copiar al correo de la empresa.

Tabla 6: Cuadro de Interesados

\begin{tabular}{|c|c|c|c|c|c|c|c|c|c|c|c|c|}
\hline \multirow{2}{*}{$\begin{array}{l}\text { Nombres y } \\
\text { Apellidos }\end{array}$} & \multirow{2}{*}{ Organización } & \multirow{2}{*}{ Cargo } & \multirow{2}{*}{$\begin{array}{l}\text { Información } \\
\text { del contacto }\end{array}$} & \multirow{2}{*}{$\begin{array}{l}\text { Requerimient } \\
\text { os sobre el } \\
\text { Producto }\end{array}$} & \multicolumn{5}{|c|}{ Influencia } & \multirow{2}{*}{$\begin{array}{l}\text { Influencia } \\
\text { sobre el } \\
\text { proyecto } \\
(1 \text { al 5) }\end{array}$} & \multirow{2}{*}{$\begin{array}{l}\text { Impacto el } \\
\text { proyecto (1 } \\
\text { al 5) }\end{array}$} & \multirow{2}{*}{ Tipo de interés } \\
\hline & & & & & I & $\mathbf{P}$ & $\mathbf{E}$ & $\mathbf{S}$ & C & & & \\
\hline $\begin{array}{c}\text { Ángel } \\
\text { Velásquez }\end{array}$ & UPC & $\begin{array}{c}\text { Gerente } \\
\text { Profesor } \\
\text { de IT- } \\
\text { Consulting }\end{array}$ & $\begin{array}{c}\text { julioqt@gmail.c } \\
\text { om }\end{array}$ & \begin{tabular}{|l} 
Información \\
sobre $\quad$ el \\
desarrollo del \\
proyecto
\end{tabular} & $凶$ & 凶 & 凶 & 凶 & 凶 & Favorable & Regular & $\begin{array}{l}\text { Colaborar con la } \\
\text { gestión del } \\
\text { proyecto. }\end{array}$ \\
\hline $\begin{array}{l}\text { Municipalid } \\
\text { ad de Villa } \\
\text { María del } \\
\text { Triunfo }\end{array}$ & Municipalidad & $\begin{array}{l}\text { Municipali } \\
\text { dad }\end{array}$ & 947972158 & $\begin{array}{l}\text { Entregable } \\
\text { final que cubra } \\
\text { sus } \\
\text { necesidades }\end{array}$ & 凶 & $\square$ & $\square$ & $\square$ & $\square$ & Favorable & Alto & $\begin{array}{l}\text { Proyecto cumpla } \\
\text { con sus } \\
\text { necesidades. }\end{array}$ \\
\hline $\begin{array}{l}\text { Allison } \\
\text { García } \\
\text { Raphael } \\
\text { Hinostroza }\end{array}$ & UPC & $\begin{array}{l}\text { Jefe de } \\
\text { Proyecto }\end{array}$ & $\begin{array}{c}\text { u201214624@u } \\
\text { pc.edu.pe } \\
\text { u201115609@u } \\
\text { pc.edu.pe }\end{array}$ & $\begin{array}{l}\text { Desarrollo del } \\
\text { proyecto }\end{array}$ & 凶 & 凶 & 凶 & 凶 & 凶 & Favorable & Alto & $\begin{array}{l}\text { Desarrollar el } \\
\text { proyecto según } \\
\text { las necesidades } \\
\text { del cliente, } \\
\text { cumpliendo con }\end{array}$ \\
\hline
\end{tabular}




\begin{tabular}{|l|l|l|l|l|l|l|l|l|l|l|l|}
\hline & & & & & & & & & & & los objetivos del \\
proyecto.
\end{tabular}

Fuente : Elaboración Propia

\section{Plan de Gestión de Riesgos}

Para el seguimiento y control de los riesgos del presente proyecto, el equipo debe realizar las siguientes actividades:

- Verificar semanalmente si alguno de los riesgos logra ocurrir.

- Mantener constante comunicación con los involucrados por si logran identificar algún riesgo.

- Iniciar seguimiento a aquellos riesgos que se considere como prioritario.

- Realizar seguimiento a los planes de contingencia y mitigación implementados para reducir la probabilidad e impacto de los riesgos del proyecto.

- En caso alguno de los riesgos identificados ha desaparecido, debe ser comunicado a todos los miembros del equipo.

Figure 2: Matriz de Riesgos - Identificación

\begin{tabular}{|c|c|c|c|c|}
\hline \multicolumn{5}{|c|}{ Identificación } \\
\hline Cód. Riesgo & Fecha de registro & Categoria - Origen & Descripción del Riesgo & Disparador \\
\hline AEGAE-R001 & 12/09/2016 & Ext - Usuarios & $\begin{array}{l}\text { Debido a que el contacto de la municipalidad no define correctamente los } \\
\text { requisitos del proyecto, podría causar demoras en el levantamiento de } \\
\text { información. }\end{array}$ & $\begin{array}{l}\text { Reunión con el contacto de la } \\
\text { municipalidad }\end{array}$ \\
\hline AEGAE-R003 & 12/09/2016 & Int - Equipo de trabajo & $\begin{array}{l}\text { Debida al abandono del proyecto por parte de un integrante del equipo, } \\
\text { podria causar que el proyecto fracase o demore en alcanzar sus tiempos } \\
\text { establecidos. }\end{array}$ & Elaboración del Project Charter \\
\hline AEGAE-R006 & 12/09/2016 & Int - Equipo de trabajo & $\begin{array}{l}\text { Debido al inadecuado seguimiento y control hacia los recursos, podria } \\
\text { ocasionar que el proyecto fracase. }\end{array}$ & Control de Calidad QS \\
\hline AEGAE-R007 & 12/09/2016 & Ext-Usuarios & $\begin{array}{l}\text { Debido al cambio de cliente luego de haber iniciado el proyecto, esto podria } \\
\text { ocasionar cambios en el proyecto ylo que el proyecto fracase. }\end{array}$ & Exposición ante el comité \\
\hline AEGAE-R008 & $5 / 10 / 2016$ & Ext-Usuarios & $\begin{array}{l}\text { Debida a a no contar con el documento de presentación por parte de la } \\
\text { universidad, esto podria ocasionar que la municipalidad no brinde la } \\
\text { información necesaria para el proyecto. }\end{array}$ & $\begin{array}{l}\text { Reunión con el contacto de la } \\
\text { municipalidad }\end{array}$ \\
\hline AEGAE-R009 & 7/111/2016 & Ext - Usuarios & $\begin{array}{l}\text { Debido a cambio de proyecto propuesto por el comité o por el cliente, esto } \\
\text { podria ocasionar que el proyecto fracase o que el proyecto no cumpla con el } \\
\text { tiempo establecido. }\end{array}$ & $\begin{array}{l}\text { Reunión con el contacto de la } \\
\text { municipalidad }\end{array}$ \\
\hline
\end{tabular}

Fuente : Elaboración Propia 
Figure 3: Matriz de Riesgos - Análisis

\begin{tabular}{|c|c|c|c|c|c|c|}
\hline \multicolumn{2}{|r|}{ Identificación } & \multicolumn{5}{|c|}{ Análisis } \\
\hline Cód. Riesgo & Descripción del Riesgo & Probabilidad & $\begin{array}{l}\text { Impacto } \\
(\mathrm{HH})\end{array}$ & Impacto & $\begin{array}{c}\text { Exp al Riesgo } \\
\text { (Horas) }\end{array}$ & $\begin{array}{l}\text { Exp al Riesgo } \\
\text { (Costo Sl.) }\end{array}$ \\
\hline AEGAE-R001 & $\begin{array}{l}\text { Debido a que el contacto de la municipalidad no define correctamente los } \\
\text { requisitos del proyecto, podría causar demoras en el levantamiento de } \\
\text { información. }\end{array}$ & 30\% Ваја & 80 & 5 Muy alta & 24.00 & 24 \\
\hline AEGAE-R002 & $\begin{array}{l}\text { Debido a la poca disponibilidad de tiempo del cliente debido a sus } \\
\text { funciones municipales, podría causar demoras en el levantamiento de } \\
\text { información. }\end{array}$ & 70\%-Alta & 70 & 5 Muy alta & 49.00 & 49 \\
\hline AEGAE-R003 & $\begin{array}{l}\text { Debido al abandono del proyecto por parte de un integrante del equipo, } \\
\text { podría causar que el proyecto fracase o demore en alcanzar sus tiempos } \\
\text { establecidos. }\end{array}$ & $30 \%$ Ваја & 60 & 5 Muy alta & 18.00 & 18 \\
\hline AEGAE-R004 & $\begin{array}{l}\text { Debido a cambios en el alcance del proyecto propuestos por el comité o por } \\
\text { el cliente, esto podria ocasionar cambios en el proyecto. }\end{array}$ & $30 \%$ Ваја & 70 & 5 Muy alta & 21.00 & 21 \\
\hline AEGAE-R005 & $\begin{array}{l}\text { Debido a no cumplir con las expectativas del cliente, esto podría ocasionar } \\
\text { que el proyecto fracase. }\end{array}$ & $50 \%$ Media & 60 & 5 Muy alta & 30.00 & 30 \\
\hline AEGAE-R006 & $\begin{array}{l}\text { Debido al inadecuado seguimiento y control hacia los recursos, podría } \\
\text { ocasionar que el proyecto fracase. }\end{array}$ & $30 \%$ Ваја & 20 & 4 Alta & 6.00 & 6 \\
\hline AEGAE-R007 & $\begin{array}{l}\text { Debido al cambio de cliente luego de haber iniciado el proyecto, esto podría } \\
\text { ocasionar cambios en el proyecto y/o que el proyecto fracase. }\end{array}$ & $10 \%$ Muy baja & 80 & 5 Muy alta & 8.00 & 8 \\
\hline AEGAE-R008 & $\begin{array}{l}\text { Debido a no contar con el documento de presentación por parte de la } \\
\text { universidad, esto podría ocasionar que la municipalidad no brinde la } \\
\text { información necesaria para el proyecto. }\end{array}$ & $30 \%$ Ваја & 85 & 5 Muy alta & 25.50 & 25.5 \\
\hline AEGAE-R009 & $\begin{array}{l}\text { Debido a cambio de proyecto propuesto por el comité o por el cliente, esto } \\
\text { podría ocasionar que el proyecto fracase o que el proyecto no cumpla con el } \\
\text { tiempo establecido. }\end{array}$ & $50 \%$ Media & 80 & 5 Muy alta & 40.00 & 40 \\
\hline
\end{tabular}

Fuente : Elaboración Propia

Figure 4: Matriz de Riesgos - Estrategia de Respuesta

\begin{tabular}{|c|c|c|c|c|c|c|c|c|c|}
\hline \multirow{2}{*}{$\begin{array}{l}\text { Identificación } \\
\text { Cód. Riesgo }\end{array}$} & \multicolumn{7}{|c|}{ Estrategia de respuesta } & \multicolumn{2}{|c|}{ Monitoreo } \\
\hline & Tipo de Estralegia & Descripción del la estralegia planteada & Rol responsable & $\begin{array}{c}\text { Ilombre } \\
\text { Responsable }\end{array}$ & Acciones realizadas & $\begin{array}{l}\text { Situación de } \\
\text { la estrattegia }\end{array}$ & Plan de Contingencia & Estado & $\begin{array}{c}\text { Fecha de cambio } \\
\text { de estado }\end{array}$ \\
\hline AEGAER001 & Mitigar & $\begin{array}{l}\text { Informar al contacto de la municipalidad sobre los } \\
\text { problemas encortrados y definii Ios requisitos con él. }\end{array}$ & Jefe & Jefe del proyedo & - & No iniciado & $\begin{array}{l}\text { Coordinar con el contacto de la municipalidad para } \\
\text { tener una reunión vitual. }\end{array}$ & No Incurrido & NA \\
\hline AEGAE-R002 & Mitigar & $\begin{array}{l}\text { Realizar con cronograma de reuniones con el contacto } \\
\text { de la municipalidad }\end{array}$ & Jefe & Jefe del proyedo & - & No iniciade & $\begin{array}{l}\text { Coordinar con el contactod de la municipalidad para } \\
\text { tener una reunión virtual. }\end{array}$ & No Incurride & NA \\
\hline AEGAE-R003 & Mitgar & $\begin{array}{l}\text { Mantener una comunicacíón constante entre los } \\
\text { paticipantes del equipo }\end{array}$ & Jefe & Jefe del proyedo to & - & No iniciado & Ajustar el alcance del proyecto. & No Incurirido & NA \\
\hline AEGAE-R004 & Mitigar & Gestionar adecuadamente la holgura del proyecto. & Jefe & Jefe del proyedo & - & No iniciado & $\begin{array}{l}\text { Coordinar con el profeseror cliente reuriones con } \\
\text { mayor frecuencia. }\end{array}$ & No Incurride & NA \\
\hline AEGAE-R005 & Mitgar & $\begin{array}{l}\text { Realizar encuestas de satisficcón al cliente de } \\
\text { manera períódica. }\end{array}$ & Jefe & Jefe del proyedo & - & No iniciado & Ajustar los requerimientos crriticos del proyecto. & No Incurrido & NA \\
\hline AEGAE-R006 & Mitgar & Realizar reuniones de seguimiento. & Jefe & Jefe del proyedo & - & No iniciado & Pedir apoye a g gerente alumno de IT-Consulting. & No Incurride & NA \\
\hline AEGAE-R007 & Mitgar & $\begin{array}{l}\text { Realizzar anáisis procesos estándares en las } \\
\text { municipaliadades. }\end{array}$ & Jefe & Jefe del proyedo & - & No iniciado & $\begin{array}{c}\text { Coordinar con el profeseor cliente reuriones con } \\
\text { mayor frecuencia. }\end{array}$ & No Incurrido & NA \\
\hline AEGAER008 & Mitigar & $\begin{array}{l}\text { Solicitar el documento de presentací́n a algún } \\
\text { miembro de comité de proyecto. }\end{array}$ & Jefe & Jefe del proyedo & & Cerrado & $\begin{array}{l}\text { Pedir información acerca de presentación formal } \\
\text { por parte de la universidad. }\end{array}$ & Desaparecio & 27092016 \\
\hline AEGAE-R009 & Mitgar & $\begin{array}{l}\text { Informar al contacto sobre el proyecto de estudio a } \\
\text { reatizary realizar un cronogograma de reuniones con el } \\
\text { contacto. }\end{array}$ & Jefe & Jefe del proyedo & - & En proceso & $\begin{array}{l}\text { Coordinar reuniones más frecuentes con la } \\
\text { municipalidadd para la entrega de información. }\end{array}$ & $\begin{array}{l}\text { Incurrido } \\
\text { (Problema) }\end{array}$ & $5 / 112016$ \\
\hline
\end{tabular}

Fuente : Elaboración Propia 


\section{Capítulo 2: Student Outcomes}

En este capítulo se detallan los student outcomes de la carrera de Ingeniería de Sistemas de Información, estos se encuentran definidos en dos grupos: competencias específicas y competencias generales; y abarca la forma cómo el proyecto ha permitido el desarrollo de dichos logros.

\section{Student Outcome A}

\section{Definición}

Los estudiantes proponen soluciones a problemas de Ingeniería de Sistemas aplicando principios de matemáticas, ciencias, computación e ingeniería.

\section{The Open Group Architecture Framework}

Framework base para la solución propuesta. Este marco de trabajo tiene como núcleo el ADM (Architecture Development Method), del cual se toma las siguientes fases:

- Fase Gestión de Requisitos: fase donde se identifican, almacenan y gestionan los requerimientos de las municipalidades, las cuales serán gestionados en las siguientes fases del ADM. Para esta fase se realizan entrevistas a representantes de las municipalidades de Villa María de Triunfo, Barranco, Santiago de Surco, Miraflores y Chorrillos.

- Fase Preliminar: fase donde se organiza la parte inicial de la arquitectura. En esta fase se determinan los principios relacionados al negocio, datos, aplicaciones, tecnología y seguridad.

- Fase Visión de Arquitectura: en esta fase se determina el alcance de la arquitectura empresarial a desarrollar, así como la misión, el sponsor y los recursos disponibles.

- Fase Arquitectura de Negocio: en esta fase se determina los objetivos y metas. 
- Fase Arquitectura de Sistemas de Información: en esta fase se obtiene la información y datos utilizados para la arquitectura empresarial para las fases del gobierno electrónico municipal desarrollado.

- Fase Arquitectura de la Tecnología: en esta fase se determina la tecnología utilizada de arquitectura empresarial para las fases del gobierno electrónico municipal desarrollado.

\section{Student Outcome B}

\section{Definición}

Los estudiantes diseñan y realizan experimentos basados en el análisis e interpretación de datos relevantes en la implementación de soluciones de sistemas de información.

\section{Modelo Propuesto}

Para la elaboración del modelo propuesto se toman datos reales obtenidos de la municipalidad de Santiago de Surco y Villa María del Triunfo gracias a la ley de transparencia que obliga a las entidades públicas a tener información de sus procesos en sus respectivas páginas web. Reuniones con la municipalidad, entrevistas a los funcionarios públicos del proceso de trámite documentario, ya que es el principal proceso para el inicio de trámites en la municipalidad, investigación acerca del gobierno electrónico, así como situación actual en el Perú, casos de éxito de aplicación del gobierno electrónico y leyes peruanas que respalden al mismo. Una vez realizada esta investigación, se inicia la elaboración del modelo con apoyo arquitectura empresarial para la implementación de este.

\section{Validación del Modelo}

Realización de un caso de estudio buscando que la municipalidad de Santiago de Surco cumpla con la fase 4 propuesta, llamada Transacción. Se identificó que el trámite de licencia de funcionamiento, por ser uno de los más solicitados por la ciudadanía en los años 2016 y 2017, cuenta con diversos servicios electrónicos propuestos para su implementación. Para lograr el objetivo se realiza el análisis del proceso actual, el planteamiento de un proceso objetivo, el cual es el proceso con mejoras luego del análisis, y el diseño de las arquitecturas de Aplicaciones, Datos y Redes para su implementación. 


\section{Student Outcome C}

\section{Definición}

Diseña sistemas y componentes para la implementación de un sistema de información, teniendo en cuenta restricciones económicas, sociales, políticas, éticas y otras propias del entorno empresarial.

\section{Modelo Propuesto}

Para el modelo propuesto se toma en cuenta las siguientes consideraciones :

- Restricciones políticas : Análisis de las leyes de gobierno electrónico desarrollados por el Estado peruano.

- Restricciones económicas : Las municipalidades se basan en el presupuesto que le brinda el Estado dependiendo de los proyectos y actividades que desarrollen dichas entidades en el año.

- Restricciones sociales : El modelo propuesto se encuentra orientado a municipalidades urbanas y no rurales.

- Restricciones éticas : El modelo propuesto se basa en procesos transparentes y reales de las municipalidades, con información de acceso público. Las modificaciones realizadas en el proceso de licencia de funcionamiento validado se desarrollaron en base a la ley de simplificación administrativa.

\section{Student Outcome D}

\section{Definición}

Los estudiantes participan en equipos multidisciplinarios, liderando o desarrollando eficientemente sus tareas con profesionales de diferentes campos de aplicación.

\section{Representantes de municipalidades}

Interacción con representantes de municipalidades de Villa María del Triunfo, Chorrillos, Barranco, Santiago de Surco y Miraflores con el fin de levantar información acerca de procesos de la municipalidad, y poder brindar una solución acorde a sus necesidades. 


\section{Abogados}

Especialistas en el tema con respecto al área legal, quienes validan que los e-servicios se alineen a las leyes peruanas de gobierno electrónico.

\section{Ingenieros}

Especialistas en el área de TI, quienes evalúan el modelo propuesto brindando sus opiniones y su aprobación acerca del mismo. Esta aprobación se basa en su amplio conocimiento con respecto al gobierno electrónico municipal.

\section{Student Outcome E}

\section{Definición}

Los estudiantes identifican y analizan problemas empresariales o tecnológicos dentro del ciclo de vida de un sistema de información.

\section{Análisis de Gobierno Electrónico}

Para este documento se analizan conceptos, definiciones y especificaciones del gobierno electrónico.

\section{Análisis de la situación actual}

En este documento se realiza un análisis de la situación actual del gobierno electrónico en el Perú, para el cual se utilizaron estadísticas, leyes y especificaciones obtenidas de la INEI, SEGDI y otras instituciones del estado.

\section{Análisis de casos de éxito del gobierno electrónico}

En este documento se detalla algunos países donde se implementó el gobierno electrónico y todas las consideraciones para tener en cuenta en dicha implementación.

\section{Investigación sobre metodologías}

La información utilizada ha sido recopilada, analizada y comparada con respecto a las metodologías consideradas para el desarrollo del proyecto. 


\section{Student Outcome F}

\section{Definición}

Los estudiantes proponen soluciones a problemas de Ingeniería de Sistemas de Información con responsabilidad profesional y ética.

\section{Análisis del tema}

Se analizan las problemáticas de las municipalidades peruanas, los casos de éxito en otros países y un estudio de gobierno electrónico junto con leyes peruanas que avalan el tema. Para este se desarrollan los entregables: Análisis de Gobierno Electrónico, Análisis de la Situación Actual y Análisis de Casos de Éxito del Gobierno Electrónico.

\section{Modelo propuesto}

Frente al problema se plantea como solución el modelo propuesto. Para la definición del modelo se realizan estudios y análisis previos, los cuales permiten encontrar la problemática, así como la situación actual del problema. Esta información es de gran importancia, ya que el modelo debe solucionar de manera efectiva dicha problemática. La validación del modelo se realiza por medio de juicio de expertos.

\section{Referencias bibliográficas}

Los documentos desarrollados a lo largo del proyecto cuentan con sus respectivas bibliografías, ya que se toman aportes e ideas de autores que contribuyen al proyecto. Con estas referencias se asegura la transparencia del trabajo y se evidencia que no hubo copia ni robo de la propiedad intelectual.

\section{Student Outcome G}

\section{Definición}

Los estudiantes se comunican oralmente o por escrito con ideas y resultados de manera clara y efectiva a audiencias con diferentes profesiones y niveles jerárquicos. 


\section{Reuniones con el profesor cliente y profesor gerente}

Estas reuniones se realizan con el fin de lograr un avance en el proyecto y atacar las dificultades presentadas. Dichas reuniones sirven de retroalimentación del proyecto y avances semanales. Las reuniones presenciales y virtuales aportan ideas, acuerdos, avances y resultados del proyecto.

\section{Reuniones de municipalidades}

Por medio de entrevistas se obtiene información acerca de la situación actual de las municipalidades de Villa María del Triunfo, Barranco, Surco, Miraflores y Chorrillos. Se les explica el propósito de la información obtenida y el beneficio de la solución planteada.

\section{Especialistas en el tema}

Presentación del desarrollo de la solución del proyecto a los abogados e ingenieros especialistas en el ámbito de gobierno electrónico, quienes brindan su apoyo en dicho tema.

\section{Actas de reunión}

Documentos donde que detallan los puntos tratados en las reuniones y acuerdos a los que se llegan. Estas actas se encuentran aprobadas y firmadas por los participantes.

\section{Exposición frente al comité}

Exposiciones de manera clara y concisa del desarrollo, y resultados del proyecto con un lenguaje fluido y con una presentación acerca del proyecto.

\section{Memoria profesional}

En este documento se detalla lo realizado en el proyecto, donde se tocan capítulos que describe el proyecto: estado del arte, marco teórico, desarrollo del proyecto y gestión de este.

\section{Student Outcome H}

\section{Definición}

Los estudiantes identifican el impacto de las soluciones de Ingeniería de Sistemas de Información en los contextos de entorno global, económico y social. 


\section{Modelo propuesto}

El modelo propuesto puede convertirse en un elemento que simplifique y propicie el proceso de implementación del gobierno electrónico municipal en el Perú, lo que genera un mejor posicionamiento del país en el ranking de la ONU con respecto al gobierno electrónico. Permite una mejor relación entre la municipalidad con sus ciudadanos y una gestión eficiente de los procesos con una eficiente gestión de sus recursos.

\section{Student Outcome I}

\section{Definición}

Los estudiantes actualizan sus conocimientos de metodologías, técnicas y herramientas, ya que son necesarios para estar al día en el desarrollo de sistemas de información.

\section{The Open Group Architecture Framework}

Es el marco de trabajo que se utiiza como base para la elaboración del proyecto, del cual se analizan las fases: preliminar, requisitos, visión de arquitectura, arquitectura de negocio, arquitectura de sistemas de información y arquitectura tecnológica, tomando algunos de los puntos de estas fases.

\section{Papers de investigación}

Se investigan papers con información relevante acerca de la aplicación del gobierno electrónico y de servicios electrónicos propuestos.

\section{Investigación sobre metodologías}

La información utilizada es recopilada de autores de las metodologías consideradas para el desarrollo del proyecto.

\section{Student Outcome J}

\section{Definición}

Los estudiantes analizan eventos del mundo contemporáneo identificando el impacto en el desempeño profesional del ingeniero de sistemas de información. 


\section{Modelo propuesto}

El proyecto busca demostrar un aumento en la eficiencia de los servicios que la municipalidad presta a los ciudadanos y empresas. Para lograr el objetivo, se propone el uso de las tecnologías de información que deben ser analizadas, implementadas y monitoreadas por un ingeniero de sistemas de información. El modelo busca simplificar la implementación de los servicios municipales, a través de e-servicios. Esto propicia una mayor demanda de actividades de ingeniería de sistemas.

\section{Student Outcome K}

\section{Definición}

Los estudiantes usan herramientas, metodologías, procesos, marcos, middleware y lenguajes de programación de vanguardia necesarios para la práctica de la ingeniería de sistemas de información.

\section{The Open Group Architecture Framework}

La elaboración del modelo propuesto se encuentra basada en las buenas prácticas del ADM, el cual es el corazón del TOGAF. Esto permite elaborar un conjunto de entregables que permiten la implementación del gobierno electrónico siguiendo la estructura de una arquitectura empresarial.

\section{LucidChart}

Herramienta que se utiliza para la creación de mockups y prototipos funcionales que complementan al proyecto.

\section{Bizagi}

Herramienta que se utiliza para el modelado del proceso que se toma para el proyecto.

\section{Metodología PMBOK}

Las buenas prácticas de PMBOK contribuyen a la gestión del proyecto. La metodología apoya de la siguiente manera : 
- Alcance : Determinar el alcance del proyecto, definiendo todos y cada una de las actividades implicadas.

- Tiempo: Gestión del tiempo para la ejecución de las actividades del proyecto, y monitorización de estos con el fin de cumplir los plazos establecidos.

- Recursos humanos: Gestión y dirección del equipo implicados en el proyecto o en cada una de las fases establecidas.

- Riesgos: Atiende a la detección, gestión y solución de los riesgos implicados en cada una de las actividades y fases.

- Skateholders: Gestiona a los interesados del proyecto y la correcta administración de las expectativas generadas con el proyecto.

\section{Comunicación Escrita}

\section{Definición}

Construye mensajes con ideas desarrolladas conectadas lógicamente entre sí. Contiene información pertinente para el desarrollo del tema. Utiliza léxico variado, preciso y académico. Respeta las convenciones de gramática, ortografía y puntuación, los errores no interfieren en la fluidez y claridad del texto.

Para el proyecto se elaboran los siguientes documentos de investigación: Gobierno Electrónico, Casos Gobierno Electrónico, Estado Perú, en donde se detalla el tema de Gobierno Electrónico, las leyes existentes en el Perú y Casos de Éxito de la aplicación de este. Se preparan plantillas a ser usadas para la implementación del Gobierno Electrónico Municipal y la elaboración de la memoria del proyecto, el cual contiene el desarrollo del proyecto.

\section{Comunicación Oral}

\section{Definición}

Estructura mensajes de manera clara y la mantiene durante toda la presentación asegurando la cohesión del contenido. Los recursos no verbales facilitan y aportan comprensión del mensaje y mantienen el interés y conexión de la audiencia. Utiliza palabras o expresiones académicas que aportan a la presentación. 
La comunicación oral con los representantes de las municipalidades de manera que las reuniones contribuyen a solicitar información y demostración del proyecto. Se tienen reuniones con abogados e ingenieros, expertos en el tema de Gobierno Electrónico, quienes brindan sus observaciones y validan el proyecto. Reuniones y exposiciones con el profesor Cliente y el profesor Gerente sirven de asesoría en los avances y resultados del proyecto.

\section{Ciudadanía}

\section{Definición}

Propone soluciones a problemas de su entorno personal y social analizando el impacto de su propuesta. Elabora iniciativas en las que evidencia claramente una perspectiva pluralista que considera la diversidad de contextos sociales, políticos y culturales.

Las reuniones con representantes de las municipalidades sirven para obtener información de los procesos municipales de acceso público. Reuniones con ciudadanos quienes realizan trámites en la municipalidad brindan información acerca de sus experiencias y opiniones al realizar dichos trámites.

\section{Pensamiento Innovador}

\section{Definición}

Reconoce problemas y oportunidades y los interpreta de manera original para proponer proyectos o propuestas funcionales e innovadoras. Desarrolla planes de acción detallados estableciendo procesos, prioridades y tareas, tiempos y recursos clave alineadas a resolver el problema planteado. Demuestra con evidencias suficientes que el proyecto es rentable y viable.

La Secretaría de Gobierno Digital (SeGDi), anteriormente ONGEI, es la entidad que regula y promueve el gobierno electrónico en el Perú, quien no cuenta con una guía de implementación del gobierno electrónico, sino que lo incentiva y es la entidad que debe buscar la forma de implementar. El proyecto busca cubrir esta necesidad con apoyo de buenas prácticas de arquitectura empresarial. 


\section{Pensamiento Crítico}

\section{Definición}

Evalúa el problema, lo plantea con claridad y lo explica exhaustivamente. Sustenta su posición entrando que detalles que enriquecen el asunto tratado tomando en cuenta el contexto. Las conclusiones están lógicamente ligadas a información pertinente e incluye diferentes puntos de vista.

El proyecto inicia en la municipalidad de Villa María del Triunfo, en el área de Trámite Documentario, ya que es el punto de partida para que los ciudadanos realicen sus trámites en la mayoría de las municipalidades. Con el análisis de las necesidades existentes y la aplicación del Gobierno Electrónico dio el surgimiento a un esquema de servicios electrónicos municipales y una guía de implementación de estos.

\section{Razonamiento Cuantitativo}

\section{Definición}

Analiza información mediante la aplicación de métodos matemáticos y estadísticos, estableciendo conclusiones coherentes. Explica los resultados de su razonamiento haciendo uso adecuado del lenguaje matemático, de forma ordenada y coherente.

Para el proyecto se realizaron encuestas para obtener información concreta y certera acerca del éxito del proyecto. El juicio de expertos a 6 personas, encuestas a 20 funcionarios municipales y 125 empresarios ayudaron a obtener estadísticas de aceptación del proyecto. El análisis financiero determina el ahorro en gastos para la municipalidad.

\section{Manejo de Información}

\section{Definición}

Plantea claramente el objetivo o problema de investigación determinando con claridad los conceptos clave. Selecciona fuentes confiables y pertinentes, sintetiza la información utilizando un sistema de referencia y las usa correcta y éticamente para construir un discurso propio, alcanzando por completo el objetivo. 
Información precisa acerca de la aplicación del Gobierno Electrónico, en qué consiste, casos de éxito y leyes en el contexto peruano que aportan al tema. Información de las municipalidades referente a sus procesos, áreas, organización y leyes municipales. 


\section{Capítulo 3: Estado del Arte}

En este capítulo se presenta una revisión del Estado del Arte del proyecto de investigación acerca del "Modelo de Mejoras de e-servicios Municipales", una búsqueda de diez artículos científicos, que van desde el año 2012 al 2017 que aportan frameworks y evaluaciones del gobierno electrónico, así como investigación acerca de los servicios electrónicos.

\section{Revisión de la Literatura}

A lo largo de la investigación realizada se identifican artículos que aportan al proyecto, los cuales se clasifican en tres temas principales: frameworks de implementación de gobierno electrónico, evaluación de modelos y servicios electrónicos correspondientes al gobierno electrónico.

Tabla 7: Temas Principales de Artículos

\begin{tabular}{|c|c|c|}
\hline \multirow{3}{*}{ 离 } & Un marco de implementación para E-Government 2.0 & $\begin{array}{l}\text { Po-Ling Sun, Cheng-Yuan Ku, } \\
\text { Dong-Her Shih }\end{array}$ \\
\hline & $\begin{array}{l}\text { Diseño y validación del marco de cultura de seguridad de la } \\
\text { información }\end{array}$ & Areej AlHogail \\
\hline & $\begin{array}{l}\text { Mapa ontológico de la arquitectura orientada a servicios para } \\
\text { servicios de administración compartidos }\end{array}$ & Hai Wanga, Shouhong Wang \\
\hline \multirow{5}{*}{ 䓛 } & $\begin{array}{l}\text { Participación de los ciudadanos en los sitios de Facebook de los } \\
\text { gobiernos locales. Un análisis empírico: El impacto de los } \\
\text { diferentes tipos de medios y contenidos en Europa Occidental }\end{array}$ & $\begin{array}{l}\text { Enrique Bonsón, Sonia Royo, } \\
\text { Melinda Ratkai }\end{array}$ \\
\hline & $\begin{array}{l}\text { Sistema de recomendación de desarrollos de aplicaciones: una } \\
\text { encuesta }\end{array}$ & $\begin{array}{l}\text { Jie Lu, DianshuangWu, } \\
\text { Mingsong Mao, Wei Wang, } \\
\text { Guangquan Zhang }\end{array}$ \\
\hline & $\begin{array}{l}\text { Facilidad de uso y la credibilidad de los sitios web de gobierno } \\
\text { electrónico }\end{array}$ & Zhao Huang, Morad Benyoucef \\
\hline & $\begin{array}{l}\text { La administración electrónica en las ciudades de la sociedad del } \\
\text { conocimiento. Una investigación empírica de los sitios web } \\
\text { gubernamentales de Smart Cities }\end{array}$ & $\begin{array}{l}\text { Kaja J. Fietkiewicz, Agnes } \\
\text { Mainka, Wolfgang G. Stock }\end{array}$ \\
\hline & $\begin{array}{l}\text { Modelo para la Calidad de los Servicios en Línea del Gobierno } \\
\text { Local }\end{array}$ & $\begin{array}{l}\text { Filipe Sá, Álvaro Rocha, } \\
\text { Joaquim Gonçalves, Manuel } \\
\text { Pérez Cota }\end{array}$ \\
\hline
\end{tabular}




\begin{tabular}{|c|c|c|c|}
\hline$\cdot \frac{\infty}{0}$ & 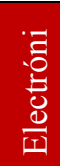 & $\begin{array}{l}\text { Investigando Discrepancias entre E-Services: Implementación o } \\
\text { No - Iso 9001: Perspectivas de los Clientes en el Ejemplo de los } \\
\text { Servicios Electrónicos en Cataluña (España) }\end{array}$ & $\begin{array}{l}\text { Petnji Yaya Luc Honore, } \\
\text { Marimon Frederic, Casadesus } \\
\text { Marti }\end{array}$ \\
\hline
\end{tabular}

\section{Fuente : Elaboración Propia}

\section{Framework}

\section{Un marco de implementación para E-Government 2.0}

Po-Ling Sun et al (2013) mencionan que las entidades del gobierno no cuentan con un marco de implementación para avanzar en la innovación de los servicios. Además, buscan promover gobiernos más eficientes y efectivos, que permitan un mayor acceso de información pública y hacer que sean más responsables ante sus ciudadanos y empresas a través del e-Gobierno 2.0. Por tal motivo, proponen un nuevo marco de implementación para E-Government 2.0. Este marco integra los procesos, recursos, back offices y front offices de los sistemas en línea para llevar a cabo el E-Government participativo orientado a las partes interesadas 2.0.

Figure 5: Visión general del marco propuesto para el gobierno electrónico 2.0

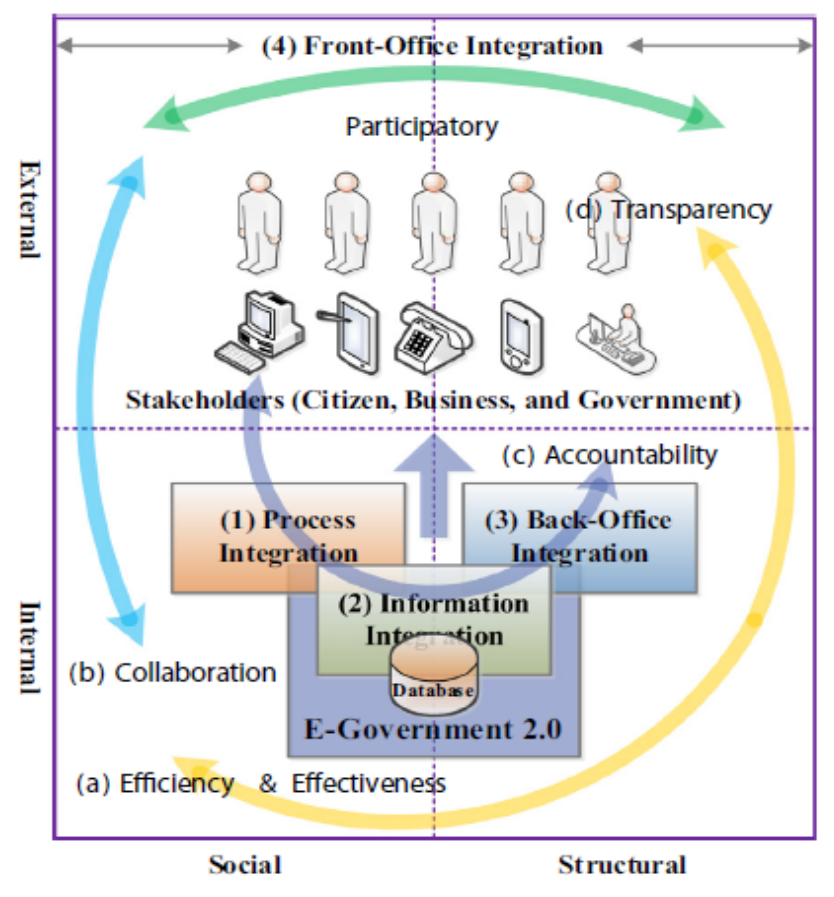

Fuente: Un marco de implementación para E-Government 2.0

El marco propuesto de la administración electrónica 2.0 es un enfoque de arriba hacia abajo que consiste en la integración de procesos, integración de recursos, Back-Office Integración, 
Integración y Front-Office. Este marco intenta mantener cuatro valores comunes: la eficiencia y la eficacia, la colaboración, la responsabilidad y la transparencia.

- Integración de procesos: Para el éxito de la transformación del Gobierno Electrónico, el entendimiento de que el gobierno electrónico no sólo se ocupa de la automatización de los procesos existentes, sino que fomenta la creación de nuevos procesos y nuevas relaciones entre las partes interesadas y el gobierno. Por lo tanto, para desarrollar un marco de E-Gobierno 2.0 competitivo y no discriminatorio, el primer paso en la evolución del gobierno abierto es identificar los servicios apropiados para atender las necesidades de las partes interesadas y determinar cómo organizarlas en la infraestructura integrada de procesos Gobierno Electrónico 2.0. Una estrategia eficiente es analizar los procesos transaccionales de los gobiernos, identificar los despidos para reducir los esfuerzos de desarrollo y hacer el mejor uso de los valiosos recursos, dinero y tiempo. Estos procesos, llevados a cabo por diferentes organizaciones, son los Procesos Comunes de Negocio (CBPs).

- Integración de Recursos: El gobierno debe dar un paso necesario en la evolución del gobierno abierto fortaleciendo los derechos de la libertad de información y construyendo sobre ellos derechos adicionales de acceso, es decir, derechos para reutilizar libremente, republicar, reutilizar y agregar valor a la información gubernamental, (IRMR). El objetivo principal del IRMR es sistematizar y estandarizar los procedimientos generales de recolección, distribución y distribución de información.

- Integración de Back-Office: En el gobierno electrónico, debe hacerse una distinción entre las oficinas de servicio público y las oficinas de apoyo de las organizaciones de prestación de servicios públicos. La interacción entre los ciudadanos y los funcionarios se produce en la oficina principal, mientras que, en la oficina de respaldo, la evaluación de las investigaciones y las actividades de registro de apoyo tienen lugar. Las actividades de back-office normalmente requieren el intercambio de información entre diferentes agencias. Por lo tanto, los proyectos de E-Gobierno 2.0 incluyen una amplia gama de contratos en los que los socios privados y los organismos gubernamentales comparten un nivel diferente de las actividades del proyecto. 
- Integración Front-Office: el modelo de gestión del portal es responsable de soportar una variedad de portales y puntos de entrada. Se recomienda que la administración del portal garantice la facilidad de uso y mantenga la información suministrada, actualizada y precisa. La actualización oportuna de la información es una necesidad para el portal de gobierno electrónico. El contenido de un portal de gobierno electrónico, que las partes interesadas perciben como más fácil de usar, probablemente aumentará la satisfacción y facilitará la reutilización. La prestación de servicios públicos es también una característica importante del portal, y tales servicios se pondrán gradualmente a disposición del público.

Para validar la arquitectura, Po-Ling Sun et al (2013) seleccionaron a Corea, Antigua y Barbuda y Ecuador como casos para demostrar que esta arquitectura es efectiva. Corea fue el líder mundial en 2010 y 2012, Antigua y Barbuda, que había logrado avances significativos, avanzó a la $49^{\mathrm{a}}$ en 2012 desde la 55 en 2010, y Ecuador, por otra parte, bajó a la $102^{\mathrm{a}}$ en 2012 desde la 95 en 2010, Basado en las encuestas de Gobierno Electrónico de las Naciones Unidas administradas en 2010 (Naciones Unidas, 2010) y 2012 (Naciones Unidas, 2012). Luego, analizaron los proyectos informáticos más representativos de dichos países y validaron si se alinean al marco propuesto. En la siguiente tabla se muestra el resultado obtenido.

Figure 6: Comparación de proyectos de gobierno electrónico con marco de e-Gobierno 2.0

\begin{tabular}{|c|c|c|c|c|c|}
\hline & & $\begin{array}{l}\text { process } \\
\text { integration }\end{array}$ & $\begin{array}{l}\text { Resource } \\
\text { integration }\end{array}$ & $\begin{array}{l}\text { Back-office } \\
\text { integration }\end{array}$ & $\begin{array}{l}\text { Front-office } \\
\text { integration }\end{array}$ \\
\hline \multirow[t]{5}{*}{ Korea } & $\begin{array}{l}\text { One-stop Service System for Export \& Import } \\
\text { Cargo (PORT-MIS) }\end{array}$ & O & $\Delta$ & $\times$ & $x$ \\
\hline & KIPOnet & 0 & $\Delta$ & $\times$ & $\times$ \\
\hline & Public Procurement Service (PPS) & 0 & 0 & $\Delta$ & $\Delta$ \\
\hline & Home Tax Service (HTS) & 0 & $\Delta$ & 0 & $\Delta$ \\
\hline & Government for Citizen (G4C) & O & O & $\Delta$ & O \\
\hline \multirow[t]{3}{*}{$\begin{array}{l}\text { Antigua and } \\
\text { Barbuda }\end{array}$} & $\begin{array}{l}\text { Electronic Government Regional Integration } \\
\text { Project (EGRIP) }\end{array}$ & ० & $\Delta$ & ० & $\Delta$ \\
\hline & $\begin{array}{l}\text { Public and Social Sector Transformation (PSST) } \\
\text { Project }\end{array}$ & $\Delta$ & $\times$ & $\times$ & $\times$ \\
\hline & National Office of Disaster Services (NODS) & $\Delta$ & $\Delta$ & $\Delta$ & $\times$ \\
\hline \multirow[t]{3}{*}{ Ecuador } & $\begin{array}{l}\text { National Plan for the Development of } \\
\text { Telecommunications }\end{array}$ & $\times$ & $\times$ & $\times$ & $\times$ \\
\hline & PRESIDENCIA Website & $\times$ & $\Delta$ & $\times$ & $\times$ \\
\hline & The Tax Office - SRI project & $\Delta$ & $\Delta$ & $\Delta$ & $\Delta$ \\
\hline
\end{tabular}

Fuente: Un marco de implementación para E-Government 2.0 


\section{Diseño y validación del marco de cultura de seguridad de la información}

Areej AlHogail (2015) considera que la literatura carece de la investigación, que se centra en el uso de tácticas de gestión del cambio en la implementación información cultura de seguridad. Por lo tanto, ha utilizado el ámbito estructurado STOPE (Strategy; Technology; Organization; People; and Environment) como base para el marco para integrar las diversas cuestiones de seguridad de la información. El marco resultante incorpora los cuatro dominios principales del factor humano diamante: preparación, responsabilidad, gestión, sociedad y regulaciones. E1 marco también incorpora principios de gestión del cambio que guían el cultivo de la cultura de la seguridad de la información.

Figure 7: Marco de cultura de seguridad de la información

\begin{tabular}{|c|c|c|c|c|c|c|}
\hline \multirow{2}{*}{$\begin{array}{l}\text { Issues: } \\
\text { Human } \\
\text { Behavior } \\
\text { Diamond }\end{array}$} & \multicolumn{5}{|c|}{ Scope: } & \multirow{2}{*}{$\begin{array}{l}\frac{\text { Development }}{\text { Tool: }} \\
\text { Change } \\
\text { Management }\end{array}$} \\
\hline & S & $\mathbf{T}$ & 0 & $\mathbf{P}$ & $\mathbf{E}$ & \\
\hline \multirow{3}{*}{ Preparedness } & \multirow{3}{*}{\multicolumn{5}{|c|}{$\begin{array}{l}\text { Prepare employees to behave securely through training, awareness, } \\
\text { knowledge acquisition, and change in perception. }\end{array}$}} & Training \\
\hline & & & & & & Focus groups \\
\hline & & & & & & Change agents \\
\hline \multirow{3}{*}{ Responsibility } & \multirow{3}{*}{\multicolumn{5}{|c|}{$\begin{array}{l}\text { Ensure employees are behaving securely through monitoring and } \\
\text { control, reward and deterrence, and applicability }\end{array}$}} & Motivation \\
\hline & & & & & & $\begin{array}{l}\text { Milestones and } \\
\text { measures }\end{array}$ \\
\hline & & & & & & Involvement \\
\hline \multirow{3}{*}{ Management } & \multirow{3}{*}{\multicolumn{5}{|c|}{$\begin{array}{l}\text { Ensure management support by showing management commitment, } \\
\text { effective communication and interaction, and facilitation of } \\
\text { resources. }\end{array}$}} & $\begin{array}{c}\text { Management } \\
\text { support }\end{array}$ \\
\hline & & & & & & Resources \\
\hline & & & & & & Communication \\
\hline $\begin{array}{l}\text { Society and } \\
\text { Regulations }\end{array}$ & \multicolumn{5}{|c|}{$\begin{array}{l}\text { Consider external factors such as national culture, ethical conduct, } \\
\text { government initiatives, and legal and regulations system }\end{array}$} & Culture analysis \\
\hline \multicolumn{7}{|c|}{ Outcome: behavior (artifacts), values, assumptions and knowledge to enhance information security } \\
\hline Older State & \multicolumn{5}{|c|}{ TIME } & New State \\
\hline
\end{tabular}

Fuente: Diseño y validación del marco de cultura de seguridad de la información

El marco cuenta con cinco dimensiones básicas basadas en el modelo STOPE y guiadas por los principios de gestión del cambio y el factor humano diamante se utilizarán para desarrollar el marco de la cultura de seguridad de la información. Una descripción de las cinco dimensiones se presenta a continuación : 
- Estrategia: En el contexto del artículo se refiere a la implementación apropiada de diferentes estrategias de seguridad de la información tales como planes de acciones, políticas, objetivos, mejores prácticas, estándares, directrices y prioridades que están diseñados para guiar a los miembros de la organización a alcanzar el objetivo de proteger los activos de información. Políticas formales, mejores prácticas, directrices y controles ayudan a los empleados a recibir un mensaje consistente y claro sobre lo que está prohibido y las consecuencias de la violación. Se ha sugerido que, para lograr una adhesión efectiva a las diferentes estrategias de seguridad, como las mejores prácticas y directrices, debe haber una cultura de seguridad de la información bien formada para apoyarla

El factor humano diamante propuesto presenta cuatro dominios de factores humanos que influyen en el comportamiento de seguridad de la información. La cultura de seguridad de la información debe considerar cuidadosamente cada factor humano para mejorar el comportamiento de seguridad del usuario. Los cuatro dominios son los siguientes:

- El dominio de la "preparación", que se ocupa principalmente de la formación y la concienciación, la adquisición de conocimientos y el cambio de prácticas antiguas.

- El dominio de "responsabilidad", que se relaciona principalmente con las prácticas y el desempeño de los empleados, tales como monitoreo y control, recompensa y disuasión, y aceptación de responsabilidad.

- El dominio de la "gestión", que se ocupa de la política de seguridad, la práctica, la dirección y las cuestiones de interacción.

- El dominio de la "sociedad y regulaciones", que se relaciona principalmente con los aspectos sociales y culturales y los asuntos de regulación.

\section{Mapa ontológico de la arquitectura orientada a servicios para servicios de administración compartidos}

Hai Wanga y Shouhong Wang (2013) indica que, en la literatura, los informes de investigación sobre SOA se han centrado más en tecnologías computacionales (por ejemplo, cloud computing, redes de servicios Web virtuales y estándares de software), mientras que los estudios sobre SS (Shared Services) han puesto más énfasis en la gestión organizativa de procesos de negocio a través de aplicaciones de tecnología de la información. Desde el punto 
de vista de la gestión de la tecnología de la información, la integración de los dos temas es imprescindible para establecer la gestión SS (SSM) que soporta la transformación de los requisitos de procesos de negocio en la informática centrada en el servicio. Debido a esto, propone un mapa ontológico para SSM para aplicar SOA. Este enfoque de mapeo, basado en el conocido marco Zachman de arquitectura de la información, especifica la perspectiva ontológica de SOA para SSM. El mapa ontológico enlaza semánticamente todos los aspectos de SOA para SSM.

Figure 8: Vista ontológica primaria de SOA para SSM

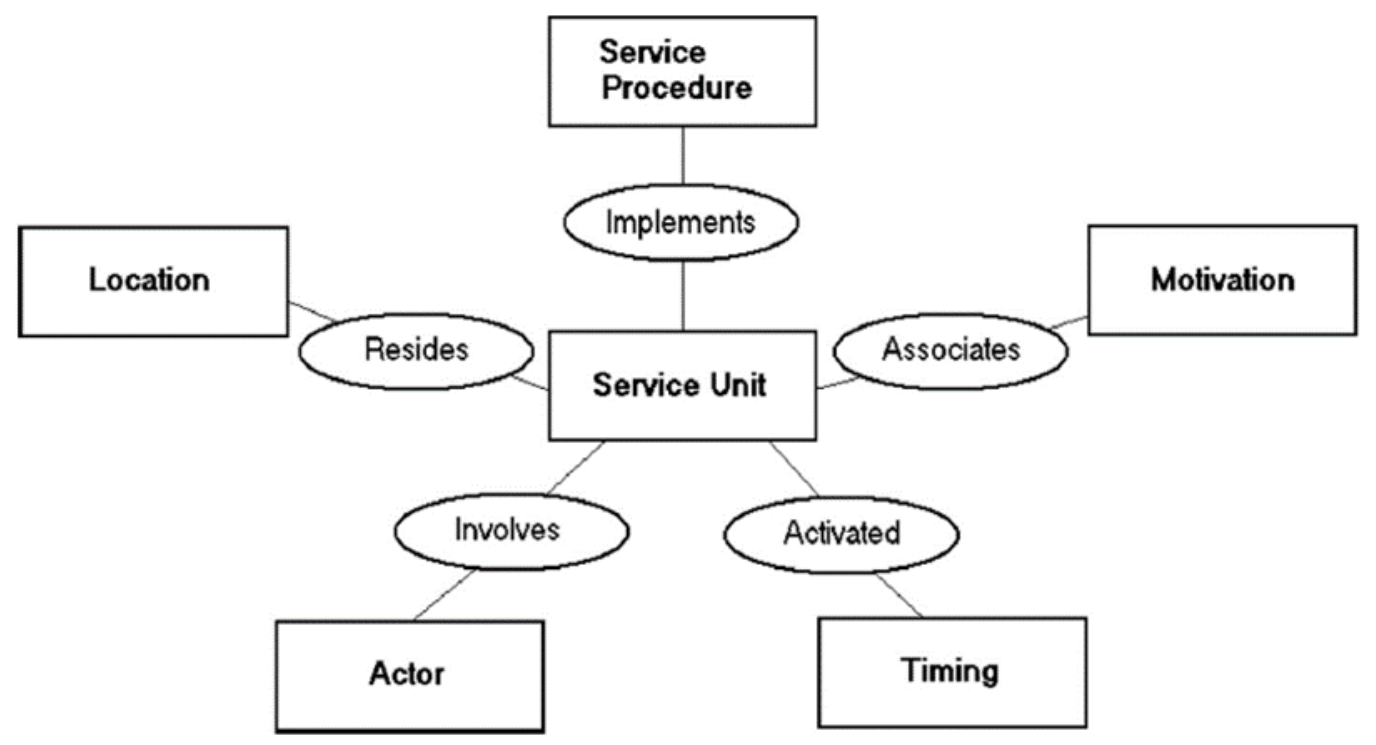

Fuente: Mapa ontológico de la arquitectura orientada a servicios para servicios de administración compartidos

El autor explica que una ontología es una red conceptual de todos los objetos relacionados que se muestran las relaciones semánticas entre estos objetos en el dominio en cuestión. Por lo tanto, la ontología es una verdadera metodología de modelado orientado a objetos unificado. En el campo de la informática, se han hecho esfuerzos para utilizar lenguajes de programación tales como Web basados en XML. El estudio indica que el mapa ontológico de SOA para SSM es un modelo ontológico para la representación visual de las clases de los aspectos de SOA y sus relaciones semíticas para SSM. Dicho mapa puede ser dinámico o interactivo para el usuario. Al construir el mapa ontológico de SOA para SSM, hace hincapié, como primero paso, se debe formalizar los aspectos más importantes de SOA para SSM basado en el marco de arquitectura de información seleccionado, el cual es Zachman. El segundo paso es integrar 
estos aspectos principales en una ontología con propiedades semánticas. El tercer paso es computarizar la ontología para que los planificadores SS y constructores SOA puedan acceder y compartir fácilmente el mapa SOA. Según el marco de arquitectura, se debe analizar en base a:

- Unidad de servicio (Qué): Una unidad de servicio se refiere a una aplicación de software de identificación que tiene cierta capacidad de servicio de negocio y apoya la interacción directa con el cliente. Una parte central de SOA para SSM es la provisión de las estructuras de servicio para SS.

- Procedimiento de servicio (Cómo): Un procedimiento de servicio se refiere a un conjunto de procesos realizados por una unidad de servicio a través de la interacción entre el cliente y el sistema anfitrión para llevar a cabo el servicio. Un procedimiento de servicio puede ser compartida por muchos servicios.

- Localización de servicio (Dónde): Un proveedor de servicio o un cliente de servicio deben tener una instalación de cálculo registrado. Una ubicación de las instalaciones de computación especifica la ubicación lógica (URL o dirección IP) del centro de la computación en la red de servicio virtual, así como la ubicación física de la instalación de computación en el entorno de computación en nube que hace posible la transparencia de ubicación. Las descripciones de la ubicación de los proveedores de servicios y clientes de servicios de información proveen al SSM en la planificación estratégica y la gestión de recursos de computación operativa de la red SS.

- Actor (Quién): Una de las principales funciones de mapeo SOA para SSM es analizar las características de los actores del sistema con el fin de proporcionar más información acerca de las personas de la red de servicios para realizar una planificación estratégica y operativa sobre los recursos humanos.

- Sincronización (Cuando): El aspecto de la sincronización de los servicios describe los horarios y las secuencias de los servicios correlacionados. Los servicios pueden ser agregados para formar los servicios compuestos y servicios de colaboración a través de las especificaciones de tiempo de SS. 
- Motivación (Porqué): La motivación general de SOA es el ahorro de costes. La motivación aspecto de SOA para SSM es la optimización de las operaciones de servicio a nivel de red SS.

Como un ejemplo de la vista ontológico de una unidad de servicio, espectáculos el segmento ontológico de un servicio de pago de impuestos línea de SS de la administración electrónica para los gobiernos municipales locales.

\section{Evaluación}

\section{Participación de los ciudadanos en los sitios de Facebook de los gobiernos locales. Un análisis empírico: El impacto de los diferentes tipos de medios y contenidos en Europa Occidental}

Las investigaciones encontradas por Enrique Bonsón et al (2014) son muy limitadas sobre el impacto de los medios de comunicación y tipos de contenido en el compromiso de las partes interesadas. Sólo hay unos cuantos documentos que miden la interacción real con las partes interesadas, e incluso se centran menos en cómo el tipo de contenido influye en la participación de los usuarios. Es por esto que el objetivo de este estudio es medir el impacto de los medios de comunicación y tipos de contenido en el compromiso de las partes interesadas en las páginas de Facebook de los gobiernos locales de Europa Occidental.

Los autores realizan la clasificación de las iniciativas de participación ciudadana en la edad de $\mathrm{SM}$ por medio de $\mathrm{C} 2 \mathrm{G}$ y relaciones $\mathrm{G} 2 \mathrm{C}$ y se refuerza la idea de que la transición de la administración electrónica (ciudadano como cliente) para que el gobierno (ciudadano como socio) es “un nuevo tipo de contrato social”, Donde el público juega un papel mucho más activo de lo que era tradicionalmente.

Esto puede ayudar a los ciudadanos y los gobiernos, como compañeros, a estar más informados y tomar decisiones socialmente responsables. También está surgiendo como un nuevo y poderoso mecanismo de resolución de problemas, a través del cual los ciudadanos utilizan sus habilidades y conocimientos para resolver los retos del gobierno. Un nuevo nivel de gobierno transparente y abierto ha sido habilitado cuando estén disponibles los conjuntos de datos como un libro abierto. 


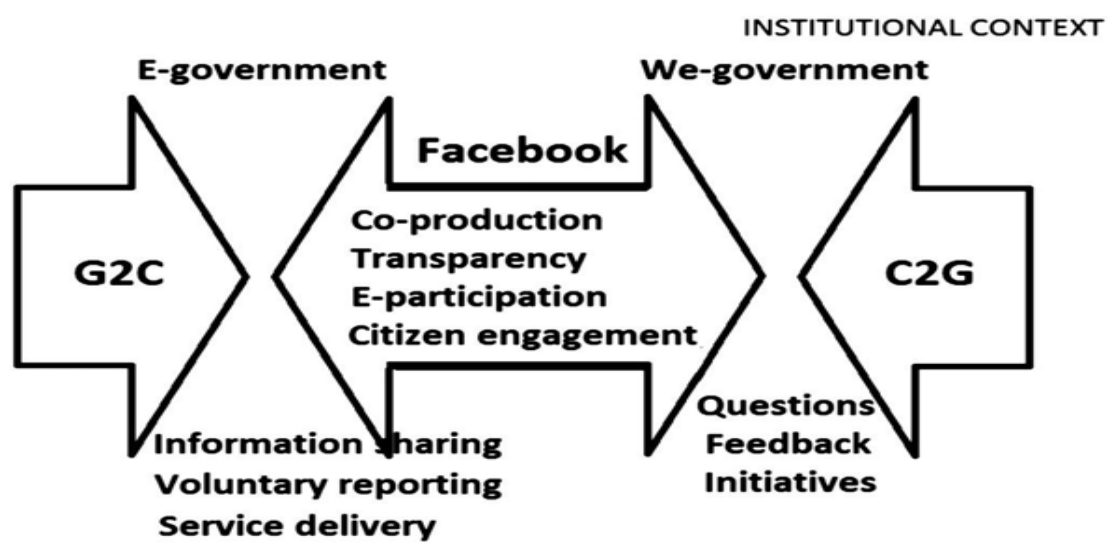

Fuente: Participación de los ciudadanos en los sitios de Facebook de los gobiernos locales. Un análisis empírico: El impacto de los diferentes tipos de medios y contenidos en Europa Occidental

Por lo que, los mensajes en el muro de Facebook se codificaron siguiendo una doble clasificación para diferenciar entre los medios y tipos de contenido, como sigue. Para el tipo de medios de comunicación, las categorías fueron los siguientes: (1) de vídeo, (2) enlace, (3) de la foto, (4) de texto y (5) otros. Sólo los vídeos incrustados fueron considerados en la categoría de video. Enlaces volver a dirigir a un vídeo con tienda de campaña fueron considerados como enlaces. A pesar de que en Facebook la mayor parte de los enlaces contienen una miniatura, que eran considerados como enlaces y no como las fotos. Fotos con textos fueron contados como fotos, porque los textos son partes complementarias de ellos. Sólo se consideraron aquellos puestos donde no se encontraron enlaces, no hay videos, y no hay fotos para ser textos. Esos mensajes que no caen en cualquiera de las cuatro categorías antes mencionadas (por ejemplo, "los eventos") Se contaron como "otros".

En cuanto al análisis del tipo de contenido, dieciséis categorías fueron utilizados para la codificación: (1) obras públicas y urbanismo, (2) el medio ambiente, (3) Atención al ciudadano, (4) la participación ciudadana, (5) los servicios sociales, (6) Protección de los ciudadanos y de seguridad, (7) de transporte público, (8) programas de empleo y formación, (9) salud, (10) educación, (11) actividades culturales y deportivas, (12) la vivienda, (13) temas de gobernabilidad, (14) fide información financiera, (15) de marketing/promoción de la 
ciudad/turismo, y (16) otros. esta clasificación de los tipos de contenido se basa en las listas de los servicios locales.

También examinaron si los municipios permiten publicaciones en el muro de los interesados. En Facebook esta función es opcional. Por lo tanto, cada municipio tiene el derecho de decidir si permiten que los interesados en publicar en su "pared" o no, que puede ser considerado como un signo de apertura por parte de los municipios

Para medir el compromiso de los ciudadanos en las páginas de Facebook, se recopiló el número de gustos, comentarios y participaciones para calcular tres métricas de Facebook definidas por Bonsón y Ratkai (2013), reflejando popularidad (P3), compromiso (C3) Y la viralidad (V3); Junto con un índice agregado adicional de compromiso (E). Como puede verse en la Tabla 9, P3, C3 y V3 se han desinflado por el número de ventiladores. Dado que estas métricas son independientes del tamaño de la audiencia, parecen ser las más representativas en cuanto a medir el compromiso. Por lo tanto, sólo estas métricas y el nivel agregado de compromiso se utilizaron en este estudio. A partir de ahora, nos referiremos a ellos como popularidad, compromiso, vialidad y compromiso, respectivamente.

Figure 10: Métricas de Facebook para la participación de los interesados

\begin{tabular}{|c|c|c|c|}
\hline \multirow{4}{*}{ Popularidad } & & Cantidad de envíos gustado / total de & Porcentaje de puestos que se han gustado \\
\hline & P1 & mensajes & Número promedio de talla por puesto \\
\hline & P2 & talla total / número total de puestos & número promedio de talla por puesto por 1000 seguidores \\
\hline & P3 & (P2/ número de fans) $\times 1000$ & Porcentaje de puestos que se han comentado \\
\hline \multirow[b]{2}{*}{ Compromiso } & & Cantidad de envíos comentado / total de & Número promedio de los comentarios por puesto \\
\hline & $\mathrm{Cl}$ & mensajes & Número promedio de los comentarios por puesto por 1000 \\
\hline \multirow{4}{*}{ viralidad } & $\begin{array}{l}\mathrm{C} 2 \\
\mathrm{C} 3\end{array}$ & $\begin{array}{l}\text { Total de comentarios } / \text { total de mensajes } \\
\text { (C2 /número de ventiladores) } \times 1000\end{array}$ & seguidores \\
\hline & & Cantidad de envíos compartida / total de & $\begin{array}{l}\text { Porcentaie de puestos que se han compartido } \\
\text { número medio de acciones por puesto }\end{array}$ \\
\hline & V2 & $\begin{array}{l}\text { mensiajes } \\
\text { El total de acciones / total de mensaies }\end{array}$ & número medio de acciones por puesto por 1000 \\
\hline & V3 & (V2 $/$ número de fans) $\times 1000$ & ventiladores de las partes interesadas indice de \\
\hline Compromiso & $\mathrm{mi}$ & $\mathrm{P} 3+\mathrm{C} 3+\mathrm{V} 3$ & participación \\
\hline
\end{tabular}

Fuente: Participación de los ciudadanos en los sitios de Facebook de los gobiernos locales. Un análisis empírico: El impacto de los diferentes tipos de medios y contenidos en Europa Occidental

Para examinar nuestras proposiciones, calcularon la medida de compromiso diferenciando entre los medios de comunicación, los tipos de contenido, los estilos de administración pública y si el gobierno local permitió o no los mensajes de pared por parte de las partes interesadas. 
Se utilizaron las pruebas t, la prueba de Kruskal-Wallis, las tablas de contingencia y la prueba de chi cuadrado de Pearson para probar posibles diferencias.

La imagen, muestra una visión general del uso de Facebook entre los gobiernos locales de Europa Occidental analizados. Municipalidades germánicas presentan la mayor tasa de adopción de Facebook (100\%), seguido de anglosajón (90\%), Nordic (85\%) y el sur de Europa (66\%) los gobiernos locales. En promedio, 59 municipios (de los 75) tenían una página de Facebook en el período examinado.

Figure 11: Utilización de Facebook en gobiernos locales

\begin{tabular}{lllr}
\hline & $\begin{array}{l}\text { municipios que utilizan } \\
\text { Facebook }\end{array}$ & $\begin{array}{l}\mathrm{n}^{0} \text { total. de } \\
\text { municipios }\end{array}$ & $\%$ \\
\hline anglosajón & 9 & 10 & 90 \\
nórdico & 17 & 20 & 85 \\
germánico & 10 & 10 & 100 \\
del sur de Europa & 23 & 35 & 66 \\
Total & 59 & 75 & 79 \\
\hline
\end{tabular}

Fuente: Participación de los ciudadanos en los sitios de Facebook de los gobiernos locales. Un análisis empírico: El impacto de los diferentes tipos de medios y contenidos en Europa Occidental

El principal resultado obtenido se muestra en la imagen siguiente, se pueden encontrar ciertos patrones según el tipo de contenido. En términos generales, el tipo de contenido más utilizado es el de "actividades culturales y deportivas" (23,7\% de los puestos), seguido por "marketing / ciudad / turismo" (15,8\%) y "obras públicas y urbanismo" (7,4\% Los tipos de contenido menos frecuentes fueron "informes financieros" (0,6\%); "Vivienda" (0,7\%) y salud $(1,6 \%)$. Estos patrones son bastante similares entre los diferentes estilos de administración pública. La actividad cultural y deportiva es el tipo de contenido más frecuente en los gobiernos locales anglosajones, nórdicos y del sur de Europa, y el segundo en los municipios germánicos, donde la mayoría de los puestos (34,8\%) se ocupan de "marketing/city promotion/tourism". "Marketing/promoción de la ciudad/Turismo "es un tema frecuente entre todos los estilos de las administraciones públicas, pero el anglosajón, donde sólo el 2,4\% de los puestos abordan este tema. Sin embargo, la gobernanza y las cuestiones medioambientales desempeñan un papel importante en los gobiernos locales anglosajones $(8,4 \%$ de los puestos para cada uno de estos dos tipos de contenido). Como se indica en la prueba de Pearson de chi cuadrado en la parte 
inferior de la tabla, existen diferencias entre la importancia relativa de los diferentes tipos de contenido entre la administración pública.

Figure 12: Porcentaje de publicaciones por tipo de contenido y estilo de administración pública

\begin{tabular}{|c|c|c|c|c|c|}
\hline \multirow[t]{2}{*}{ Content types } & \multicolumn{5}{|c|}{ Public administration style } \\
\hline & Angb-Saxon & Nordic & Germanic & Napoleonic & Total \\
\hline $\begin{array}{l}\text { Public works and town } \\
\text { planning }\end{array}$ & 8.2 & 8.4 & 2.6 & 8.4 & 7.4 \\
\hline Environment & 8.4 & 6.8 & 3 & 3 & 4.9 \\
\hline Attention to the citizen & 8.2 & 6.4 & 2.8 & 9 & 7.1 \\
\hline Citizen participation & 5.6 & 6 & 1.2 & 2 & 3.6 \\
\hline Social services & 6.4 & 4.2 & 1.2 & 3.2 & 3.7 \\
\hline $\begin{array}{l}\text { Citizen protection and } \\
\text { security }\end{array}$ & 5.6 & 1.3 & 1 & 1.9 & 2.1 \\
\hline Public transport & 1.3 & 1.8 & 0.6 & 3.9 & 2.3 \\
\hline $\begin{array}{l}\text { Employment and training } \\
\text { schemes }\end{array}$ & 1.8 & 3.8 & 0 & 0.9 & 1.7 \\
\hline Health & 0.4 & 2.7 & 0.4 & 1.7 & 1.6 \\
\hline Education & 4.2 & 4.2 & 1.6 & 3.3 & 3.4 \\
\hline Cultural activities and sports & 19.1 & 20 & 29 & 25.8 & 23.7 \\
\hline Housing & 0.7 & 0.5 & 0.8 & 0.8 & 0.7 \\
\hline Governance issues & 8.4 & 4 & 2.2 & 5.7 & 5.1 \\
\hline Financial reporting & 0.9 & 0.2 & 0.4 & 1 & 0.6 \\
\hline $\begin{array}{l}\text { Marketing/city } \\
\text { promotion/tourism }\end{array}$ & 2.4 & 14.9 & 34.8 & 13.5 & 15.8 \\
\hline Other & 18.2 & 14.8 & 18.4 & 16 & 16.4 \\
\hline Total & 100 & 100 & 100 & 100 & 100 \\
\hline
\end{tabular}

Note: value of Pearson's chi-squared test $=449.607$; significant at the $1 \%$ level.

Fuente: Participación de los ciudadanos en los sitios de Facebook de los gobiernos locales. Un análisis empírico: El impacto de los diferentes tipos de medios y contenidos en Europa Occidental

\section{Sistema de recomendación de desarrollos de aplicaciones : una encuesta}

Según Jie Lu et al (2015), los aumentos de sobrecarga de información podrían obstaculizar claramente la eficacia de los servicios de gobierno electrónico, y generar dificultad en la localización de la información adecuada para los usuarios adecuados teniendo un alto impacto en la lealtad de los usuarios. Para comprender y analizar los desarrollos de aplicaciones de los sistemas de recomendación, el autor revisa primero las principales técnicas de recomendación, incluyendo métodos tradicionales como el filtrado colaborativo, el basado en el contenido, el conocimiento y los métodos híbridos, y los métodos avanzados desarrollados recientemente, 
Como los enfoques basados en conjuntos difusos, basados en redes sociales, basados en la confianza, basados en el conocimiento del contexto y en grupos.

- Técnicas de recomendación basadas en contenido: Las técnicas de recomendación basadas en el contenido (CB) recomiendan artículos o productos similares a los elementos previamente preferidos por un usuario específico. Los principios básicos de los sistemas de recomendación CB son:

1. Analizar la descripción de los elementos preferidos por un usuario en particular para determinar los principales atributos comunes (preferencias) que pueden utilizarse para distinguir estos elementos. Estas preferencias se almacenan en un perfil de usuario.

2. Comparar los atributos de cada ítem con el perfil de usuario para que solo se recomienden ítems que tengan un alto grado de similitud con el perfil de usuario.

- Técnicas de recomendación basadas en filtros colaborativos: Las técnicas de recomendación basadas en el filtrado colaborativo (CF) ayudan a las personas a tomar decisiones basadas en las opiniones de otras personas que comparten intereses similares. La técnica de la FC se puede dividir en enfoque basado en el usuario y basado en ítems CF. En el enfoque de FC basado en el usuario, un usuario recibirá recomendaciones de artículos que gustan de usuarios similares. En el enfoque de CF basado en ítems, un usuario recibirá recomendaciones de ítems que son similares a los que han amado en el pasado.

- Técnicas de recomendación basadas en el conocimiento: La recomendación basada en el conocimiento $(\mathrm{KB})$ ofrece artículos a los usuarios basados en el conocimiento sobre los usuarios, artículos y / o sus relaciones. Por lo general, las recomendaciones de KB mantienen una base de conocimientos funcional que describe cómo un ítem en particular satisface la necesidad de un usuario específico, que se puede realizar basándose en inferencias sobre la relación entre la necesidad de un usuario y una posible recomendación.

- Técnicas de recomendación híbridas: Para lograr un mayor rendimiento y superar los inconvenientes de las técnicas de recomendación tradicionales, se ha propuesto una 
técnica de recomendación híbrida que combina las mejores características de dos o más técnicas de recomendación en una técnica híbrida.

- Técnicas de recomendación basada en la inteligencia computacional: Las técnicas de inteligencia computacional (CI) incluyen técnicas bayesianas, redes neuronales artificiales, técnicas de agrupamiento, algoritmos genéticos y técnicas de conjuntos difusos. En sistemas de recomendación, estas técnicas de inteligencia computacional se utilizan ampliamente para construir modelos de recomendación.

- Técnicas de recomendación basadas en redes sociales: El análisis de redes sociales (SNA) se ha utilizado en sistemas de recomendación como resultado del dramático crecimiento de las herramientas de redes sociales en sistemas basados en Web en los últimos años. Para ayudar a mejorar la experiencia del usuario, los sistemas de recomendación proporcionan cada vez más a los usuarios la capacidad de interactuar socialmente con otros usuarios, como la amistad en línea, hacer comentarios sociales, etiquetas sociales, etc. Estas tendencias ofrecen oportunidades para hacer recomendaciones utilizando los lazos sociales de los usuarios, Especialmente para sistemas cuyos datos de calificación son demasiado escasos para realizar el filtrado colaborativo.

- Técnicas de recomendación basadas en el conocimiento de contexto: Define el contexto como -alguna información que puede utilizarse para caracterizar la situación de una entidad. Una entidad podría ser una persona, un lugar o un objeto que se considere relevante para la interacción entre un usuario y una aplicación, incluido el usuario y la propia aplicación. "La información de contexto, como el tiempo, la información geométrica o la compañía de Otras personas (amigos, familias o colegas, por ejemplo) ha sido recientemente considerada en los sistemas de recomendación existentes; Por ejemplo, la información obtenida con el rápido crecimiento del uso de teléfonos móviles.

- Técnicas de recomendación de grupo: Se proponen sistemas de recomendación de grupo (GRS) para producir un grupo de sugerencias de los usuarios cuando los miembros del grupo no pueden reunirse para la negociación cara a cara, o sus preferencias no son claras a pesar de reunirse entre sí. GRS también se llaman sistemas de recomendación de actividades de grupo electrónico, y se han aplicado a muchos 
dominios incluyendo películas, música, páginas web, eventos y problemas complejos como planes de viaje. Muchas estrategias, inspiradas en la teoría de la elección social y el procedimiento de toma de decisiones, se utilizan para agregar a todos los miembros en un grupo.

Por esta razón, hace un análisis de sistema de recomendación de G2C y G2B.

- Recomendación sobre el servicio G2C

Para apoyar a los ciudadanos en su acceso a servicios personalizados y adaptados suministrados por las oficinas de la administración pública, un sistema multi-agente fue presentado por De Meo et al. El sistema propuesto identifica y sugiere los servicios más interesantes para un usuario, considerando tanto el perfil del usuario y el perfil del dispositivo que se utilice. Para ayudar a los votantes a tomar decisiones en el proceso de e-electoral, se propuso un sistema de recomendación, que utiliza métodos de agrupamiento difuso y proporciona información sobre los candidatos cercanos a las preferencias de los votantes.

- Recomendación sobre el servicio G2B

En los servicios G2B, muchos artículos desde una perspectiva de negocio son artículos de un solo uso, tales como eventos, que por lo general reciben una calificación de sólo después de que hayan acabado. Las técnicas tradicionales de Filtración colaborativa (como CF), no pueden recomendar este tipo de artículos debido a los datos de calificación dispersos. Para hacer frente a este problema, propusieron un nuevo enfoque que se ocupa de un problema recomendación de atributos considerados por la integración de las técnicas de similitud semántica con la tradicional basada en la FQ elemento Un sistema de recomendación llamada Smart Comercio Buscador de Exposiciones (STEF), lo que sugiere exposiciones comerciales adecuados para las empresas, se ha desarrollado. Para reflejar de forma flexible la información graduada / incierto en el dominio G2B, modelados similitudes de usuario y de artículo como relaciones difusas. También propusieron un nuevo enfoque híbrido CF-CB cuya razón se resume de manera concisa como recomendación artículos futuros si son similares a los elementos del pasado que los usuarios similares. Luego se desarrolló un marco recomendación basada en la lógica difusa híbrido para mejorar el sistema de recomendación exposición comercial para el gobierno electrónico.

A continuación, se resumen de los sistemas de recomendación encontrados por el autor. 
Figure 13: Resumen de técnicas de recomendación en cada dominio de aplicación

\begin{tabular}{|c|c|c|c|c|c|c|c|c|c|}
\hline Domains & $\mathrm{CB}$ & $\mathrm{CF}$ & $\mathrm{KB}$ & Hybrid & $\begin{array}{l}\text { Computational } \\
\text { Intelligence }\end{array}$ & $\begin{array}{l}\text { Social } \\
\text { Network }\end{array}$ & $\begin{array}{l}\text { Context } \\
\text { Aware }\end{array}$ & $\begin{array}{l}\text { Group } \\
\text { Aggregation }\end{array}$ & $\begin{array}{l}\text { No. of listed } \\
\text { references }\end{array}$ \\
\hline E-government & 1 & 5 & 1 & 5 & 4 & & & & 9 \\
\hline E-business & & 1 & 3 & 3 & 4 & 1 & & & 5 \\
\hline E-commerce/E-shopping & 3 & 1 & 4 & 1 & 4 & 2 & & & 8 \\
\hline E-library & 2 & 2 & & 3 & 1 & & & & 6 \\
\hline E-learning & 2 & & 11 & & 2 & & & & 10 \\
\hline E-tourism & 5 & 9 & 9 & 9 & 3 & 2 & 11 & & 18 \\
\hline E-resource & 9 & 16 & 6 & 15 & 8 & 1 & 1 & & 27 \\
\hline E-group activity & 9 & 5 & 2 & 5 & 1 & & & 2 & 21 \\
\hline Total & 31 & 39 & 36 & 41 & 27 & 6 & 12 & 2 & 104 \\
\hline
\end{tabular}

Fuente: Sistema de recomendación de desarrollos de aplicaciones: una encuesta

\section{Facilidad de uso y la credibilidad de los sitios web de gobierno electrónico}

En su investigación Zhao Huang y Morad Benyoucef (2014) encontraron que muchos estudios se han centrado en definir constructos de usabilidad de sitios web de gobierno electrónico. Algunos estudios midieron las dimensiones multifacéticas de la usabilidad del sitio web de gobierno electrónico, mientras que otros evaluaron su influencia en la actitud y los comportamientos de los usuarios.

Para la elaboración de su propuesta, tomaron tres sitios web fueron que seleccionados por una serie de razones. En primer lugar, los sitios web de gobierno electrónico locales son los más cercanos a los usuarios (en comparación con los sitios web regionales o nacionales) y son utilizados con frecuencia por el público en general. El gobierno electrónico local se centra en las necesidades directas de los usuarios en el acceso a la información y los servicios. En segundo lugar, dado que el gobierno local debe liderar la creación de contenidos y servicios de alta calidad, es importante comprender los efectos del gobierno electrónico local en los usuarios. En tercer lugar, la evidencia de estudios previos sugiere que existen mayores desafíos a nivel local del gobierno electrónico, así como el diseño de su sitio web Tales desafíos (por ejemplo, errores en el sitio web) pueden resultar en un bajo compromiso del usuario con el gobierno electrónico. 
Se plantearon tareas representativas, ya que son las que normalmente se esperaría que los usuarios llevar a cabo en un sitio web del gobierno electrónico. Mencionan que hay tres categorías de servicios de gobierno electrónico :

a. Distribución de la información: se refiere a la prestación de todo tipo de información a través de la página web de e-gobierno.

b. Los servicios ofrecidos: Se refieren a la prestación de servicios de ida a los usuarios, tales como descargas de documentos, y la búsqueda de información.

c. Participación del usuario: implica interactuar los usuarios con los servicios de dos vías en el sitio web, por ejemplo, registros de nacimiento electrónicos o pagos de impuestos.

Sobre la base de estas categorías se plantearon las tareas.

Figure 14: Tareas asignadas a los usuarios antes de llenar el cuestionario

\begin{tabular}{lll}
\multicolumn{2}{l}{ Tasks assigned to users prior to filling the questionnaire. } & Service category \\
\hline No & Task & $1 \& 2$ \\
\hline 1 & Find the name of the Chief Executive officer of London Authority 1 & $1 \& 2$ \\
2 & Find the title of any job related to social work in London Authority 1, including reference number, job description & $1 \& 2$ \\
3 & Search the telephone number of the Planning Department in London Authority 1 & $1 \& 2$ \\
4 & Find the Revenue Budget 2008-09 of London Authority 1 & 2 \\
5 & Use the search engine on this website to find the place to apply for "Free School Meals" & 183 \\
6 & Use "A to Z service" to find information about how to join the local library, fill in the adult library membership form and submit the form via the website & $2 \& 3$ \\
7 & Find the latest news about the reopening date of London Authority 1 Leisure centre & 2 \\
8 & Download the Primary School Guide 2009-10 to the computer (Drive C:|Form download) & 2 \\
9 & Sign-in to the system first, and fill in a "compliments, comments and complaints online form" to complain that there is no street lamp on XXX Road and & $2 \& 3$ \\
\hline & submit to London Authority 1 & \\
\hline
\end{tabular}

Fuente: Facilidad de uso y la credibilidad de los sitios web de gobierno electrónico

Elaboró un cuestionario para evaluar la percepción de la facilidad de uso y la credibilidad de los sitios web de destino de gobierno electrónico de los participantes. Hay tres pasos en el diseño del cuestionario. En primer lugar, hay una necesidad de ampliar las directrices existentes para cumplir con la especificación de requisitos del gobierno electrónico. En segundo lugar, un conjunto de criterios asociados para cada directriz se desarrolló con el fin de centrarse en los aspectos detallados de la usabilidad y la credibilidad. En tercer lugar, las especificaciones de preguntas se desarrollan en base a estos criterios. 
Figure 15: Nielsen (1994) y las pautas de usabilidad

\begin{tabular}{lll}
\multicolumn{2}{l}{ Nielsen's (1994) and extend usability guidelines. } \\
\hline No. & Usability guidelines & Interpretation \\
\hline U1 & Visibility of system status & To keep users informed about their progress \\
U2 & Match between system and the real world & To use the user' language, follow real-world conventions, make information appear in a natural and logical order \\
U3 & User control and freedom & To make undo, redo functions available during interaction \\
U4 & Consistency and standards & To keep the same design features and follow platform conventions through website \\
U5 & Error prevention & To support users to overcome errors and prevent same problem occurrence \\
U6 & Recognition rather than recall & To make information easily remembered \\
U7 & Flexibility, efficiency of use & To consider usage for both novice and experienced users \\
U8 & Aesthetic design & To make minimalist design \\
U9 & Help user recover errors & To precisely indicate the problem and constructively suggest a solution \\
U10 & Help and documentation & To provide help to support user's task completion \\
U11 & Interoperability & To make all service parts, design elements, and website functions work as a whole to support user task completion \\
U12 & Support users' skills & To support and develop users' current skills and knowledge \\
U13 & Respectful interaction & To present a pleasant design and treat users with respect \\
\hline
\end{tabular}

Fuente: Facilidad de uso y la credibilidad de los sitios web de gobierno electrónico

Figure 16: Fogg's (2002) y extensas pautas de credibilidad

\begin{tabular}{lll}
\multicolumn{2}{l}{ Fogg's (2002) and extended credibility guidelines. } \\
\hline No. & Credibility guidelines & Interpretation \\
\hline C1 & Design look & A clean, professional layout that fits the purpose and makes a good impression \\
C2 & Information accuracy & Third party references, links to source materials, proof that information is from a trusted source. \\
C3 & Real world feel & Providing information like a physical address and detailed company background \\
C4 & Expertise & Providing credentials and any awards won in the field \\
C5 & Trustworthiness & Photographs of department directors and the management team help give users dues to who is behind the website. \\
C6 & Contact information & Providing clear and easy to find contact information helps to portray the image that the organization cares about the needs of its users. \\
C7 & Ease of use & Users can easily complete their tasks using the website. \\
C8 & Content update & Providing proof of when content was last updated or reviewed shows evidence that the website is being used and is current. \\
C9 & Promotional content & Using restraint with any promotional content \\
C10 & Avoid errors & Preventing problems from all types, such as typographical errors and broken links \\
C11 & Transparency & The website should keep users informed of governmental operations and make government budgeting and spending information available. \\
C12 & Service agility & The website should provide flexible services to fit different user paths. \\
C13 & Privacy and security & The website should protect users' information and secure its services. \\
\hline
\end{tabular}

Fuente: Facilidad de uso y la credibilidad de los sitios web de gobierno electrónico

Para evaluar la propuesta, seleccionaron 36 participantes que fueron asignados a los 3 sitios web municipales (12 para cada sitio). Esta fue planteada en base a tres actividades, las cuales son (1) revisión gratuita; (2) interacción basada en tareas; (3) Cuestionario. Luego de la realización de estas tareas por los participantes, se obtuvieron los siguientes resultados.

Figure 17: Debilidad de la usabilidad

\begin{tabular}{|c|c|c|c|c|}
\hline $\mathrm{U}$ & Q & Usability problems & Mean (SD) & Significance \\
\hline \multicolumn{5}{|c|}{ London Authority 1} \\
\hline 8 & 33 & Users are confused by links that have many different colours & $2.32(1.084)$ & $\mathbf{t}=-3.303, p=0.007$ \\
\hline 10 & 40 & Online help function is not clearly indicated on the website & $2.33(1.155)$ & $\mathrm{t}=-3.350, \mathrm{p}=0.006$ \\
\hline 10 & 41 & It is difficult to switch between online help and current work & $2.75(0.866)$ & $\mathrm{t}=-2.800, \mathrm{p}=0.017$ \\
\hline \multicolumn{5}{|c|}{ London Authority 2} \\
\hline 1 & 2 & Some options on the home page are not clearly presented & $2.17(1.030)$ & $\mathrm{t}=-3.879, \mathrm{p}=0.003$ \\
\hline 8 & 33 & Users are confused by links that have many different colours & $2.25(0.866)$ & $t=-4.280, p=0.001$ \\
\hline 5 & 22 & The website sometimes does not indicate a task's progress & $2.33(0.888)$ & $\mathrm{t}=-3.851, \mathrm{p}=0.003$ \\
\hline 8 & 32 & Links already visited are not clearly marked & $2.50(1.243)$ & $\mathrm{t}=-2.285, \mathrm{p}=0.043$ \\
\hline 5 & 19 & The website allows users to skip over the order of the process & $2.67(0.778)$ & $\mathrm{t}=-2.907, \mathrm{p}=0.014$ \\
\hline \multicolumn{5}{|c|}{ London Authority 3} \\
\hline 8 & 33 & Users are confused by links that have many different colours & $2.58(0.669)$ & $\mathrm{t}=-6.511, \mathrm{p}=0.000$ \\
\hline 4 & 16 & Subject categories are presented without a logical order & $2.83(1.030)$ & $\mathrm{t}=-3.386, \mathrm{p}=0.006$ \\
\hline 8 & 32 & Links already visited are not clearly marked & $2.92(1.084)$ & $\mathrm{t}=-2.952, \mathrm{p}=0.013$ \\
\hline 3 & 13 & Information is unbalanced between breadth and depth & $3.00(0.853)$ & $\mathrm{t}=-3.412, \mathrm{p}=0.006$ \\
\hline
\end{tabular}

Fuente: Facilidad de uso y la credibilidad de los sitios web de gobierno electrónico 
Los resultados del ANOVA unidireccional muestran que existe una diferencia significativa en la percepción general de usabilidad de los participantes $(\mathrm{F}(2,33)=8,784, \mathrm{P}=0,001)$ entre los tres sitios web. Puesto que un promedio bajo indica una mala evaluación general, London Authority 2 tiene la peor evaluación general, con una media de usabilidad general de $3.323 \mathrm{y}$ una desviación estándar de 0.367. London Authority 1 se ubicó en segundo lugar, con una media de usabilidad global de 3.445 y una desviación estándar de 0.304. London Authority 3 tiene la mejor puntuación con una media de evaluación general de usabilidad de 3.843 y una desviación estándar de 0.275.

Figure 18: Debilidad de la credibilidad

\begin{tabular}{|c|c|c|c|c|}
\hline c & Q & Credibility problems & Mean (SD) & Significance \\
\hline \multicolumn{5}{|c|}{ London Authority 1} \\
\hline 1 & 2 & Information is not presented by the consistent colours & $2.58(0.996)$ & $\mathrm{t}=-3.883, \mathrm{p}=0.003$ \\
\hline 1 & 6 & Subject/topic categories are not presented with order & $2.58(0.872)$ & $\mathrm{t}=-3.356, \mathrm{p}=0.018$ \\
\hline 4 & 14 & Instruments and messages displayed by the website are not concise & $2.65(0.756)$ & $\mathrm{t}=-3.122, \mathrm{p}=0.034$ \\
\hline 5 & 16 & The website does not display any awards it has eamed & $2.72(0.784)$ & $t=-3.658, p=0.046$ \\
\hline 6 & 20 & The website does not show detailed contact information & $2.75(0.682)$ & $\mathrm{t}=-3.252, \mathrm{p}=0.025$ \\
\hline 7 & 24 & Information is arranged without a balance between breadth and depth & $2 . \oplus(0.458)$ & $\mathrm{t}=-2.543, \mathrm{p}=0.012$ \\
\hline 7 & 22 & Navigating the website is not easy & $2.83(0.743)$ & $t=-3.358, p=0.018$ \\
\hline 7 & 23 & It is not clear what page I am on and how far left of the quote process & $2.86(0.642)$ & $t=-3.682, p=0.038$ \\
\hline 8 & 25 & The website has not a latest update & $2.72(0.632)$ & $\mathrm{t}=-3.345, \mathrm{p}=0.023$ \\
\hline \multicolumn{5}{|c|}{ London Authority 2} \\
\hline 5 & 16 & The website does not display any awards it has earned & $2.17(0.866)$ & $\mathrm{t}=-4.280, \mathrm{p}=0.001$ \\
\hline 7 & 22 & Navigating the website is not easy & $2.17(0.937)$ & $\mathrm{t}=-2.242, \mathrm{p}=0.047$ \\
\hline 7 & 24 & Information is arranged without a balance between breadth and depth & $2.17(1.030)$ & $t=-3.879, p=0.003$ \\
\hline 6 & 20 & The website does not show detailed contact information & $2.33(0.888)$ & $\mathrm{t}=-3.851, \mathrm{p}=0.003$ \\
\hline 5 & 15 & It is not easy to find an "about us" page & $2.50(1.243)$ & $\mathrm{t}=-2.285, \mathrm{p}=0.043$ \\
\hline 1 & 2 & Information is not presented by the consistent colours & $2.67(0.778)$ & $\mathrm{t}=-2.907, \mathrm{p}=0.014$ \\
\hline 7 & 23 & It is not clear what page I am on and how far left of the quote process & $2.67(0.985)$ & $t=-2.720, p=0.020$ \\
\hline 8 & 25 & The website has not a latest update & $2.92(0.515)$ & $\mathrm{t}=-3.521, \mathrm{p}=0.005$ \\
\hline \multicolumn{5}{|c|}{ London Authority 3} \\
\hline 8 & 25 & The website has not a latest update & $2.58(0.669)$ & $t=-6.511, p=0.000$ \\
\hline 13 & 38 & Protected or confidential areas can be accessed without certain password & $2.58(0.872)$ & $\mathrm{t}=-3.323, \mathrm{p}=0.004$ \\
\hline 13 & 39 & A secure message is not appeared when access some confidential information & $2.75(0.866)$ & $\mathrm{t}=-4.560, \mathrm{p}=0.001$ \\
\hline 5 & 17 & The website does not display information about who is in charge of & $2.83(1.030)$ & $\mathrm{t}=-3.386, \mathrm{p}=0.006$ \\
\hline 5 & 16 & The website does not display any awards it has eamed & $2.92(1.084)$ & $\mathrm{t}=-2.952, \mathrm{p}=0.013$ \\
\hline 11 & 34 & User status is not indicated in an action & $3.00(0.853)$ & $\mathrm{t}=-3.412, \mathrm{p}=0.006$ \\
\hline
\end{tabular}

Fuente: Facilidad de uso y la credibilidad de los sitios web de gobierno electrónico

Por otro lado, los resultados también muestran una diferencia significativa en la percepción general de credibilidad de los participantes $(\mathrm{F}(2,33)=4.885, \mathrm{P}=0.014)$ entre los tres sitios. En concreto, London Authority 2 tiene la peor evaluación general, con una media de credibilidad general de 3,436 y una desviación estándar de 0,322. London Authority 1 es el segundo, con una media de credibilidad general de 3.699 y una desviación estándar de 0.432 . London Authority 3 tiene la mejor puntuación, con una media de credibilidad general de 3.885 y una desviación estándar de 0.291. 


\section{La adminoistración electrónica en las ciudades de la sociedad del}

conocimiento. Una investigación empírica de los sitios web gubernamentales de Smart Cities

Kaja J. Fietkiewicz et al (2016) menciona que, en términos de usabilidad, Holzer et al. se centran en indicadores formales para un sitio web "utilizable". La propuesta tiene un enfoque es más orientado, ya que examina la usabilidad de los sitios web mientras se están cumpliendo tareas típicas. Los aspectos restantes investigados por Holzer y otros, contenido, servicio y participación ciudadana, corresponden parcialmente con nuestro enfoque. Sin embargo, consideramos que algunos de sus indicadores aplicados no son comparables, por ejemplo, menciona qué dentro de la dimensión de la participación ciudadana, aspectos tales como boletines de noticias o retroalimentación se ponen junto con utilidades más sofisticadas como video sincrónico o capacidades de chat. Su modelo distingue entre utilidades más desafiantes de las simples que hoy en día son muy comunes. Por lo tanto, formularon un modelo de criterios ampliado para la cuantificación de la madurez de la administración electrónica, analizamos la calidad media de la arquitectura de información de 31 sitios web oficiales de Informational World Cities y estudiaron el procesamiento de documentos fronterizos. Elaboraron el modelo de criterios en base a los 5 pilares de administración electrónica. 
Figure 19: Cinco pilares

\begin{tabular}{|c|c|c|c|}
\hline Pillar & Question & Points & $\begin{array}{l}\text { Total } \\
\text { points }\end{array}$ \\
\hline \multicolumn{3}{|c|}{ INFORMATION } & \multirow[t]{13}{*}{100} \\
\hline & Are press releases available? & 8,3 & \\
\hline & Is basic information available? & 8,3 & \\
\hline & Is information on healthcare available? & 8,3 & \\
\hline & Is information on politics available? & 8,3 & \\
\hline & Is information on services available? & 8,3 & \\
\hline & Are forms for services available? & 8,3 & \\
\hline & Is information for various user-groups available? & 8,3 & \\
\hline & Is the website accessible via smartphones? & 8,3 & \\
\hline & Are applications for smartphones available? & 8,3 & \\
\hline & Are push services available? & 8,3 & \\
\hline & Is the website available in English? & 8,3 & \\
\hline & $\begin{array}{l}\text { Is the website available in the languages of the three } \\
\text { most important immigrant groups? }\end{array}$ & 8,3 & \\
\hline \multicolumn{3}{|c|}{ COMMUNICATION } & \multirow[t]{6}{*}{100} \\
\hline & Are social media services used? & 20 & \\
\hline & $\begin{array}{l}\text { Is it possible to make appointments with an authority } \\
\text { via the web? }\end{array}$ & 20 & \\
\hline & Do I get answers to email requests? & 20 & \\
\hline & Is emailing possible instead of written (snail) mail? & 20 & \\
\hline & Is it possible to leave feedback or complaints? & 20 & \\
\hline \multicolumn{3}{|c|}{ TRANSACTION } & \multirow[t]{7}{*}{100} \\
\hline & Is it possible to fill out forms online? & 16,6 & \\
\hline & Is it possible to pay taxes online? & 16,6 & \\
\hline & Is it possible to pay penalties online? & 16,6 & \\
\hline & Is it possible to pay fees online? & 16,6 & \\
\hline & Are services for libraries available? & 16,6 & \\
\hline & Is a personalized portal available? & 16,6 & \\
\hline \multicolumn{3}{|c|}{ INTEGRATION } & \multirow[t]{4}{*}{100} \\
\hline & Is an entry homepage available? & 50 & \\
\hline & Email: Cooperation with authorities? & 50 & \\
\hline & Software/safety measure/intranet/database? & & \\
\hline \multicolumn{3}{|c|}{ PARTICIPATION } & \multirow[t]{5}{*}{100} \\
\hline & Are online questionnaires available? & 25 & \\
\hline & Do forums and platforms for asking questions exist? & 25 & \\
\hline & $\begin{array}{l}\text { Is it possible to participate in a community meet ing via } \\
\text { the WWW? }\end{array}$ & 25 & \\
\hline & Is it possible to vote online? & 25 & \\
\hline
\end{tabular}

Fuente: La administración electrónica en las ciudades de la sociedad del conocimiento. Una investigación empírica de los sitios web gubernamentales de Smart Cities

De acuerdo con esta interpretación dada por ellos, las etapas serán vistas como pilares de la administración electrónica. El primer paso de este modelo, con el objetivo de apoyar un sitio web con información, debe ser establecido antes de que cualquier otra función pueda ser implementada. Por esta razón, los aspectos de usabilidad y la existencia de documentos fronterizos son analizados adicionalmente para el pilar de información (también catálogo etiquetado). Los pilares restantes no tienen que ser necesariamente logrados en un orden estricto. Los detalles de los cinco pilares de la administración electrónica son explicados a continuación: 
- Pilar 1: Difusión de la información (catálogo): De importancia en este punto es el contenido publicado en Internet, usabilidad y accesibilidad.

- Pilar 2: Comunicación: El segundo pilar se refiere a la bidireccionalidad de la comunicación, que hoy en día gira en torno a cada vez más las redes sociales.

- Pilar 3: Transacción: Este pilar consiste en los servicios transaccionales de administración electrónica, como la renovación de la licencia, votante de un conductor registro, información del parque estatal y reserva, el pago de impuestos y penalidades, etc.

- Pilar 4: Interoperabilidad (integración): Reclamación que el componente clave de iniciativas de administración electrónica es la posibilidad de múltiples organizaciones gubernamentales y no gubernamentales para compartir e integrar información a través de sus fronteras de la organización.

- Pilar 5: Participación: Participación electrónica se centra en la democracia e incluye servicios tales como encuestas políticas, foros de discusión o votación en línea políticos.

Además, define 3 conceptos más que son evaluados:

a. La usabilidad de los sistemas de navegación: Para la evaluación, optó por el método introducido por Röttger y Stock (2003), donde la calidad media de la arquitectura de información es usada como el indicador para un análisis comparativo de los sitios web. La medición de la calidad se basa en las tasas de clic y las tasas de rotura controlada en las pruebas de usuario basada en tareas. las tasas de clic de los usuarios nos permiten calcular la media de calidad de los sistemas de navegación para cada sitio web gubernamental.

b. Formulamos: Se plantearon diez tareas de búsqueda y navegación para comprobar si los usuarios pudieron acceder a los servicios básicos de información o de núcleo en los sitios web sin ningún problema. Diseñamos diez tareas típicas, por ejemplo, “¿Quién es el jefe de gobierno?” o "Encontrar información sobre la biblioteca pública". Se presentaron los casos a nuestras personas de la prueba.

c. Documentos de frontera: Evalúa que tan entendible es la documentación que tiene la página web para explicar cómo esta funciona, además de explicar que comunidades que participan en la web.

Para la evaluación, cada pilar se valora en 100 puntos, lo que lleva a una puntuación máxima de 500 puntos. La investigación se basa en los sitios web gubernamentales oficiales de cada 
una de las 31 Ciudades Mundiales Informativas en su idioma nativo o en inglés, traducido con Google Translate. Además, enviaron correos electrónicos a los contactos oficiales y preguntaron sobre la integración horizontal y vertical en sus ciudades. Se realizó más información utilizando los programas de administración electrónica, la prensa y los sitios oficiales de las ciudades mundiales de la información. La evaluación fue realizada por los autores entre diciembre de 2012 y enero de 2013. De esta manera, se obtuvo los siguientes resultados :

Figure 20: Madurez de 31 e-Gobiernos

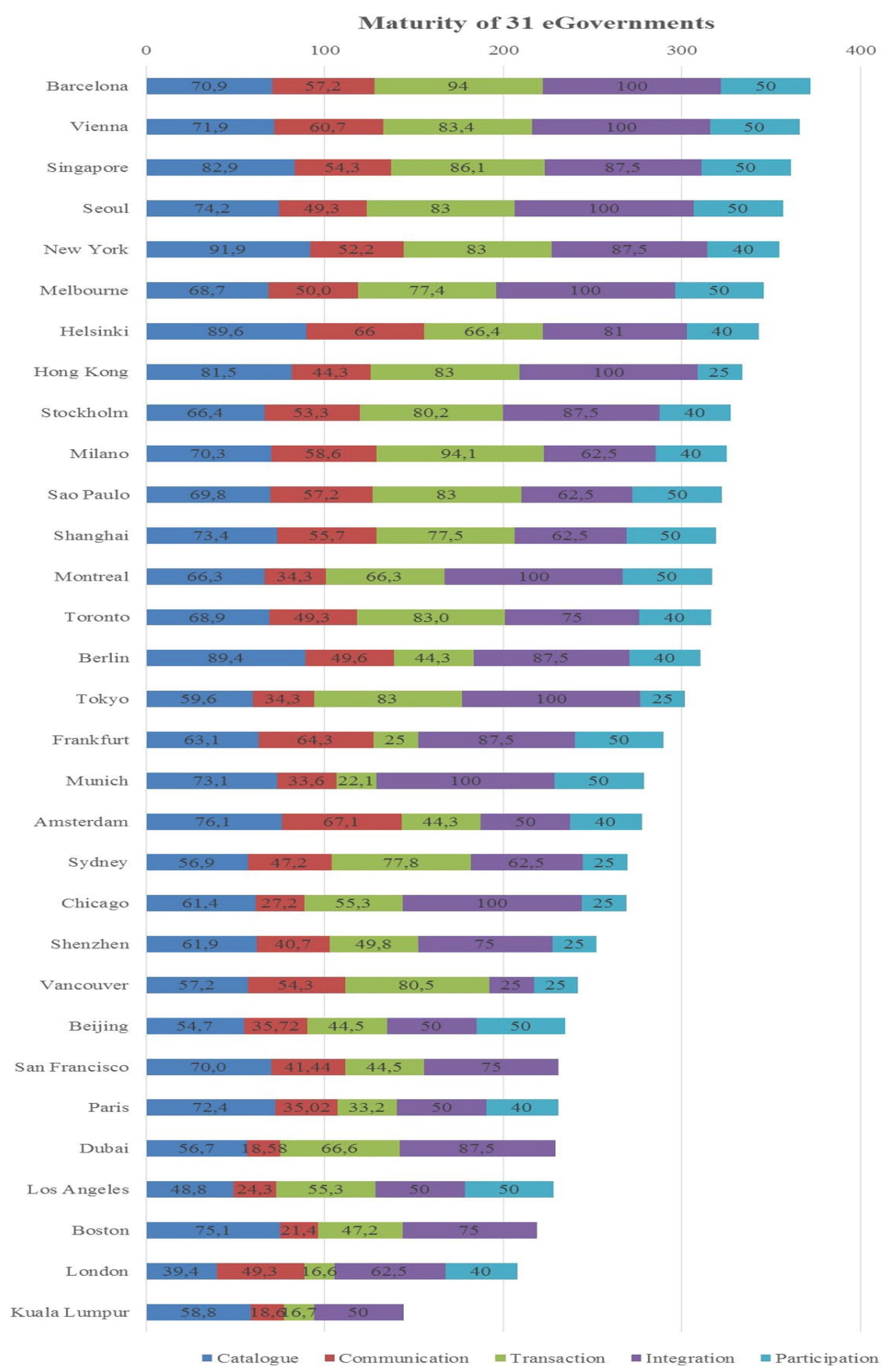

Fuente: La administración electrónica en las ciudades de la sociedad del conocimiento. Una investigación empírica de los sitios web gubernamentales de Smart Cities 


\section{Modelo para la Calidad de los Servicios en Línea del Gobierno Local}

Filipe Sá et al. Mencionan que las calidades de estos servicios en línea no son analizados ni tomados en cuenta con el fin de fortalecer y desarrollar estrategias que mejoren los servicios ofrecidos y aumentar el nivel de satisfacción entre los usuarios. Con este trabajo, los autores pretenden desarrollar un modelo integral para evaluar la calidad de los servicios del gobierno local en línea. Realizaron un estudio empírico basado en 21 entrevistas con expertos del gobierno local. A partir de esta recolección y análisis de evidencias, identificamos 30 dimensiones que evalúan específicamente los servicios en línea del gobierno local. El siguiente paso consistió en enviar esta lista a un proceso de método Delphi, para validar, agregar, eliminar o expandir dimensiones y dominios. Este método les permitió llegar a un consenso en dos rondas y contó con la participación de 44 expertos. Como resultado del proceso de Delphi Method, se desarrolló un modelo específico compuesto por 32 dimensiones (criterios de evaluación) divididos en cuatro áreas para la evaluación de los servicios en línea del gobierno local, las cuales son explicadas en las siguientes líneas.

Figure 21: Dimensiones finales

\begin{tabular}{|c|c|c|c|c|c|c|c|}
\hline \multicolumn{2}{|l|}{ Management } & \multicolumn{2}{|l|}{ Services } & \multicolumn{2}{|c|}{ Information } & \multicolumn{2}{|l|}{ Technical } \\
\hline Dimension & 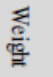 & Dimension & 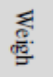 & Dimension & $\underset{\substack{g \\
g}}{\stackrel{y}{g}}$ & Dimension & 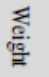 \\
\hline Transparency & 4 & Reliability & 4 & $\begin{array}{l}\text { Information } \\
\text { Quality }\end{array}$ & 3 & Usability & 4 \\
\hline Process Management & 4 & $\begin{array}{l}\text { Deadline } \\
\text { Compliance }\end{array}$ & 4 & $\begin{array}{c}\text { Task } \\
\text { Information }\end{array}$ & 2 & Accessibility & 4 \\
\hline $\begin{array}{l}\text { Online Services } \\
\text { Advantage }\end{array}$ & 4 & Security & 4 & & & Compatibility & 3 \\
\hline E-Participation & 3 & Privacy & 4 & & & $\begin{array}{c}\text { Website } \\
\text { Technical Quality }\end{array}$ & 3 \\
\hline $\begin{array}{l}\text { Democratisation of } \\
\text { the Decision }\end{array}$ & 3 & Complaints & 3 & & & $\begin{array}{l}\text { Website Access } \\
\text { Speed }\end{array}$ & 2 \\
\hline Capacitation & 2 & $\begin{array}{l}\text { Customer } \\
\text { Support } \\
\end{array}$ & 3 & & & Website Design & 1 \\
\hline E-Democracy & 2 & Usefulness & 3 & & & $\begin{array}{r}\text { Website } \\
\text { Innovation }\end{array}$ & 1 \\
\hline Alternative Channels & 1 & 2. Payment & 2 & & & & \\
\hline Politicians Role & 1 & $\begin{array}{c}\text { Service } \\
\text { Availability }\end{array}$ & 2 & & & & \\
\hline & & Interoperability & 2 & & & & \\
\hline & & $\begin{array}{l}\begin{array}{l}\text { Processing } \\
\text { Speed }\end{array} \\
\end{array}$ & 1 & & & & \\
\hline & & $\begin{array}{c}\text { Variety of } \\
\text { Offered Services }\end{array}$ & 1 & & & & \\
\hline & & Online Integrity & 1 & & & & \\
\hline & & Customization & 1 & & & & \\
\hline
\end{tabular}

Fuente: Modelo para la Calidad de los Servicios en Línea del Gobierno Local

Mencionan que, la calidad de estos servicios en línea debe analizarse y tenerse en cuenta con el fin de fortalecer y desarrollar estrategias que mejoren los servicios ofrecidos y aumenten el nivel de satisfacción entre los usuarios. Con esto en mente, en el presente trabajo de 
investigación, desarrollamos un modelo integral para evaluar la calidad de los gobiernos locales en línea.

Para la evaluación, las preguntas del 1 al 9 - los evaluadores puntúan las dimensiones relativas a la "Gestión", "Transparencia", "Gestión de procesos", "Ventajas de los servicios en línea", "E Participación", "Democratización de la decisión", "Capacitación", "Democracia electrónica", "Canales alternativos" y "Políticos". Al final de esta evaluación, se estima el valor N1, derivado de la suma de las puntuaciones asignadas a cada dimensión multiplicada por el peso de cada dimensión dentro del dominio, se estima.

$$
N 1=\frac{\sum_{i=1}^{n} \text { Clasificación asignación de dimensiones }_{i} x \text { Peso de dimesión }_{i}}{\sum_{j} \text { Peso del dominio de la gestión } n_{j}}
$$

Las preguntas del 10 al 23 - estos aspectos impactan directamente el servicio en línea real proporcionado por el gobierno local, el dominio "Servicios". Estas cuestiones, que los evaluadores deben evaluar, se refieren a las siguientes dimensiones: "Confiabilidad", "Cumplimiento de la fecha límite", "Seguridad", "Privacidad", "Reclamaciones", "Atención al cliente", "Utilidad", "Pagos" "Disponibilidad de servicio", "Interoperabilidad", "Velocidad de procesamiento", "Variedad de servicios ofrecidos", "Integridad en línea" y "Personalización" Al final de esta evaluación, el valor N2, derivado de la suma de puntuaciones asignadas a cada uno Dimensión veces el peso de cada dimensión dentro del dominio, se estima.

$$
N 2=\frac{\sum_{i=1}^{n} \text { Clasificación asignación de dimensiones }_{i} x \text { Peso de dimesión }_{i}}{\sum_{j} \text { Peso del dominio del servicio } \text { dim }_{j}}
$$

Las preguntas 24 y 25 - se refieren a la calidad y al contenido del dominio de la información. En estas preguntas, los evaluadores deben, después de consultar los servicios en línea ofrecidos por el gobierno local, evaluar la calidad de la información y las dimensiones de la información de la tarea. Al final de la evaluación, se estima el valor N3, derivado de la suma de las puntuaciones asignadas a cada dimensión por el peso de cada dimensión dentro del dominio, se estima.

$$
N 3=\frac{\sum_{i=1}^{n} \text { Clasificación asignación de dimensiones }_{i} x \text { Peso de dimesión } n_{i}}{\sum_{j} \text { Peso del dominio de la calidad de la información } n_{j}}
$$


Preguntas 26 a 32 - las últimas siete preguntas se refieren al dominio de la "Calidad Técnica", particularmente las dimensiones: "Usabilidad", "Accesibilidad", "Compatibilidad", "Calidad Técnica del Sitio Web", " Y "Innovación de sitios web". Al igual que con las preguntas anteriores, al final de la evaluación del dominio "Técnico", el valor N4, derivado de la suma de las puntuaciones asignadas a cada dimensión multiplicado por el peso que representa la importancia de cada dimensión dentro del dominio, se estima.

$$
N 3=\frac{\sum_{i=1}^{n} \text { Clasificación asignación de dimensiones }_{i} \times \text { Peso de dimesión }_{i}}{\sum_{j} \text { Peso del dominio de la calidad técnica }}
$$

El resultado final corresponde a la suma de las cuatro tablas de evaluación anteriores, expresadas en la siguiente fórmula:

$$
\text { Total }=\frac{N 1+N 2+N 3+N 4}{4}
$$

Los usuarios evalúan los servicios en una escala de Likert. En la versión web, se entrega un resultado calculado automáticamente a los evaluadores que presentan sus respuestas, teniendo en cuenta las puntuaciones y los pesos dados a cada dimensión.

\begin{tabular}{|c|c|c|c|c|c|c|c|c|c|}
\hline & & & & & & & & & \\
\hline & & & lue & & & & Weio & & \\
\hline Domain & Dimension & 1 & 2 & 3 & 4 & 5 & & & \\
\hline & Transparency & & & & & & 4 & & \\
\hline & Process Management & & & & & & 4 & & \\
\hline & Online Services Advantage & & & & & & 4 & & \\
\hline & E-Participation & & & & & & 3 & & \\
\hline & Democratization of the Decision & & & & & $\mathrm{x}$ & $\mathrm{x} 3$ & $=$ & \\
\hline & Capacitation & & & & & & 2 & & \\
\hline $\bar{\Xi}$ & E-Democracy & & & & & & 2 & & \\
\hline$\underset{\Xi}{\mathscr{E}}$ & Alternative Channels & & & & & & 1 & & \\
\hline$\sum^{\pi}$ & Politicians Role & & & & & & 1 & & \\
\hline $\mathrm{N} 1=$ & & & & & & & & & 0 \\
\hline & Reliability & & & & & & 4 & & \\
\hline & Deadline Compliance 4 & & & & & & 4 & & \\
\hline & Security 4 & & & & & & 4 & $=$ & \\
\hline & Privacy 4 & & & & & & 4 & & \\
\hline.$\stackrel{0}{5}$ & Complaints 3 & & & & & & 3 & & \\
\hline 岕 & Customer Support 3 & & & & & & 3 & & \\
\hline
\end{tabular}

Figure 22: Hoja de trabajo de evaluación para los servicios en línea del gobierno local 


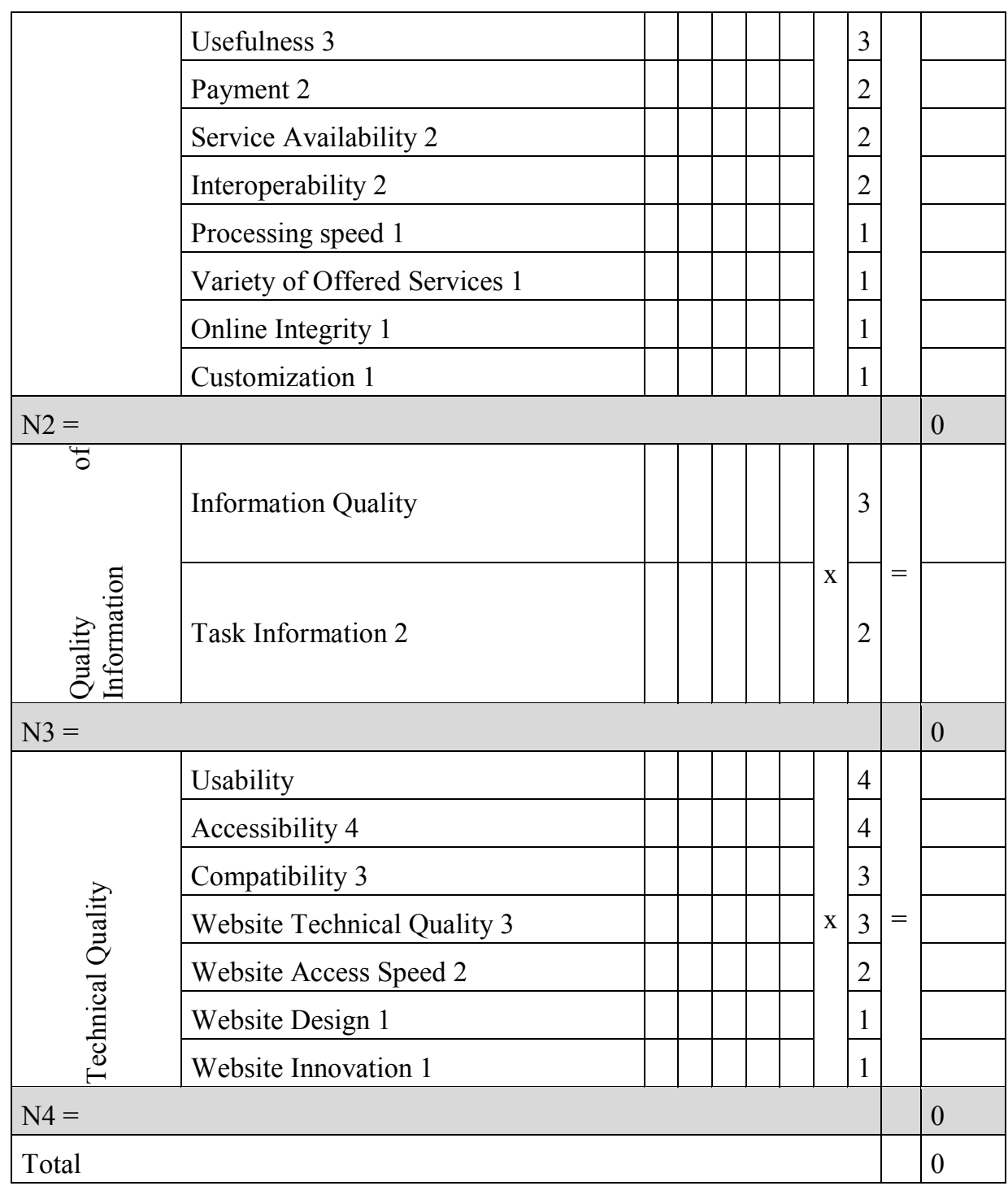

Fuente: Modelo para la Calidad de los Servicios en Línea del Gobierno Local

\section{Servicios Electrónicos}

\section{Investigando Discrepancias entre E-Services: Implementación o No - Iso} 9001: Perspectivas de los Clientes en el Ejemplo de los Servicios Electrónicos en Cataluña (España)

Petnji Yaya Luc Honore et al (2012) analizan estudios acerca de satisfacción del cliente entiendo la necesidad del cliente, ayuda a construir una lealtad a una marca y a dar mayor confianza al cliente. Además, identifican a la norma ISO 9001:2008 como el sistema de gestión de calidad que es aplicada a todos los productos y servicios de las organizaciones. Con esta norma se puede asegurar que una organización cuente con políticas de calidad, que sus procedimientos se encuentren estandarizados, los errores identificados y los sistemas de acción 
correctiva y preventiva se encuentren elaborados. Así mismo, indican que la calidad del servicio desempeña un papel importante como factor clave en la diferenciación de las ofertas de servicios. Adicionalmente, identificaron que la construcción del valor es una de las medidas más importantes para ganar una mayor ventaja competitiva. Identificaron la lealtad del cliente como parte esencial para la supervivencia de un negocio, especialmente en el contexto del comercio electrónico, y que la recuperación de un servicio se refiere a las medidas que se toman para la percepción negativa de un cliente a la prestación de servicio inicial.

Los investigadores analizan el servicio de banca electrónica de Cataluña en España, en donde un gran número de bancos se cerrará y se dará paso a la banca en línea. Es por esto que es necesario la exploración y entendimiento acerca de la opinión de los clientes en cuanto a la calidad del servicio de la banca en línea luego de la implementación de la ISO 9001:2008.

Se analizaron 22 artículos de los cuales 3 fueron descartados, quedando 19 para el estudio. Estos artículos fueron divididos en cuatro temas principales: eficiencia (8 artículos), disponibilidad del sistema (4 artículos), cumplimiento (4 artículos) y privacidad (3 artículos).

Figure 23: E-Service quality fact

\begin{tabular}{|l|l|}
\hline Eficiencia & It is easy to find what I need on my bank X web site \\
\hline EFF1 & It is easy to get anywhere on my bank X site \\
\hline EFF2 & My bank X enables me to complete a transaction quickly \\
\hline EFF3 & Information at this site is well organized. \\
\hline EFF4 & My bank X site loads its pages faster \\
\hline EFF5 & This site is simple to use. \\
\hline EFF6 & This site enables me to get on to it quickly. \\
\hline EFF7 & This site is well organized. \\
\hline EFF8 & This site is always available for business. \\
\hline Disponibilidad de/ Sistema \\
\hline SAV1 & This site launches and runs right away \\
\hline SAV2 & This site does not crash. \\
\hline SAV3 & Pages at my bank X site does not freeze after I enter my order information \\
\hline SAV4 & It performs orders when promised. \\
\hline Cumplimiento & It quickly delivers what I order. \\
\hline FUL1 & It is truthful about its offerings. \\
\hline FUL2 & It makes accurate promises about performance of online banking. \\
\hline FUL3 & My bank web site protect information about my online banking behaviour \\
\hline FUL4 & It does not share my personal information with other sites. \\
\hline Privacidad & My bank X site protects information about my credit and debit cards \\
\hline PRI1 &
\end{tabular}

Fuente: Investigando Discrepancias entre E-Services: Implementación o No - Iso 9001: Perspectivas de los Clientes en el Ejemplo de los Servicios Electrónicos en Cataluña (España) 
Además, obtuvieron ítems para el valor percibido, lealtad y satisfacción electrónica, como se muestra en el cuadro siguiente.

Figure 24: Perceived value, loyalty intention and e-satisfaction factors

\begin{tabular}{|l|l|}
\hline Volor Percibido & The prices of the services available at this site (how economical the site is). \\
\hline PVA1 & The overall convenience of using this site. \\
\hline PVA2 & The extent to which the site gives you a feeling of being in control. \\
\hline PVA3 & The overall value you get from this site for your money and effort. \\
\hline PVA4 & Say positive things about this online banking site to other people. \\
\hline Intenciones de Lealtad \\
\hline LOY1 & Recommend this online banking site to someone who seeks your advice. \\
\hline LOY2 & Encourage friends and others to do business with this site. \\
\hline LOY3 & Consider this online banking site to be your first choice for future transactions. \\
\hline LOY4 & Do more business with this site in the coming months. \\
\hline LOY5 & I am generally pleased with Bank X's online services. \\
\hline E-satisfacción & The web site of this online bank X is enjoyable. \\
\hline ESA1 & I am very satisfied with this bank X's online services. \\
\hline ESA2 & I am happy with this online bank X. \\
\hline ESA3 &
\end{tabular}

Fuente: Investigando Discrepancias entre E-Services: Implementación o No - Iso 9001: Perspectivas de los Clientes en el Ejemplo de los Servicios Electrónicos en Cataluña (España)

Adicionalmente, obtuvieron siete ítems acerca de tres grandes temas, según muestra la tabla 3: capacidad de respuesta ( 3 elementos), contacto ( 1 artículo) y compensación ( 3 elementos).

Figure 25: E-Service recovery factors

\begin{tabular}{|c|c|}
\hline \multicolumn{2}{|c|}{ Sensibilidad/ } \\
\hline RESl & This site offers a meaningful guarantee. \\
\hline RES2 & It tells me what to do if max transaction is not processoed. \\
\hline RES3 & It takers care of problems promptlx \\
\hline \multicolumn{2}{|c|}{ Compenzación } \\
\hline CPS1 & This site compensates me for problems it creates. \\
\hline \multicolumn{2}{|c|}{ Contact } \\
\hline CON1 & This site provides a telephorpe number to reach the companx. \\
\hline $\mathrm{CON2}$ & This site has customer gerwice representatives arailable online. \\
\hline CON3 & It offers the abilitx to speals to a live person if there is a problem \\
\hline
\end{tabular}

Fuente: Investigando Discrepancias entre E-Services: Implementación o No - Iso 9001: Perspectivas de los Clientes en el Ejemplo de los Servicios Electrónicos en Cataluña (España) 
Se realizó una encuesta, la cual se subdividió en cuatro secciones.

- La primera sección: con preguntas filtradas, con el fin de buscar sólo los encuestados que utilizan Internet para hacer su banca. Además, se puso a disposición una lista de bancos. Se les solicitó que informaran sobre el banco que utilizaban de manera regular.

- La segunda sección: con preguntas demográficas.

- La tercera sección: con artículos adaptados de E-S-QUAL, así como artículos de valor percibido, e-satisfacción y lealtad.

El cuestionario fue traducido del original en inglés al español y catalán. Se llevó a cabo una prueba con un pequeño grupo de 15 personas que hacían uso de la banca en línea para verificar la validez del contenido del cuestionario en términos de ambigüedad de los términos o malentendidos de los términos técnicos. Todos los encuestados encontraron que la mayoría de los ítems del cuestionario eran comprensibles.

La encuesta se realizó en tres idiomas: español, catalán e inglés. Esta encuesta se envió a 1600 potenciales encuestados, a quienes se invitó por correo electrónico a realizar la encuesta. La recopilación de datos se completó en mayo de 2010, un total de 20 bancos y 1200 cuestionarios que fueron enviados a los usuarios del banco. Logró una respuesta de $52 \%$ de los usuarios de los bancos y de $80 \%$ de los administradores de los bancos. Luego de descartar cuestionarios incompletos o inválidos, 16 bancos fueron retenidos y 428 cuestionarios válidos con 123 que experimentaron problemas con el servicio.

La siguiente tabla presenta una muestra resumida de las características demográficas y perfil de los encuestados por bancos. 
Figure 26: Características demográficas y perfil de los encuestados por bancos

\begin{tabular}{|c|c|c|c|c|c|}
\hline & \multirow[t]{2}{*}{ Complete sample } & & & \multicolumn{2}{|c|}{$\begin{array}{l}\text { Sub sample of } \\
\text { customer that have } \\
\text { reported a problem }\end{array}$} \\
\hline & & $\mathrm{n}$ & $\%$ & $\mathrm{n}$ & $\%$ \\
\hline \multirow[t]{2}{*}{ Gender } & Female & 225 & 52,6 & 62 & 50,4 \\
\hline & Male & 203 & 47,4 & 61 & 49,6 \\
\hline \multirow[t]{2}{*}{ Age } & $\begin{array}{l}17-24 \\
25-34\end{array}$ & $\begin{array}{l}106 \\
150\end{array}$ & $\begin{array}{l}24,8 \\
35,0\end{array}$ & $\begin{array}{l}15 \\
48\end{array}$ & $\begin{array}{l}12,2 \\
39,0\end{array}$ \\
\hline & $\begin{array}{l}35-44 \\
45 \text { and above }\end{array}$ & $\begin{array}{r}102 \\
70\end{array}$ & $\begin{array}{l}23,8 \\
16,4\end{array}$ & $\begin{array}{l}40 \\
20\end{array}$ & $\begin{array}{l}32,5 \\
16,3\end{array}$ \\
\hline \multirow[t]{3}{*}{ Education } & $\begin{array}{l}\text { College or institute diploma } \\
\text { and below }\end{array}$ & 102 & 23,8 & 35 & 28,5 \\
\hline & University degree & 196 & 45,8 & 48 & 39,0 \\
\hline & $\begin{array}{l}\text { Others } \\
\text { Othe }\end{array}$ & $\begin{array}{l}91 \\
39\end{array}$ & $\begin{array}{r}21,2 \\
9,1\end{array}$ & $\begin{array}{r}32 \\
8\end{array}$ & $\begin{array}{r}20,0 \\
6,5\end{array}$ \\
\hline \multirow[t]{3}{*}{ Annual income $(€)$} & Less than 12,000 & 134 & 31,3 & 27 & 22,0 \\
\hline & $12,001-24,000$ & 148 & 34,6 & 44 & 35,8 \\
\hline & 24.001 and above & 146 & 34,1 & 52 & 42,3 \\
\hline \multirow[t]{3}{*}{ Last use of e-banking } & Less than 1 week & 268 & 62,6 & 75 & 61,0 \\
\hline & Over 1 week - lmonth & 101 & 23,6 & 33 & 26,8 \\
\hline & lmonth and above & 59 & 13,8 & 15 & 12,2 \\
\hline \multirow[t]{3}{*}{ Respondents per banks with ISO or not } & No ISO & 246 & 57,5 & 67 & 54,5 \\
\hline & ISO & 133 & 31,1 & 40 & 32,5 \\
\hline & Others & 49 & 11,4 & 16 & 13,0 \\
\hline \multirow{2}{*}{$\begin{array}{l}\text { Customers who experienced any problem or } \\
\text { needed help }\end{array}$} & No & 305 & 71,3 & & \\
\hline & Yes & 123 & 28,7 & & \\
\hline
\end{tabular}

Fuente: Investigando Discrepancias entre E-Services: Implementación o No - Iso 9001:

Perspectivas de los Clientes en el Ejemplo de los Servicios Electrónicos en Cataluña (España)

Se realizó una ANOVA para detectar efectos de interacción entre variables, comparar medias entre las dos muestras independientes (bancos que implementan ISO 9001 o no) basadas en: calidad de servicio, satisfacción del cliente y cliente percibido Valor, fidelización de clientes y recuperación de servicios al cliente. Así se muestra en las tablas a continuación.

Figure 27: Análisis de ANOVA y valor Eta por categoría ISO

\begin{tabular}{llrrrrrrr}
\hline ISO_CAT & & $\begin{array}{c}\text { Sum of } \\
\text { sqquares }\end{array}$ & $\begin{array}{l}\text { Degree of } \\
\text { freedom }\end{array}$ & $\begin{array}{l}\text { Mean } \\
\text { sum of } \\
\text { sqquare }\end{array}$ & F & Sig. & $\begin{array}{c}\text { Eta } \\
\text { Eta } \\
\text { squa } \\
\text { red }\end{array}$ \\
\hline EFF5 & Between & 4,821 & 1 & 4,821 & 5,495 &, 020 &, 120 &, 014 \\
& Within & $\begin{array}{r}330,76 \\
7\end{array}$ & 377 &, 877 & & & & \\
& Total & 335,58 & 378 & & & & & \\
PVAl & Between & 4,803 & 1 & 4,803 & 4,007 &, 046 &, 103 &, 011 \\
& Within & & 377 & 1,198 & & & & \\
& Total & 456,63 & 378 & & & & & \\
\hline
\end{tabular}

Fuente: Investigando Discrepancias entre E-Services: Implementación o No - Iso 9001:

Perspectivas de los Clientes en el Ejemplo de los Servicios Electrónicos en Cataluña (España) 
Figure 28: Medios por categoría ISO

\begin{tabular}{llrr}
\hline ISO_CAT & & \multicolumn{1}{c}{ EFF5 } & PVAl \\
\hline No ISO & Mean & 3,94 & 3,31 \\
& $\mathrm{~N}$ & 246 & 246 \\
ISO & Mean & 3,71 & 3,55 \\
& $\mathrm{~N}$ & 133 & 133 \\
Total & Mean & 3,86 & 3,40 \\
& $\mathrm{~N}$ & 379 & 379 \\
\hline
\end{tabular}

Fuente: Investigando Discrepancias entre E-Services: Implementación o No - Iso 9001:

Perspectivas de los Clientes en el Ejemplo de los Servicios Electrónicos en Cataluña (España)

Los resultados mostraron que los clientes de la banca en línea en Cataluña no eran sensibles al uso de ISO 9001 en relación con el cliente. Es decir, ISO 9001 no afecta su percepción de todos los constructos de fidelización de clientes y sus antecedentes, así como la recuperación de servicios. Los clientes de los bancos que no cuentan con la implementación del ISO 9001 identificaron que el sitio bancario en línea era más rápido y los precios de los servicios disponibles eran más económicos.

\section{Conclusiones}

En primer lugar, se divide en tres grandes grupos de papers de investigación, el primero orientado a frameworks, con las cuales se obtiene información acerca de un marco de implementación de e-government 2.0, cultura de seguridad información y arquitectura orientada a servicios. El segundo gran grupo con respecto a evaluación, por ejemplo, una mirada a la participación de ciudadanos en Facebook, una encuesta de sistema de recomendación de desarrollos de aplicaciones, facilidad en el uso y la credibilidad de los sitios de gobierno electrónico, administración electrónica con respecto a Smart Cities y calidad de los servicios en línea. El último grupo en relación a los servicios electrónicos y ejemplos de los mismos. 


\section{Capítulo 4. Marco Teórico}

En este capítulo se desarrollan las definiciones que soportan el planteamiento del modelo, tales como los conceptos de arquitectura empresarial y sus beneficios; el marco de trabajo de arquitectura empresarial TOGAF y sus fases descritas en el ADM; el gobierno electrónico, sus ventajas y los cuatro tipos de aplicación, tales como Gobierno a Ciudadano (G2C), Gobierno a Negocio (G2B), Gobierno a Empleados (G2E) y Gobierno a Gobierno (G2G); el PMBOK para la gestión del proyecto; la definición de municipalidad y servicios que ofrecen a los ciudadanos; y el concepto de e-Servicios y los beneficios de su implementación.

\section{Arquitectura Empresarial}

La arquitectura Empresarial es una metodología que, basada en una visión integral de las organizaciones, permite alinear procesos, datos, aplicaciones e infraestructura tecnológica con los objetivos estratégicos del negocio o con la razón de ser de las entidades. En general, dentro de la Arquitectura Empresarial se identifican seis componentes: Estrategia, gobierno de TI, información, sistemas de información, servicios de tecnología, uso y apropiación. Su principal objetivo es garantizar la correcta alineación de la tecnología y los procesos de negocio en una organización, con el propósito de alcanzar el cumplimiento de sus objetivos estratégicos ${ }^{1}$.

La arquitectura Empresarial señala un esquema que incluye los procesos, tecnologías de información, procesos, sistemas, estructura organizacional, personas que integran la organización, componentes y políticas de una organización, y debe servir de apoyo en la toma de decisiones estratégicas.

\footnotetext{
${ }^{1}$ Cfr. CIO@GOV 2016:4
} 
Figure 29: Componentes de la Arquitectura Empresarial

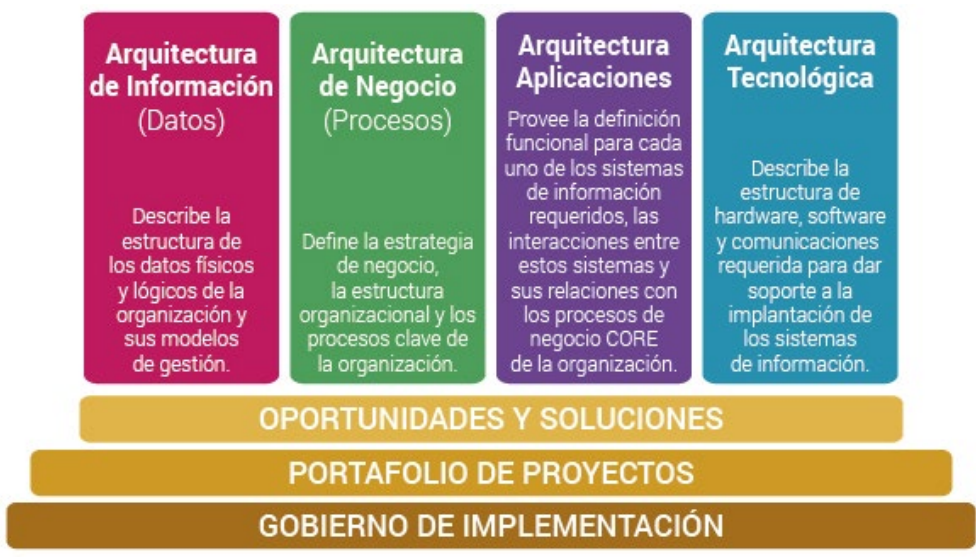

Fuente: Colombia Digital

Beneficios de la Arquitectura Empresarial :

- Identifica ineficiencias y reprocesos en el negocio.

- Reduce tiempos, costos y riesgos en los proyectos.

- Mejora las operaciones del negocio.

- Alinea la tecnología con el negocio.

\section{TOGAF}

The Open Group Architecture Framework, Togaf por sus siglas en inglés, es desarrollado y mantenido por el foro de arquitectura de The Open Group. Es un marco de referencia de arquitectura, una herramienta para asistir en la aceptación, creación, uso y mantenimiento de arquitecturas. Está basado en un modelo iterativo de procesos apoyado por las mejores prácticas y un conjunto reutilizable de activos arquitectónicos existentes ${ }^{2}$.

Tabla 8: Tipos de Arquitectura soportados por TOGAF

\begin{tabular}{|c|l|}
\hline \multicolumn{2}{|c|}{ Tipo de Arquitectura } \\
\hline Arquitectura de Negocio & La estrategia de negocio, gobierno, organización y procesos clave de la organización. \\
\hline Arquitectura de Datos & $\begin{array}{l}\text { La estructura de datos lógicos y físicos que posee una organización y sus recursos de } \\
\text { gestión de datos. }\end{array}$ \\
\hline
\end{tabular}

\footnotetext{
${ }^{2}$ Cfr. Josey, A et al (2013)
} 


\begin{tabular}{ll} 
Arquitectura de & Un plano (blueprint, en inglés) de las aplicaciones individuales a implementar, sus \\
Aplicación & $\begin{array}{l}\text { interacciones y sus relaciones con los procesos de negocio principales de la } \\
\text { organización. }\end{array}$ \\
\hline Arquitectura & Las capacidades de software y hardware que se requieren para apoyar la \\
Tecnológica & implementación de servicios de negocio, datos y aplicación. Esto incluye \\
& infraestructura de TI, capa de mediación (middleware, en inglés), redes, \\
& comunicaciones, procesamiento y estándares.
\end{tabular}

Fuente: TOGAF Versión 9.1 Guía de Bolsillo

\section{ADM}

El Método de Desarrollo de la Arquitectura (ADM, por sus siglas en inglés) constituye el núcleo de TOGAF, es un método para obtener una arquitectura empresarial específica para la organización.

\section{El ADM describe:}

- Un modo confiable y probado para desarrollar y utilizar una arquitectura empresarial.

- Un método para desarrollar arquitecturas en diferentes dominios (negocio, aplicaciones, datos, tecnología) que permiten al arquitecto asegurar que un conjunto complejo de requerimientos se aborde adecuadamente.

- Un conjunto de guías y técnicas para el desarrollo de arquitectura ${ }^{3}$.

Las fases del ADM son las siguientes :

- Fase Preliminar: prepara a la organización para aplicar una arquitectura empresarial.

- Fase A - Visión de la Arquitectura: tiene el objetivo de validar el contexto del negocio y establecer una Declaración de Trabajo de Arquitectura.

- Fase B - Arquitectura de Negocio: desarrolla una arquitectura de negocio que apoye a la fase A - Visión de Arquitectura.

- Fase C - Arquitectura de Sistemas de Información: se realiza la documentación de los sistemas de TI y aplicaciones que tiene la organización. Aquí se pueden desarrollar la arquitectura de datos y la arquitectura de aplicación.

\footnotetext{
${ }^{3}$ Cfr. Josey, A. et al (2013)
} 
- Fase D - Arquitectura Tecnológica: se realiza la documentación del hardware, software y las tecnologías de información de la organización.

- Fase E - Oportunidades y Soluciones: primera de las fases que se refiere a la implementación.

- Fase F - Planificación de la Migración: desarrolla un plan de implementación y migración detallada de una arquitectura inicial a una arquitectura destino.

- Fase G - Gobierno de la Implementación: formula recomendaciones para proyectos de implementación y construye un contrato de arquitectura.

- Fase H - Gestión de Cambios de la Arquitectura: supervisa y controla los cambios que se presenten en la arquitectura.

- Existe una fase de Gestión de Requerimientos, la cual se toma en cuenta en todas las fases del ADM, aquí se identifican los requerimientos de la organización y se gestiona en cada fase. 


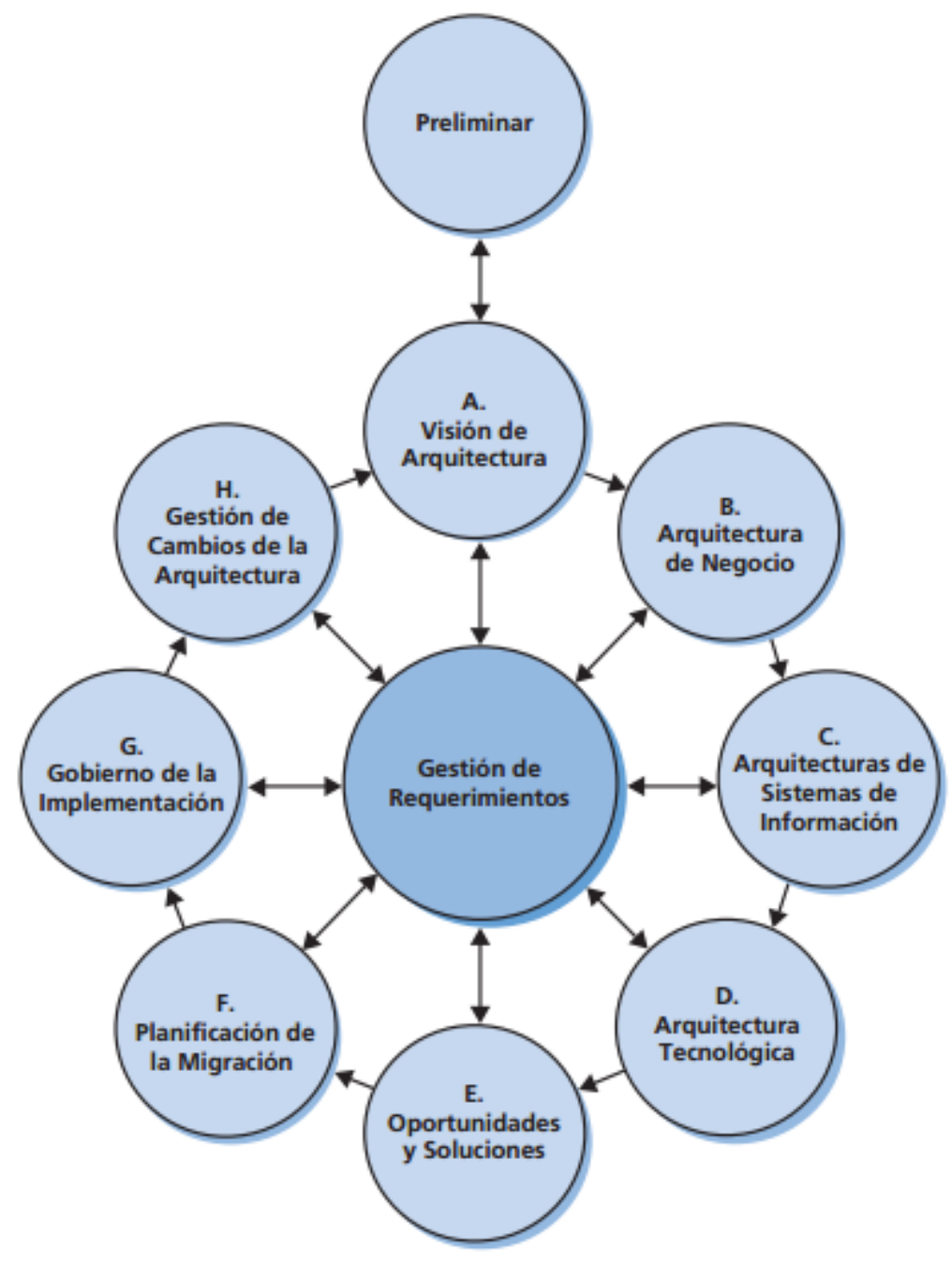

Fuente: TOGAF Versión 9.1 Guía de Bolsillo

\section{E-Government}

Según la UNESCO (United Nations Educational, Scientific and Cultural Organization), eGovernment, el gobierno electrónico se refiere las tecnologías de la información y comunicación en la administración del sector público para la mejora en el suministro de información y el servicio proporcionado. Estimular la participación del ciudadano para la toma de decisiones, y un gobierno más responsable, transparente y eficaz.

Entonces, definimos que e-Government consiste en la integración y uso de las tecnologías de información en los procesos gubernamentales que entrega servicios a los ciudadanos. Esto, con el propósito de lograr que los ciudadanos puedan participar activamente en el proceso de 
gobernanza con el fin de obtener la información deseada, mejorar la calidad de los servicios brindados, incrementar la transparencia en sus procesos y evitar corrupción.

Ventajas:

- Reducir el tiempo en las operaciones que realiza el ciudadano.

- Mejorar la eficiencia y eficacia en la administración.

- Reducción de costos.

- Transparencia en la gestión pública.

- Mejora el acceso de los ciudadanos a la información más completa.

El e-Government contiene cuatro tipos de aplicaciones:

- Gobierno a Ciudadanos (Government to Citizens, G2C), el Estado entrega servicios y/o productos a los ciudadanos.

- Gobierno a Negocio (Government to Business, G2B), el Estado entrega servicios y/o productos para el desarrollo profesional de los recursos humanos del gobierno.

- Gobierno a Empelados (Government to Employee, G2E), el Estado entrega servicios y/o productos a las empresas.

- Gobierno a Gobierno (Government to Government, G2G), satisface los requerimientos coordinados entre diferentes instituciones.

\section{PMBOK}

Project Management Body of Knowledge o PMBOK por sus siglas en inglés, es una guía para la dirección de proyectos y describe el conocimiento y prácticas aplicables a la mayoría de los proyectos desde que se inicia hasta su finalización. Esta guía brinda normas, métodos, procesos y prácticas establecidas ${ }^{4}$, además de un vocabulario propio para la dirección de proyectos.

\footnotetext{
${ }^{4}$ Cfr. Guía PMBOK - Quinta Edición. (2013:1)
} 
Debemos entender por proyecto, según la definición del PMBOK en su quinta edición, al esfuerzo temporal que se lleva a cabo para crear un producto, servicio o resultado único. Por su naturaleza, un proyecto tiene un principio y un final definidos 5 .

Esta guía ha sido desarrollada por Project Management Institute, una organización que tiene por socios a profesionales interesados y relacionados con la Gestión de Proyectos.

Grupo de Procesos :

El PMBOK se divide en 5 grupos de procesos de gestión que son:

- Inicio, grupo relacionado a la definición de un proyecto nuevo o una nueva fase en un proyecto existente.

- Planificación, en este grupo se establece el alcance, los objetivos y el plan de acción para cumplir los objetivos.

- Ejecución, en este grupo se tienen conjuntos de actividades o procesos que deben desarrollarse para cumplir los objetivos.

- Monitoreo y Control, en este grupo se rastrea y revisa el desempeño del proyecto.

- Cierre, en este grupo se realizan las actividades para realizar el fin del proyecto.

Áreas de Conocimiento :

Además, PMBOK identifica 10 áreas de conocimiento que son:

- Integración

- Alcance

- Tiempo

- Costos

- Calidad

- Recursos Humanos

- Comunicación

\footnotetext{
${ }^{5}$ Cfr. Guía PMBOK - Quinta Edición. (2013:3)
} 
- Riesgos

- Adquisición e Interesados

\section{Municipalidad}

Una municipalidad es una corporación estatal que se ocupa de la gestión y administración de un municipio, que puede ser una ciudad, un distrito o un pueblo y cual está compuesta por un alcalde y sus regidores municipales.

La municipalidad debe encargarse además de temas administrativos, temas económicos, sociales y culturales, por lo que entre sus funciones está la de mantener el orden y la limpieza de la localidad, arreglo e iluminación de calles, vigilancia, mantenimiento de parques, entre otros.

También se llama municipalidad, al edificio que se encuentra dentro del municipio y sirve de sede de este. Aquí, los ciudadanos se acercan para realizar trámites en relación con dicho municipio.

Entre los servicios que ofrece la municipalidad tenemos:

- Convocatoria administrativa de Servicios; aquí se realizan las convocatorias y resultados CAS, el cual es un contrato del Estado con una persona natural que presta sus servicios de una manera no autónoma.

- Gestión de Riesgos de Desastre e ITSE; la cual se dedica a la prevención y sensibilización de los riesgos de desastre y las inspecciones técnicas de seguridad en edificaciones.

- Registro Civil, la cual se dedica a la programación; coordinar y controlar las actividades de los registros de estado civil.

- Presupuesto Participativo; instrumento de gestión en donde se define cómo y a dónde estarán orientados los recursos.

- Apoyo a la Mujer, Demuna, Adulto Mayor; la cual se orienta a brindar solución a determinados conflictos familiares.

- Desarrollo Económico Local; la cual se orienta a gestionar y controlar las actividades económicas dentro de la municipalidad. 
- Comercialización y Promoción Empresarial; la cual se dedica a gestionar las actividades relacionadas a la promoción del desarrollo empresarial, actividades comerciales, industriales y servicios profesionales.

- Juventud, Educación, Cultura y Deporte; la cual se dedica a gestionar programas, proyectos y actividades para el desarrollo de la juventud.

- Oficina de Orientación a las Personas con Discapacidad; la cual se dedica a brindar apoyo y orientación a organizaciones, instituciones y familias que requieran servicios que ayuden a colaborar con la formación integral de las personas con discapacidad.

- Ornato, Parques y Jardines; la cual se dedica al mantenimiento de las áreas verdes públicas del distrito.

- Sanidad y Servicio Social; la cual se dedica a gestionar temas de salud y asistencia sanitaria.

- Codisec; la cual se dedica a gestionar políticas, planes y actividades relacionadas a la seguridad distrital.

- Serenazgo; el cual se dedica a la velar por la protección de las personas y bienes, por la tranquilidad y orden ciudadano).

\section{E-Servicios}

E-Servicios o servicios electrónicos, se refiere a los servicios que cuentan con la utilización de las tecnologías de información y comunicación. Prestación de servicios automatizados por medio del internet.

Se identifica la siguiente serie de beneficios ${ }^{6}$ :

- Ampliación del alcance del mercado

- Reducción de la barrera de entrada a nuevos mercados y costo de adquisición de nuevos clientes

- Canal de comunicación alternativo para los clientes

- Aumentar los servicios a los clientes

\footnotetext{
${ }^{6}$ Cfr. Lu, J. (2001)
} 
- Mejorar la imagen de la empresa percibida

- Obtención de ventajas competitivas

- Posibilidad de aumentar el conocimiento del cliente. 


\section{Capítulo 5: Desarrollo del Proyecto}

En este capítulo se explica las secciones del modelo propuesto, tales como las fases de gobierno electrónico y su objetivo; los e-Servicios que están alineados a las leyes peruanas y su clasificación en las fases propuestas; el índice de Gobierno Electrónico Municipal (GEM) y su importancia para el cumplimiento del modelo. Para el diseño del e-Servicio, en el capítulo se detalla un conjunto de consideraciones que deben estar presentes al momento de su realización en el modelo, tales como el presupuesto, el equipo del proyecto, los principios de arquitectura, la usabilidad, los objetivos del negocio que se desean alcanzar, las leyes peruanas a considerar y los recursos disponibles que cuenta la municipalidad; para luego poder explicar la ejecución de los cuatro procesos de análisis y diseño que permiten el desarrollo de un e-Servicio basado en las cuatro arquitecturas. Estas son la arquitectura de negocios, datos, aplicaciones e infraestructura.

\section{Desarrollo del Modelo}

El modelo de mejoras de e-Servicios municipales peruanas busca que las entidades gubernamentales locales implementen de manera exitosa el Gobierno Electrónico, mediante la digitalización de los servicios municipales que utilizan los ciudadanos.

Figure 31: Secuencia de ejecución del modelo

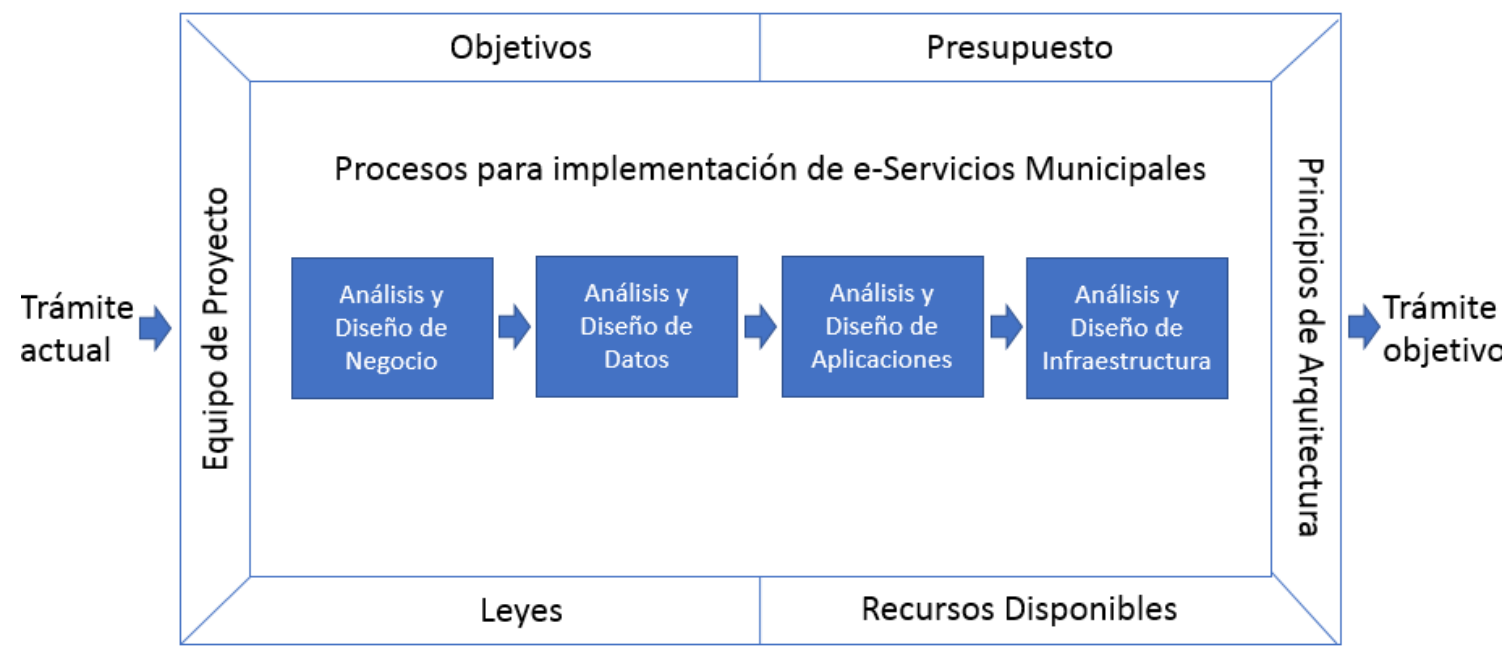

Fuente: Elaboración Propia 
Para la elaboración del modelo se han tomado las buenas prácticas de TOGAF, las cuales han sido adaptadas al contexto municipal peruano. La propuesta se ha dividido en dos partes para su correcto desarrollo. El primero es el marco del modelo, el cual contiene las consideraciones que se deben tener en cuenta a lo largo del proyecto. Estos son: objetivos, equipo de proyecto, leyes, recursos disponibles, principios de arquitectura y presupuesto. El segundo es el conjunto de procesos que van a transformar el actual proceso orientado a los ciudadanos en un proceso basado en e-Servicios. Estos son: análisis y diseño de negocio, análisis y diseño de datos, análisis y diseño de aplicaciones y; análisis y diseño de infraestructura.

El modelo propuesto busca complementar el trabajo de investigación "Modelo de Desarrollo de Sitios Web Municipales basado en Benchmarking y Segmentación”, el cual recomienda eServicios distribuidos en cinco fases. Esto permitirá una mejor percepción de la municipalidad por parte del ciudadano, con respecto a la transparencia y confianza hacia la misma. Se propone un índice de Gobierno Electrónico Municipal (GEM), que permita medir el cumplimiento de e-Servicios, usabilidad y la correcta implementación de estos. Este índice permite medir el cumplimiento de los objetivos de una municipalidad.

\section{A. Marco del Modelo}

Antes de utilizar el modelo, se debe conocer cuál va a ser su entrada. Dicha entrada es lo que el modelo propuesto va a transforma, es decir, un proceso tradicional de la municipalidad que desea que sea llevado a la web. Dicho proceso puede ser ejecutado de forma total o parcialmente manual.

El marco del modelo es la parte inicial del proyecto de gobierno electrónico, los cuales deben ser elaborados y tomados en cuenta a lo largo del proyecto. Este consta de seis partes que son detallados a continuación:

\section{Objetivos}

Son los objetivos municipales que deben encontrarse orientados a los objetivos planteados por el Estado. Estos, serán cumplidos de manera parcial o por completo con ayuda del proyecto. (Ver Recomendaciones para Implementación de e-Servicios - Objetivos)

\section{Equipo de Proyecto}


Son los roles que utilizarán el modelo para la elaboración del e-Trámite. (Ver Recomendaciones para Implementación de e-Servicios - Roles y Responsabilidades)

3. Recursos disponibles

Son los recursos tecnológicos, software y hardware, con los que cuenta la municipalidad antes del inicio del proyecto. (Ver Recomendaciones para Implementación de e-Servicios - Recursos Disponibles)

\section{Leyes}

Los e-Servicios están basados en leyes peruanas de gobierno electrónico. (Ver Recomendaciones para Implementación de e-Servicios - Restricciones organizacionales Leyes para Municipalidades y de Gobierno Electrónico Local)

5. Principios de arquitectura:

Son los principios que se deben cumplir en todas las fases del proyecto, estos son de arquitectura de negocio, arquitectura de datos, arquitectura de aplicaciones, arquitectura de redes. (Ver Recomendaciones para Implementación de e-Servicios - Principios de Arquitectura)

6. Presupuesto:

Se debe asignar un presupuesto al proyecto. (Ver Recomendaciones para Implementación de e-Servicios - Presupuesto)

\section{B. Procesos del Modelo}

1. Análisis y Diseño del Negocio

En este punto se analiza el actual proceso municipal que debe ser orientado a los ciudadanos, el cual debe ser elegido para satisfacer el cumplimento de sus objetivos. Dicho proceso debe ser diagramado para poder identificar los puntos de mejora en su flujo de actividades (Ver Recomendaciones para Implementación de e-Servicios - Modelamientos de Procesos). Posteriormente, plantear los e-Servicios que van a contribuir en el incremento de su eficiencia y eficacia. Cabe resaltar que, la municipalidad puede plantear nuevos servicios electrónicos en 
base al marco legal vigente. Estos deben ser clasificados en una de las cinco fases propuestas según sus características.

Al conocerlos, dependerá de la entidad si selecciona el total o parcial de e-Servicios determinados anteriormente. Dichos servicios deben encontrarse alineados a las leyes peruanas como se muestra en la Tabla 17. Se diagrama el e-Trámite objetivo (Ver Recomendaciones para Implementación de e-Servicios - Modelamientos de Procesos), el cual servirá como entrada para la siguiente fase.

Tabla 9: Relación Leyes - e-Servicios

\begin{tabular}{|c|c|}
\hline Leyes & e-Servicios \\
\hline \multirow{3}{*}{$\begin{array}{l}\text { LEY N. } .^{\circ} 27806 \text { - Ley de Transparencia y } \\
\text { Acceso a la Información Pública }\end{array}$} & Formulario \\
\hline & Actas de consejo \\
\hline & Portal de transparencia \\
\hline \multirow{3}{*}{$\begin{array}{l}\text { LEY N. }{ }^{\circ} 28976 \text { - Ley Marco de Licencia De } \\
\text { Funcionamiento y los Formatos de } \\
\text { Declaración Jurada }\end{array}$} & Agenda municipal \\
\hline & Autoridades comunales \\
\hline & TUPA \\
\hline \multirow{3}{*}{$\begin{array}{l}\text { LEY N. }{ }^{\circ} 27972 \text { - Ley Orgánica de } \\
\text { Municipalidades }\end{array}$} & E-mail \\
\hline & Teléfono \\
\hline & Respuesta e-mail \\
\hline \multirow{2}{*}{$\begin{array}{l}\text { LEY N. }{ }^{\circ} 29733 \text { - Ley de Protección de } \\
\text { Datos } \\
\text { Personales }\end{array}$} & Trámite en línea \\
\hline & Pago en línea \\
\hline \multirow{4}{*}{$\begin{array}{l}\text { LEY N. }{ }^{\circ} 27269-\text { Ley de Firmas y } \\
\text { Certificados } \\
\text { Ley N. } .^{\circ} 27444 \text { - Ley del Procedimiento } \\
\text { Administrativo General }\end{array}$} & Certificado y firmas digitales \\
\hline & Carpeta del ciudadano \\
\hline & Seguimiento \\
\hline & Celular \\
\hline $\begin{array}{l}\text { RESOLUCIÓN MINISTERIAL N. }{ }^{\circ} 126 \text { - } \\
\text { 2009-PCM }\end{array}$ & PIDE \\
\hline $\begin{array}{l}\text { LEY N. }{ }^{\circ} 27972-\text { Ley Orgánica de } \\
\text { Municipalidades }\end{array}$ & Chat online \\
\hline $\begin{array}{l}\text { LEY N. }{ }^{\circ} 28976 \text { - Ley Marco de Licencia de } \\
\text { Funcionamiento y los Formatos de } \\
\text { Declaración Jurada }\end{array}$ & Foro \\
\hline
\end{tabular}

Fuente: Elaboración Propia 
Figure 32: Entrada y salida del Sub Proceso de Análisis y Diseño del negocio

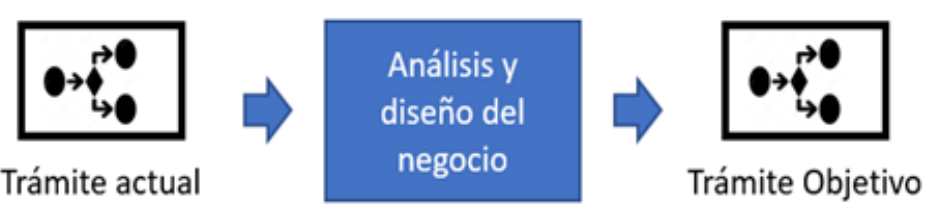

Fuente: Elaboración Propia

Para hacer esta actividad, se debe llenar la plantilla MMEM - Análisis de Situación Actual de Servicios Municipales y MMEM - Plantilla de e-Servicios Afectados por Servicios.

\section{Análisis y Diseño de Datos}

Al determinar qué e-Servicios se van a implementar y conociendo el nuevo flujo del proceso para su ejecución, se procede a identificar los datos que van a viajar por él. Esto con el fin de poder diseñar una base de datos que soporte la propuesta. Se debe evitar la redundancia de datos, de manera que se cuente con un diseño de base de datos más eficiente. (Ver Recomendaciones para Implementación de Arquitectura - Catálogo de Portafolio de Entidades, Matriz Entidad de Datos - Función de Negocio y Diagrama de Base de Datos).

Figure 33: Entrada y salidas del Sub Proceso Análisis y Diseño de Datos

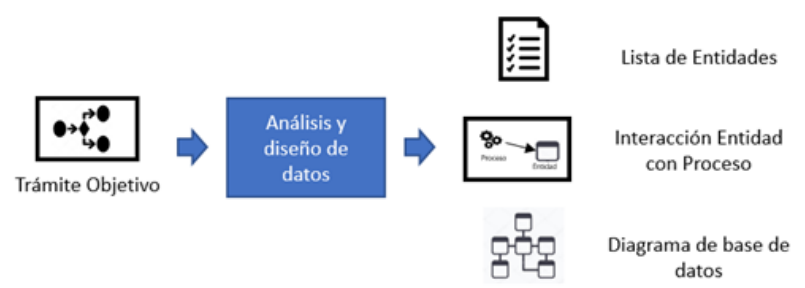

Fuente: Elaboración Propia

3. Análisis y Diseño de Aplicaciones

Con los resultados de los temas anteriormente, se puede realizar tres puntos. El primero, conocer qué nuevos aplicativos servirán de apoyo a los e-Servicios que van a ser implementados en el proceso identificado. En segundo lugar, identificar la interacción de los e-Servicios con el nuevo proceso y de esta manera, diseñar los entregables necesarios. En tercer 
lugar, identificar la interacción de todas las aplicaciones entre sí. (Ver Recomendaciones para Implementación de Arquitectura - Catálogo de Portafolio de Aplicaciones, Matriz Aplicaciones - Función de Negocio, Diagrama de Caso de Uso y Matriz de Interacción de Aplicaciones).

Figure 34: Entradas y salidas del Sub Proceso de Aplicaciones

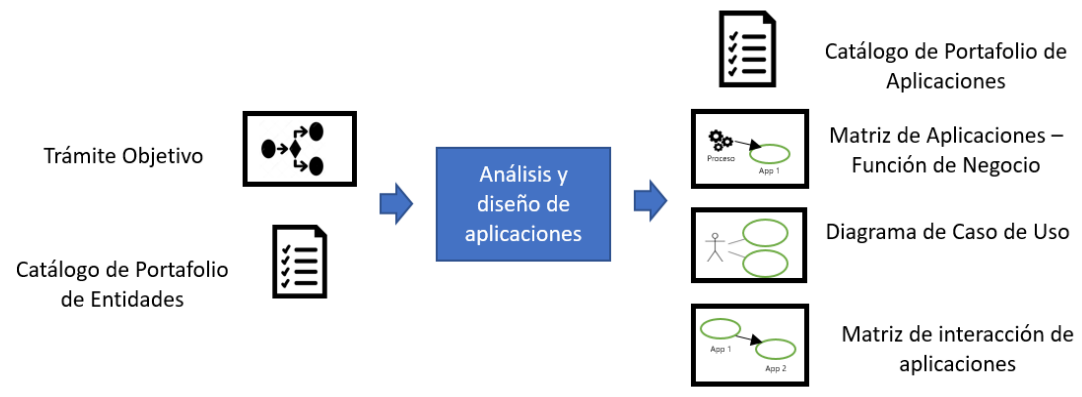

Fuente: Elaboración Propia

\section{Análisis y Diseño de Infraestructura}

Se recibe como entrada las aplicaciones identificadas en el punto anterior, de manera que se elabore una infraestructura tecnológica que la soporte. El primer proceso de arquitectura entregará el flujo del trámite objetivo para determinar la interacción de toda la infraestructura con dicho trámite. (Ver Recomendaciones para Implementación de Arquitectura-Catálogo de Portafolio de Tecnología, Diagrama de Red y Matriz de Tecnología).

Figure 35: Entradas y salidas del Sub Proceso de Análisis y Diseño de Infraestructura

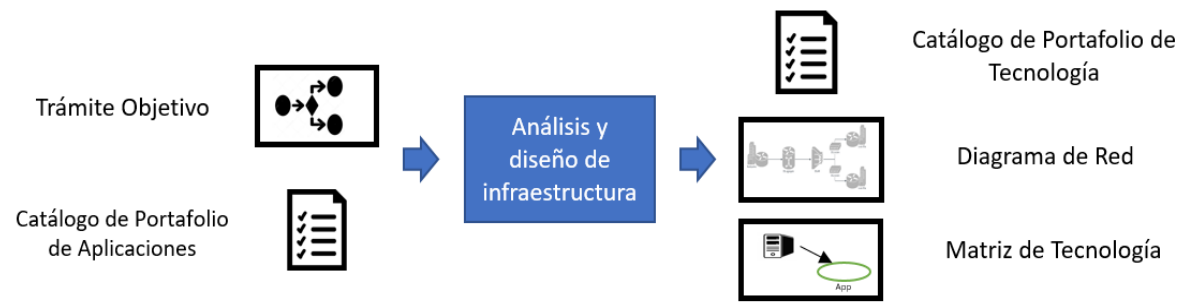

Fuente: Elaboración Propia 


\section{Evaluar el Cumplimiento de e-Servicios}

En este punto, el modelo permitirá un auto diagnóstico del e-Servicio que se desea implementar por parte de la municipalidad mediante el índice del Gobierno Electrónico Municipal (GEM). De esta manera, se puede conocer si estos cumplen con los criterios del modelo propuesto, los cuales son: la implementación del e-Servicio, usabilidad de este y que se encuentre basado en un enfoque de arquitectura empresarial.

El índice de Gobierno Electrónico Municipal contempla tres subíndices que se definen a continuación:

1. Índice de e-Servicios: Evalúa los servicios electrónicos de cada fase propuesto. Este indicador equivale al 60\% del Índice de Gobierno Electrónico Municipal.

2. Índice de Usabilidad: Evalúa la usabilidad de la web municipal. Este indicador representa el 15\% del Índice de Gobierno Electrónico Municipal.

3. Índice de AE: Mide las buenas prácticas de arquitectura empresarial propuestas, el cual se encuentra basada en TOGAF. Este índice representa el 25\% del Gobierno Electrónico Municipal.

Figure 36: Componentes del Índice de Gobierno Electrónico Municipal

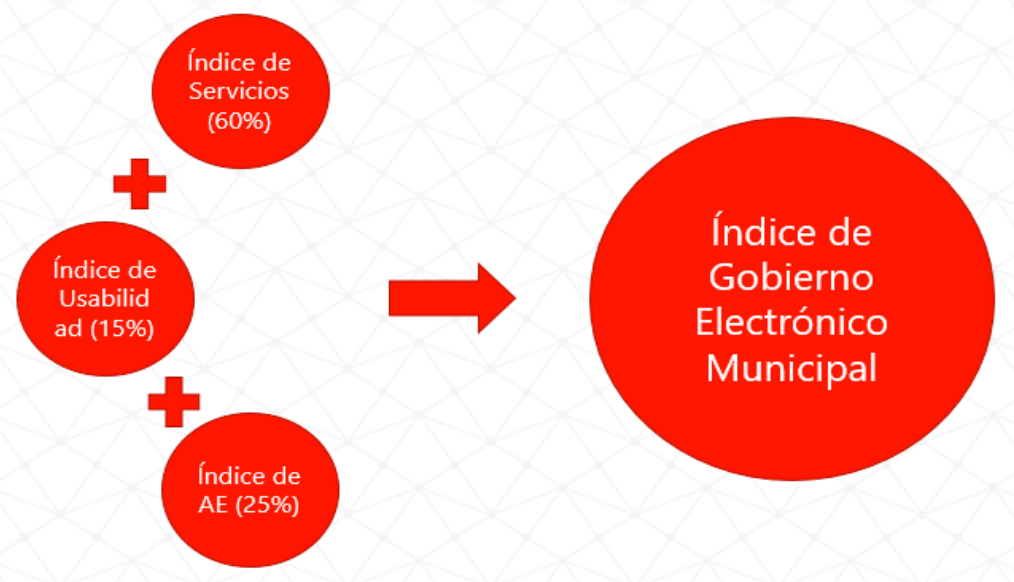

Fuente: Elaboración Propia

Para la medición de dichos índices se cuenta con tres encuestas. En cada encuesta se colocó un puntaje por pregunta para, posteriormente, lograr determinar el índice de Gobierno 
Electrónico Municipal. Para ver las encuestas, se encuentra la plantilla MMEM Evaluación.

Por otro lado, las fases recomendadas ayudan a que una municipalidad conozca el impacto generado en los ciudadanos de los e-Servicios recomendados o propuestos.

Figure 37: Fases de Gobierno Electrónico Municipal propuestas por Esteves

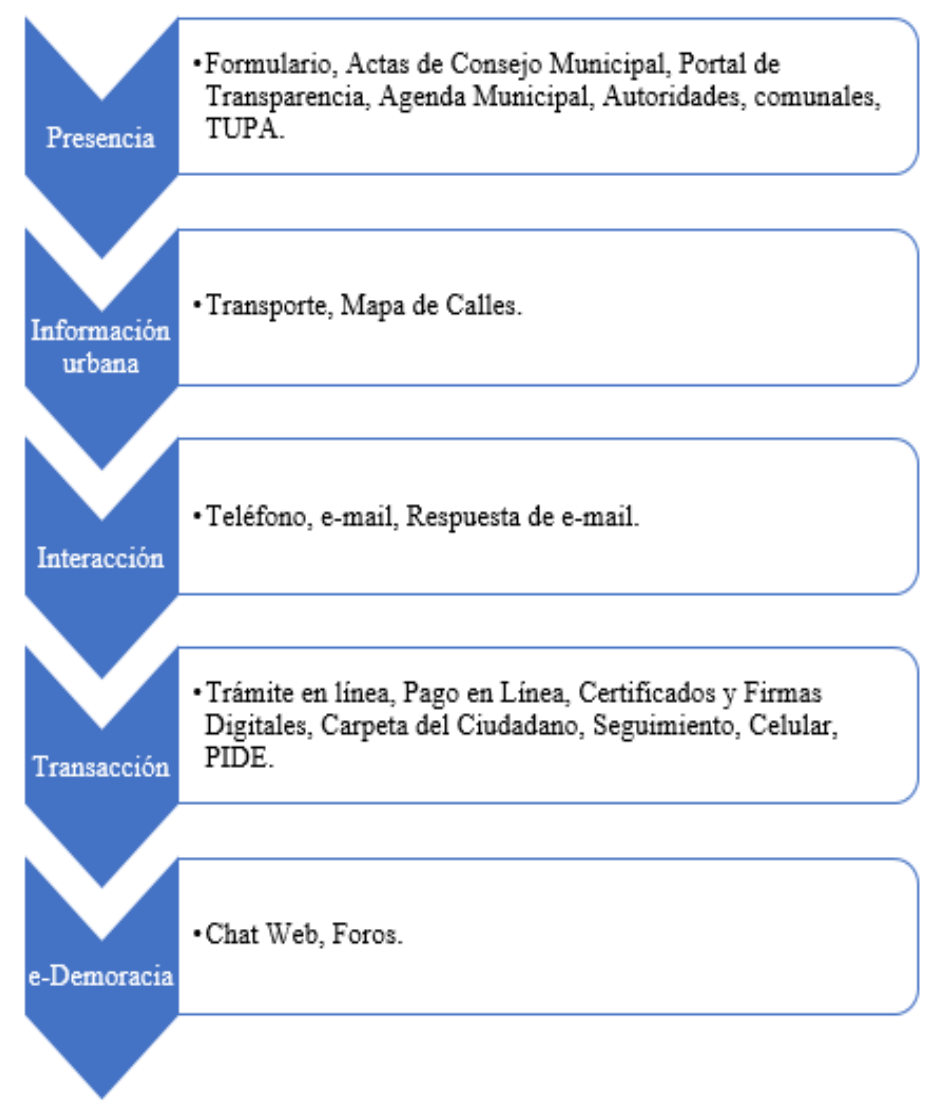

Fuente: Elaboración Propia

A continuación, se detalla los e-Servicios planteados:

Presencia:

- Formulario: Documentos necesarios para la ejecución de un trámite.

- Actas de Consejo Municipal: Es el documento que contiene los temas tocados y los acuerdos llegados por el consejo municipal.

- Portal de transparencia: Es una sección de la web que debe tener toda municipalidad según la ley de transparencia.

- Agenda Municipal: Es el documento que contiene todas las actividades que va a realizar la municipalidad en la comuna. 
- Autoridades comunales: Contiene información de dichas autoridades, ya sea nombre, cargo, entre otros.

- TUPA: Es el Texto Único de Procesos Administrativos, el cual contiene todos los procesos que realiza la municipalidad, sus requerimientos, tiempos de ejecución, entre otros.

Información Urbana:

- Mapa municipal: Son los planos municipales donde se puede conocer la zonificación de usos de suelos, planos de altura de edificación, entre otros.

- Transporte Urbano: Muestra las rutas de las líneas de transporte público.

Interacción:

- E-mail: Permite una comunicación vía correo electrónico.

- Teléfono: Permite una comunicación directa por teléfono con el ciudadano.

- Respuesta de e-mail: La municipalidad debe responder por correo electrónico a cualquier pregunta o solicitud que inicio por este medio.

Transacción:

- Trámite en línea: Permite que el ciudadano pueda realizar sus trámites por medio de la web, estos están contenidos en el TUPA.

- Pago en Línea: Los trámites realizados tienen un costo por su ejecución, dichos cobros, entre otros, deben ser pagados por medio de la web.

- Certificados y firmas digitales: Permite firmar digitalmente documentos del mismo tipo.

- Carpeta del Ciudadano: Es una carpeta que almacena los trámites y pagos realizados por el ciudadano. Permite ver sus datos históricos.

- Seguimiento: El ciudadano podrá ver el estado de sus expedientes inconclusos, en que área orgánica se encuentra, entre otros.

- Celular: Todos los servicios anteriores deben ser utilizados desde una aplicación de un dispositivo móvil.

- PIDE: Conectarse con la plataforma de interoperabilidad del estado peruano para poder adquirir y suministrar información a otras entidades del gobierno para tener un proceso más completo.

e-Democracia:

- Chat Web: Permite una interacción directa entre el funcionario y el ciudadano para absolver sus dudas. 
- Foros: Brinda una ventana para que la ciudadanía pueda opinar o participar en un tema de importancia para la comuna.

\section{Recomendaciones para Implementación de e-Servicios}

\section{A. Reconocimiento para la Usabilidad}

Bórquez propone la usabilidad como parte de su guía de recomendaciones, en donde incluye una evaluación de este concepto a partir de un subconjunto de recomendaciones del gobierno chileno. Los componentes considerar se pueden agrupar en las siguientes dimensiones:

- Identidad corporativa: qué tan bien refleja el sitio Web la pertenencia a la institución. Se busca si en el sitio web se encuentran presentes los elementos propios de la imagen institucional de un municipio. Se evalúan las siguientes variables:

- Identidad del municipio reflejada en la página principal.

- Uso de elementos de la imagen corporativa en la portada del sitio como el logo o escudo).

- Repetición de la imagen corporativa en todas las páginas (vale decir, si en la totalidad de las páginas, la aparición de la imagen corporativa era consistente).

○ Información de contactos (e-mail, teléfono) al pie o encabezado de la página.

- Facilidad del sitio Web: qué tan útil es el sitio Web para el visitante. Se mide evaluando qué tan fácil es encontrar la información de los servicios más importantes entregados por el municipio en la página principal. Se considera que en un sitio en el cual no sea fácil encontrar tal información, es poco útil, desde el punto de vista del ciudadano.

- Navegación: qué tan fácil es navegar dentro del sitio. Se mide a través de las siguientes variables:

○ Rapidez o fluidez de la navegación

○ Qué tan intuitiva es la navegación

- Organización de temas del sitio

- Facilidad para encontrar contenidos

○ Posición del menú de navegación 
- Facilidad para ver el menú de navegación (Visibilidad)

- Coherencia y consistencia de la navegación

○ Distinción de botones y links

- Posibilidad para rehacer o deshacer operaciones

- Visibilidad del estado del sistema: qué tanta información del estado del sitio Web se le proporciona al usuario. Esta dimensión se obtiene midiendo las siguientes variables:

○ Información acerca del sitio que se está visitando.

○ Información de pasos faltantes para terminar un trámite en línea.

- Ayuda: qué tanta ayuda sobre el sitio Web se le proporciona al usuario. Se mide la presencia de teléfonos de soporte web, o mesa de ayuda, presencia de un FAQ6, y una sección de ayuda, ofreciendo una explicación de cómo utilizar el sitio.

- Feedback: cómo puede el usuario proporcionar feedback a los responsables del sitio Web. Se mide la presencia de una instancia de contacto (sea en formulario, teléfono o mail) con el Web Master7, y el estado de funcionamiento de los formularios de contacto, en caso de que corresponda.

- Estética y diseño: cómo estos factores ayudan o confunden al usuario dentro del sitio. Se mide fundamentalmente la presencia de jerarquías visuales que permitan determinar los elementos más importantes.

- Actualización: qué tan actualizados el usuario percibe los contenidos del sitio. Se mide la presencia de la publicación de información acerca de contenidos nuevos en la portada, con fecha de publicación.

- Otros componentes esenciales: características deseables de un sitio web municipal. Se miden aspectos tales como:

- Garantía de respuesta a solicitudes.

- Presencia de párrafos largos en textos.

- Políticas de confidencialidad.

○ Presencia de exceso de elementos en la página principal. 
- Uso de pop ups.

- Uso de sitios Web separados para información del municipio y para los trámites municipales.

\section{B. Presupuesto}

Para el proyecto el presupuesto es un punto muy importante, ya que se refiere a la proyección de los movimientos económicos, monetarios y financieros relacionadas a las actividades del proyecto. En caso se presenten dudas, se procede desarrolla este punto.

El presupuesto abarca toda actividad financiera respecto al proyecto, en donde, los ingresos se determinan en base a los objetivos planteados y los gastos se obtienen de la cantidad de gastos operativos e inversión. Este presupuesto debe ser proyectado para la duración del proyecto, debe ser lo más exacto, detallado y sincero posible. Además, debe incluir costos directos, indirectos, contingencias que puedan existir y las ganancias que se espera obtener.

Para elaborar el presupuesto debemos realizar lo siguiente:

- Estimar los ingresos y los gastos, dependiendo de lo que se espera realizar con el proyecto.

- Calcular el costo del proyecto.

- Realizar la asignación de los recursos financieros.

- Tener en cuenta y solicitar de acuerdo a la jerarquía establecida la aprobación del Presupuesto Institucional de las Municipalidades.

- Al poner en ejecución el presupuesto estimado del proyecto, se concretará los ingresos, se ejecutarán los gastos previstos y se realizarán modificaciones financieras que sean necesarias.

- Tener en cuenta que luego de la ejecución, se deberá realizar una evaluación con respecto al presupuesto proyectado, en donde se muestra el avance financiero de la ejecución presupuestal, y el grado de cumplimiento de lo proyectado.

- Tener en cuenta que se debe llevar un control periódico del resultado del proyecto. 


\section{Restricciones Organizacionales - Leyes para Municipalidades y de Gobierno Electrónico Local}

Para la elaboración del proyecto se debe tener en cuenta las leyes referentes al gobierno electrónico implementadas en el Perú. En caso no se haya tomado en cuenta estas leyes o se presenten dudas al respecto, se pasa a presentar estas leyes.

\section{LEY N 27444 - Ley del Procedimiento Administrativo General}

\section{TÍTULO PRELIMINAR}

Hace referencia a las siguientes entidades del estado.

1. El Poder Ejecutivo, incluyendo Ministerios y Organismos Públicos Descentralizados

2. El Poder Legislativo

3. El Poder Judicial

4. Los Gobiernos Regionales

5. Los Gobiernos Locales

6. Los Organismos a los que la Constitución Política del Perú y las leyes confieren autonomía.

7. Las demás entidades y organismos, proyectos y programas del Estado, cuyas actividades se realizan en virtud de potestades administrativas $\mathrm{y}$, por tanto, se consideran sujetas a las normas comunes de derecho público, salvo mandato expreso de ley que las refiera a otro régimen.

8. Las personas jurídicas bajo el régimen privado que prestan servicios públicos o ejercen función administrativa, en virtud de concesión, delegación o autorización del Estado, conforme a la normativa de la materia ${ }^{7}$.

\footnotetext{
${ }^{7}$ Cfr. Indecopi $(2017: 1,5,6)$
} 
DECRETO LEGISLATIVO $\mathrm{N}^{\circ} 1353$ - Decreto Legislativo que crea la Autoridad Nacional de Transparencia y Acceso a la Información Pública, Fortalece el Régimen de Protección de Datos Personales y la Regulación de la Gestión de Intereses

Indica que todas las entidades que se encuentran en el Artículo I Título Preliminar de la Ley No 27444, Ley del Procedimiento Administrativo General, empresas del estado y personas jurídicas deben proponer políticas, emitir directivas, supervisar su cumplimiento, absolver consultas que las entidades, personas jurídicas o naturales, fomenten una cultura, puedan solicitar información que considere necesarias de otras entidades sobre materia de transparencia y acceso a la información pública. Además, se debe presenta un informe anual al congreso de la república sobre dicho tema.

\section{DECRETO LEGISLATIVO $\mathbf{N}^{\circ} 1246$ - Decreto Legislativo que Aprueba Diversas Medidas de Simplificación Administrativa}

La presente ley busca simplificar, optimizar y eliminar procedimientos administrativos de todas las entidades que se encuentran en el Artículo I Título Preliminar de la Ley N ${ }^{\circ} 27444$. Se desea tomar en cuenta 3 servicios sociales en los 3 niveles del gobierno.

a. Normas generales y específicas para la estandarización de los procedimientos administrativos.

b. Dictar medidas para la optimización de servicios en las entidades públicas del estado.

c. Contribuir el fortalecimiento institucional y la calidad del servicio al ciudadano.

Por otro lado, manera gratuita, las entidades en mención deben permitir el acceso o suministrar información o bases de datos actualizadas que administren, posean, entre otros, respecto a los usuarios o administrados a las demás entidades requieran necesariamente y de acuerdo con la ley, para la tramitación de sus procesos administrativos y para sus actos de administración interna. Si la información requerida necesita datos protegidos por la ley $\mathrm{N}^{\circ} 29733$, Ley de Protección de Datos Personales, estas deben ser autorizadas por el administrado o usuario.

\section{LEY Na 27269 - Ley de Firmas y Certificados Digitales}


Según el artículo 1 de la presente ley, tiene como objetivo regular la utilización de la firma electrónica otorgándole la misma validez y eficacia jurídica que el uso de una firma manuscrita u otra análoga que el conlleve manifestación de voluntad.

La firma digital es aquella firma electrónica que utiliza una técnica de cristología asimétrica, basada en el uso de un par de claves únicos, asociada a una clave privada y una clave pública relacionadas matemáticamente entre sí, de forma que las personas que conocen la clave pública no puedan llegar a la privada.

El certificado digital es el documento electrónico generado y formado digitalmente por una entidad de certificación, la cual vincula un par de claves con una persona determinada confirmando su identidad.

\section{DECRETO SUPREMO No 026-2016-PCM - Aprueban Medidas para el Fortalecimiento de la Infraestructura Oficial de Firma Electrónica y la Implementación Progresiva de la Firma Digital en el Sector Público y Privado}

Según el artículo 1, tiene como objeto aprobar las medidas para el fortalecimiento de la Infraestructura Oficial de Firma Electrónica - IOFE y la implementación progresiva de la firma digital en el sector público y privado.

Detalla los pasos a seguir para que las entidades de Certificación que cumplan con estándares técnicos internacionales o sellos de confianza internacional sean reconocidas oficialmente por el estado peruano.

La Infraestructura Oficial de Firma Electrónica (IOFE) es un concepto macro que se refiere al sistema confiable, acreditado, regulado y supervisado por la AAC; es decir, por la Comisión de Reglamentos Técnicos y Comerciales del INDECOPI. Entidad designada para tales efectos por el artículo $36^{\circ}$ del Reglamento, concordante con el artículo $2^{\circ}$ del Decreto Supremo que lo aprueba $^{8}$.

RESOLUCIÓN MINISTERIAL No 244-2007-PCM - Aprueban Uso Obligatorio de la Norma Técnica Peruana “Ntp-Iso/ Iec 17799:2007 Edi. Tecnología de la Información.

\footnotetext{
${ }^{8}$ Cfr. Indecopi (2017:12)
} 
Código de Buenas Prácticas para la Gestión de la Seguridad de la Información. 2a. Edición” en Todas las Entidades Integrantes del Sistema Nacional de Informática

NTP-ISO/IEC 17799:2007 EDI. TECNOLOGÍA DE LA INFORMACIÓN. CÓDIGO DE BUENAS PRÁCTICAS PARA LA GESTIÓN DE LA SEGURIDAD DE LA INFORMACIÓN. 2a EDICIÓN

"Esta norma ofrece recomendaciones para realizar la gestión de a seguridad de la información que pueden utilizarse por los responsables de iniciar, implementar o mantener y mejorar la seguridad en una organización. Persigue proporcionar una base común para desarrollar normas de seguridad dentro de las organizaciones y ser una práctica eficaz de la gestión de la seguridad"9.

DECRETO LEGISLATIVO No 1211 - Decreto Legislativo que Aprueba Medidas para el Fortalecimiento e Implementación de Servicios Públicos Integrados a Través de Ventanillas Únicas e Intercambio de Información entre Entidades Públicas

Según el artículo 1 del presente decreto legislativo establece el marco normativo que promueve la integración de los servicios y procedimientos del Estado, bajo las modalidades presenciales y virtuales, a través del diseño, desarrollo e implementación de ventanillas únicas y el intercambio de información entre entidades públicas, facilitando el comercio, el desarrollo productivo y eliminando las regulaciones excesivas.

El presente decreto legislativo es aplicable a las entidades públicas previstas en el artículo I del Título Preliminar de la Ley No 27444, Ley del Procedimiento Administrativo General.

RESOLUCIÓN MINISTERIAL No 241-2014-PCM - Aprueban Directiva No 001-2014Pcm/ Ongei, "Directiva Sobre Estándares de Servicios Web de Información Georreferenciada para el Intercambio de Datos entre Entidades de la Administración Pública

La directiva tiene como objetivo "definir los estándares de los servicios web para el intercambio de información georreferenciada entre entidades de la Administración Pública, en el marco de la Política Nacional de Gobierno Electrónico"10.

\footnotetext{
${ }^{9}$ Cfr. Ongei (2007:13)

${ }^{10}$ Cfr. Ongei (2014:6)
} 
Debe ser cumplido por "todas las entidades de la Administración Pública a que se refiere el Artículo I del Título Preliminar de la Ley 27444, Ley del Procedimiento Administrativo General, que en el marco de sus funciones y competencias administren datos georreferenciados" $"$.

DECRETO SUPREMO $\mathrm{N}^{\circ}$ 133-2013-PCM - Decreto Supremo Mediante el cual se establece el Acceso e Intercambio de Información Especial entre Entidades de la Administración Pública

Establece los lineamientos y mecanismos de aplicación nacional que facilitan el acceso e intercambio de información especial o georreferenciar entre las entidades de la administración pública. Las entidades públicas que deben aplicarla son las que refiere el Artículo I del Título Preliminar de la Ley $\mathrm{N}^{\circ}$ 2744, Ley del Procedimiento Administrativo General que utilicen, produzcan o financien la producción de datos especiales o georreferénciales.

\section{LEY N2 30096 - Ley de Delitos Informáticos}

La presente Ley tiene por objeto prevenir y sancionar las conductas ilícitas que afectan los sistemas y datos informáticos y otros bienes jurídicos de relevancia penal, cometidas mediante la utilización de tecnologías de la información o de la comunicación, con la finalidad de garantizar la lucha eficaz contra la ciberdelincuencia.

\section{DECRETO SUPREMO $\mathrm{N}^{0}$ 004-2013-PCM - Aprueba la Política Nacional de Modernización de la Gestión Pública}

Apruébese la Política Nacional de Modernización de la Gestión Pública, la cual forma parte integrante del presente Decreto Supremo como Anexo, siendo el principal instrumento orientador de la modernización de la gestión pública en el Perú, que establecerá la visión, los principios y lineamientos para una actuación coherente y eficaz del sector público, al servicio de los ciudadanos y el desarrollo del país.

RESOLUCIÓN MINISTERIAL No. 073-2004-PCM - Aprueban Guía para la Administración Eficiente del Software Legal en la Administración Publica

${ }^{11}$ Cfr. Ongei (2014:6) 
“Aprobar la Guía para la Administración Eficiente del Software Legal en la Administración Pública elaborada coordinadamente por el Instituto Nacional de Defensa de la Competencia y de la Protección de la Propiedad Intelectual - INDECOPI y la Oficina Nacional de Gobierno Electrónico e Informática - ONGEI, que forma parte de la presente resolución"12.

"La Guía explica la importancia de realizar un inventario detallado y la forma apropiada de elaborarlo. Asimismo, determina cómo identificar copias ilegales de software y describe los pasos necesarios para verificar que el uso del software se realice de acuerdo con los términos de la licencia. Por otra parte, se identifican herramientas útiles para realizar el inventario, aunque, si usted no tiene acceso a una aplicación de inventario de software, hallará instrucciones detalladas para identificar el software instalado en sus computadoras"13.

\section{RESOLUCIÓN MINISTERIAL No 139-2004-PCM - Aprueban Documento “Guía Técnica Sobre Evaluación de Software para la Administración Pública"}

"Las entidades de la Administración Pública, integrantes del Sistema Nacional de Informática, deberán aplicar lo establecido en la "Guía Técnica Sobre Evaluación de Software para la Administración Pública” en los productos de software que desarrollen o adquieran a partir de la fecha de publicación de la presente Resolución. ${ }^{14}$ "

La presente guía consta de las siguientes partes:

a. Modelo de la calidad: Se describe un modelo de calidad para los productos de software, dividido en dos partes:

a. Calidad interna y externa

b. Calidad en uso.

b. Métricas

c. Proceso de evaluación de software

LEY No 286121 - Ley que Norma el Uso, Adquisición y Adecuación del Software en la Administración Pública

\footnotetext{
${ }^{12}$ Cfr. Ongei (2004:2)

${ }^{13}$ Cfr. Ongei (2004:8)

${ }^{14}$ Cfr. Ongei (2004:1)
} 
"La presente Ley tiene por objeto establecer las medidas que permitan a la administración pública la contratación de licencias de software y servicios informáticos en condiciones de neutralidad, vigencia tecnológica, libre concurrencia y trato justo e igualitario de proveedores" $" 15$.

"La evaluación técnica de los recursos de software y hardware requeridos por la administración pública se sujetará a las normas dictadas por el ente rector del Sistema Nacional de Informática" 16 .

\section{RESOLUCIÓN JEFATURAL N 088-2003-INEI - Aprueban Directiva sobre "Normas} Para el Uso del Servicio de Correo Electrónico en las Entidades de la Administración Pública"

La norma pretende "Dar lineamientos para el uso correcto del servicio de correo electrónico oficia" ${ }^{17}$.

DECRETO SUPREMO $\mathrm{N}^{\circ}$ 063-2010-PCM - Decreto Supremo que Aprueba la Implementación del Portal de Transparencia Estándar en las Entidades de la Administración Pública

“Aprobar la implementación del Portal de Transparencia estándar en las entidades de la administración pública. Dicha herramienta informática contiene formatos estándares bajo los cuales cada entidad registrará y actualizará su información de gestión de acuerdo a lo establecido por la Ley de Transparencia y Acceso a la información Pública y a los plazos establecidos en ella, sin perjuicio de la información adicional que la Entidad considere pertinente publicar. Dicha herramienta se presenta en una versión amigable con definiciones expresadas en un lenguaje claro y sencillo para un mejor entendimiento de la ciudadanía en general" 18 .

"El presente Decreto Supremo de obligatorio cumplimiento será de aplicación a todas las entidades públicas, entendiéndose como tales, a aquellas referidas en el Artículo I del Título Preliminar de la Ley $N^{\circ}$ 27444, Ley del Procedimiento Administrativo General" ${ }^{19}$.

\footnotetext{
${ }^{15}$ Cfr. UNAC.edu.pe $(2005: 1)$

${ }^{16}$ Cfr. UNAC.edu.pe (2005:1)

${ }^{17}$ Cfr. Inei (2003:2)

${ }^{18}$ Cfr. El Peruano (2010:2)

${ }^{19}$ Cfr. El Peruano (2010:2)
} 


\section{LEY Nº 29733 - Ley de Protección de Datos Personales}

La presente ley tiene el objetivo de garantizar el derecho fundamental a la protección de los datos personales, previsto en el artículo 2 numeral 6 de la Constitución Política del Perú, a través de su adecuado tratamiento, en un marco de respeto de los demás derechos fundamentales que en ella se reconoce.

\section{DECRETO SUPREMO No 081-2006-PCM - Exoneran del Pago de Derechos, Tasas o} Precios Públicos a Entidades que Requieran Información de otra Entidad de la Administración Pública

"Mediante el presente Decreto Supremo se exonera del pago de derechos, tasas o precios públicos a las entidades de la Administración Pública, que requieran información a otra entidad de la Administración Pública a efecto de facilitar los procesos de interconexión e integración entre las mismas" 20 .

\section{RESOLUCIÓN JEFATURAL No 207-2002-INEI - Aprueban Directiva «Normas Técnicas para la Asignación de Nombres de Dominio de las Entidades de la Administración Pública»}

La presente norma tiene como objetivo "Uniformizar los nombres de dominio en las entidades de la Administración Pública a nivel nacional" ${ }^{21}$.

\section{Sponsor}

En este punto se desarrollará el sponsor, en caso no se tenga claro o se presenten dudas al respecto. El sponsor es una persona u organización que patrocina, apoya o financia el proyecto. Idealmente, quien asume este rol debe ser de alguien lo suficientemente responsable para poder tomar decisiones grandes e importantes, es responsable de facilitar el éxito del proyecto, establece prioridades, proporciona recursos y e el portavoz del proyecto. Es por esto, que el que asuma este rol debe ser de gran autoridad dentro del proyecto. Un sponsor debe contar con las siguientes características:

- El sponsor debe ser alguien con autoridad jerárquica dentro del proyecto.

\footnotetext{
${ }^{20}$ Cfr. Softwarepublico.gob.pe (2006:2)

${ }^{21}$ Cfr. Inei (2002:2)
} 
- El sponsor debe ser líder del proyecto.

- El sponsor debe demostrar y transmitir confianza y credibilidad a todos los miembros del equipo del proyecto.

- El sponsor debe contar con habilidades de comunicación.

- El sponsor debe participar en el éxito del proyecto y debe encontrarse disponible cuando se lo requiera.

Debe llevarse un registro de las personas que asumen el rol de sponsor dentro del proyecto, por lo que se definen los siguientes puntos:

- ID: Identificador

- Nombre: Nombre completo del Sponsor

- Organización: Nombre de la organización a la que pertenece el sponsor

- Posición: Posición que el sponsor tiene en la organización

- Email: Correo electrónico del sponsor

- Teléfono: Número de teléfono del sponsor

*Ver plantilla MMEM-Sponsor

\section{E. Misión}

La misión describe el rol que la organización desempeña para el logro de la visión, permite establecer objetivos, formular estrategias y ejecutar tareas. La misión es de vital importancia, ya que explica la razón de ser de la organización o del proyecto y sirve de referencia para la toma de decisiones, ya que indica que es lo que la organización o proyecto hace y qué es lo que la diferencia del resto. En el caso en que la misión no se encuentre desarrollada ni documentada o se presenten dudas al respecto, en este punto se trata acerca de este tema.

La misión debe tener las siguientes características:

- Debe ser clara y comprensible para todos los miembros.

- Decir en pocas palabras en qué consiste el negocio.

- Distinguir la organización de las demás.

- No debe provocar confusiones sobre lo que hace la empresa. 
- No debe limitar el accionar de los miembros del equipo.

Para lograr establecer una correcta misión debemos respondernos las siguientes preguntas:

- ¿Cuál es nuestra razón de ser?

- ¿Quiénes somos?

- ¿Qué buscamos?

- ¿Qué hacemos?

- ¿Dónde lo hacemos?

- ¿Por qué lo hacemos?

- ¿Para quién trabajamos?

- ¿Quiénes son nuestros clientes?

- ¿Cuáles son nuestros principales productos o servicios?

- ¿Cuáles son nuestros mercados?

- ¿Cuál es nuestra diferenciación o mayor ventaja competitiva?

Ejemplos:

"Contribuir a mejorar la vida de nuestros clientes, modificando sus formas de trabajar, de aprender y de comunicarse, a través de delicados productos de cómputo personal e innovadores servicios."

"Ayudar a nuestros clientes a alcanzar sus metas de negocio proveyéndoles servicios y soluciones innovadoras."

*Ver plantilla MMEM-Misión

\section{F. Recursos Disponibles}

En todo proyecto se debe contar con un listado de los recursos, elementos que cuenta la organización, es por esto que se elabora una plantilla para contar con dicha información. Los recursos son aquellos activos, elementos, insumos y/o bienes tangibles o intangibles que contribuyen en el funcionamiento de la organización y a lograr los objetivos. Los recursos disponibles de la empresa pueden ser de tipo financiero, tecnológico, material o humanos. 
Contar con esta descripción es muy importante, ya que de esta manera podremos saber con qué recursos se dispone y cuáles se necesitan.

Los recursos son:

- Recursos Financieros: Referido al recurso monetario de la empresa y ajeno con que la empresa cuenta para el desarrollo de las actividades de la organización. Este puede ser: dinero en efectivo, utilidades, acciones, préstamo, créditos, entre otros.

- Recursos Tecnológicos: Referido al medio tecnológico tangibles o intangibles por el cual las empresas desarrollan sus actividades.

- Recursos Materiales: Relacionado a los bienes tangibles de la empresa como muebles, enseres, edificios, terrenos, herramientas, entre otros.

- Recursos Humanos: Relacionado a los servicios que ofrecen las personas a la empresa, en cuanto a sus habilidades, conocimientos, realización de actividades y toma de decisiones para el funcionamiento de la empresa.

*Ver plantilla MMEM-Recursos Disponibles

Se proponen puntos o recomendaciones se serán tomados por cada fase del esquema de eGovernment. A continuación, se pasará a desarrollar dichos puntos.

\section{G. Roles y Responsabilidades}

En este punto se desarrollará o aclarará ciertas dudas con respecto a los roles y responsabilidades de los miembros del equipo de proyecto.

Para el proyecto a desarrollar, es importante contar con una lista de roles y responsabilidades definidas; de esta manera, se tendrá conocimiento de quiénes participan y qué papeles ocupan para llevar a cabo el proyecto. La definición de los roles y las responsabilidades de cada miembro del equipo es una parte muy importante para el proyecto, ya que proporciona una descripción definida de las tareas que va a realizar cada recurso humano, comprobar que no existen vacíos y evitar ambigüedades de cada rol. Esta definición nos permite responder a las siguientes preguntas: 
- ¿Quiénes forman parte del equipo?

- ¿Qué funciones se atribuyen a cada una de ellas?

- ¿Cuáles son sus responsabilidades específicas?

- ¿Qué obligaciones deben cumplir?

- ¿Cuál es la información de contacto de cada uno de los miembros del equipo?

Para definir los roles y responsabilidades del equipo de trabajo se debe considerar lo siguiente:

- Definir los roles del proyecto y la cantidad de personal que demandará.

- Definir las responsabilidades de cada rol.

- Elaborar un documento llamado "Descripción del Trabajo". En este documento se describe detalladamente las responsabilidades específicas de cada rol.

- Identificar e iniciar el proceso de reclutamiento, en donde se convoca a candidatos para cubrir los roles establecidos.

- Designar al personal a cada rol.

*Ver plantilla MMEM-Roles y Responsabilidades

\section{H. Principios de Arquitectura}

Es necesario proponer principios para el proyecto a desarrollar, ya que los principios definen las normas y directrices para el uso y despliegue de los recursos y activos de TI. En caso no se haya propuesto principios o se presenten dudas al respecto; a continuación, se desarrolla dicho punto.

Los principios reflejan un nivel de consenso entre los distintos elementos de la empresa, y constituyen la base para la toma de futuras decisiones de TI. Son reglas generales y pautas, destinadas a ser duraderas y poco modificadas, que informan y apoyan la forma en que una organización se pone a cumplir su misión. A su vez, los principios pueden ser solo un elemento de un conjunto estructurado de ideas que definen y guían colectivamente la organización, desde los valores hasta las acciones y los resultados. Un buen conjunto de principios se fundará en las creencias y valores de la organización y se expresará en un lenguaje que la empresa entiende y utiliza. Los principios deben ser pocos en número, orientados al futuro, y respaldados y defendidos por la alta dirección. Proporcionan una base firme para tomar decisiones de 
arquitectura, enmarcar políticas, procedimientos y estándares, y apoyar la resolución de situaciones contradictorias. Un conjunto de principios pobres se desvanecerá rápidamente, y las arquitecturas, políticas y estándares resultantes carecerán de credibilidad. Esencialmente, los principios conducen el comportamiento.

Existen cinco criterios que distinguen un buen conjunto de principios:

- Comprensible: los principios subyacentes pueden ser rápidamente comprendidos y entendidos por los individuos en toda la organización. La intención del principio es clara y sin ambigüedades.

- Robusto: Cada principio debe ser suficientemente preciso para apoyar una toma de decisiones coherente en situaciones complejas y potencialmente polémicas.

- Completo: Los principios cubren cada situación percibida.

- Consistente: El conjunto de principios debe expresarse de una manera que permita un equilibrio de interpretaciones entre los principios. Estos no deben ser contradictorios hasta el punto de que adherirse a un principio violaría el espíritu de otro. Cada palabra en una declaración de principios debe ser cuidadosamente elegida para permitir una interpretación coherente y flexible.

- Estable: los principios deben ser duraderos, pero capaces de acomodar los cambios. Debería establecerse un proceso de enmienda para agregar, remover o alterar principios después de haber sido ratificados inicialmente.

Tener en cuenta que debemos definir 4 tipos de principios los cuales son:

- Los principios de negocio definen las directrices para el negocio, ya sean procesos, reglas de negocio, roles y responsabilidades, entro otros.

- Los principios de datos definen las directrices para los datos ya sea para su almacenamiento, formato, etc.

- Los principios de aplicaciones definen las directrices para los softwares que se utilizan o están en desarrollo. 
- Los principios de tecnología definen las directrices para los software y hardware de la municipalidad.

- Los principios de seguridad definen las directrices para los procedimientos de seguridad de software y hardware de la municipalidad.

Para la elaboración de los principios se debe tener en cuenta lo siguiente.

- ID: Identificador

- Nombre: Nombre del Principio

- Declaración: La declaración debe comunicar brevemente y sin ambigüedad la regla fundamental. Es vital que la declaración de principios sea inequívoca.

- Fundamento: El fundamento explica o detalla la regla definida en la declaración. En este punto se puede mencionar los beneficios del negocio de adherirse al principio, las circunstancias para su aplicación, entro otros. Si es necesario, se debe describir las situaciones en las que un principio tendría prioridad o tendría más peso que otro para tomar una decisión.

- Implicaciones: Las implicaciones son las condiciones deben existir o acciones que se deben de realizar, en términos de recursos, costos y tareas, para el cumplimiento del principio, tanto para el negocio como para TI. E impacto en el negocio y las consecuencias de la adopción de un principio deben ser claramente establecidos. El lector debe discernir fácilmente la respuesta a: ¿Cómo me afecta esto?" Es importante no simplificar, trivializar o juzgar el mérito del impacto. Algunas de las implicaciones se identificarán como posibles impactos solamente, y pueden ser especulativas en lugar de ser analizadas en su totalidad.

- Fecha: Fecha de creación o modificación del principio.

- Creador: Creador o propietario

*Ver plantilla MMEM-Catálogo de Principios 


\section{Objetivos}

Para el proyecto se debe tener definido los objetivos, en caso no se tenga desarrollado o se presenten dudas al respecto; a continuación, se desarrolla dicho punto.

Los objetivos son resultados que una organización desea alcanzar en un período de tiempo y empleando recursos, de los cuales dispone o pretende disponer. Deben determinar qué es lo que se desea lograr y encontrarse relacionados con la misión. Son esenciales, ya que establece un curso a seguir para llegar al éxito de la organización, y permite enfocar los esfuerzos hacia una dirección.

Los objetivos deben contar con las siguientes características:

- Deben ser medibles y deben estar ligados a un límite de tiempo.

- Deben ser claros, precisos y entendibles.

- Deben encontrarse dentro de las posibilidades de la organización, teniendo en cuenta el tiempo y los recursos que dispone.

- Deben ser realistas y desafiantes.

- Deben encontrarse alineados con otros objetivos, con la misión, visión, política y valores de la organización.

- Los objetivos pueden ser: generales, específicos, estratégicos, tácticos, operacionales, de largo, mediano y corto plazo.

Ejemplo Objetivo General: "Ser una marca que los demandantes reconozcan por su variedad de productos."

Ejemplo Objetivo Específico: “Aumentar las ventas en un 20\% en los próximos 12 meses, para poder empezar la ampliación de nuestra nueva planta."

Ejemplo Objetivo Específico: “Adquirir 2 nuevas maquinarias para el segundo semestre.” Ejemplo Objetivo Específico: "Abrir 3 tiendas para el primer trimestre del próximo año." 
*Ver plantilla MMEM-Objetivos

\section{J. Requerimientos}

Para el proyecto es necesario definir lo requerimientos. En caso no se cuenten con requerimientos definidos o exista alguna duda. A continuación, se desarrolla dicho punto.

Un requerimiento es una necesidad del contenido o funcionalidad del proyecto, producto o servicio. Como parte de la funcionalidad o contenido identifica los atributos, las características o las cualidades que debe cumplir el producto, servicio o proyecto para brindar un valor o utilidad. Los requerimientos se dividen en:

- Requerimientos funcionales: que determina lo que debe hacer, con las relaciones que debe tener, teniendo en cuenta lo que no se debe hacer.

- Requerimientos no funcionales: referente a las cualidades y/o función que debe cumplir.

Para la definición de los requerimientos debemos tener en cuenta que:

- Debe cumplir con las necesidades definidas.

- Deben ser claros y concretos.

- Deben ser redactados de manera que pueda ser comprensible por todos.

- Deben estar organizados de manera jerárquica.

- No debe contradecir a cualquier otro requerimiento.

- No debe ser obsoleto con el paso del tiempo.

- No debe ser ambiguo y debe poder ser implementado.

Ejemplo: "El jefe del área de Recursos Humanos debe ser capaz de actualizar el listado de empleados que existe en la organización, indicando los nuevos ingresantes."

*Ver plantilla MMEM-Requerimientos 


\section{K. Modelamiento de Procesos}

Un proceso, es un conjunto de actividades secuenciales con el fin de lograr un resultado determinado. Contar con la documentación de estos procesos de la organización es clave, ya que permite obtener información específica acerca de los pasos que se deben realizar para completarlos. Por lo que, se debe identificar los procesos de la organización y pasar a documentarlos.

La documentación de procesos brinda uniformidad para realizar las actividades de los procesos, funciona como un mapa de ruta de la organización y sirve de guía para empleados y directores. Además, ayuda a saber cómo se encuentra actualmente el proceso, permite identificar posibles mejoras para el mismo y, posibilita el monitoreo y supervisión. Esta documentación permite también, que el conocimiento quede en la empresa y no se vaya con los empleados que dejan la organización. Adicional a esto, permite que los empleados nuevos y antiguos entiendan su rol dentro de la organización.

Documentación de procesos permite:

- Corregir y eliminar errores.

- Reducir tiempos en el desarrollo de las tareas de los procesos.

- Reducir recursos y disminuir costos.

- Mejorar la eficiencia y calidad de los procesos.

- Aumentar la satisfacción de los usuarios.

Es por esto, que se propone la utilización de la gestión de procesos, el cual es una metodología que permite diseñar, modelar, documentar, controlar y optimizar los procesos de la organización. Business Process Management (BPM) es un sistema de gestión enfocado a perseguir la mejora continua en el funcionamiento de las actividades empresariales mediante la identificación, selección, descripción, documentación y mejora de procesos, partiendo del despliegue de la estrategia de la organización, asegurando la misión empresarial y alineada a la visión de la empresa. BPM se alinea con la estrategia, con la gestión de recursos humanos, con la gestión financiera, con la gestión de la información, con la gestión de la calidad y con las disciplinas tradicionales de gestión definiendo indicadores de funcionamiento y objetivos, 
que incrementen la mejora y estén alineados, en tiempo real, con los objetivos estratégicos y tengan en cuenta las necesidades y expectativas de los clientes ${ }^{22}$.

Para el desarrollo de la gestión de los procesos de la organización, la cual es una entidad pública, se debe tener en cuenta que cualquier cambio realizado se debe considerar las regulaciones brindadas por el Estado y se tomarán las plantillas desarrolladas en la tesis Modelo de Implementación de una Solución BPM con Open Source para Pymes desarrollada por Renzo Hohagen y Renato Chapeyquén.

\section{Recomendaciones para la Implementación de Arquitecturas}

Para la realización de las arquitecturas planteadas se tomaron las buenas prácticas del marco de trabajo TOGAF, la cual proporciona un enfoque para el diseño, la planificación, implementación y gobierno de esta. Se plantean cuatro arquitecturas que cubren cuatro fases de gobierno electrónico municipal, las cuales son Presencia, Información Urbana, Interacción y Transacción. Cada fase tiene un nivel de cumplimiento diferente, ya sea por contenido de información registrada o por entregables desarrollados. A continuación, explicaremos estos últimos para una mejor comprensión de su utilización.

1. Diagrama de Casos de Uso: Un diagrama de casos de uso del sistema muestra las relaciones entre consumidores y proveedores de servicios de aplicaciones. Los servicios de aplicaciones son consumidos por los agentes u otros servicios. Es decir, describe el comportamiento de un sistema al afrontar una tarea de negocio. Es por esta razón porque la que se debe contar con este documento, la municipalidad de conocer las funcionalidades que va a tener su sub y quienes van a interactuar con ella. Esto beneficia al momento de hacer un cambio, ya se conoce como va a importar y a quienes.

2. Catálogo de Portafolio de Aplicaciones: Identifica una lista de todas las aplicaciones. Esta lista ayuda a definir el propósito de las iniciativas de cambio que pueden impactar en los tipos de aplicaciones ${ }^{23}$.

3. Catálogo de Portafolio de Entidades: Identifica la lista de entidades con las que va a contar el sistema propuesto. Permite evitar redundancias de información.

\footnotetext{
${ }^{22}$ Cfr. Libro del BPM 2011:6-7

${ }^{23}$ Crf Andrés Felipe García Osorio (2014)
} 
4. Matriz de interacción de aplicaciones: Muestra la relación de comunicación que tienen las aplicaciones con otras.

5. Catálogo de Portafolio de Tecnología: El propósito de este catálogo es identificar y mantener una lista de toda la tecnología en uso en toda la empresa, incluyendo hardware, software de infraestructura y software de aplicación. El catálogo de portafolio de tecnología proporciona una base sobre la cual basar las matrices y diagramas restantes.

6. Diagrama de Red: Muestra la relación de los componentes de infraestructura. Como va a estar diseñada la red de la municipalidad.

7. Matriz de Tecnología: Mapea la relación entre las aplicaciones con los componentes tecnológicos.

8. Matriz Entidad de Datos - Función de Negocio: Su propósito es describir la relación entre entidades de datos y funciones empresariales dentro de la empresa. Las funciones empresariales están soportadas por servicios empresariales con límites definidos explícitamente y serán soportadas y realizadas por procesos empresariales.

9. Matriz de Aplicaciones - Función de Negocio: Su propósito es describir la relación entre las aplicaciones y las funciones empresariales dentro de la empresa ${ }^{24}$.

10. Diagrama de Base de Datos: Su propósito es mostrar la lógica de la base de datos, sus relaciones, como se almacena los datos y como se accede a ellos. Cuentan con reglas que deben ser cumplidas, tales como evitar la redundancia, duplicidad de llaves, entre otros.

Tabla 10: Arquitecturas por Fase

\begin{tabular}{|l|l|l|l|}
\hline \multicolumn{1}{|c|}{ Presencia } & \multicolumn{1}{|c|}{ Información urbana } & \multicolumn{1}{c|}{ Interacción } \\
\hline \multicolumn{2}{|c|}{ Fase C } & Caso de uso \\
\hline Caso de uso & Caso de uso & Caso de uso \\
\hline $\begin{array}{l}\text { Catálogo de Portafolio de } \\
\text { Aplicaciones }\end{array}$ & $\begin{array}{l}\text { Catálogo de Portafolio de } \\
\text { Aplicaciones }\end{array}$ & $\begin{array}{l}\text { Catálogo de Portafolio de } \\
\text { Aplicaciones }\end{array}$ & $\begin{array}{l}\text { Catálogo de Portafolio de } \\
\text { Aplicaciones }\end{array}$ \\
\hline
\end{tabular}

\footnotetext{
${ }^{24}$ Crf. Open Group
} 


\begin{tabular}{|c|c|c|c|}
\hline $\begin{array}{l}\text { Catálogo de Portafolio de } \\
\text { Entidades }\end{array}$ & $\begin{array}{l}\text { Catálogo de Portafolio de } \\
\text { Entidades }\end{array}$ & $\begin{array}{l}\text { Catálogo de Portafolio de } \\
\text { Entidades }\end{array}$ & $\begin{array}{l}\text { Catálogo de Portafolio de } \\
\text { Entidades }\end{array}$ \\
\hline $\begin{array}{l}\text { Matriz de Interacción de } \\
\text { Aplicaciones }\end{array}$ & $\begin{array}{l}\text { Matriz de Interacción de } \\
\text { Aplicaciones }\end{array}$ & $\begin{array}{l}\text { Matriz de Interacción de } \\
\text { Aplicaciones }\end{array}$ & $\begin{array}{l}\text { Matriz de Interacción de } \\
\text { Aplicaciones }\end{array}$ \\
\hline & & & $\begin{array}{l}\text { Matriz Entidad de Datos - } \\
\text { Función de Negocio }\end{array}$ \\
\hline & & & $\begin{array}{l}\text { Matriz Aplicaciones } \\
\text { Función de Negocio }\end{array}$ \\
\hline \multicolumn{4}{|c|}{ Fase D } \\
\hline $\begin{array}{l}\text { Catálogo de Portafolio de } \\
\text { Tecnología }\end{array}$ & $\begin{array}{l}\text { Catálogo de Portafolio de } \\
\text { Tecnología }\end{array}$ & $\begin{array}{l}\text { Catálogo de Portafolio de } \\
\text { Tecnología }\end{array}$ & $\begin{array}{l}\text { Catálogo de Portafolio de } \\
\text { Tecnología }\end{array}$ \\
\hline Diagrama de Red & Diagrama de Red & Diagrama de Red & Diagrama de Red \\
\hline Matriz de Tecnología & Matriz de Tecnología & Matriz de Tecnología & Matriz de Tecnología \\
\hline
\end{tabular}

Fuente: Elaboración Propia

Figure 38: Modelo de Mejoras de e-Servicios Municipales

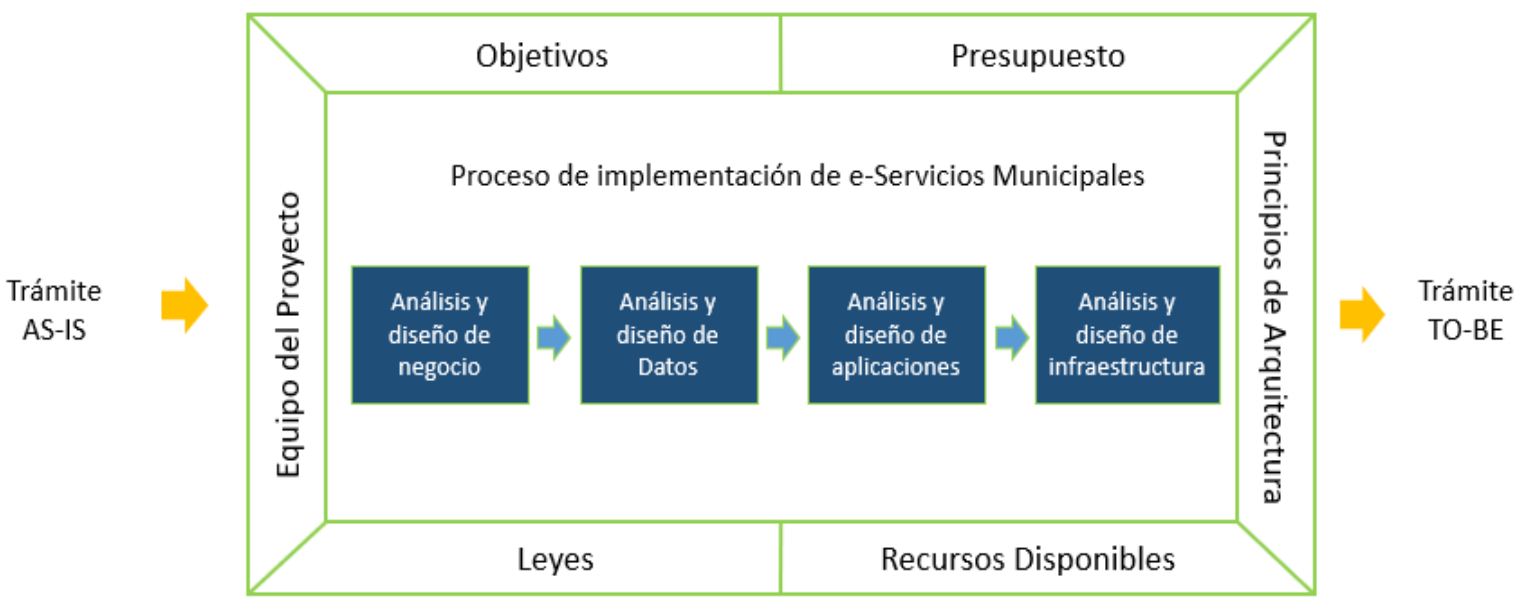

Fuente: Elaboración Propia 
Figure 39: Gráfico Modelo de Mejoras de e-Servicios Municipales
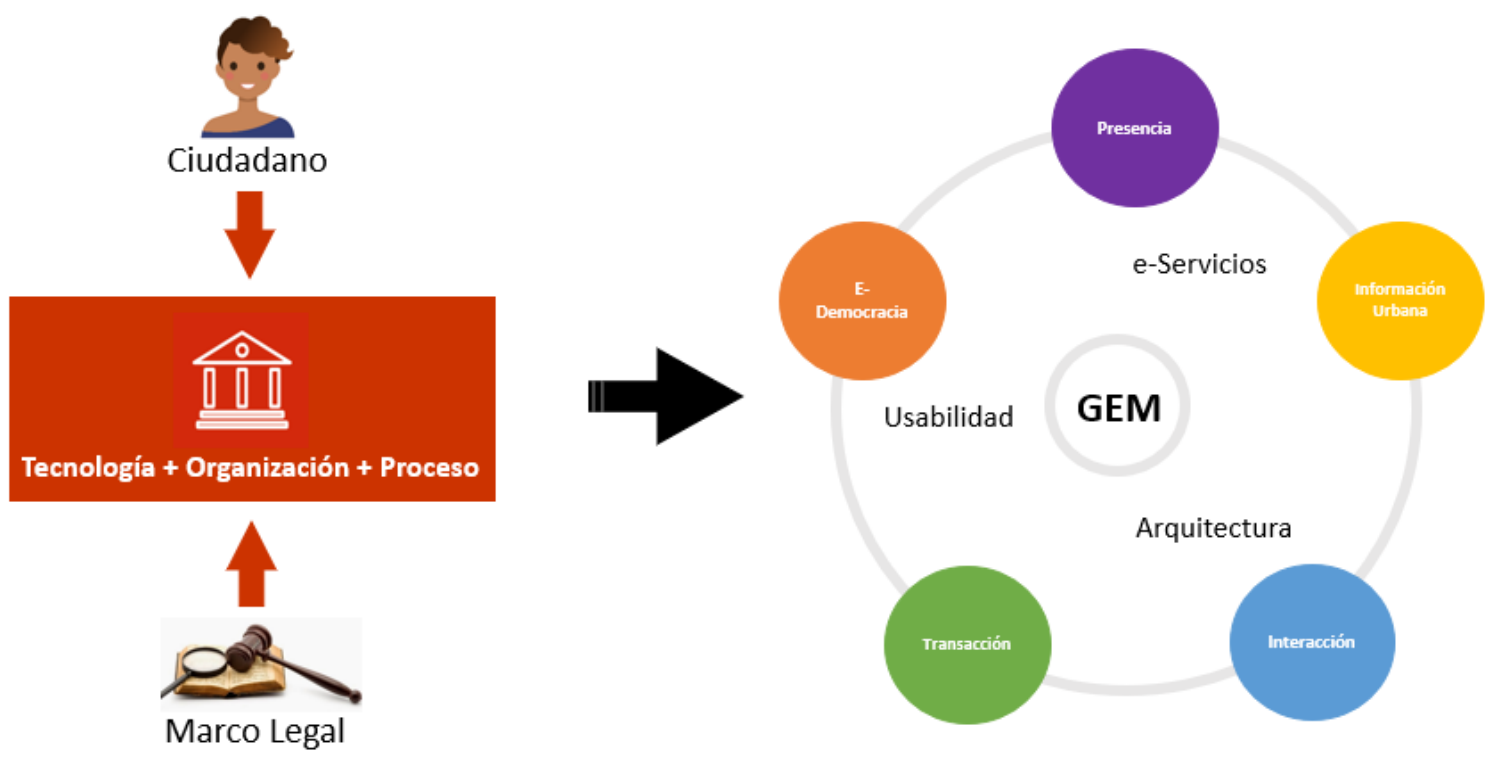

Fuente: Elaboración Propia 


\section{Capítulo 6: Resultados del Proyecto}

En este capítulo se realiza la validación del caso de estudio, para esto se elabora el eServicio llamado Trámite Documentario Electrónico utilizando el modelo propuesto. La validación se realiza por medio de encuestas a tres grupos, los cuales son expertos en el área de tecnología de municipalidades, ciudadanos y funcionarios públicos. Estas encuestas se desarrollaron por medio de la escala de Likert, el cual se ha definido en 5 niveles: 1 Muy Alto, 2 Alto, 3 Medio, 4 Bajo, 5 Nada.

\section{Introducción}

Para el presente proyecto, existen dos tipos de validación. El primero es un caso de estudio donde se utilizó el modelo en la municipalidad de Surco. El objetivo es que la entidad diseñe su gobierno electrónico en base a e-Servicios y, de esta manera, se le facilite su implementación. Para lograrlo, se identificó un trámite que sea utilizado por muchos ciudadanos para que el impacto de la propuesta sea alto. El trámite tiene relación con muchos otros e-Servicios de la fase objetivo y otros de fases anteriores. Para obtener los resultados, se elaboraron prototipos y una encuesta que mostraban los beneficios del nuevo trámite, tanto a los funcionarios que participan en el mismo como a los ciudadanos que tienen un local con licencia de funcionamiento. El segundo es una validación por juicio de expertos, una encuesta para especialista de tecnología que pertenezcan a una municipalidad. Los expertos son Sub Gerentes de las municipalidades de Santiago de Surco, Barranco, Miraflores, Villa María del Triunfo y Chorrillos. A continuación, se explica el desarrollo del proceso de ambos tipos de validación empezando por el caso de estudio.

\section{Caso de Estudio}

El caso de estudio se realizó en la municipalidad de Santiago de Surco, con el trámite de licencia de funcionamiento. Según el informe de la entidad, este proceso ha sido el más solicitado entre los años 2016 - 2017 por la ciudadanía. Su traslado a la web disminuiría considerablemente la carga procesal de la municipalidad.

\section{A. Marco del Modelo}

Antes de empezar la ejecución del modelo en el trámite, se realiza el marco propuesto. 
1. Objetivos: Los objetivos que se alinean a la misión planteada.

*Ver Anexo - MMEM-Objetivos

2. Equipo de Proyecto: Los funcionarios que participan en el trámite se muestran en la siguiente tabla.

*Ver Anexo - MMEM-Roles y Responsabilidades

3. Recursos disponibles

4. Leyes: Se basa en el marco legal vigente.

5. Principios de arquitectura: Se han definido los cinco grupos de arquitectura, las cuales son de negocio, aplicaciones, datos, tecnología y seguridad.

*Ver Anexo - MMEM-Catálogo de Principios

6. Presupuesto: No aplica para el caso de estudio.

Se realizaron las siguientes recomendaciones planteadas en el modelo:

7. Misión: Se propone una misión para que este alineada a una propuesta de gobierno electrónico.

*Ver Anexo - MMEM-Misión

8. Sponsor: Si bien para la presente evaluación se contó con un sponsor, se dejan las propuestas de posibles en la municipalidad de Surco.

*Ver Anexo - MMEM-Sponsor

9. Requerimientos: Son los requerimientos identificados para el cumplimiento de la propuesta.

*Ver Anexo - MMEM-Requerimientos 


\section{B. Procesos del Modelo}

La entrada del proceso propuesto es el trámite de licencia de funcionamiento como se encuentra actualmente. Para su ejecución, el ciudadano debe acercarse a la entidad y entregar dos solicitudes firmadas. Al ser aceptadas, se programa una fecha de inspección para que el personal de Defensa Civil se acerque a la dirección indicada. Luego, el Gerente de Desarrollo Urbano firma la licencia de funcionamiento. En paralelo, se realiza la inspección y es el inspector quien ingresa los resultados al sistema. Al ser aprobado, la inspección técnica es firmada por la Sub Gerencia de Defensa Civil y es entregada al Gerente de Desarrollo Urbano. Tanto la licencia de funcionamiento como la inspección técnica son entregadas al ciudadano solicitante.

*Ver Anexo - MMEM-Proceso-Actual

\section{Análisis y Diseño del Negocio}

Al conocer cómo funciona el proceso de licencia de funcionamiento, se debe analizar las oportunidades de mejora para el proceso e identificar qué e-Servicios de la propuesta pueden ser consumidos por él.

Tabla 11: Funcionalidades y e-Servicios que serán utilizados en el e-Trámite de Licencia de Funcionamiento

\begin{tabular}{|c|c|c|}
\hline & Actividades & Funcionalidad \\
\hline \multirow{6}{*}{ 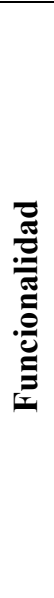 } & Envíos de información & $\begin{array}{c}\text { Enviar información de la sesión del } \\
\text { usuario }\end{array}$ \\
\hline & Archivar expediente & $\begin{array}{l}\text { Registrar documentos en el servidor } \\
\text { de archivos }\end{array}$ \\
\hline & $\begin{array}{l}\text { Registro de información en } \\
\text { otros sistemas }\end{array}$ & $\begin{array}{c}\text { Intercambiar información con otros } \\
\text { sistemas }\end{array}$ \\
\hline & Recibir documentos & Cargar documentos \\
\hline & Verificar requerimientos & Verificar documentos \\
\hline & $\begin{array}{l}\text { Programar fecha de inspección } \\
\text { ocular }\end{array}$ & Programar fecha de inspección \\
\hline \multirow{4}{*}{ } & Pago por derecho a trámite & Pago en línea \\
\hline & Firma de documentos & Firma y certificado digital \\
\hline & Asesorías al ciudadano & Chat en línea \\
\hline & & \\
\hline
\end{tabular}




\begin{tabular}{|c|c|} 
Entrega de formatos & Formatos en línea \\
\cline { 2 - 3 } Consultar TUPA web & TUPA en línea \\
\hline
\end{tabular}

Fuente: Elaboración Propia

En base a la información analizada, se brinda una propuesta del trámite objetivo. En el nuevo proceso, el ciudadano puede cargar las solicitudes desde la web de la municipalidad. El sistema valida la información y registra en la base de datos. Se programa automáticamente la inspección. Al concluir esta tarea, el sistema calcula el pago por derecho a trámite y le muestra al ciudadano el importe y los medios de pago. Una vez el ciudadano realiza el pago, se confirma la inspección. El sistema elabora licencia de funcionamiento con la información del ciudadano y se almacena en el servidor de archivos hasta que se apruebe la inspección técnica. Al ser aprobada por el área de Sub Gerencia de Defensa Civil, el sistema elabora la inspección técnica, la cual es firmada digitalmente por el Sub Gerente de dicha área para luego ser enviada a la cuenta del ciudadano previamente creada. En todo momento se podrá monitorear el estado del trámite.

Figure 40: Comparación Trámite Actual vs Trámite Objetivo

\begin{tabular}{|c|c|c|c|c|c|}
\hline \multirow{2}{*}{ 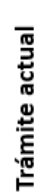 } & Ciudadano & Inspector & Sub Gerente & Sub Gerente & Asesor CAS \\
\hline & $\begin{array}{c}\text { Entregar } \\
\text { documentos en } \\
\text { ventanilla }\end{array}$ & $\begin{array}{l}\text { Programar } \\
\text { inspección }\end{array}$ & $\vec{c} \begin{array}{c}\text { Firmar licencia } \\
\text { de } \\
\text { funcionamiento }\end{array}$ & $\begin{array}{l}\text { Firmar } \\
\text { inspección } \\
\text { técnica }\end{array}$ & $\begin{array}{c}\text { Entregar } \\
\text { documentos en } \\
\text { ventanilla }\end{array}$ \\
\hline \multirow[b]{2}{*}{ 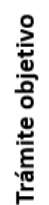 } & Ciudadano & Sistema & Sub Gerente & Sub Gerente & Sistema \\
\hline & $\begin{array}{l}\text { Cargar } \\
\text { documentos } \\
\text { por la web }\end{array}$ & $\begin{array}{l}\text { Programar } \\
\text { inspección }\end{array}$ & $\begin{array}{c}\text { Firma } \\
\text { electrónica en } \\
\text { licencia de } \\
\text { funcionamiento }\end{array}$ & $\begin{array}{c}\text { Firma } \\
\text { electrónica en } \\
\text { inspección } \\
\text { técnica } \\
\end{array}$ & $\begin{array}{c}\text { Entrega de } \\
\text { documentos en } \\
\text { carpeta del } \\
\text { ciudadano } \\
\end{array}$ \\
\hline
\end{tabular}

Fuente: Elaboración Propia

*Ver Anexo - MMEM-Proceso-Objetivo

\section{Análisis y Diseño de Datos}

Luego de saber qué funcionalidades y e-Servicios se van a implementar, se procede a identificar las entidades necesarias para su desarrollo. Algunos de ellos se encuentran en la siguiente tabla. 
Tabla 12: Muestra de entidades identificadas

\begin{tabular}{|c|l|}
\hline Entidad & \multicolumn{1}{|c|}{ Descripción } \\
\hline Formulario & Almacena los formularios ingresados por el ciudadano o funcionario. \\
\hline TUPA & Se encuentran los requerimientos del TUPA. \\
\hline Comprobante & Información de los pagos realizados por la web y de manera presencial. \\
\hline Trámite_Formulario_Firma & $\begin{array}{l}\text { Almacena la relación entre los documentos legales, el trámite y los usuarios } \\
\text { que la han firmado. }\end{array}$ \\
\hline
\end{tabular}

Fuente: Elaboración Propia

*Ver Anexo - MEMM-EDM-05-Catálogo de Entidades

Luego, se elabora la Matriz Entidad de Datos - Función de Negocio donde muestra la relación de las entidades con el negocio, la cual permite entender qué entidades van a ser consumidas por el proceso propuesto y por los demás.

Para contar el diseño de la base de datos, se realiza un diagrama de base de datos donde se encuentra todas las entidades identificadas anteriormente. La siguiente figura muestra un extracto del planteado.

Figure 41: Extracto de Diagrama de Base de Datos

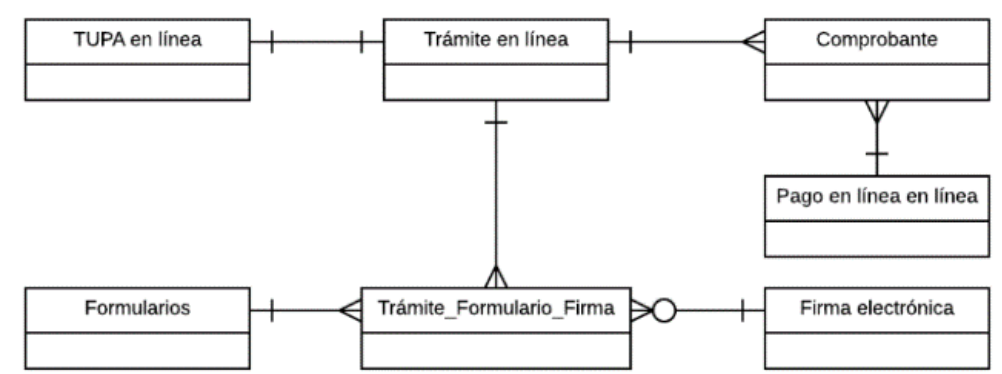

Fuente: Elaboración Propia

3. Análisis y Diseño de Aplicaciones

Al contar con el proceso objetivo y las entidades para la propuesta, podemos definir las aplicaciones que se deben desarrollar para implementar el trámite objetivo. Algunas de las aplicaciones identificadas se encuentran en la siguiente tabla. 
Tabla 13: Extracto de Aplicaciones Propuestas

\begin{tabular}{|c|l|}
\hline Aplicación & \multicolumn{1}{|c|}{ Descripción } \\
\hline Formulario & $\begin{array}{l}\text { Permite elaborar un documento para que se inicie un trámite, este será } \\
\text { llenado por el ciudadano o el funcionario de manera digital. La información } \\
\text { restante, será llenada por el sistema. }\end{array}$ \\
\hline Pago online & Permite realizar el pago por medio de la web con tarjeta de crédito o débito. \\
\hline $\begin{array}{c}\text { Trámite de emisión de } \\
\text { licencia de funcionamiento } \\
\text { menor a } 100 \mathrm{~m} 2\end{array}$ & $\begin{array}{l}\text { Permite la ejecución de un trámite de licencia de funcionamiento de un } \\
\text { establecimiento menor a } 100 \mathrm{~m} 2 \text { desde la web sin que el ciudadano tenga que } \\
\text { ir a la municipalidad }\end{array}$ \\
\hline
\end{tabular}

Fuente: Elaboración Propia

*Ver Anexo - MEMM-EDM-06-Catálogo de aplicaciones

Al conocer las aplicaciones necesarias para alcanzar el proceso objetivo, se debe conocer cómo estas van a interactuar con los roles que participan en el proceso. En la siguiente figura se muestra un extracto del diagrama de caso de uso del trámite de licencia de funcionamiento.

Figure 42: Extracto de Diagrama de Caso de Uso

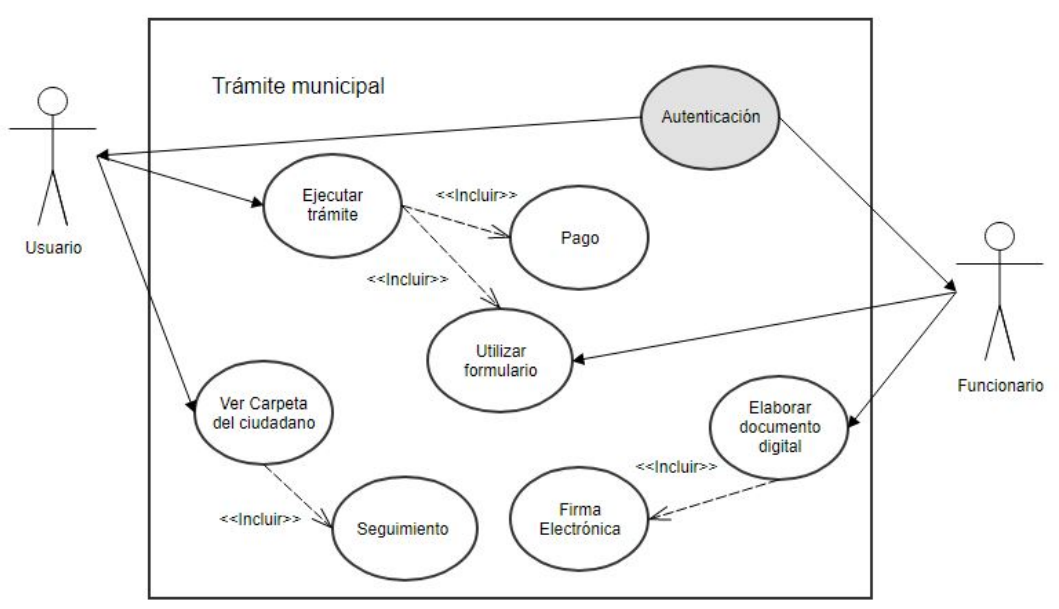

Fuente: Elaboración Propia

*Ver Anexo - MEMM-EDM-07-Caso de uso - Trámite Municipal

*Ver Anexo - MEMM-EDM-08-Caso de uso - Información Municipal

*Ver Anexo - MEMM-EDM-09-Caso de uso - Contacto con el Ciudadano 
Para entender cómo van a interactuar las aplicaciones entre ellas, se utiliza en artefacto matriz interacción entre aplicaciones. Se muestra una parte de la matriz mostrando como se relaciona el e-Trámite con otras aplicaciones. La siguiente tabla muestra dos columnas, la primera es Consume, la cual se refiere a las aplicaciones utilizadas por el sistema para ejecutar una función, mientras que la columna Comunica se refiere al intercambio de información con otra aplicación.

Tabla 14: Interacción del e-Trámite con las Otras Aplicaciones

\begin{tabular}{|c|c|}
\hline Consume & Comunica \\
\hline Mapa web & Chat en línea \\
\hline Llama IP & Tupa en línea \\
\hline & Carpeta del ciudadano \\
\hline & Formulario \\
\hline & Pago en línea \\
\hline
\end{tabular}

Fuente: Elaboración Propia

*Ver Anexo - MEMM-EDM-03-Matriz de interacción de aplicaciones

Si bien las aplicaciones identificadas van a ser consumidas por el proceso, se debe mapear como estas van a interactuar con todo el negocio. Por lo que, se debe realizar una relación entre los procesos con todas las aplicaciones de la entidad municipal.

Debido a que no se cuenta con el acceso a la información de todas las aplicaciones de la municipalidad de Santiago de Surco, no se elabora el documento.

\section{Análisis y Diseño de Infraestructura}

Como último paso, se debe determinar qué infraestructura va a soportar la propuesta. Primero, se identifica la parte lógica, es decir los sistemas que va a necesitar la infraestructura para que pueda ejecutar su función correctamente. Para esto, se usará un sistema gestor de base de datos, el cual permite el almacenamiento, modificación y extracción de la información en una base de datos; y un servidor web, referido a un programa informático que procesa una aplicación del lado del servidor realizando conexiones bidireccionales y/o unidireccionales y, síncronas o asíncronas con el cliente generando o cediendo una respuesta en cualquier lenguaje o aplicación del lado del cliente. 
Si bien ya se conoce la parte lógica, se procede a identificar la parte física de la infraestructura. Esta viene a ser el hardware necesario para alcanzar el objetivo.

Tabla 15: Hardware

\begin{tabular}{|c|c|}
\hline Nombre & Descripción \\
\hline & $\begin{array}{l}\checkmark \text { Procesadores: Hasta dos procesadores Intel }{ }^{R} \text { Xeon }{ }^{\mathrm{TM}} \text { con } \text { Tecnología de } 64 \text { bits de } \\
\text { memoria ampliada Intel de hasta } 3,6 \mathrm{GHz} \\
\checkmark \text { Memoria: } 12 \text { GB DDR2 } 400 \text { SDRAM; } 12 \text { GB con disponibilidad de } \\
\text { rack único de } 2 \text { GB DIMMS1 } \\
\checkmark \text { Unidad de disco: Ocho unidades de } 1 \text { “ + Dos unidades de } 1 \text { “ SCSI Ultra320 de conexión } \\
\text { en caliente con soporte de unidad de cinta interna } \\
\checkmark \text { Almacenamiento interno máximo: Hasta } 1,46 \quad \text { TB } \text { de } 300 \text { GB } \\
\text { Unidades de disco duro: } 300 \text { GB2 Ultra320 SCSI } \\
\checkmark \text { Tarjeta de interfaz de red: Incorporado doble Intel } 1000 \text { Gigabit NIC; Intel PRO/1000 MT }\end{array}$ \\
\hline
\end{tabular}

Fuente: Elaboración Propia

*Ver Anexo - MEMM-EDM-03-Matriz de interacción de aplicaciones

*Ver Anexo - MEMM-EDM-12-Catálogo de portafolio de tecnología

Al utilizar el modelo con el proceso actual de licencia de funcionamiento, el resultado es el etrámite de licencia de funcionamiento listo para su implementación, analizado y diseñado con las buenas prácticas de la arquitectura empresarial TOGAF.

\section{Resultados}

Para validar el caso de estudio, se elaboran prototipos que fueron mostrados a los ciudadanos con licencia de funcionamiento para su local y a los participantes del trámite actual. La validación se realiza por medio de dos encuestas, una para cada grupo. Estas encuestas fueron desarrollas por medio de la escala de Likert, el cual se ha definido en 5 niveles: 1 Muy Alto, 2 Alto, 3 Medio, 4 Bajo, 5 Nada.

Además, se calcula la reducción de carga procesal mediante las actividades del flujo del proceso, midiendo los tiempos del trámite actual vs objetivo.

Las encuestas realizadas a los funcionarios contaron con cinco preguntas las cuales se detallan en la siguiente tabla. 
Tabla 16: Encuestas a Funcionarios

\begin{tabular}{|c|l|}
\hline Código & \multicolumn{1}{|c|}{ Pregunta } \\
\hline FP1 & $\begin{array}{l}\text { ¿Considera que la propuesta presentada disminuye la carga procesal de los } \\
\text { funcionarios? }\end{array}$ \\
\hline FP2 & ¿Considera que la propuesta presentada facilitaría al ciudadano a realizar sus trámites? \\
\hline FP3 & $\begin{array}{l}\text { ¿Considera que la propuesta presentada contribuye a mejorar la relación entre el ciudadano y } \\
\text { la municipalidad? }\end{array}$ \\
\hline FP4 & $\begin{array}{l}\text { ¿Considera que la propuesta presentada contribuye a que los procesos de la municipalidad } \\
\text { sean más transparentes para el ciudadano? }\end{array}$ \\
\hline FP5 & En general, ¿Cómo considera la propuesta? \\
\hline
\end{tabular}

\section{Fuente: Elaboración Propia}

Por otro lado, las preguntas realizadas a los ciudadanos en la encuesta se pueden acontinuación.

Tabla 17: Preguntas de Encuestas a Ciudadanos

\begin{tabular}{|c|l|}
\hline Código & \multicolumn{1}{|c|}{ Pregunta } \\
\hline $\mathrm{CP} 1$ & $\begin{array}{l}\text { ¿Considera que la propuesta presentada le facilita solicitar una licencia de } \\
\text { funcionamiento? }\end{array}$ \\
\hline $\mathrm{CP} 2$ & ¿Considera que la municipalidad debería utilizar una solución como esta? \\
\hline $\mathrm{CP} 3$ & $\begin{array}{l}\text { ¿Considera que la propuesta presentada contribuye a mejorar la relación entre el } \\
\text { ciudadano y la municipalidad? }\end{array}$ \\
\hline $\mathrm{CP} 4$ & ¿Considera que la propuesta beneficiaría a los ciudadanos? \\
\hline $\mathrm{CP} 5$ & En general, ¿cómo considera la propuesta? \\
\hline
\end{tabular}

\section{Fuente: Elaboración Propia}

En primer lugar, se valida el trámite objetivo en cuatro municipalidades de Lima, las cuales fueron Chorrillos, Villa María del Triunfo, Barranco y Santiago de Surco. En estas, se encuestaron a 15 funcionarios públicos que participan en el proceso. Los resultados se muestran en la siguiente tabla.

Tabla 18: Resultado de Evaluación de Encuestas a Funcionarios

\begin{tabular}{|c|c|c|c|c|c|c|c|}
\hline Cód/Puntaje & $\mathbf{1}$ & $\mathbf{2}$ & $\mathbf{3}$ & $\mathbf{4}$ & $\mathbf{5}$ & Media & Análisis \\
\hline FP1 & 0 & 0 & 0 & 6 & 9 & 4.6 & Muy aceptable \\
\hline
\end{tabular}




\begin{tabular}{|c|c|c|c|c|c|c|c|}
\hline FP2 & 0 & 1 & 2 & 5 & 7 & 4.2 & Aceptable \\
\hline FP3 & 0 & 0 & 0 & 3 & 12 & 4.8 & Muy aceptable \\
\hline FP4 & 0 & 0 & 3 & 5 & 7 & 4.3 & Aceptable \\
\hline FP5 & 0 & 0 & 0 & 6 & 9 & 4.6 & Muy aceptable \\
\hline
\end{tabular}

Fuente: Elaboración Propia

Como se puede apreciar, en la pregunta FP5, el 60\% de los funcionarios entrevistados indican que es muy aceptable la propuesta mostrada, mientras que el 40\% lo consideran como aceptable. En términos generales, la propuesta de licencia de funcionamiento tuvo muy buena aceptación.

En segundo lugar, la siguiente encuesta se realiza a 25 ciudadanos que cuentan con un local y una licencia de funcionamiento para del mismo, de las municipalidades antes mencionadas, obteniendo el resultado que se muestra a continuación.

Tabla 19: Resultado de Evaluación de Encuestas a Ciudadanos

\begin{tabular}{|c|c|c|c|c|c|c|c|}
\hline Cód/Puntaje & $\mathbf{1}$ & $\mathbf{2}$ & $\mathbf{3}$ & $\mathbf{4}$ & $\mathbf{5}$ & Media & Análisis \\
\hline CP1 & 0 & 0 & 1 & 4 & 20 & 4.8 & Muy aceptable \\
\hline CP2 & 0 & 0 & 0 & 2 & 23 & 4.9 & Muy aceptable \\
\hline CP3 & 0 & 0 & 0 & 1 & 24 & 5.0 & Muy aceptable \\
\hline CP4 & 0 & 0 & 1 & 3 & 21 & 4.8 & Muy aceptable \\
\hline CP5 & 0 & 0 & 0 & 0 & 25 & 5.0 & Muy aceptable \\
\hline
\end{tabular}

Fuente: Elaboración Propia

La tabla muestra que el 92\% de los ciudadanos encuestados considera en la pregunta CP5 que la propuesta, es muy aceptable y el $8 \%$ lo considera aceptable. Por lo cual, se demuestra que la ciudadanía considera que un trámite de licencia de funcionamiento que se pueda ejecutar desde la web es una propuesta muy atractiva.

Para demostrar la reducción de carga procesal, se contabiliza las actividades ejecutadas por los funcionarios públicos tanto en el trámite actual como en el objetivo. La ventaja de este último es que hay un Sistema que ejecuta actividades que antes eran manuales para facilitar el trabajo a los funcionarios. La siguiente figura muestra el resultado obtenido. 
Figure 43: Resultado de Reducción de Carga Procesal del Trámite de Licencia de Funcionamiento

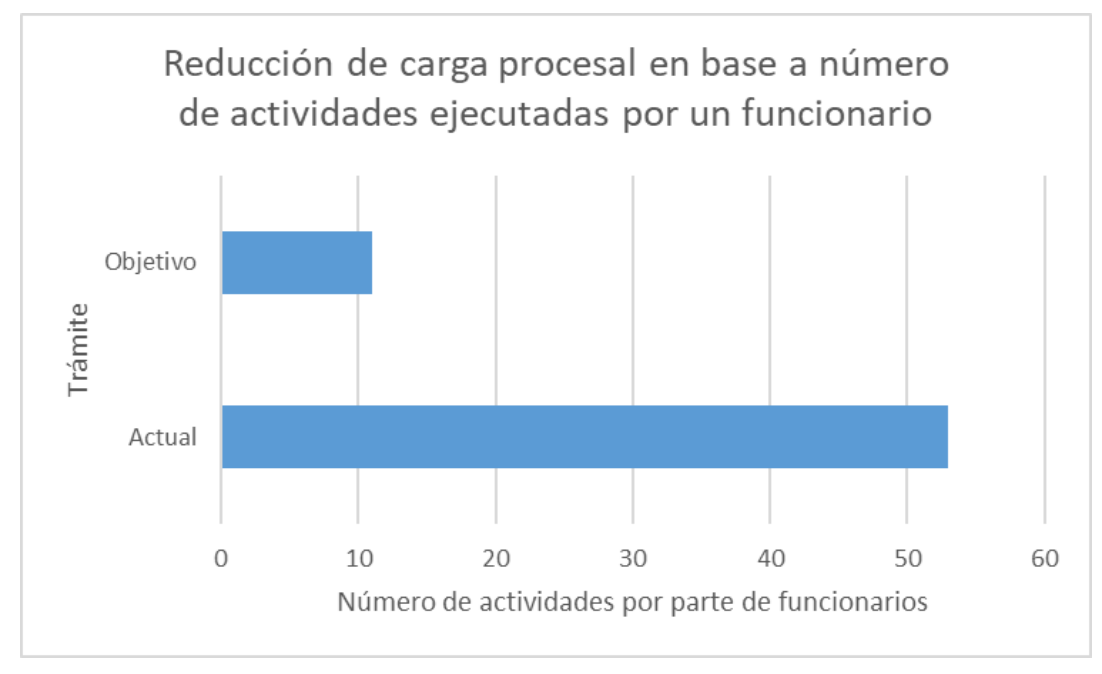

Fuente: Elaboración Propia

Las actividades en el trámite actual son de 54 para que se entregue la licencia de funcionamiento. La mayoría de estas son ejecutadas por los trabajadores recibiendo un pequeño apoyo de sistemas con los que cuenta la entidad. Por otro lado, el trámite objetivo cuenta con 11 actividades ejecutadas por los funcionarios públicos. Las demás han sido automatizadas por funcionalidades o e-Servicios. Esta diferencia representa una reducción de carga procesal del $79.63 \%$, lo cual evidencia una mejora sustancial en las actividades municipales.

\section{Juicio de Expertos}

Para la validación de juicio de expertos, se muestra el modelo a 6 profesionales en el área de tecnología de las municipalidades de Santiago de Surco, Barranco, Chorrillos, Miraflores y Villa María del Triunfo. Luego de la explicación del modelo y de los artefactos, se realiza una encuesta donde se obtuvo el siguiente resultado. 
Figure 44: Resultado de Juicio de Expertos Municipales en Tecnología

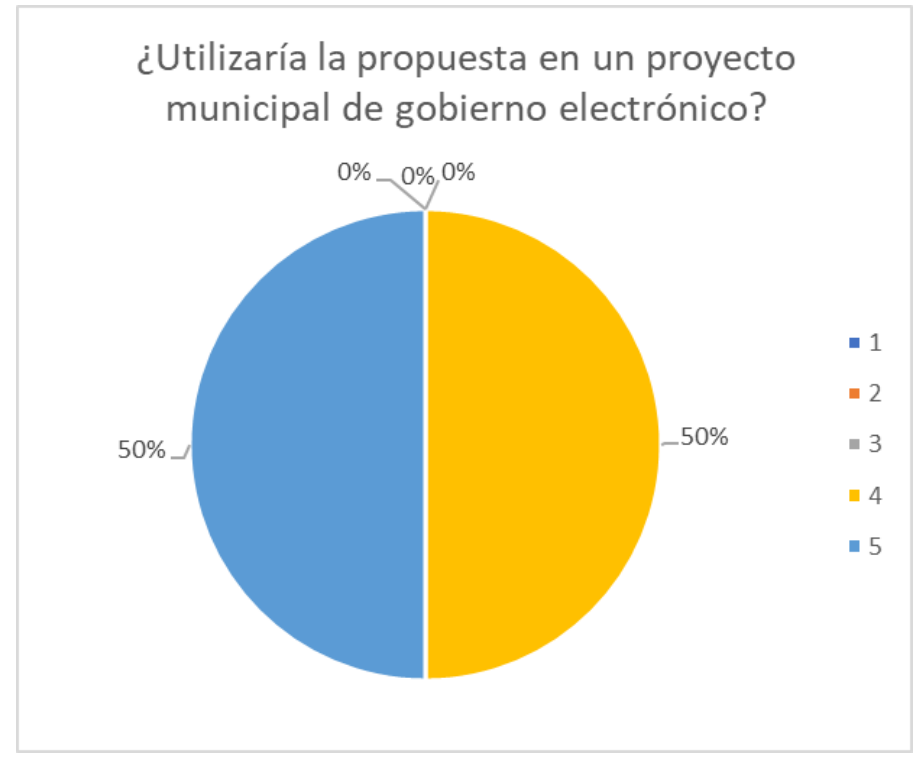

Fuente: Elaboración Propia

Como se puede apreciar, el 50\% de los expertos califican como "Muy aceptable" a la pregunta si utilizaría la propuesta en un proyecto de implementación de gobierno electrónico, mientras que el otro 50\% lo considera como "Aceptable". Estos resultados muestran una gran aceptación de la propuesta por parte de los expertos municipales de tecnología.

\section{Plan de Continuidad}

1. Framework de Implementación de Gobierno Electrónico Municipal enfocado en la fase e-Democracia

Problemática

Creciente interés de las municipalidades por una incentiva participación de los ciudadanos en las actividades del municipio y una relación más cercana con los mismos.

Causas

- No existe un framework de implementación de gobierno electrónico, específicamente de una de sus fases.

- El estado busca la modernización de sus instituciones.

- Las áreas de la municipalidad no se encuentran interconectados 
- La mayoría de las municipalidades no cuentan con información integrada.

Objetivos del Proyecto

Objetivo General: Proponer un framework de implementación de la fase de eDemocracia del Gobierno Electrónico Municipal.

OE1: Analizar el contexto actual del Gobierno Electrónico, en especial del gobierno electrónico municipal

OE2: Diseñar el framework de implementación de gobierno electrónico municipal enfocado en la fase de eDemocracia

OE3: Validar el framework de implementación de gobierno electrónico municipal enfocado en la fase de eDemocracia

OE4: Definir una cartera de proyectos que aseguran el éxito del modelo

Entregable o Resultado

Framework de implementación de gobierno electrónico municipal enfocado en la fase de eDemocracia

Paper

- eParticipation research: Systematizing the field (ISSN: 0740-624X)

En este paper se realiza un estudio de literatura de publicaciones conceptuales sobre el tema de eParticipation / eDemocracy en el período de tiempo 2007-2009, para poder rastrear el desarrollo teórico reciente en el campo, revelar las restricciones y limitaciones del área, y ofrecer algunas sugerencias para una mayor investigación. Los resultados del estudio muestran que la mayoría de las teorías actualmente utilizadas en la investigación conceptual eParticipation provienen de los campos de Ciencias Políticas, Medios y Estudios de Comunicación. Pero junto con esto, los autores contemporáneos de eParticipation contribuyen a fortalecer el campo con algunos modelos y marcos "internos" también. Los problemas centrales con la investigación eParticipation se refieren a la inmadurez del campo, las brechas tópicas y las suposiciones sesgadas. La revisión muestra que los temas de las publicaciones recientes se pueden agrupar en tres categorías principales: partes interesadas, medio ambiente 
y aplicaciones y herramientas. También encuentra algunas interconexiones entre estas categorías; sin embargo, en general, la tecnología de acoplamiento-stakeholders(participativos) es débil.

- The shape of eParticipation: Characterizing an emerging research area (ISSN: 0740$624 X)$

En este paper se realiza la revisión de literatura, identificando 131 artículos científicos considerados importantes para el desarrollo teórico del campo. Esta muestra proporciona el punto de partida para un análisis fundamentado que conduce al desarrollo de un modelo general: el campo de eParticipation visto desde la perspectiva de un investigador. El modelo proporciona una estructura para comprender la forma emergente del campo, así como una indicación inicial de su contenido. También proporciona la base para desarrollar agendas de investigación para el futuro.

- Characterizing eParticipation (ISSN: 0268-4012)

En este paper se traza algunas de las teorías y disciplinas académicas que aborda el área de eParticipation, utilizando técnicas de estudio de la literatura convencional, se identifican 99 artículos que se consideran altamente relevantes para eParticipation. Desarrollan un esquema de definición que sugiere diferentes formas de entender un área de investigación emergente, y usan este esquema para identificar artículos académicos clave que ayudan a definir eParticipation. Adaptam Deetz's, una taxonomía de los discursos en la ciencia organizacional para proporcionar un esquema general de categorización para la investigación en el área, y mapear la literatura. El artículo contribuye así a una imagen en desarrollo que ayudará a los futuros investigadores a comprender y navegar el área de investigación.

2. Seguridad de la Información para la fase e-Democracia del Gobierno Electrónico Municipal

\section{Problemática}

Creciente necesidad de las municipalidades por introducir la participación ciudadana, usando para este caso el voto electrónico, el cual es parte de la fase e-Democracia del gobierno electrónico municipal. 


\section{Causas}

- Se requiere implementar la última fase de gobierno electrónico municipal, el cual incluye la participación ciudadana.

- El voto electrónico es parte de la participación ciudadana, en donde los ciudadanos pueden participar en decisiones de la municipalidad y poder llegar a un consenso.

- Creciente demanda de transparencia de los procesos gubernamentales por parte de la ciudadanía.

- Se busca la incorporación de los gobiernos locales con los ciudadanos.

Objetivos del Proyecto

Objetivo General: Proponer un modelo de gestión de seguridad de la información para la fase de e-Democracia del Gobierno Electrónico Municipal

OE1: Analizar el contexto actual del uso de seguridad de la información

OE2: modelo de gestión de seguridad de la información para la fase de e-Democracia del Gobierno Electrónico Municipal.

OE3: modelo de gestión de seguridad de la información para la fase de e-Democracia del Gobierno Electrónico Municipal.

OE4: Definir una cartera de proyectos que aseguran el éxito del esquema.

Entregable o Resultado

Modelo de gestión de seguridad de la información para la fase de e-Democracia del Gobierno Electrónico Municipal

Paper

- Trading old errors for new errors? The impact of electronic voting technology on party label votes in Brazil (ISSN: 0261-3794)

En este paper se emplea un diseño de discontinuidad de regresión similar al de estudios previos de la tecnología de votación electrónica brasileña para mostrar que la tecnología electrónica 
también causó un fuerte aumento en los votos de etiqueta de partido que solo pueden explicarse por error de votación. Se muestra, además, que este error compensa una gran parte de las ganancias en el derecho al voto, destacando el hecho de que incluso los cambios generalmente positivos en los procedimientos de votación pueden tener efectos negativos. Los resultados sugieren que los votos de etiqueta del partido no se deben considerar una medida de la fuerza del partido en el contexto brasileño.

- A practical, secure, and auditable e-voting system (ISSN: 2214-2126)

En este paper se propone un sistema de votación electrónica criptográfica que reemplaza el método tradicional de votación, ampliamente utilizados en la mayoría de los países en desarrollo en la región de Medio Oriente y el Norte de África. El sistema de votación electrónica propuesto se basa en el concepto de Prêt àVoter, que es un esquema de voto electrónico en papel. Los esquemas de votación electrónica basados en MixNet, como Prêt àVoter, usan servidores de mezcla para crear canales anónimos. El esquema de votación electrónica propuesto elimina la necesidad de canales anónimos para anonimizar los votos en los esquemas de voto electrónico basados en Mixnet, pero proporciona un nivel comparable de seguridad y anonimato de voto con menos complejidad del sistema. El esquema de votación electrónica propuesto utiliza boletas de papel, debido a su familiaridad entre el público, pero con fuertes algoritmos criptográficos con funciones de seguridad comprobadas, para proporcionar un nivel mejorado de secreto de la boleta, verificabilidad y seguridad.

- Full privacy preserving electronic voting scheme (ISSN: 1005-8885)

En este paper se toca el tema de privacidad en el voto electrónico, más específicamente privacidad total, no solo la privacidad de los votantes, sino también la de los candidatos. Se presenta la preservación de la privacidad de la arquitectura de las elecciones electrónicas sin ningún tercero de confianza y también se proporciona una técnica general para la elección kout-of-m basada en el cifrado distribuido de ElGamal y el mix-match. Los votantes pueden calcular el resultado por sí mismos sin revelar su voluntad y el voto de los candidatos perdedores. Además, si el voto del candidato ganador es más de la mitad se puede verificar directamente. Este esquema satisface el patrón de "votar y continuar" y logra una privacidad total. La corrección y la seguridad también se analizan.

3. Aplicación de DataMining como aporte a la fase e-Democracia del Gobierno Electrónico Municipal 
Problemática

Las municipalidades cuentan con una gran cantidad de datos de información y requiere de esta información para la realización de sus trámites y procesos.

\section{Causas}

- Las municipalidades cuentan con gran cantidad de información.

- La información de las municipalidades se encuentra en documentos físicos.

- Las instituciones públicas como las municipalidades se deben encontrar asociados a la transparencia, eficiencia y eficacia.

- Búsqueda de las instituciones públicas de brindar facilidades al ciudadano para obtener información pública.

Objetivos del Proyecto:

Objetivo General: Proponer un modelo de aplicación de DataMining para el Gobierno Electrónico Municipal

OE1: Analizar el contexto DataMining

OE2: Diseñar el modelo de aplicación de DataMining para el desarrollo del Gobierno Electrónico Municipal

OE3: Validar el modelo de aplicación de DataMining para el desarrollo del Gobierno Electrónico Municipal

OE4: Definir una cartera de proyectos que aseguran el éxito del modelo

Entregable o Resultado

Modelo de aplicación de DataMining para el desarrollo del Gobierno Electrónico Municipal.

Paper

- Enhancing usability testing through datamining techniques: A novel approach to detecting usability problem patterns for a context of use (ISSN: 0950-5849) 
En este paper se presenta un nuevo enfoque de usabilidad, aquí se utilizan dos técnicas de datamining (reglas de asociación y árboles de decisión) para extender el proceso de prueba de usabilidad cualitativa existente a fin de proporcionar un diagnóstico de usabilidad general de un contexto dado de uso de un punto de vista cualitativo Para validar nuestra propuesta, los patrones de problemas de usabilidad pertenecientes a páginas web académicas en países de habla hispana se evalúan procesando 3450 registros que almacenan información cualitativa recopilada mediante una Evaluación Heurística.

- Class dependent feature scaling method using naive Bayes classifier for text datamining (ISSN: 0167-8655)

Una parte crítica de la selección de características es clasificar las características según su importancia. El clasificador ingenuo de Bayes se ha usado ampliamente en la categorización de texto. Se ha desarrollado un nuevo método de escalado de funciones, ponderación de características dependientes de la clase (CDFW) usando el clasificador Naive Bayes (NB). Un nuevo método de escalado de funciones, CDFW-NB-RFE, combina CDFW y eliminación de características recursivas (RFE). Los resultados experimentales mostraron que CDFW-NBRFE superó a otros esquemas de clasificación de características populares utilizados en conjuntos de datos de texto.

- Accounting and Financial Data Analysis Data Mining Tools (ISSN: 2067-9211)

En este paper los autores analizan los sistemas de contabilidad computarizados de los últimos años, los cuales han aumentado la complejidad debido al entorno económico competitivo, pero con ayuda de soluciones de análisis de datos como OLAP y Data Mining pueden ser datos multidimensionales, asegurando que dicha información sea útil para la toma de decisiones dentro de la organización. Realizan la literatura acerca de la definición de minería de datos, pero encuentran que todo se reduce a la misma idea: el proceso se lleva a cabo para extraer nueva información de grandes colecciones de datos difíciles de obtener. La información obtenida por el proceso de minería de datos tiene la ventaja de que solo responde a la pregunta de qué sucede, pero al mismo tiempo argumenta y muestra por qué ciertas cosas están sucediendo. En este documento, presentan técnicas avanzadas para el análisis y la explotación de datos almacenados en una base de datos multidimensional. 


\section{Capítulo 7: Gestión del Proyecto}

En este capítulo se da a conocer la gestión del proyecto luego de haberlo realizado. Este se desarrolló bajo la metodología PMBOK. Se detalla el tiempo empleado con la planificación, la gestión para la realización del proyecto, tales como la gestión de los recursos humanos, comunicaciones y riesgos; y las lecciones aprendidas obtenidas al finalizar la elaboración del proyecto.

\section{Producto Final}

El producto resultante es un modelo de mejora de servicios electrónicos municipales, el cual se encuentra basado por buenas prácticas del gobierno electrónico y para el cual se analiza la selección de artefactos del ADM. Este esquema permitirá que una municipalidad pueda autoevaluarse con respecto al nivel de gobierno electrónico que presenta y brinda una guía de implementación de este. Con este modelo se busca mejorar la calidad, eficiencia y eficacia de los servicios brindados a los ciudadanos y otras empresas.

El producto que se obtendrá estará alineado totalmente al alcance planteado al inicio del proyecto y contempla lo siguiente:

- Realización de un estudio acerca de definición de e-Government, sus características y sus ventajas.

- Realización de un estudio de casos de éxito en otros países.

- Realización de un estudio del estado actual del Perú con respecto al gobierno electrónico.

- Análisis de entregables y artefactos de las fases Requerimientos, Preliminar, A - Visión de la Arquitectura, B - Arquitectura de Negocio, C - Arquitectura de Sistemas de Información y D - Arquitectura Tecnológica del ADM.

- Realización de análisis de Retorno de Inversión (ROI) que evidencie la rentabilidad del proyecto de implementación.

Así mismo, el proyecto no abarcó: 
- La realización de las fases E, F, G y H de TOGAF para el esquema de e-Government.

- No se implementará el esquema propuesto de e-Government.

\section{Gestión del Tiempo}

Se detalla el cronograma que ha sido elaborado al inicio del proyecto, el cual es actualizado conforme el avance de este. El cronograma elaborado a inicio del proyecto es el siguiente: 
Figure 45: Cronograma de Proyecto 2016-02 (Parte 1)

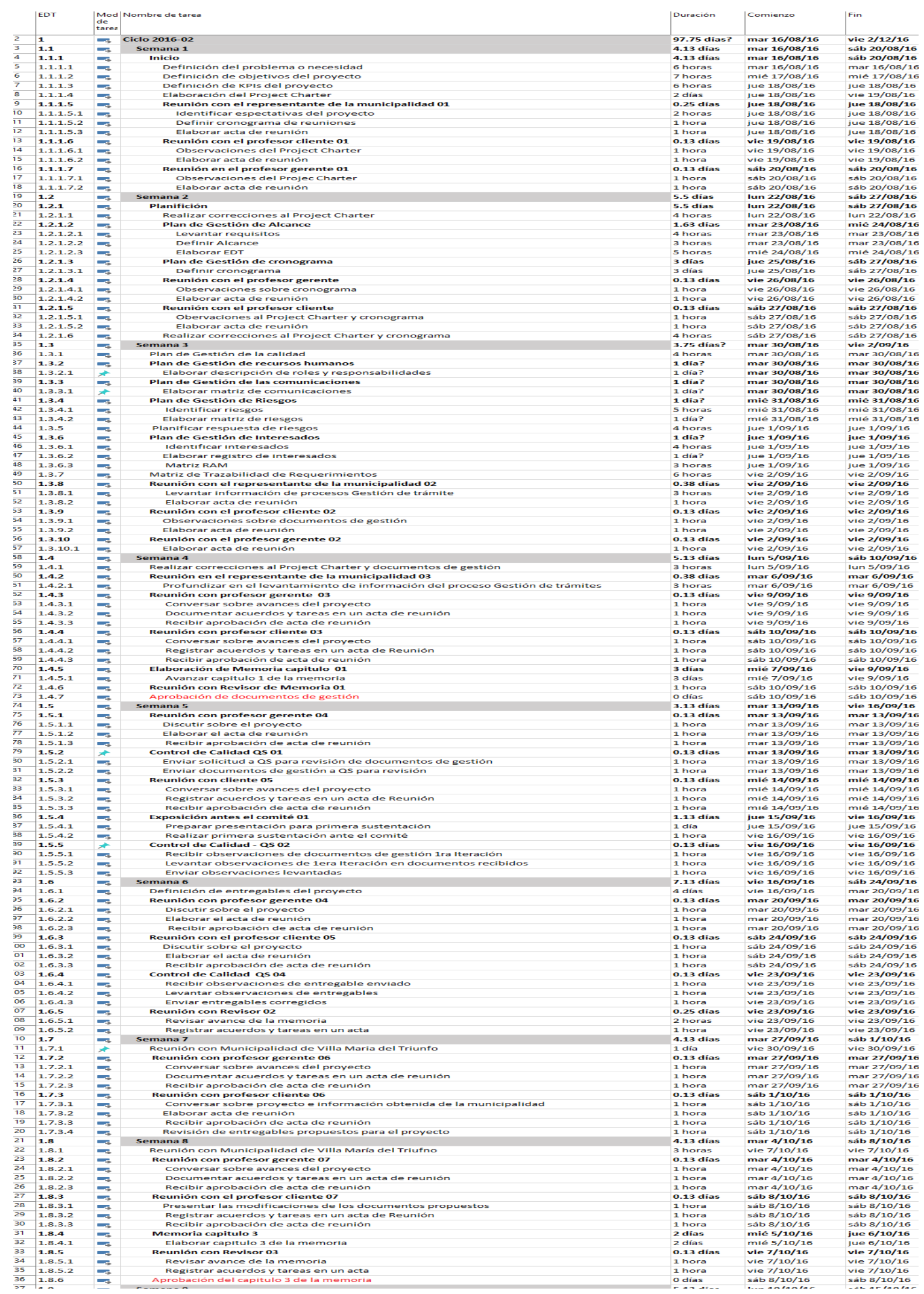

Fuente: Elaboración Propia 
Figure 46: Cronograma de Proyecto 2016-02 (Parte 2)

\begin{tabular}{|c|c|c|c|c|c|c|}
\hline $1 د$ & |.9 & -5 & semanta y & 3.13 ulas & $\operatorname{Iun} 10 / 10 / 10$ & Sav $13 / 10 / 10$ \\
\hline 138 & 1.9.1 & - & Elaboración de la primera versión del proceso de la municipalidad & 2 días & Iun $10 / 10 / 16$ & $\operatorname{mar} 11 / 10 / 16$ \\
\hline 139 & 1.9 .2 & - & Reunión con Municipalidad de Villa María del Triunfo & 3 horas & vie $14 / 10 / 16$ & vie $14 / 10 / 16$ \\
\hline 140 & 1.9 .3 & -6 & Reunión con profesor gerente 08 & 0.13 días & mar 11/10/16 & $\operatorname{mar} 11 / 10 / 16$ \\
\hline 141 & 1.9.3.1 & - & Conversar sobre avances del proyecto & 1 hora & $\operatorname{mar} 11 / 10 / 16$ & $\operatorname{mar} 11 / 10 / 16$ \\
\hline 142 & 1.9.3.2 & -6 & Documentar acuerdos y tareas en un acta de reunión & 1 hora & $\operatorname{mar} 11 / 10 / 16$ & $\operatorname{mar} 11 / 10 / 16$ \\
\hline 143 & 1.9.3.3 & - & Recibir aprobación de acta de reunión & 1 hora & $\operatorname{mar} 11 / 10 / 16$ & $\operatorname{mar} 11 / 10 / 16$ \\
\hline 144 & 1.9.4 & - & Reunión con cliente 08 & 0.13 días & sáb 15/10/16 & sáb 15/10/16 \\
\hline 145 & 1.9.4.1 & - & Conversar sobre el proyecto & 1 hora & sáb 15/10/16 & sáb 15/10/16 \\
\hline 146 & 1.9.4.2 & -5 & Registrar acuerdos y tareas en un acta de Reunión & 1 hora & sáb 15/10/16 & sáb 15/10/16 \\
\hline 147 & 1.9.4.3 & - & Recibir aprobación de acta de reunión & 1 hora & sáb 15/10/16 & sáb 15/10/16 \\
\hline 148 & 1.10 & 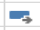 & Semana 10 & 5 días? & $\operatorname{mar} 18 / 10 / 16$ & sáb 22/10/16 \\
\hline 149 & 1.10 .1 & $=$ & Reunión con Municipalidad de Villa María del Triunfo & 3 horas & vie $21 / 10 / 16$ & vie $21 / 10 / 16$ \\
\hline 150 & 1.10 .2 & $=$ & Reunión con profesor gerente 09 & 0.13 días & $\operatorname{mar} 18 / 10 / 16$ & $\operatorname{mar} 18 / 10 / 16$ \\
\hline 151 & 1.10.2.1 & $\Rightarrow$ & Conversar sobre avances del proyecto v1.0 & 1 hora & $\operatorname{mar} 18 / 10 / 16$ & $\operatorname{mar} 18 / 10 / 16$ \\
\hline 152 & 1.10.2.2 & $\Rightarrow$ & Documentar acuerdos y tareas en un acta de reunión & 1 hora & $\operatorname{mar} 18 / 10 / 16$ & $\operatorname{mar} 18 / 10 / 16$ \\
\hline 153 & 1.10 .2 .3 & $=$ & Recibir aprobación de acta de reunión & 1 hora & $\operatorname{mar} 18 / 10 / 16$ & $\operatorname{mar} 18 / 10 / 16$ \\
\hline 154 & 1.10 .3 & $\Rightarrow$ & Reunión con profesor cliente 09 & 1 día? & sáb 22/10/16 & sáb 22/10/16 \\
\hline 155 & 1.10.3.1 & - & Conversar sobre el proyecto & 1 hora & sáb 22/10/16 & sáb 22/10/16 \\
\hline 156 & 1.10.3.2 & - & Registrar acuerdos y tareas en un acta de Reunión & 1 hora & sáb 22/10/16 & sáb 22/10/16 \\
\hline 157 & 1.10.3.3 & - & Recibir aprobación de acta de reunión & 1 hora & sáb 22/10/16 & sáb 22/10/16 \\
\hline 158 & 1.10.3.4 & t? & Revisión de la primera versión del proceso & & & \\
\hline 159 & 1.10 .4 & -5 & Memoria capitulo 4 & 0.38 días & mié 19/10/16 & mié 19/10/16 \\
\hline 160 & 1.10.4.1 & 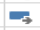 & Elaborar capitulo 4 de la memoria & 3 horas & mié 19/10/16 & mié 19/10/16 \\
\hline 161 & 1.10 .5 & - & Reunión con Revisor 04 & 0.13 días & vie $21 / 10 / 16$ & vie 21/10/16 \\
\hline 162 & 1.10.5.1 & - & Revisar avance de la memoria & 1 hora & vie $21 / 10 / 16$ & vie $21 / 10 / 16$ \\
\hline 163 & 1.10.5.2 & - & Registrar acuerdos y tareas en un acta & 1 hora & vie $21 / 10 / 16$ & vie $21 / 10 / 16$ \\
\hline 164 & 1.11 & -6 & Semana 11 & 5 días? & mar 25/10/16 & sáb 29/10/16 \\
\hline 165 & 1.11 .1 & - & Elaboración de segunda versión del proceso & 1 día & mié 26/10/16 & mié 26/10/16 \\
\hline 166 & 1.11.2 & - & Reunión con Munícipalidad de Villa María del Triunfo & 3 horas & $\operatorname{mar} 25 / 10 / 16$ & $\operatorname{mar} 25 / 10 / 16$ \\
\hline 167 & 1.11 .3 & -5 & Reunión con el profesor gerente 10 & 0.13 días & mar 25/10/16 & $\operatorname{mar} 25 / 10 / 16$ \\
\hline 168 & 1.11.3.1 & - & Conversar sobre avances del proyecto & 1 hora & mar 25/10/16 & $\operatorname{mar} 25 / 10 / 16$ \\
\hline 169 & 1.11.3.2 & - & Documentar acuerdos y tareas en un acta de reunión & 1 hora & mar 25/10/16 & $\operatorname{mar} 25 / 10 / 16$ \\
\hline 170 & 1.11.3.3 & - & Recibir aprobación de acta de reunión & 1 hora & mar 25/10/16 & $\operatorname{mar} 25 / 10 / 16$ \\
\hline 171 & 1.11 .4 & - & Reunión con el profesor cliente 10 & 1 día? & sáb 29/10/16 & sáb 29/10/16 \\
\hline 172 & 1.11.4.1 & $\Rightarrow$ & Conversar sobre el proyecto & 1 hora & sáb 29/10/16 & sáb 29/10/16 \\
\hline 173 & 1.11.4.2 & -5 & Registrar acuerdos y tareas en un acta de Reunión & 1 hora & sáb 29/10/16 & sáb 29/10/16 \\
\hline 174 & 1.11.4.3 & -5 & Recibir aprobación de acta de reunión & 1 hora & sáb 29/10/16 & sáb 29/10/16 \\
\hline 175 & 1.11.4.4 & $\lambda^{*}$ & Aprobación de segunda versión del proceso & & & \\
\hline 176 & 1.12 & $\Rightarrow$ & Semana 12 & 6 días? & Iun 31/10/16 & sáb 5/11/16 \\
\hline 177 & 1.12 .1 & $\Rightarrow$ & Reunión con Municipalidad de Villa María del Triunfo & 3 horas & Iun $31 / 10 / 16$ & Iun $31 / 10 / 16$ \\
\hline 178 & 1.12 .2 & - & Elaboración de primera versión de segundo proceso & 2 dias & $\operatorname{mar} 1 / 11 / 16$ & mié $2 / 11 / 16$ \\
\hline 179 & 1.12 .3 & -5 & Reunión con profesor gerente 11 & 0.13 días & $\operatorname{mar} 1 / 11 / 16$ & $\operatorname{mar} 1 / 11 / 16$ \\
\hline 180 & 1.12.3.1 & - & Conversar sobre avances del proyecto & 1 hora & $\operatorname{mar} 1 / 11 / 16$ & $\operatorname{mar} 1 / 11 / 16$ \\
\hline 181 & 1.12.3.2 & $-\rightrightarrows$ & Documentar acuerdos y tareas en un acta de reunión & 1 hora & $\operatorname{mar} 1 / 11 / 16$ & $\operatorname{mar} 1 / 11 / 16$ \\
\hline 182 & 1.12.3.3 & - & Recibir aprobación de acta de reunión & 1 hora & $\operatorname{mar} 1 / 11 / 16$ & $\operatorname{mar} 1 / 11 / 16$ \\
\hline 183 & 1.12 .4 & $=$ & Reunión con profesor cliente 11 & 1 día? & sáb 5/11/16 & sáb 5/11/16 \\
\hline 184 & 1.12.4.1 & 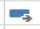 & Conversar sobre el proyecto & 1 hora & sáb 5/11/16 & sáb 5/11/16 \\
\hline 185 & 1.12.4.2 & $=$ & Registrar acuerdos y tareas en un acta de Reunión & 1 hora & sáb 5/11/16 & sáb 5/11/16 \\
\hline 186 & 1.12 .4 .3 & - & Recibir aprobación de acta de reunión & 1 hora & sáb 5/11/16 & sáb 5/11/16 \\
\hline 187 & 1.12.4.4 & t? & Revisión de primera versión del segundo proceso & & & \\
\hline 188 & 1.13 & -6 & Semana 13 & 6.25 días? & sáb 5/11/16 & sáb 12/11/16 \\
\hline 189 & 1.13 .1 & -6 & Reunión con Municipalidad de Villa María del Triunfo & 3 horas & Iun $7 / 11 / 16$ & Iun $7 / 11 / 16$ \\
\hline 190 & 1.13 .2 & - & Elaboración de segunda versión del segundo proceso & 3 días & sáb 5/11/16 & mié 9/11/16 \\
\hline 191 & 1.13.3 & -5 & Reunión con profesor gerente 12 & 0.13 días & $\operatorname{mar} 8 / 11 / 16$ & $\operatorname{mar} 8 / 11 / 16$ \\
\hline 192 & 1.13.3.1 & $\Rightarrow$ & Conversar sobre avances del proyecto & 1 hora & $\operatorname{mar} 8 / 11 / 16$ & $\operatorname{mar} 8 / 11 / 16$ \\
\hline 193 & 1.13.3.2 & $\Rightarrow$ & Documentar acuerdos y tareas en un acta de reunión & 1 hora & $\operatorname{mar} 8 / 11 / 16$ & $\operatorname{mar} 8 / 11 / 16$ \\
\hline 194 & 1.13.3.3 & $\Rightarrow$ & Recibir aprobación de acta de reunión & 1 hora & $\operatorname{mar} 8 / 11 / 16$ & $\operatorname{mar} 8 / 11 / 16$ \\
\hline 195 & 1.13 .4 & $\Rightarrow$ & Reunión con cliente 12 & 1 día? & sáb 12/11/16 & sáb 12/11/16 \\
\hline 196 & 1.13.4.1 & $\Rightarrow$ & Conversar sobre el proyecto & 1 hora & sáb 12/11/16 & sáb 12/11/16 \\
\hline 197 & 1.13.4.2 & $\Rightarrow$ & Registrar acuerdos y tareas en un acta de Reunión & 1 hora & sáb 12/11/16 & sáb 12/11/16 \\
\hline 198 & 1.13 .4 .3 & $\Rightarrow$ & Recibir aprobación de acta de reunión & 1 hora & sáb 12/11/16 & sáb 12/11/16 \\
\hline 199 & 1.13.4.4 & $x_{3}$ & Revisión de segunda versión del segundo proceso & & & \\
\hline 200 & 1.14 & $\Rightarrow$ & Semana 14 & 5.38 días? & sáb 12/11/16 & sáb 19/11/16 \\
\hline 201 & 1.14 .1 & $\Rightarrow$ & Solicitud de cambio de nombre del proyecto & 1 día? & sáb 12/11/16 & Iun 14/11/16 \\
\hline 202 & 1.14.1.1 & $\Rightarrow$ & Aprobación del profesor gerente & 6 horas & sáb 12/11/16 & Iun $14 / 11 / 16$ \\
\hline 203 & 1.14.1.2 & $\Rightarrow$ & Aprobación del profesor cliente & 4 horas & sáb 12/11/16 & Iun $14 / 11 / 16$ \\
\hline 204 & 1.14.1.3 & t? & Aprobación de comité & & & \\
\hline 205 & 1.14 .2 & $\Rightarrow$ & Reunión con profesor gerente 13 & 0.13 días & $\operatorname{mar} \mathbf{1 5 / 1 1 / 1 6}$ & $\operatorname{mar} 15 / 11 / 16$ \\
\hline 206 & 1.14.2.1 & $=$ & Conversar sobre avances del proyecto & 1 hora & $\operatorname{mar} 15 / 11 / 16$ & $\operatorname{mar} 15 / 11 / 16$ \\
\hline 207 & 1.14.2.2 & $\Rightarrow$ & Documentar acuerdos y tareas en un acta de reunión & 1 hora & $\operatorname{mar} 15 / 11 / 16$ & $\operatorname{mar} 15 / 11 / 16$ \\
\hline 208 & 1.14 .2 .3 & - & Recibir aprobación de acta de reunión & 1 hora & $\operatorname{mar} 15 / 11 / 16$ & $\operatorname{mar} 15 / 11 / 16$ \\
\hline 209 & 1.14 .3 & - & Reunión con profesor cliente 13 & 0.13 días & sáb 19/11/16 & sáb 19/11/16 \\
\hline 210 & 1.14.3.1 & -5 & Conversar sobre el proyecto & 1 hora & sáb 19/11/16 & sáb 19/11/16 \\
\hline 211 & 1.14.3.2 & - & Registrar acuerdos y tareas en un acta de Reunión & 1 hora & sáb 19/11/16 & sáb 19/11/16 \\
\hline 212 & 1.14.3.3 & $\Rightarrow$ & Recibir aprobación de acta de reunión & 1 hora & sáb 19/11/16 & sáb 19/11/16 \\
\hline 213 & 1.15 & $\Rightarrow$ & Semana 15 & 5 días? & mar 22/11/16 & sáb 26/11/16 \\
\hline 214 & 1.15 .1 & $\Rightarrow$ & Reunión con profesor gerente 14 & 0.13 días & mar 22/11/16 & $\operatorname{mar} 22 / 11 / 16$ \\
\hline 215 & 1.15.1.1 & -5 & Conversar sobre avances del proyecto & 1 hora & mar 22/11/16 & $\operatorname{mar} 22 / 11 / 16$ \\
\hline 216 & 1.15.1.2 & -5 & Documentar acuerdos y tareas en un acta de reunión & 1 hora & mar 22/11/16 & $\operatorname{mar} 22 / 11 / 16$ \\
\hline 217 & 1.15.1.3 & -5 & Recibir aprobación de acta de reunión & 1 hora & mar 22/11/16 & $\operatorname{mar} 22 / 11 / 16$ \\
\hline 218 & 1.15 .2 & - & Reunión con profesor cliente 14 & 1 dia? & sáb 26/11/16 & sáb 26/11/16 \\
\hline 219 & 1.15.2.1 & $\Rightarrow$ & Conversar sobre el proyecto & 1 hora & sáb 26/11/16 & sáb 26/11/16 \\
\hline 220 & 1.15.2.2 & $\Rightarrow$ & Registrar acuerdos y tareas en un acta de Reunión & 1 hora & sáb 26/11/16 & sáb 26/11/16 \\
\hline 221 & 1.15 .2 .3 & 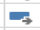 & Recibir aprobación de acta de reunión & 1 hora & sáb 26/11/16 & sáb 26/11/16 \\
\hline 222 & 1.15.2.4 & t? & Exposición ante profesor cliente & & & \\
\hline 223 & 1.16 & 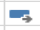 & Semana 16 & 5.25 días & sáb 26/11/16 & vie $2 / 12 / 16$ \\
\hline 224 & 1.16.1 & $\Rightarrow$ & Exposición antes el comité 02 & 5.25 dias & sáb 26/11/16 & vie $2 / 12 / 16$ \\
\hline 225 & 1.16.1.1 & $\Rightarrow$ & Preparar presentación para sustentación final & 8 horas & vie $2 / 12 / 16$ & vie $2 / 12 / 16$ \\
\hline 226 & 1.16.1.2 & - & Realizar primera sustentación ante el comité final & 1 hora & sáb 26/11/16 & sáb 26/11/16 \\
\hline 227 & 1.16 .2 & -3 & Aprobación de Primera parte del Proyecto & 0 días & sáb 26/11/16 & sáb 26/11/16 \\
\hline
\end{tabular}

Fuente: Elaboración Propia 
A continuación, se presenta el cronograma desarrollado para el ciclo 2017-2.

Figure 47: Cronograma de Proyecto 2017-02 (Parte 1)

\begin{tabular}{|c|c|}
\hline 232 & 2.1 \\
\hline 233 & 2.1.1 \\
\hline 234 & 2.1.1.1 \\
\hline 235 & 2.1.1.2 \\
\hline 236 & 2.1 .1 .3 \\
\hline 237 & 2.1.1.4 \\
\hline 238 & 2.1 .2 \\
\hline 239 & 2.1 .2 .1 \\
\hline 240 & 2.1 .2 .2 \\
\hline 241 & 2.1 .2 .3 \\
\hline 242 & 2.2 \\
\hline 243 & 2.2 .1 \\
\hline 244 & 2.2 .1 .1 \\
\hline 245 & 2.2 .1 .2 \\
\hline 246 & 2.2 .1 .3 \\
\hline 247 & 2.2 .2 \\
\hline 248 & 2.2 .2 .1 \\
\hline 249 & 2.2 .3 \\
\hline 250 & 2.2.3.1 \\
\hline 251 & 2.2 .3 .2 \\
\hline 252 & 2.2.3.3 \\
\hline 253 & 2.2 .4 \\
\hline 254 & 2.2 .4 .1 \\
\hline 255 & 2.2 .4 .2 \\
\hline 256 & 2.2 .4 .3 \\
\hline 257 & 2.2 .4 .4 \\
\hline 258 & 2.2 .5 \\
\hline 259 & 2.2 .5 .1 \\
\hline 260 & 2.2 .5 .2 \\
\hline 261 & 2.2 .5 .3 \\
\hline 262 & 2.2 .5 .4 \\
\hline 263 & 2.2 .5 .5 \\
\hline 264 & 2.2 .5 .6 \\
\hline 265 & 2.2 .5 .7 \\
\hline 266 & 2.2 .5 .8 \\
\hline 267 & 2.2 .5 .9 \\
\hline 268 & 2.3 \\
\hline 269 & 2.3.1 \\
\hline 270 & 2.3.1.1 \\
\hline 271 & 2.3.1.2 \\
\hline 272 & 2.3.1.3 \\
\hline 273 & 2.3 .2 \\
\hline 274 & 2.3.2.1 \\
\hline 275 & 2.3 .3 \\
\hline 276 & 2.3.3.1 \\
\hline 277 & 2.3.3.2 \\
\hline 278 & 2.3.3.3 \\
\hline 279 & 2.3.3.4 \\
\hline 280 & 2.3 .4 \\
\hline 281 & 2.3.4.1 \\
\hline 282 & 2.3 .4 .2 \\
\hline 283 & 2.3.4.3 \\
\hline 284 & 2.3.4.4 \\
\hline 285 & 2.3 .4 .5 \\
\hline 286 & 2.3 .4 .6 \\
\hline 287 & 2.3.4.7 \\
\hline 288 & 2.3 .5 \\
\hline 289 & 2.3 .5 .1 \\
\hline 290 & 2.3 .5 .2 \\
\hline 291 & 2.3 .5 .3 \\
\hline 292 & 2.3 .5 .4 \\
\hline 293 & 2.3 .5 .5 \\
\hline 294 & 2.3 .5 .6 \\
\hline 295 & 2.3 .5 .7 \\
\hline 296 & 2.3 .5 .8 \\
\hline 297 & 2.3.5.9 \\
\hline 298 & 2.3 .5 .9 .1 \\
\hline 299 & 2.3 .5 .9 .2 \\
\hline 300 & 2.3 .5 .9 .3 \\
\hline 301 & 2.3 .5 .9 .4 \\
\hline 302 & 2.4 \\
\hline 303 & 2.4 .1 \\
\hline 304 & 2.4.1.1 \\
\hline 305 & 2.4.1.2 \\
\hline 306 & 2.4 .1 .3 \\
\hline 307 & 2.4 .1 .4 \\
\hline 308 & 2.4 .1 .5 \\
\hline 309 & 2.4 .1 .6 \\
\hline 310 & 2.4.1.7 \\
\hline 311 & 2.4 .1 .8 \\
\hline 312 & 2.4.1.9 \\
\hline 313 & 2.4.1.10 \\
\hline 314 & 2.4 .1 .10 .1 \\
\hline 315 & 2.4.1.10.2 \\
\hline 316 & 2.4 .1 .10 .3 \\
\hline 317 & 2.4.1.11 \\
\hline 318 & 2.4 .1 .11 .1 \\
\hline 319 & 2.4.1.12 \\
\hline 320 & 2.4 .1 .12 .1 \\
\hline 321 & 2.4 .1 .12 .2 \\
\hline 322 & 2.4.1.12.3 \\
\hline 323 & 2.4 .1 .12 .4 \\
\hline 324 & 2.4.1.12.5 \\
\hline 325 & 2.4.1.12.5 \\
\hline 326 & 2.4 .1 .12 .5 \\
\hline 327 & 2.4 .1 .12 .5 \\
\hline 328 & 2.4.1.12.5 \\
\hline
\end{tabular}

Fuente: Elaboración Propia 
Figure 48: Cronograma de Proyecto 2017-02 (Parte 2)

\begin{tabular}{|c|}
\hline$\cdots$ \\
\hline 329 \\
\hline 330 \\
\hline 331 \\
\hline 332 \\
\hline 333 \\
\hline 334 \\
\hline 335 \\
\hline 336 \\
\hline 337 \\
\hline 338 \\
\hline 339 \\
\hline 340 \\
\hline 341 \\
\hline 342 \\
\hline 343 \\
\hline 344 \\
\hline 345 \\
\hline 346 \\
\hline 347 \\
\hline 348 \\
\hline 349 \\
\hline 350 \\
\hline 351 \\
\hline 352 \\
\hline 353 \\
\hline 354 \\
\hline 355 \\
\hline 356 \\
\hline 357 \\
\hline 358 \\
\hline 359 \\
\hline 360 \\
\hline 361 \\
\hline 362 \\
\hline 363 \\
\hline 364 \\
\hline 365 \\
\hline 366 \\
\hline 367 \\
\hline 368 \\
\hline 369 \\
\hline 370 \\
\hline 371 \\
\hline 372 \\
\hline 373 \\
\hline 374 \\
\hline 375 \\
\hline 376 \\
\hline 377 \\
\hline 378 \\
\hline 379 \\
\hline 380 \\
\hline 381 \\
\hline 382 \\
\hline 383 \\
\hline 384 \\
\hline 385 \\
\hline 386 \\
\hline 387 \\
\hline 388 \\
\hline 389 \\
\hline 390 \\
\hline 391 \\
\hline 392 \\
\hline 393 \\
\hline 394 \\
\hline 395 \\
\hline 396 \\
\hline 397 \\
\hline 398 \\
\hline 399 \\
\hline 400 \\
\hline 401 \\
\hline 402 \\
\hline 403 \\
\hline 404 \\
\hline 405 \\
\hline 406 \\
\hline 407 \\
\hline 408 \\
\hline 409 \\
\hline 410 \\
\hline 411 \\
\hline 412 \\
\hline 413 \\
\hline 414 \\
\hline 415 \\
\hline 416 \\
\hline 417 \\
\hline 418 \\
\hline 419 \\
\hline 420 \\
\hline 421 \\
\hline 422 \\
\hline 423 \\
\hline 424 \\
\hline 425 \\
\hline
\end{tabular}

Fuente: Elaboración Propia 
Figure 49: Cronograma de Proyecto 2017-02 (Parte 3)

\begin{tabular}{|c|c|c|}
\hline & - & \\
\hline 426 & 2.10 & \\
\hline 427 & 2.10 .1 & \\
\hline 428 & 2.10 .2 & \\
\hline 429 & 2.10.2.1 & \\
\hline 430 & 2.10.2.2 & \\
\hline 431 & 2.10 .2 .3 & \\
\hline 432 & 2.10 .3 & \\
\hline 433 & 2.10.3.1 & \\
\hline 434 & 2.10 .4 & \\
\hline 435 & 2.10.4.1 & \\
\hline 436 & 2.10.4.2 & \\
\hline 437 & 2.10.4.3 & \\
\hline 438 & 2.10.4.4 & \\
\hline 439 & 2.11 & \\
\hline 440 & 2.11.1 & \\
\hline 441 & 2.11.1.1 & \\
\hline 442 & 2.11.1.2 & \\
\hline 443 & 2.11.1.3 & \\
\hline 444 & 2.11 .2 & \\
\hline 445 & 2.11.2.1 & \\
\hline 446 & 2.11 .3 & \\
\hline 447 & 2.11.3.1 & \\
\hline 448 & 2.11.3.2 & \\
\hline 449 & 2.11.3.3 & \\
\hline 450 & 2.11 .4 & \\
\hline 451 & 2.12 & \\
\hline 452 & 2.12.1 & \\
\hline 453 & 2.12.1.1 & \\
\hline 454 & 2.12.1.2 & \\
\hline 455 & 2.12.1.3 & \\
\hline 456 & 2.12 .2 & \\
\hline 457 & 2.12.2.1 & \\
\hline 458 & 2.12 .3 & \\
\hline 459 & 2.12.3.1 & \\
\hline 460 & 2.12.3.2 & \\
\hline 461 & 2.12.3.3 & \\
\hline 462 & 2.13 & \\
\hline 463 & 2.13 .1 & \\
\hline 464 & 2.13.2 & \\
\hline 465 & 2.13.2.1 & \\
\hline 466 & 2.13.2.2 & \\
\hline 467 & 2.13.2.3 & \\
\hline 468 & 2.13 .3 & \\
\hline 469 & 2.13.3.1 & \\
\hline 470 & 2.13 .4 & \\
\hline 471 & 2.13.4.1 & \\
\hline 472 & 2.13.4.2 & \\
\hline 473 & 2.13.4.3 & \\
\hline 474 & 2.14 & \\
\hline 475 & 2.14.1 & \\
\hline 476 & 2.14 .2 & \\
\hline 477 & 2.14 .3 & \\
\hline 478 & 2.14.3.1 & \\
\hline 479 & 2.14 .4 & \\
\hline 480 & 2.14.4.1 & \\
\hline 481 & 2.14 .5 & \\
\hline 482 & 2.14.5.1 & \\
\hline 483 & 2.14.5.2 & \\
\hline 484 & 2.14.5.3 & \\
\hline 485 & 2.15 & \\
\hline 486 & 2.15 .1 & \\
\hline & & \\
\hline
\end{tabular}

\begin{tabular}{|c|c|}
\hline & \\
\hline Semana 10 & 5.19 días \\
\hline Corrección observaciones del parcial & 3 días \\
\hline Reunión con profesor gerente & 0.13 días \\
\hline Conversar sobre avances del proyecto & 1 hora \\
\hline Documentar acuerdos y tareas en un acta de reunión & 1 hora \\
\hline Recibir aprobación de acta de reunión & 1 hora \\
\hline Clase de taller de paper & 0.13 días \\
\hline Recibir asesoría de Paper & 1 hora \\
\hline Reunión con profesor cliente & 0.19 días \\
\hline Conversar sobre el proyecto & 1.5 horas \\
\hline Aprobación corrección de observaciones & 1.5 horas \\
\hline Registrar acuerdos y tareas en un acta de Reunión & 1.5 horas \\
\hline Recibir aprobación de acta de reunión & 1.5 horas \\
\hline Semana 11 & 5.19 días \\
\hline Reunión con profesor gerente & 0.13 días \\
\hline Conversar sobre avances del proyecto & 1 hora \\
\hline Documentar acuerdos y tareas en un acta de reunión & 1 hora \\
\hline Recibir aprobación de acta de reunión & 1 hora \\
\hline Clase de taller de paper & 0.13 días \\
\hline Recibir asesoría de Paper & 1 hora \\
\hline Reunión con profesor cliente & 0.19 días \\
\hline Conversar sobre el proyecto & 1.5 horas \\
\hline Registrar acuerdos y tareas en un acta de Reunión & 1.5 horas \\
\hline Recibir aprobación de acta de reunión & 1.5 horas \\
\hline Correcciones adicionales & 5 dias \\
\hline Semana 12 & 2.19 días \\
\hline Reunión con profesor gerente & 0.13 dias \\
\hline Conversar sobre avances del proyecto & 1 hora \\
\hline Documentar acuerdos y tareas en un acta de reunión & 1 hora \\
\hline Recibir aprobación de acta de reunión & 1 hora \\
\hline Clase de taller de paper & 0.13 días \\
\hline Recibir asesoría de Paper & 1 hora \\
\hline Reunión con cliente & 0.19 días \\
\hline Conversar sobre el proyecto & 1.5 horas \\
\hline Registrar acuerdos y tareas en un acta de Reunión & 1.5 horas \\
\hline Recibir aprobación de acta de reunión & 1.5 horas \\
\hline Semana 13 & 2.19 dias \\
\hline Entrega Final del DVD del proyecto & 1 hora \\
\hline Reunión con profesor gerente & 0.13 días \\
\hline Conversar sobre avances del proyecto & 1 hora \\
\hline Documentar acuerdos y tareas en un acta de reunión & 1 hora \\
\hline Recibir aprobación de acta de reunión & 1 hora \\
\hline Clase de taller de paper & 0.13 días \\
\hline Recibir asesoría de Paper & 1 hora \\
\hline Reunión con cliente 27 & 0.19 días \\
\hline Conversar sobre el proyecto & 1.5 horas \\
\hline Registrar acuerdos y tareas en un acta de Reunión & 1.5 horas \\
\hline Recibir aprobación de acta de reunión & 1.5 horas \\
\hline Semana 14 & 6.25 días \\
\hline Poster & 2 días \\
\hline Actas de cierre (capacitación y conformidad) & 3 días \\
\hline Reunión con profesor gerente & 0.19 días \\
\hline Exposición con el profesor gerente & 1.5 horas \\
\hline Clase de taller de paper & 0.13 días \\
\hline Recibir asesoría de Paper & 1 hora \\
\hline Reunión con profesor cliente & 0.19 días \\
\hline Conversaciones finales acerca del proyecto & 1.5 horas \\
\hline Registrar acuerdos y tareas en un acta de Reunión & 1.5 horas \\
\hline Recibir aprobación de acta de reunión & 1.5 horas \\
\hline Semana 15 & 1.19 días \\
\hline Exposición antes el comité 02 & 1.19 días \\
\hline Preparar presentación para sustentación final & 1 día \\
\hline
\end{tabular}
Iun $16 / 10 / 17$ lun $16 / 10 / 17$ vie $20 / 10 / 17$ vie $20 / 10 / 17$ vie $20 / 10 / 17$ vie $20 / 10 / 17$ jue 19/10/17 jue 19/10/17 sáb 21/10/17 sáb 21/10/17 sáb $21 / 10 / 17$ sáb 21/10/17 sáb 21/10/17 lun $23 / 10 / 17$ vie $27 / 10 / 17$ vie $27 / 10 / 17$ vie $27 / 10 / 17$ vie $27 / 10 / 17$ jue 26/10/17 jue $26 / 10 / 17$ sáb 28/10/17 sáb 28/10/17 sáb 28/10/17 sáb 28/10/17 Iun $23 / 10 / 17$ jue $2 / 11 / 17$ vie $3 / 11 / 17$ vie $3 / 11 / 17$ vie $3 / 11 / 17$ vie $3 / 11 / 17$ jue $2 / 11 / 17$ jue $2 / 11 / 17$ sáb 4/11/17 sáb $4 / 11 / 17$ sáb $4 / 11 / 17$ sáb 4/11/17 jue 9/11/17 vie $10 / 11 / 17$ vie 10/11/17 vie $10 / 11 / 17$ vie $10 / 11 / 17$ vie $10 / 11 / 17$ jue $9 / 11 / 17$ jue $9 / 11 / 17$ sáb $11 / 11 / 17$ sáb $11 / 11 / 17$ sáb $11 / 11 / 17$ sáb $11 / 11 / 17$ sáb 11/11/17 sáb 11/11/17 sáb 11/11/17 vie 17/11/17 vie $17 / 11 / 17$ jue 16/11/17 jue $16 / 11 / 17$ sáb 18/11/17 sáb 18/11/17 sáb $18 / 11 / 17$ sáb 18/11/17 lun 20/11/17 Iun 20/11/17 sáb 21/10/17 mié $18 / 10 / 17$ vie $20 / 10 / 17$ vie $20 / 10 / 17$ vie $20 / 10 / 17$ vie $20 / 10 / 17$ jue 19/10/17 jue $19 / 10 / 17$ sáb 21/10/17 sáb 21/10/17 sáb 21/10/17 sáb $21 / 10 / 17$ sáb $21 / 10 / 17$ sáb 28/10/17 vie $27 / 10 / 17$ vie $27 / 10 / 17$ vie $27 / 10 / 17$ vie $27 / 10 / 17$ jue $26 / 10 / 17$ jue $26 / 10 / 17$ sáb 28/10/17 sáb 28/10/17 sáb $28 / 10 / 17$ sáb $28 / 10 / 17$ vie $27 / 10 / 17$ sáb 4/11/17 vie $3 / 11 / 17$ vie $3 / 11 / 17$ vie $3 / 11 / 17$ vie $3 / 11 / 17$ jue $2 / 11 / 17$ jue $2 / 11 / 17$ sáb 4/11/17 sáb 4/11/17 sáb $4 / 11 / 17$ sáb $4 / 11 / 17$ sáb 11/11/17 vie $10 / 11 / 17$ vie 10/11/17 vie $10 / 11 / 17$ vie $10 / 11 / 17$ vie $10 / 11 / 17$ jue $9 / 11 / 17$ jue $9 / 11 / 17$ sáb 11/11/17 sáb $11 / 11 / 17$ sáb 11/11/17 sáb 11/11/17 sáb 18/11/17 lun $13 / 11 / 17$ mar $14 / 11 / 17$ vie 17/11/17 vie $17 / 11 / 17$ jue 16/11/17 jue $16 / 11 / 17$ sáb 18/11/17 sáb 18/11/17 sáb 18/11/17 sáb 18/11/17 mar 21/11/17 mar 21/11/17 Iun 20/11/17

Fuente: Elaboración Propia

Existieron algunos contratiempos que no se tuvieron previstos y las cuales se detallan.

Tabla 20: Mitigación de Contratiempos 


\begin{tabular}{|c|c|c|}
\hline Semana 2,3,4 & $\begin{array}{l}\text { Problemas para contactar con la } \\
\text { municipalidad de VMT para la cual se realiza } \\
\text { el proyecto }\end{array}$ & $\begin{array}{l}\text { - Conversar con el comité del proyecto } \\
\text { para cambiar de municipalidad. } \\
\text { - Comunicación con el contacto de la } \\
\text { municipalidad por medio de correos y } \\
\text { llamadas telefónicas. } \\
\text { - Solicitud de carta de presentación de la } \\
\text { universidad para poder obtener acceso a } \\
\text { la información. }\end{array}$ \\
\hline Semana 33 & Actualización de entregables planteados & $\begin{array}{l}\text { - Se revisaron los entregables y llegó a la } \\
\text { conclusión que debían desestimarse } \\
\text { algunos de los ya seleccionados } \\
\text { anteriormente. } \\
\text { - Se determinó que los documentos a } \\
\text { realizar serían plantillas adaptadas a los } \\
\text { requerimientos del proyecto. }\end{array}$ \\
\hline
\end{tabular}

Fuente: Elaboración Propia

\section{Gestión de los Recursos Humanos}

A lo largo del desarrollo del proyecto se llevó los siguientes roles, según lo acordado.

- Comité de Proyectos

Son los encargados de aprobar la correcta realización del proyecto y se encargan de evaluar, asesorar y calificar el proyecto los avances del proyecto. Conformado por la directora de la Escuela de Ingeniería de Sistemas y Computación y los coordinadores de las carreras de Ingeniería de Sistemas de Información, Ingeniería de Software y Ciencias de la Computación.

- Profesor Gerente ITConsulting

Es el encargado de establecer y cumplir los objetivos principales de la empresa ITConsulting; con respecto a la participación en el proyecto, el profesor gerente realizará las siguientes funciones:

- Presentar oportunidades de mejora para el cumplimiento de objetivos de la empresa ITConsulting en base a los proyectos propuestos.

- Realizar un seguimiento del proyecto con el fin de evaluar si se cumple con lo estipulado de acuerdo con el cronograma establecido. 
- Brindar comentarios y observaciones de los entregables realizados para su mejora y levantamiento antes de la presentación de estos al cliente y comité.

- Profesor Cliente

Es el rol que corresponde al cliente del proyecto, encargado de la solicitud de requerimientos para el desarrollo y ejecución del proyecto, y de la orientación para la realización de los entregables.

\section{- Profesor Revisor}

Este rol corresponde al revisor de la memoria profesional del proyecto, por lo que su función es validar y certificar que este documento se encuentre alineada a la tesis desarrollada.

- Jefe de Proyecto

Este es el rol que corresponde a los encargados de planificar, ejecutar y controlar el avance del proyecto cumpliendo lo que se estableció en el cronograma. Encargados de la investigación y documentación de lo requerido por el proyecto. Realizan las coordinaciones respectivas con los involucrados en el proyecto.

- Analista de Calidad QS

Es el rol correspondiente al personal de QS, encargado de la revisión y aseguramiento de la calidad de los entregables de gestión. 
Figure 50: Organigrama de Recursos Humanos

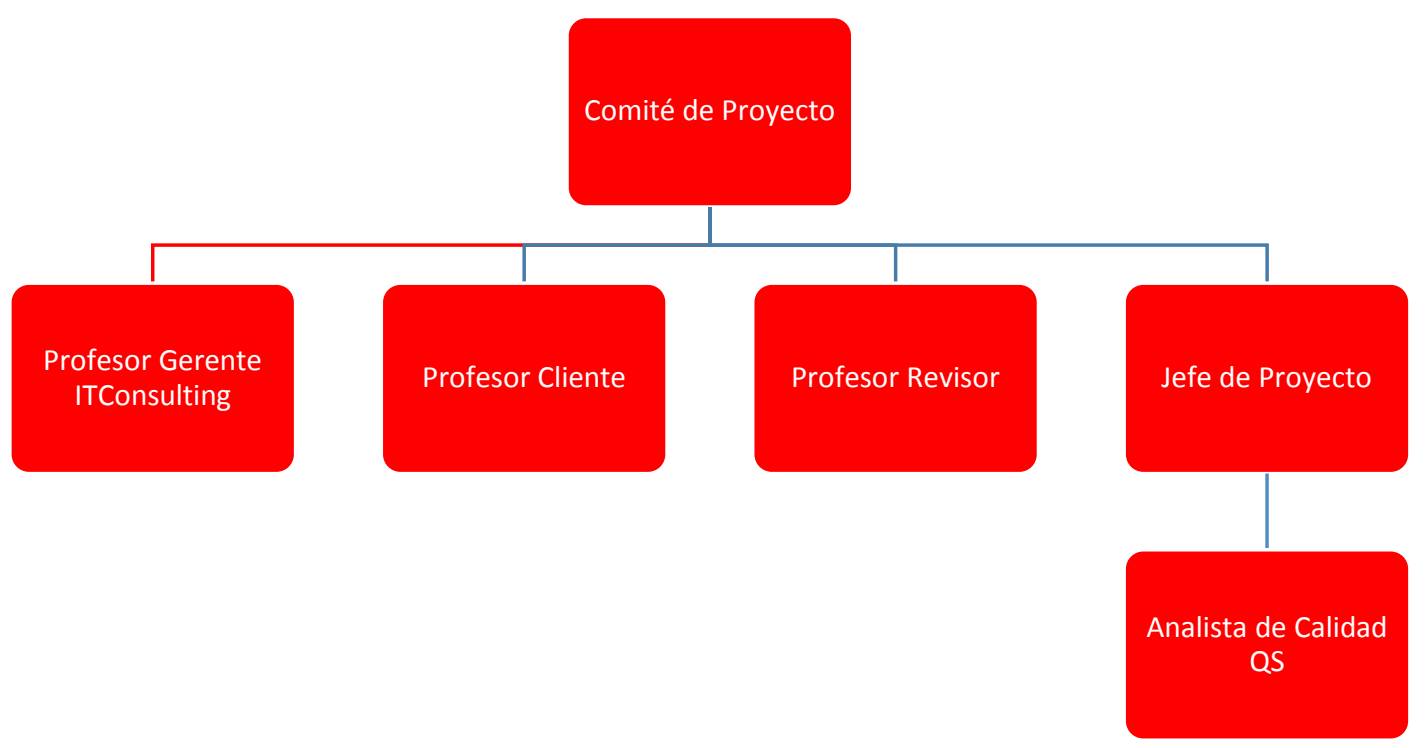

Fuente: Elaboración Propia

\section{Gestión de las Comunicaciones}

El plan de gestión de comunicaciones tiene como finalidad definir los lineamientos de comunicación, tanto interna como externa, con los involucrados en el proyecto. Este plan se cumplió según lo acordado.

Guía para las reuniones:

- En caso de tener un nuevo miembro en cada reunión, se hará la respectiva presentación de este ante los asistentes.

- Se manejará una agenda para cada reunión de acuerdo a los temas de interés a tratarse, así como también las tareas pendientes de reuniones anteriores. Para este caso, se debe tener en cuenta el entregable a realizar según el diccionario EDT.

- Cada punto de la agenda contará con un nivel de prioridad a ser tratado.

- Se cuenta con un horario específico para cada reunión, sin embargo, será necesario confirmar/recordar la reunión vía correo electrónico un día antes como máximo. 
- En caso se deba postergar una reunión, se deberá justificar y además acordar el nuevo día de esta.

- Al finalizar cada reunión se deberá recopilar lo tratado, resaltando los acuerdos para posteriormente elaborar el acta de reunión.

- Todas las actas de reunión deberán ser firmadas por el jefe de proyecto, asistente de proyecto y gerente general o cliente, respectivamente.

Guías para el correo electrónico:

- Cada correo electrónico debe ser redactado de una manera formal.

- Todo correo electrónico al cliente debe ser copiado a todo el equipo de proyecto; en especial a gerente, jefe, asistente de proyecto.

- Los correos electrónicos entre el gerente de la empresa y el cliente, deberá ser enviado por el jefe de proyecto para establecer un estándar en la conexión.

- En caso de envíos de solicitud de servicios a empresas externas, se debe copiar al correo de la empresa.

\section{Gestión de los Riesgos}

En relación con lo planteado al inicio del proyecto se presentó un riesgo adicional (9), el cual pudo impactar de manera importante si no se aplicaba la estrategia de mitigación adecuada. A continuación, se detallan los riesgos identificados para el proyecto con sus respectivas estrategias de mitigación.

Tabla 21: Riesgos Identificados

\begin{tabular}{|c|l|c|c|c|}
\hline$\#$ & \multicolumn{1}{|c|}{ Riesgo } & Probabilidad & Impacto & Estrategia de mitigación \\
\hline 1 & $\begin{array}{l}\text { El cliente no define } \\
\text { correctamente los requisitos del } \\
\text { proyecto. Esto puede causar } \\
\text { demoras en el levantamiento de } \\
\text { información. }\end{array}$ & Baja & Muy Alto & $\begin{array}{l}\text { Informar al cliente sobre los } \\
\text { problemas encontrados y } \\
\text { definir los requisitos con él. }\end{array}$ \\
\hline
\end{tabular}




\begin{tabular}{|c|c|c|c|c|}
\hline$\#$ & Riesgo & Probabilidad & Impacto & Estrategia de mitigación \\
\hline 2 & $\begin{array}{l}\text { Poca disponibilidad de tiempo } \\
\text { del cliente debido a sus } \\
\text { funciones municipales. }\end{array}$ & Alta & Muy Alto & $\begin{array}{l}\text { Realizar con cronograma de } \\
\text { reuniones con el cliente. }\end{array}$ \\
\hline 3 & $\begin{array}{l}\text { Abandono del proyecto por parte } \\
\text { de un integrante del equipo. }\end{array}$ & Baja & Muy Alto & $\begin{array}{l}\text { Mantener una comunicación } \\
\text { constante entre los } \\
\text { participantes del equipo }\end{array}$ \\
\hline 4 & $\begin{array}{l}\text { Cambios en el alcance del } \\
\text { proyecto propuestos por el } \\
\text { comité o por el cliente. }\end{array}$ & Baja & Muy Alto & $\begin{array}{l}\text { Gestionar adecuadamente la } \\
\text { holgura del proyecto. }\end{array}$ \\
\hline 5 & $\begin{array}{l}\text { No cumplir con las expectativas } \\
\text { del cliente }\end{array}$ & Medio & Muy Alto & $\begin{array}{l}\text { Realizar encuestas de } \\
\text { satisfacción al cliente de } \\
\text { manera periódica. }\end{array}$ \\
\hline 6 & $\begin{array}{l}\text { Inadecuado seguimiento } \quad \mathrm{y} \\
\text { control hacia los recursos. }\end{array}$ & Bajo & Alto & $\begin{array}{l}\text { Realizar reuniones de } \\
\text { seguimiento. }\end{array}$ \\
\hline 7 & $\begin{array}{l}\text { Cambio de cliente luego de } \\
\text { haber iniciado el proyecto. }\end{array}$ & Muy Bajo & Muy Alto & $\begin{array}{l}\text { Realizar análisis procesos } \\
\text { estándares en las } \\
\text { municipalidades. }\end{array}$ \\
\hline 8 & $\begin{array}{l}\text { No contar con el documento de } \\
\text { presentación por parte de la } \\
\text { universidad por lo que } \\
\text { imposibilita } \\
\text { municipalidad no brinde la } \\
\text { información. }\end{array}$ & Bajo & Muy Alto & $\begin{array}{l}\text { Solicitar el documento de } \\
\text { presentación a algún } \\
\text { miembro del comité de } \\
\text { proyecto. }\end{array}$ \\
\hline 9 & $\begin{array}{l}\text { Cambio de proyecto propuesto } \\
\text { por el comité o por el cliente. }\end{array}$ & Medio & Muy Alto & $\begin{array}{l}\text { Informar al contacto sobre el } \\
\text { proyecto de estudio a realizar } \\
\text { y realizar un cronograma de } \\
\text { reuniones con el contacto. }\end{array}$ \\
\hline
\end{tabular}

Fuente: Elaboración Propia

\section{Lecciones Aprendidas}

Se procede a detallar las lecciones aprendidas a lo largo del desarrollo del proyecto, las cuales se recomiendan tomar en cuenta para posteriores proyectos de tesis. 
- Es fundamental tener un entendimiento acerca del tema del proyecto para un adecuado levantamiento de información y elaboración de entregables. En caso se presente alguna duda, es necesario realizar las preguntas respectivas con los responsables.

- La actualización del cronograma del proyecto es importante para la reasignación de tiempo y recursos para las actividades actualizadas y las nuevas actividades.

- Es importante determinar a tiempo si el proyecto continúa o procede con algún cambio, ya que esto afecta de algún modo o a gran medida al proyecto inicial.

- Es importante contar con una trazabilidad en cuanto a los entregables del proyecto para garantizar la calidad del proyecto.

- Es importante tener conocimiento de los entregables y artefactos de las fases de Togaf usados para el proyecto, ya que estos serán usados como base para el proyecto y deben ser realizados adecuadamente. 


\section{Conclusiones}

- En este trabajo se introduce una forma de implementación de trámites digitales basadas en e-Servicios para municipalidades distritales peruanas urbanas utilizando las buenas prácticas del marco de trabajo de arquitectura empresarial TOGAF.

- El modelo permite a una municipalidad urbana implementar los e-Trámites basándose en e-Servicios Municipales que se encuentran alineados a las leyes peruanas. Esto, mediante un conjunto de entregables con los cuales se puede ir a la etapa de desarrollo e implementar el trámite propuesto de una forma ordenada.

- Al realizar la evaluación de juicio de expertos se concluye que su utilización permite una mejor implementación de los e-Trámites y que el 100\% se encuentra dispuesto a utilizar el modelo para su siguiente proyecto de trámite electrónico, el 50\% lo considera como "Muy aceptable" y el otro 50\% como "Aceptable".

- Los funcionarios de la municipalidad brindan una gran aceptación al modelo propuesto, ya que el 60\% lo califica como "Muy aceptable" y el 40\% como "Aceptable", lo cual indica como prometedor los de e-Trámites.

- Por otro lado, el $92 \%$ de los ciudadanos encuestados lo califican como "Muy aceptable" y el 8\% como "Aceptable", lo cual muestra una gran aceptación por parte de la ciudadanía, que son las personas más importantes en una propuesta de gobierno electrónico.

- Los resultados encontrados muestran una gran ventaja respecto a las otras guías de implementación encontradas en la literatura. Esto se debe, a que se ha unido exitosamente las buenas prácticas de arquitectura empresarial con los e-Servicios que cumplen con las leyes peruanas. 


\section{Recomendaciones}

Las recomendaciones obtenidas del proyecto son las siguientes :

- Se recomienda tener en cuenta el punto de marco de modelo para iniciar el proyecto de implementación.

- Para la implementación del modelo, se debe elaborar todas las plantillas propuestas y en el orden recomendado, debido a que esto garantiza las buenas prácticas de TOGAF.

- El equipo de proyecto debe encontrarse al tanto de las tecnologías emergentes para proponer e-Servicios innovadores.

- Se recomienda analizar los costos del proyecto de acuerdo a la realidad de la municipalidad. 


\section{Glosario}

A continuación, se listan los términos pocos comunes en el proyecto.

- STUDENT OUTCOMES: Competencias técnicas y blandas que deben ser alcanzadas por los alumnos de la carrera. Estas son definidas por la acreditadora ABET.

- TOGAF: The Open Group Architecture Framework, conjunto de herramientas de apoyo para el desarrollo de una Arquitectura Empresarial, proporciona un enfoque para el diseño, planificación, implementación y gobierno de una arquitectura empresarial.

- ADM: Architecture Development Method, compuesto por diferentes fases en forma cíclica y conforme se vaya desarrollando cada etapa la madurez de la Arquitectura Empresarial va aumentando.

- E-Government: Gobierno electrónico, se refiere a la interacción entre los gobiernos de distintos países y sus ciudadanos o personas que tengan contacto con ellos. Consiste en la realización de las actividades que cumple el gobierno haciendo uso de las tecnologías de información.

- PMBOK: Project Management Body of Knowledge, presenta estándares, pautas y normas para la gestión de proyectos

- E-Servicios: Los servicios electrónicos se refiere a los servicios prestados mediante el internet. Estas se encuentran automatizadas y requieren de una intervención mínima humana. 


\section{Siglario}

A continuación, se listan los acrónimos que son usados en el proyecto.

- UNESCO: United Nations Educaional, Scientific and Cultural Organization

- EDT: Estructura de Descomposición de Trabajo

- PMBOK: Project Management Body of Knowledge

- ADM: Architecture Development Metod (Método de Desarrollo de la Arquitectura)

- TOGAF: The Open Group Architecture Framework

- OE: Objetivo Específico

- IE: Indicadores de Éxito 
Anexos

Anexo 1: Emisión de Licencia de Funcionamiento (As-Is)

Figure 51: Proceso As-Is

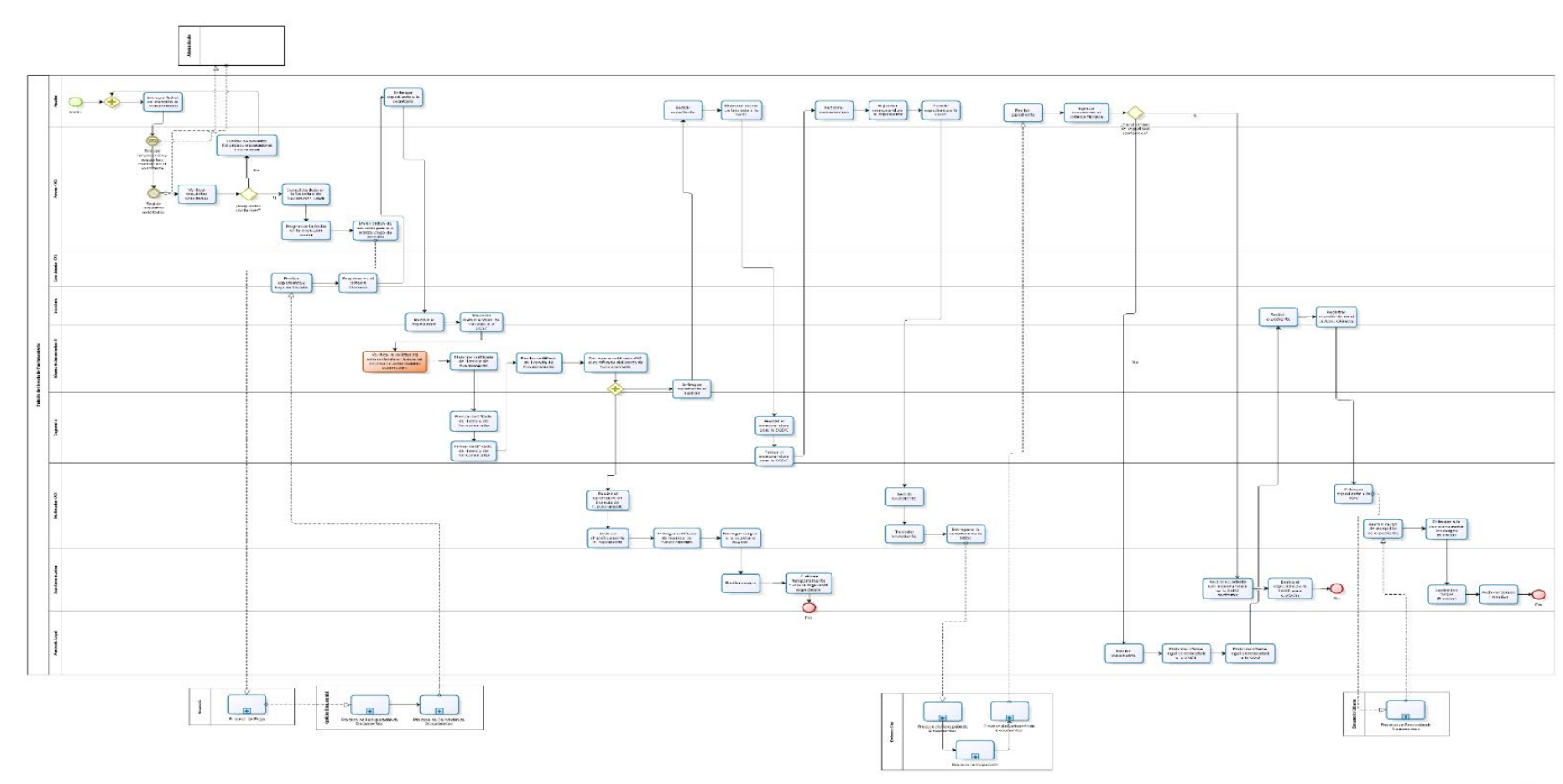


Fuente : Elaboración Propia

Anexo 2: Emisión de Licencia de Funcionamiento (To-Be)

Figure 52: Proceso To-Be

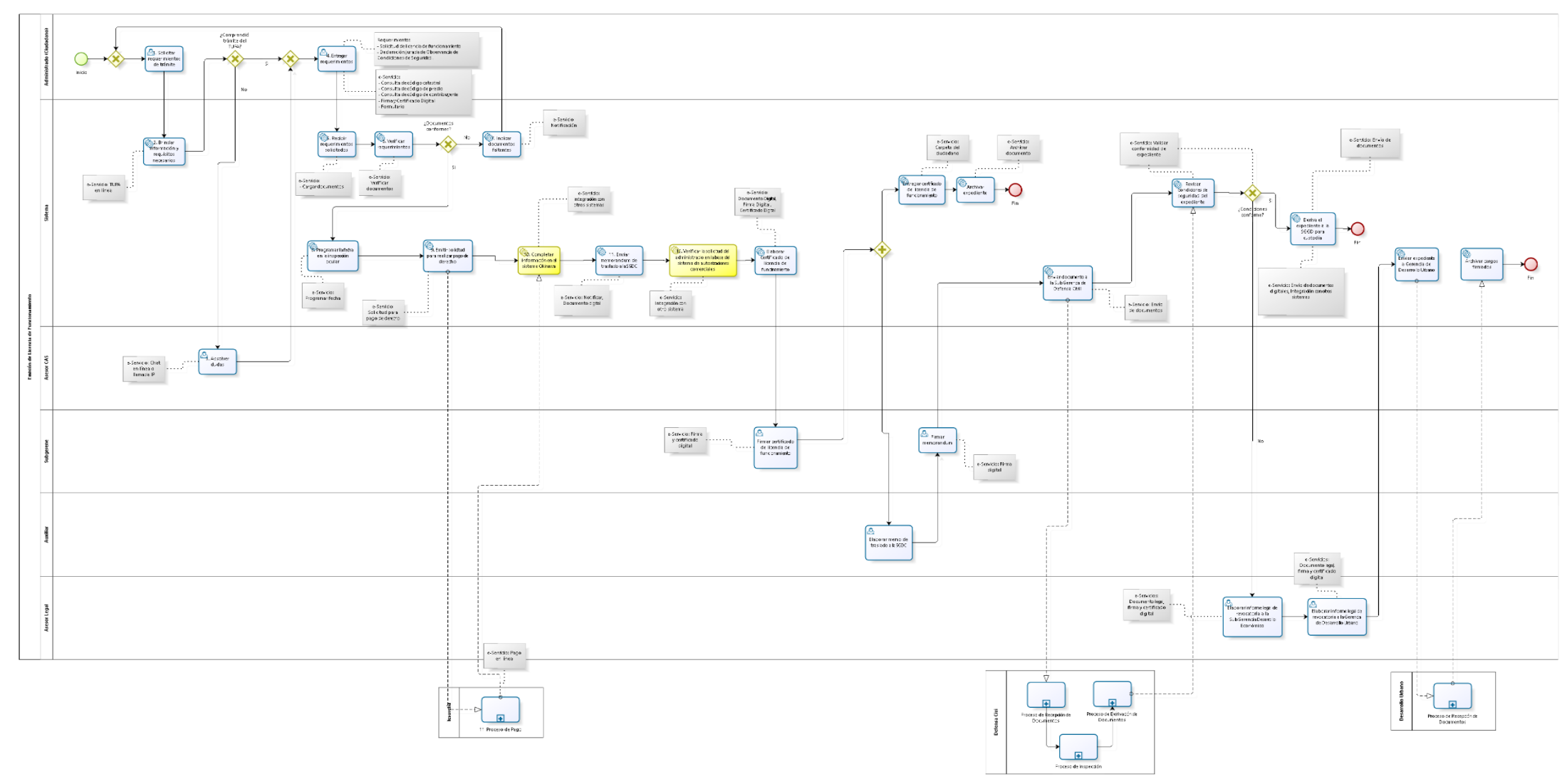


Fuente : Elaboración Propia

Anexo 3 : Caso de Uso - Contacto con el Ciudadano

Figure 53: Caso de Uso 1

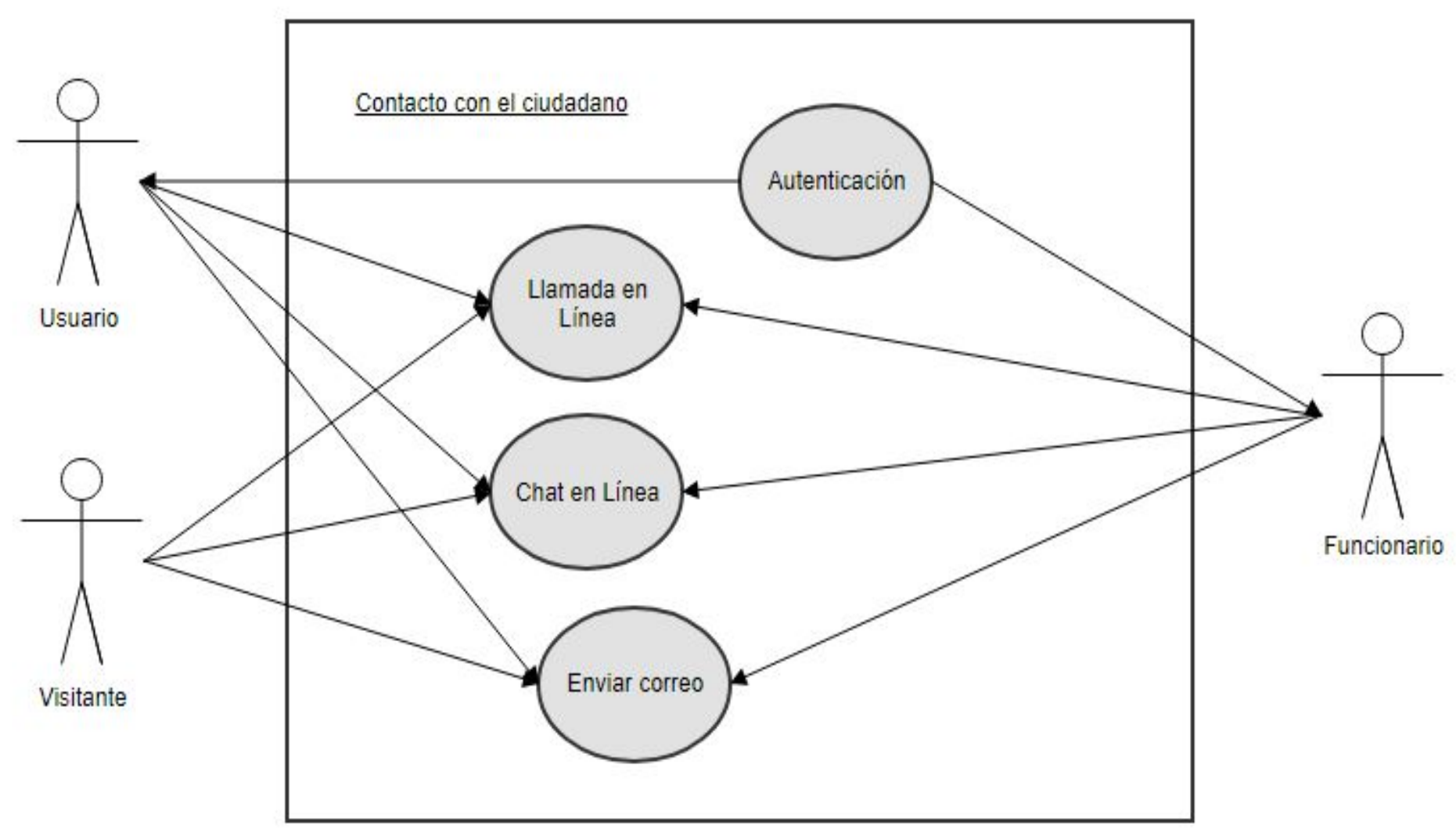

[158] 
Fuente : Elaboración Propia

Anexo 4 : Caso de Uso - Información Municipal

Figure 54: Caso de Uso 2

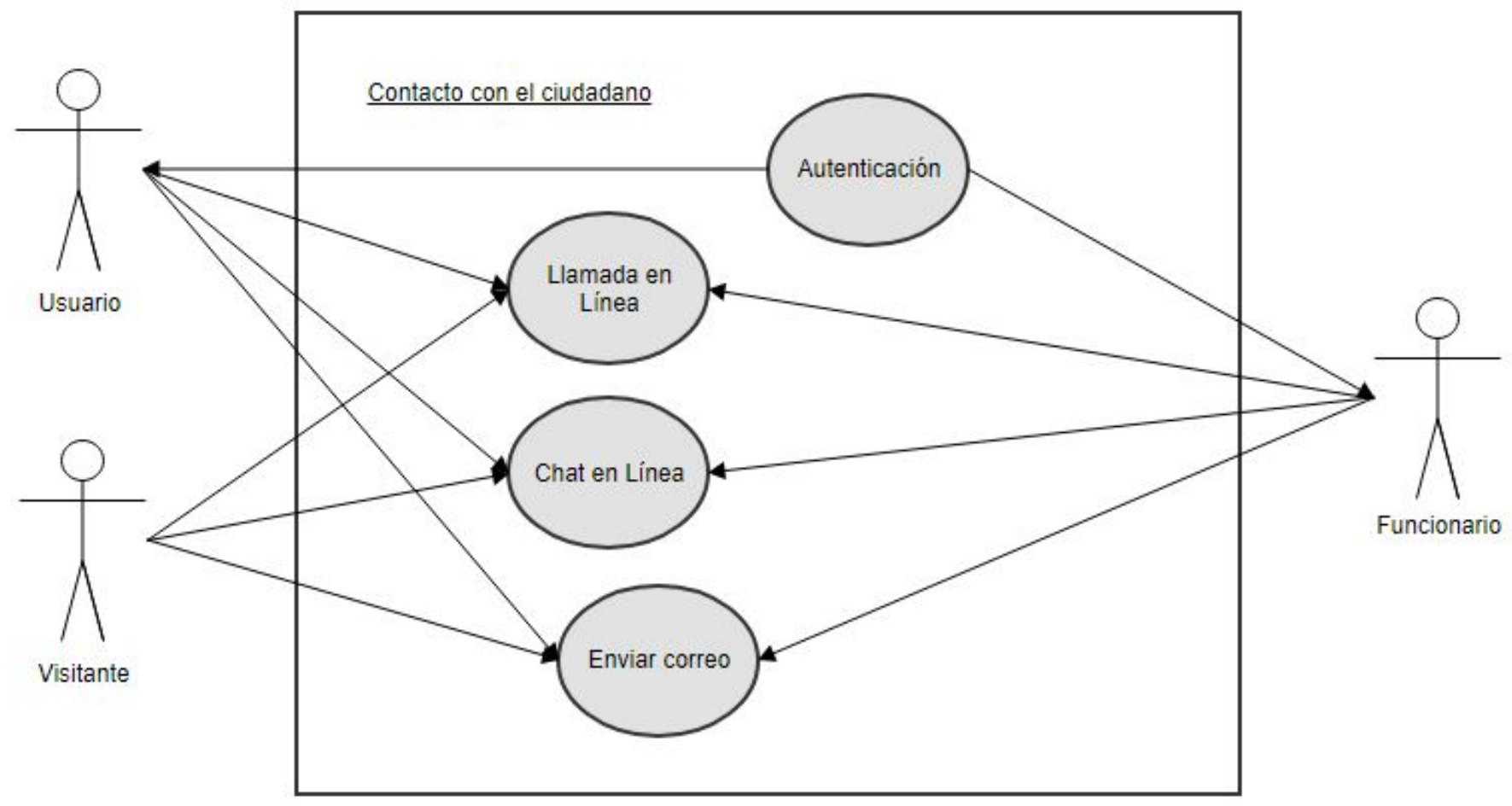

[159] 
Fuente : Elaboración Propia

Anexo 5: Caso de Uso - Trámite Municipal 
Figure 55: Caso de Uso 3

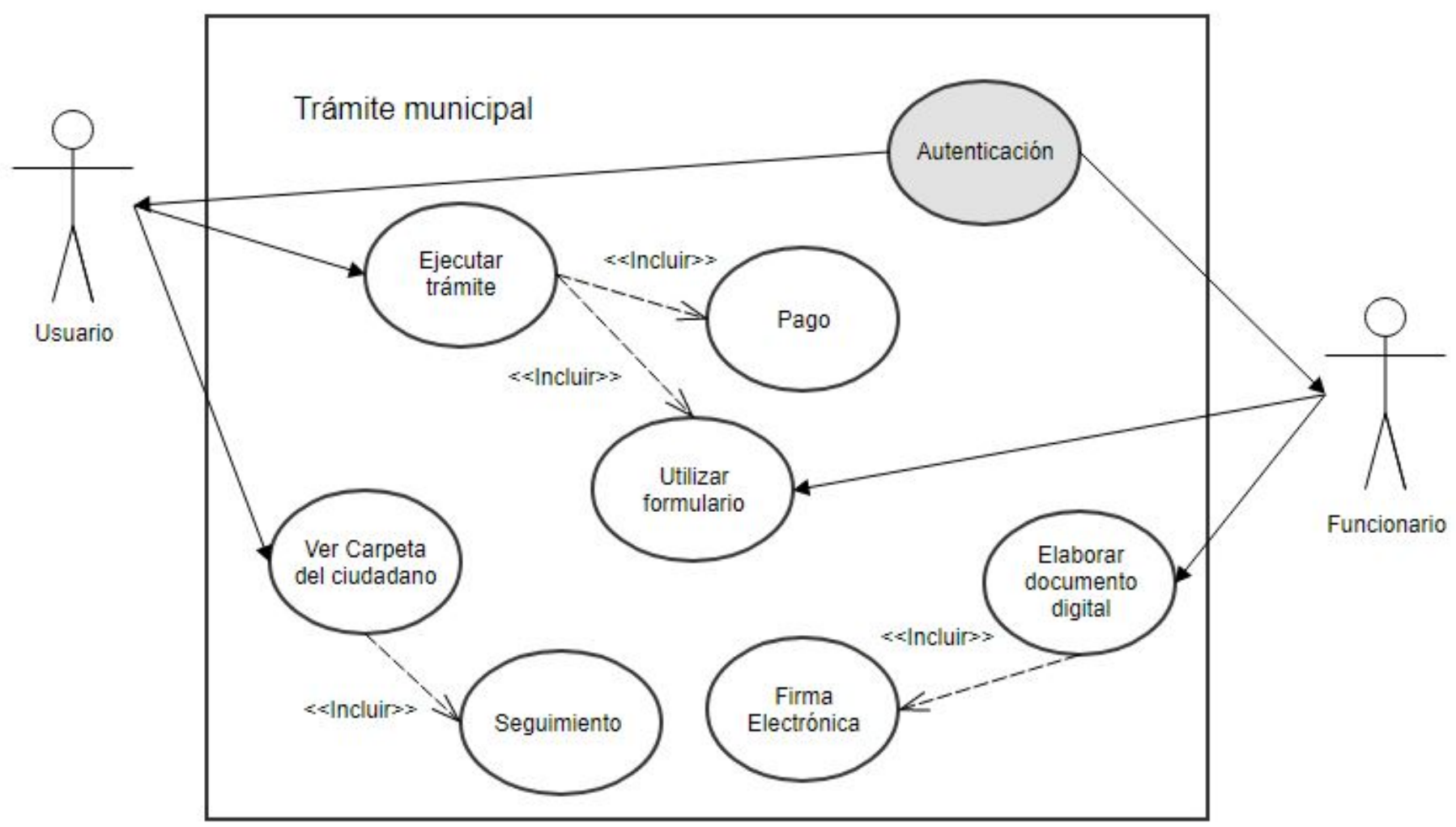

Fuente : Elaboración Propia

\section{Anexo 6: Principios de Negocio}


Figure 56: Principios de Negocio

\begin{tabular}{|c|c|c|c|c|c|c|}
\hline \multicolumn{7}{|c|}{ Principios de Negocio } \\
\hline ID & Nombre & Declaración & Fundamento & \begin{tabular}{|c|} 
Implicaciones \\
\end{tabular} & Fecha & Creador \\
\hline PRN_BU_01 & Cumplimiento de la ley & $\begin{array}{l}\text { Definir políticas, procesos y procedimientos que } \\
\text { faciliten el crecimiento de la gestión de TI de la } \\
\text { municipalidad. }\end{array}$ & $\begin{array}{l}\text { La municipalidad debe cumplir con las leyes, } \\
\text { políticas y regulaciones propuestas por el estado } \\
\text { peruano. }\end{array}$ & $\begin{array}{l}\text { 1. Estar al tanto de las normas, políticas o } \\
\text { regulaciones que decrete el estado peruano } \\
\text { 2. Se ajustarán los procesos para el } \\
\text { cumplimiento de las leyes. }\end{array}$ & $01 / 09 / 2017$ & $\begin{array}{r}\text { Raphael } \\
\text { Hinostroza }\end{array}$ \\
\hline PRN_BU_02 & Responsabilidad de TI & \begin{tabular}{|l|} 
El área de Tl es responsable de la propiedad e \\
implementación de los procesos e \\
infraestructura de TI, las cuales permiten que las \\
soluciones satisfagan los requisitos definidos \\
por el usuario con el cumplimiento la \\
funcionalidad, los niveles de servicio, costo y \\
tiempo de entrega.
\end{tabular} & $\begin{array}{l}\text { Alinear eficientemente las expectativas con las } \\
\text { capacidades del área. Implementando soluciones } \\
\text { eficientes y eficaces que tienen costos razonables y } \\
\text { con claros beneficios. }\end{array}$ & $\begin{array}{l}\text { 1. La función de TI debe definir los procesos } \\
\text { para gestionar las expectativas de las } \\
\text { unidades municipales. } \\
\text { 2. Implementar las arquitecturas de } \\
\text { aplicaciones, datos y tecnología para } \\
\text { brindar soluciones integradas de calidad y } \\
\text { maximizar los resultados. }\end{array}$ & $01 / 09 / 2017$ & $\begin{array}{l}\text { Raphael } \\
\text { Hinostroza }\end{array}$ \\
\hline PRN_BU_03 & Orientación a los servicios & $\begin{array}{l}\text { Establecer los servicios que ofrece la } \\
\text { municipalidad, los cuales comprenden las } \\
\text { actividades de diferentes áreas. }\end{array}$ & $\begin{array}{l}\text { Los servicios ofrece a la municipalidad una } \\
\text { agilidad en sus procesos y dejar de lado el uso del } \\
\text { papel. }\end{array}$ & $\begin{array}{l}\text { 1. Identificar el objetivo del servicio y las } \\
\text { áreas que intervienen. } \\
\text { 2. Identificar las reglas o leyes existentes } \\
\text { para la aplicación de los mismo. }\end{array}$ & $01 / 09 / 2017$ & $\begin{array}{l}\text { Allison } \\
\text { Garcia }\end{array}$ \\
\hline PRN_BU_04 & $\begin{array}{l}\text { Cambios basados en } \\
\text { requerimientos }\end{array}$ & $\begin{array}{l}\text { Solo para necesidades del negocio se procederá } \\
\text { a realizar cambios en las aplicaciones y la } \\
\text { tecnología. }\end{array}$ & $\begin{array}{l}\text { Asegurar que para cualquier cambio propuesto, la } \\
\text { información es el soporte de las operaciones del } \\
\text { negocio. }\end{array}$ & $\begin{array}{l}\text { 1. Las mejoras o cambios requeridos deben } \\
\text { estar documentados. } \\
\text { 2. Los cambios deberán ser analizados } \\
\text { minuciosamente. }\end{array}$ & 01/09/2017 & $\begin{array}{l}\text { Allison } \\
\text { Garcia }\end{array}$ \\
\hline PRN_BU_05 & Negocio sin fines de lucro & $\begin{array}{l}\text { El objetivo principal de la municipalidad debe } \\
\text { ser el bienestar social de sus ciudadanos. }\end{array}$ & $\begin{array}{l}\text { La municipalidad no busca un beneficio económico } \\
\text { sino que su principal objetivo es el beneficio para } \\
\text { sus ciudadanos. }\end{array}$ & $\begin{array}{l}\text { 1. Los servicios ofrecidos deben cumplir con } \\
\text { las necesidades del cliente. } \\
\text { 2. Las mejoras y/o cambios realizados deben } \\
\text { ser orientados al bienestar de los } \\
\text { ciudadanos y no para el beneficio } \\
\text { económico de la municipalidad. }\end{array}$ & $01 / 09 / 2017$ & $\begin{array}{l}\text { Allison } \\
\text { Garcia }\end{array}$ \\
\hline
\end{tabular}

Fuente : Elaboración Propia

\section{Anexo 7: Principios de Datos}


Figure 57: Principios de Datos

\begin{tabular}{|c|c|c|c|c|c|c|}
\hline \multicolumn{7}{|c|}{ Principios de Datos } \\
\hline ID & Nombre & Declaración & Fundamento & Implicaciones & Fecha & Creador \\
\hline PRN_IN_01 & $\begin{array}{l}\text { Los datos son un activo que tiene } \\
\text { valor para la municipalidady, en } \\
\text { consecuencia, se gestiona. }\end{array}$ & $\begin{array}{l}\text { Los datos son recursos valiosos para la municipalidad ya } \\
\text { que son medibles. Esto, además de tenerlos de manera } \\
\text { oportuna y precisa, facilita a la toma de decisiones. La } \\
\text { mayoria de los activos de la municipalidad son } \\
\text { gestionados con cuidado y los datos no deben ser la } \\
\text { excepción. Por último, se deben manejar con cuidado } \\
\text { para asegurarse su ubicación, que se pueda confiar en su } \\
\text { exactitudv ve oueda obtener en el momento ouese }\end{array}$ & $\begin{array}{l}\text { Los datos son recursos valiosos para la municipalidad ya que } \\
\text { son medibles. Esto, además de tenerlos de manera oportuna y } \\
\text { precisa, facilita a la toma de decisiones. La mayoría de los } \\
\text { activos de la municipalidad son gestionados con cuidado y los } \\
\text { datos no deben ser la excepción. Por último, se deben manejar } \\
\text { con cuidado para asegurarse su ubicación, que se pueda } \\
\text { confiar en su exactitud y se pueda obtener en el momento que } \\
\text { senecesite. }\end{array}$ & $\begin{array}{l}\text { 1. Los administradores deben tener la autoridad y los medios para } \\
\text { gestionar los datos de los que son responsables. } \\
\text { 2. El papel de administrador de datos es critico porque los datos } \\
\text { obsoletos, inexactos o incoherentes se podrian pasar a los funcionarios } \\
\text { municipales y afectar negativamente a las decisiones. } \\
\text { 3. Puesto que los datos es un activo de valor para toda la municipalidad, } \\
\text { los administradores de datos responsables de gestionar } \\
\text { adecuadamente los datos deben ser asignados a nivel de emoresa. }\end{array}$ & $01 / 09 / 2017$ & \begin{tabular}{|c|c} 
Raphael \\
Hinostroza
\end{tabular} \\
\hline PRN_IN_02 & $\begin{array}{l}\text { Vocabulario común y definición } \\
\text { de datos }\end{array}$ & $\begin{array}{l}\text { El dato se define constantemente en toda la } \\
\text { municipalidad, y las definiciones son comprensibles } y \\
\text { disponible para todos los usuarios. }\end{array}$ & $\begin{array}{l}\text { Los datos que se utilizará en el desarrollo de aplicaciones debe } \\
\text { tener una definición común a través de la entidad para permitir } \\
\text { el intercambio de datos. Un vocabulario común facilitará la } \\
\text { comunicación y permitirá el diálogo eficaz entre aplicaciones. } \\
\text { Además, se requiere para interconectar sistemas y cambio de } \\
\text { datos. }\end{array}$ & $\begin{array}{l}\text { 1. La municipalidad debe establecer el vocabulario común inicial para el } \\
\text { negocio. Las definiciones serán utilizadas de manera uniforme en toda } \\
\text { la entidad. } \\
\text { 2. Siempre que se requiera una nueva definición de algún dato, se debe } \\
\text { definir según las normas o reglas planteadas en el glosario de datos. } \\
\text { 3. Se deben asignar las responsabilidades del administrador de datos. }\end{array}$ & $01 / 09 / 2017$ & \begin{tabular}{|c|c} 
Raphael \\
Hinostroza
\end{tabular} \\
\hline PRN_IN_03 & Los datos son compartidos & $\begin{array}{l}\text { Los usuarios tienen acceso a los datos que se comparten } \\
\text { entre las diferentes áreas para llevar a cabo sus labores. }\end{array}$ & $\begin{array}{l}\text { El contar con acceso a estos datos es de suma importancia } \\
\text { para la toma de decisiones de la municipalidad. Además de } \\
\text { evitar la duplicidad de datos en la organización. }\end{array}$ & $\begin{array}{l}\text { 1. Se debe establecer políticas, normas y procedimientos para la } \\
\text { gestión de datos y el acceso a los mismo, los cuales deben ser divulgado } \\
\text { a todos los empleados de la municipalidad. } \\
\text { 2. Desarrollar un gestor de almacenamiento de datos. }\end{array}$ & 01/09/2017 & $\begin{array}{l}\text { Allison } \\
\text { Garcia }\end{array}$ \\
\hline PRN_IN_04 & $\begin{array}{l}\text { Restricción de datos } \\
\text { confidenciales }\end{array}$ & $\begin{array}{l}\text { La municipalidad cuenta con cierta información } \\
\text { confidencial que no puede ser compartida abiertamente } \\
\text { al público en general. }\end{array}$ & $\begin{array}{l}\text { Es necesario establecer datos que son confidenciales y no } \\
\text { pueden ser compartidas abiertamente a cualquier persona, } \\
\text { para el cual se requiere ciertas restricciones y permisos. }\end{array}$ & $\begin{array}{l}\text { 1. Conocimiento de la ley № } 29733 \text { - Ley de protección de datos } \\
\text { personales. } \\
\text { 2. Se debe establecer roles que cuenten con acceso a cierta información } \\
\text { confidencial. } \\
\text { 3. Cada usuario debe contar con un usuario y contraseña únicoy } \\
\text { personal. }\end{array}$ & $01 / 09 / 2017$ & $\begin{array}{l}\text { Allison } \\
\text { Garcia }\end{array}$ \\
\hline PRN_IN_05 & Datos públicos & $\begin{array}{l}\text { Los datos que las municipalidad son de acceso público } \\
\text { para quienes lo requieran. }\end{array}$ & $\begin{array}{l}\text { Los datos que una municipalidad maneja son de acceso } \\
\text { público, ya que al ser una entidad pública existe una ley que } \\
\text { indica esto. }\end{array}$ & $\begin{array}{l}\text { 1. Conocimiento de la ley № } 27806 \text { - Ley de Transparencia y Acceso de la } \\
\text { Información Pública. } \\
\text { 2. Los datos son públicos, al menos que exista una lev que lo restrinja. }\end{array}$ & $01 / 09 / 2017$ & \begin{tabular}{|c|c|} 
Raphael \\
Hinostroza
\end{tabular} \\
\hline
\end{tabular}

Fuente : Elaboración Propia

\section{Anexo 8: Principios de Aplicación}


Figure 58: Principios de Aplicación

\begin{tabular}{|c|c|c|c|c|c|c|}
\hline \multicolumn{7}{|c|}{ Principios de Aplicaciones } \\
\hline ID & Nombre & Declaración & Fundamento & Implicaciones & Fecha & Creador \\
\hline PRN_AP_01 & Facilidad de uso & $\begin{array}{l}\text { Sistema intuitivos para el usuario sin necesidad } \\
\text { de una capacitación exahustiva. }\end{array}$ & $\begin{array}{l}\text { La facilidad de uso permite una } \\
\text { navegabilidad agradable para el usuario, } \\
\text { tanto los sistemas que interactúan con } \\
\text { funcionarios o como los sistemas } \\
\text { individuales. }\end{array}$ & $\begin{array}{l}\text { 1. Definir estándares de diseño de } \\
\text { aplicaciones. } \\
\text { 2. Realizar pruebas con usuarios que no hayan } \\
\text { tenido contacto con el sistema antes de que } \\
\text { salga a producción. } \\
\text { 3. Contar con el sistema con al menos dos } \\
\text { idiomas para el usuario, si es necesario. }\end{array}$ & $01 / 09 / 2017$ & $\begin{array}{l}\text { Allison } \\
\text { Garcia }\end{array}$ \\
\hline PRN_AP_02 & Tecnología independiente & $\begin{array}{l}\text { Las aplicaciones de la municipalidad son } \\
\text { independientes de una tecnología específica, } \\
\text { por lo tanto pueden operar en varias } \\
\text { plataformas tecnológicas. }\end{array}$ & $\begin{array}{l}\text { La tecnología independiente permite que } \\
\text { las aplicaciones seleccionadas sean } \\
\text { desarrolladas y operadas de la manera } \\
\text { más rentable y oportuna. }\end{array}$ & $\begin{array}{l}\text { 1. Desarrollar interfaces entre los sistemas } \\
\text { que permita a las aplicaciones interoperar } \\
\text { con las aplicaciones desarrolladas en la } \\
\text { Arquitectura Empresarial. } \\
\text { 2. Definir estándares de soporte a la } \\
\text { portabilidad. }\end{array}$ & $01 / 09 / 2017$ & $\begin{array}{l}\text { Allison } \\
\text { Garcia }\end{array}$ \\
\hline PRN_AP_03 & Interoperabilidad & $\begin{array}{l}\text { Las aplicaciones deben comunicarse entre ellas } \\
\text { de una manera ágil. }\end{array}$ & $\begin{array}{l}\text { Los estándares para la interoperabilidad } \\
\text { permiten la conexión de varias } \\
\text { aplicaciones y facilitan la integración para } \\
\text { una transferencia de información eficaz. }\end{array}$ & $\begin{array}{l}\text { 1. Los estándares de interoperabilidad serán } \\
\text { seguidos a menos que haya una razón de } \\
\text { negocios para implementar una solución no } \\
\text { estándar. } \\
\text { 2. Las aplicaciones existentes deben ser } \\
\text { identificadas y documentadas. }\end{array}$ & $01 / 09 / 2017$ & $\begin{array}{l}\text { Allison } \\
\text { Garcia }\end{array}$ \\
\hline
\end{tabular}

Fuente : Elaboración Propia

\section{Anexo 9: Principios de Tecnología}


Figure 59: Principios de Tecnología

\begin{tabular}{|c|c|c|c|c|c|c|}
\hline \multicolumn{7}{|c|}{ Principios de Tecnología } \\
\hline ID & Nombre & Declaración & \begin{tabular}{|c|} 
Fundamento \\
\end{tabular} & \begin{tabular}{|c|} 
Implicaciones \\
\end{tabular} & Fecha & Creador \\
\hline PRN_TI_O1 & Alta disponibilidad & $\begin{array}{l}\text { Software de servicio municipal y Hardware } \\
\text { disponible } 24 \times 7 \text {. }\end{array}$ & $\begin{array}{l}\text { Los servicios municipales deben ser } \\
\text { accedidos por la ciudadanía en cualquier } \\
\text { momento, si así lo requiere. }\end{array}$ & $\begin{array}{l}\text { 1. Contar con un equipo de soporte las } 24 \times 7 . \\
\text { 2. Mantenimiento periódico del hardware. } \\
\text { 3. Elaborar y publicar SLA. }\end{array}$ & $01 / 09 / 2017$ & $\begin{array}{c}\text { Rahael } \\
\text { Hinostroza }\end{array}$ \\
\hline PRN_TI_O2 & Interoperabilidad & $\begin{array}{l}\text { El Software y hardware deben ajustarse a las } \\
\text { normas definidas que promueven la } \\
\text { interoperabilidad de los datos, las aplicaciones y } \\
\text { la tecnologia }\end{array}$ & \begin{tabular}{|l|} 
Las normas ayudan a garantizar la \\
coherencia, mejorando así la capacidad de \\
gestionar los sistemas, mejorar la \\
satisfacción del usuario y proteger las \\
inversiones de Tl existentes, maximizando asi \\
la rentabilidad de la inversión y la reducción \\
de costes. Los estándares para la \\
interoperabilidad, además, ayudan a \\
asegurar la conexión de varios sistemas, y \\
facilitan la integración de las entidades \\
gubernamentales para una transferencia de \\
información eficaz.
\end{tabular} & $\begin{array}{l}\text { 1. Los estándares de interoperabilidad y } \\
\text { estándares de la industria serán seguidos a menos } \\
\text { que haya una razón de negocios para implementar } \\
\text { una solución no estándar. } \\
\text { 2. Las plataformas existentes deben ser } \\
\text { identificadas y documentadas. } \\
\text { 3. Cumplimiento del decreto legislativo que } \\
\text { aprueba diversas medidas de simplificación } \\
\text { administrativa }\end{array}$ & $01 / 09 / 2017$ & $\begin{array}{c}\text { Rahael } \\
\text { Hinostroza }\end{array}$ \\
\hline PRN_TI_O3 & Acuerdo de Niveles de Servicio & $\begin{array}{l}\text { La prestación de los servicios se debe negociar } \\
\text { mediante un Acuerdo de Nivel de Servicio. Esto con } \\
\text { el propósito de llegar a un acuerdo de } \\
\text { expectativas. }\end{array}$ & \begin{tabular}{|l|} 
El Acuerdo de Nivel de Servicios establece un \\
acuerdo entre elproveedor de TI con la \\
municipalidad, los servicios ofrecidos deben \\
contar con un nivel para poder asegurar la \\
calidad de dicho servicio, los aspectos \\
relacionados son tiempo de respuesta, \\
disponibilidad horaria, documentación \\
disponible, personal asignado al servicio, \\
entre otros.
\end{tabular} & $\begin{array}{l}\text { 1. Contar con un manual de políticas y lineamientos } \\
\text { de proceso. } \\
\text { 2. Establecer el servicio ofrecido. } \\
\text { 3. Establecer los costos incurridos en la prestación } \\
\text { del servicio. } \\
\text { 4. Establecer el aporte de las Tecnologías de } \\
\text { Información al cumplimiento de los objetivos de la } \\
\text { municipalidad. }\end{array}$ & $01 / 09 / 2017$ & $\begin{array}{l}\text { Allison } \\
\text { Garcia }\end{array}$ \\
\hline PRN_TI_O4 & $\begin{array}{l}\text { Administración de catálogo de } \\
\text { servicios }\end{array}$ & $\begin{array}{l}\text { Los servicios de Tl que preste la organización } \\
\text { informática deberán estar definidos en el catálogo } \\
\text { de servicios con su respectivo atributos. }\end{array}$ & $\begin{array}{l}\text { El cátalogo de servicios sirve para definir los } \\
\text { servicios de Tl que se vayan a solicitar, este } \\
\text { debe contener atributos. Con este catálogo } \\
\text { se podrán generar nuevas ofertas de servicio } \\
\text { de acuerdo a las necesidades. }\end{array}$ & $\begin{array}{l}\text { 1. Contar con un manual de Políticas y Lineamientos } \\
\text { de proceso. } \\
\text { 2. Los servicios deben estar definidos con sus } \\
\text { atributos correspondientes. } \\
\text { 3. Los atributos de los servicios son: Niveles de } \\
\text { servicio, público objetivo, costo y alcance. }\end{array}$ & $01 / 09 / 2017$ & $\begin{array}{l}\text { Allison } \\
\text { Garcia }\end{array}$ \\
\hline
\end{tabular}

Fuente : Elaboración Propia

\section{Anexo 10: Principios de Seguridad}


Figure 60: Principios de Seguridad

\begin{tabular}{|c|c|c|c|c|c|c|}
\hline \multicolumn{7}{|c|}{ Principios de Seguridad } \\
\hline ID & Nombre & Declaración & \begin{tabular}{|c|} 
Fundamento \\
\end{tabular} & Implicaciones & Fecha & Creador \\
\hline PRN_SE_01 & Integridad de datos & $\begin{array}{l}\text { La información de la municipalidad no sufre } \\
\text { alteraciones o modificaciones. }\end{array}$ & $\begin{array}{l}\text { La empresa debe almacenar información de primera } \\
\text { mano, cuya modificación puede poner en juego la } \\
\text { integridad de los datos. }\end{array}$ & $\begin{array}{l}\text { 1. No tomar decisiones en base a data incorrecta } \\
\text { 2. Implementar un proceso de validación de } \\
\text { información. } \\
\text { 3. Manejar roles y permisos para modificación de } \\
\text { información. }\end{array}$ & $01 / 09 / 2017$ & $\begin{array}{l}\text { Raphael } \\
\text { Hinostroza }\end{array}$ \\
\hline PRN_SE_02 & Seguridad de datos & $\begin{array}{l}\text { Los datos están protegidos del uso no } \\
\text { autorizado y la divulgación. }\end{array}$ & $\begin{array}{l}\text { El intercambio abierto y la divulgación de la } \\
\text { información debe equilibrarse con la necesidad de } \\
\text { restringio la disponibilidad de la información } \\
\text { clasificada y sensible. }\end{array}$ & \begin{tabular}{|l|} 
1. Cumplimiento de la ley № 29733 - Ley de \\
protección de datos personales \\
2. Con el fin de proveer adecuadamente el \\
acceso a la información mientras se mantiene la \\
información sensible segura, las necesidades de \\
seguridad deben ser identificadas y \\
desarrolladas a nivel de datos, no el nivel de \\
aplicación.
\end{tabular} & $01 / 09 / 2017$ & $\begin{array}{l}\text { Allison } \\
\text { Garcia }\end{array}$ \\
\hline PRN_SE_03 & $\begin{array}{l}\text { Perímetros de seguridad } \\
\text { informática }\end{array}$ & $\begin{array}{l}\text { Protección del sistema de información de la } \\
\text { municipalidad. }\end{array}$ & $\begin{array}{l}\text { La municipalidad debe contar con seguridad } \\
\text { informática, la cual se encarga de diseñar las } \\
\text { normas, procedimientos, métodos y técnicas } \\
\text { destinados a conseguir un sistema de información } \\
\text { seguro y confiable. }\end{array}$ & $\begin{array}{l}\text { 1. Establecer una serie de estándares, protocolos } \\
\text { y métodos para evitar riesgos de información. } \\
\text { 2. Establecer reglas, herramientas y leyes para } \\
\text { minimizar los posibles riesgos a la } \\
\text { infraestructura o a la información. }\end{array}$ & $01 / 09 / 2017$ & $\begin{array}{l}\text { Allison } \\
\text { Garcia }\end{array}$ \\
\hline
\end{tabular}

Fuente : Elaboración Propia

\section{Anexo 11: Misión}


Figure 61: Misión Municipalidad de Miraflores

\section{Declaración de la Misión}

Brindar servicios públicos a través de una gestión moderna y eficiente, con el fin de entregar a los ciudadanos un lugar grato para desarrollarse $y$ vivir.

Fuente : Municipalidad de Miraflores

\section{Anexo 12: Sponsor de la Organización}

Figure 62: Sponsor

\begin{tabular}{|c|c|c|c|c|c|}
\hline \multicolumn{6}{|c|}{ Sponsor de la Organización } \\
\hline ID & Nombre & Organización & Posición & Email & Teléfono \\
\hline SPS_01 & Roberto Hipolito Gómez Baca & Municipalidad de Santiago de Surco & Alcalde & alcaldia@munisurco.gob.pe & 411-5560 Anexo 2204 \\
\hline SPS_02 & Waldo Felipe Olivos Rengifo & Municipalidad de Santiago de Surco & Gerente Municipal & gm@munisurco.gob.pe & $\begin{array}{c}\text { 411-5560 Anexos: } 2207 \\
2208\end{array}$ \\
\hline SPS_03 & Héctor Luis Santivañez Cotera & Municipalidad de Santiago de Surco & Gerente de Desarrollo Económico & gde@munisurco.gob.pe & $\begin{array}{c}\text { 411-5560 Anexos: } 1251 \\
1252\end{array}$ \\
\hline SPS_04 & $\begin{array}{l}\text { Milagros Pamela Arteaga } \\
\text { Delgado }\end{array}$ & Municipalidad de Santiago de Surco & Gerente de Desarrollo Urbano & gdu@munisurco.gob.pe & $\begin{array}{c}\text { 411-5560 Anexos: } 2101 \\
2102\end{array}$ \\
\hline SPS_05 & Rosa María Ita Martínez & Municipalidad de Santiago de Surco & Subgerente de Licencias y Habilitación & sglh@munisurco.gob.pe & $\begin{array}{c}\text { 411-5560 Anexos: } 2107 \\
2108\end{array}$ \\
\hline SPS_06 & & & & & \\
\hline
\end{tabular}

Fuente : Elaboración Propia

\section{Anexo 13: Objetivos}


Figure 63: Objetivos

\begin{tabular}{|c|c|c|c|}
\hline \multicolumn{4}{|c|}{ Objetivos } \\
\hline ID & Nombre del Objetivo & Tipo & Indicador \\
\hline \multirow{3}{*}{ OBJ_01 } & \multirow{3}{*}{ Fortalecer la seguridad ciudadana. } & \multirow{3}{*}{ Estratégico } & Disminuir en a un $20 \%$ el nivel de percepción de la inseguridad ciudadana. \\
\hline & & & Disminuir a un $10 \%$ el ratio de victimización. \\
\hline & & & Disminuir a un $50 \%$ el porcentaje de accidentes de tránsito en los puntos negros identificados. \\
\hline \multirow{4}{*}{ OBJ_02 } & \multirow{4}{*}{ Asegurar la calidad ambiental de la ciudad. } & \multirow{4}{*}{ Estratégico } & Aumentar a un 5\% el porcentaje de residuos sólidos inogánicos domiciliarios destinados a reciclaje. \\
\hline & & & Disminuir a un $23.5 \mu \mathrm{g} / \mathrm{m} 3$ el nivel de concentración de material particulado PM 2,5. \\
\hline & & & Aumentar a un $6.0 \mathrm{~m} 2 /$ hab la superficie de área verde pública per cápita. \\
\hline & & & Aumentar a un $70 \%$ el porcentaje de agua de canal y agua tratada para la irrigación de las áreas verdes. \\
\hline OBJ_03 & Reducir la vulnerabilidad del riesgo de desastres del distrito. & Estratégico & Aumentar a un $35 \%$ el porcentaje de la población con capacidad de respuesta ante emergencias y desastres. \\
\hline \multirow{3}{*}{ OBJ_04 } & \multirow{3}{*}{ Lograr el crecimiento ordenado de la ciudad. } & \multirow{3}{*}{ Estratégico } & Reducir a un $34 \%$ el porcentaje de condición de terreno rústico y semi-rústico. \\
\hline & & & Disminuir el tiempo promedio de circulación vehicular en hora punta a 11 minutos. \\
\hline & & & Aumentar a un $5 \%$ el porcentaje de ejecución presupuestal del gasto en infraestructura vial. \\
\hline OBJ_05 & Promover el desarrollo económico de la ciudad. & Estratégico & Aumentar a 23342 establecimientos con licencias de funcionamiento activas. \\
\hline OBJ_06 & Fortalecer el desarrollo humano de la población. & Estratégico & Aumentar a 0,79 el índice de desarrollo humano (IDH). \\
\hline \multirow[t]{2}{*}{ OB__07 } & \multirow[t]{2}{*}{$\begin{array}{l}\text { Mejorar la calidad y el acceso de los servicios de educación y salud de la } \\
\text { población. }\end{array}$} & \multirow[t]{2}{*}{ Estratégico } & $\begin{array}{l}\text { Aumentar a } 81 \% \text { el porcentaje de estudiantes de } 2^{\circ} \text { grado de primaria de instituciones educativas que se } \\
\text { encuentran en el nivel satisfactorio en comprensión lectora. } \\
\text { Aumentar a } 48 \% \text { el porcentaje de estudiantes de } 2^{\circ} \text { grado de primaria de instituciones educativas que se } \\
\text { encuentran en el nivel satisfactorio en matemáticas. } \\
\text { Aumentar a } 51 \% \text { el porcentaje de estudiantes de } 2^{\circ} \text { grado de secundaria de instituciones educativas que se } \\
\text { encuentran en el nivel satisfactorio en comprensión lectora. } \\
\text { Aumentar a } 34 \% \text { el porcentaje de estudiantes de } 2^{\circ} \text { grado de secundaria de instituciones educativas que se } \\
\text { encuentran en el nivel satisfactorio en matemáticas }\end{array}$ \\
\hline & & & Aumentar a $90 \%$ el porcentaje de población afiliada a algún tipo de seguro de salud. \\
\hline \multirow{3}{*}{ OBJ_08 } & \multirow{3}{*}{ Mejorar la gobernanza de la ciudad. } & \multirow{3}{*}{ Estratégico } & Aumentar a 266 agentes participantes del proceso de presupuesto participativo. \\
\hline & & & Aumentar a 7 el nivel de cumplimiento de información publicada en el portal de transparencia. \\
\hline & & & Aumentar a $65 \%$ el porcentaje de atención de solicitudes, quejas, reclamos y sugerencias finalizadas. \\
\hline
\end{tabular}

Fuente : Elaboración Propia

\section{Anexo 14: Requerimientos}


Figure 64: Requerimientos

\begin{tabular}{|c|c|c|}
\hline \multicolumn{3}{|r|}{ Requerimientos } \\
\hline ID & Tipo & Requerimiento \\
\hline REQ_01 & Funcional & El sistema enviará una notificación cuando se registre alguna solicitud de emisión de licencia de funcionamiento. \\
\hline REQ_02 & Funcional & El sistema debe poder comunicarse con todas las áreas de la municipalidad para que éstas puedan estar integradas. \\
\hline REQ_03 & Funcional & $\begin{array}{l}\text { El jefe del área de recursos humanos debe ser capaz de actualizar el listado de empleados que existe en la organización, indicando los nuevos } \\
\text { ingresantes, nuevos puestos y salidas. }\end{array}$ \\
\hline REQ_04 & Funcional & Para la realización de trámites, el sistema solicitará el registro del usuario. \\
\hline REQ_05 & Funcional & El sistema otorgará a cada solicitud un único identificador de trámite. \\
\hline REQ_06 & Funcional & Se debe verificar que la documentación necesaria para iniciar el trámite esté correcta y completa cumpliendo con las leyes y normas establecidas. \\
\hline REQ_07 & Funcional & Se debe contar con una asesoría en línea disponible al ciudadano cuando este lo requiera. \\
\hline REQ_08 & Funcional & Para la emisión de la licencia de funcionamiento es necesario que defensa civil realice una inspección del establecimiento. \\
\hline REQ_09 & No Funcional & $\begin{array}{l}\text { El plazo máximo para la emisión de la licencia de funcionamiento debe ser de } 7 \text { días hábiles luego de haber presentado correctamente todos los } \\
\text { requisitos. }\end{array}$ \\
\hline REQ_10 & No Funcional & $\begin{array}{l}\text { La licencia de funcionamiento emitida solo es válida en el distrito en que se solicitó la emisión, más no si el solicitante desea abrir el mismo negocio en } \\
\text { otro distrito. }\end{array}$ \\
\hline REQ_11 & No Funcional & $\begin{array}{l}\text { La licencia de funcionamiento tiene un tiempo indeterminado pero en caso se cesen las actividades del negocio se debe informar inmediatamente a la } \\
\text { municipalidad. }\end{array}$ \\
\hline REQ_12 & No Funcional & En caso se desee cambiar el local de establecimiento del negocio se debe solicitar una nueva licencia de funcionamiento. \\
\hline REQ_13 & Funcional & Los usuarios deben ingresar al sistema con usuario y contraseña. \\
\hline REQ_14 & Funcional & Se deben asignar los permisos correspondientes al rol de cada usuario. \\
\hline REQ_15 & No Funcional & La actualización de los datos modificados en la base de datos debe ser en menos de 3 segundos. \\
\hline REQ_16 & No Funcional & Los permisos de acceso al sistema correspondiente a cada rol solo podrán ser cambiados por el administrador de acceso a datos. \\
\hline
\end{tabular}

Fuente : Elaboración Propia

\section{Anexo 15: Roles}


Figure 65: Roles

\begin{tabular}{|l|l|l|l|}
\hline \multicolumn{2}{|c|}{ Área } & \multicolumn{2}{c}{ Nombre del Rol } \\
\hline \multicolumn{1}{|c|}{ ID } & \multicolumn{1}{|c|}{ Nombre de Usuario } \\
\hline RESP_PYP_01 & $\begin{array}{l}\text { Gerencia de Desarrollo Urbano } \\
\text { Subgerencia de Desarrollo }\end{array}$ & Asesor CAS & Rosa María Ita Martínez \\
\hline RESP_PYP_02 & $\begin{array}{l}\text { Gerencia de Desarrollo Urbano } \\
\text { Subgerencia de Desarrollo }\end{array}$ & Subgerente & Milagros Pamela Arteaga Delgado \\
\hline RESP_PYP_03 & $\begin{array}{l}\text { Gerencia de Desarrollo Urbano } \\
\text { Subgerencia de Desarrollo } \\
\text { Económico }\end{array}$ & Auxiliar & Eva Rocío Cubillas Quispe \\
\hline RESP_PYP_04 & Gerencia de Asesoría Jurídica & Asesor Legal & Edwin Jim Valdivia Devoto \\
\hline RESP_PYP_05 & Equipo de Proyecto & Analista Funcional & Allison García Girón \\
\hline RESP_PYP_06 & Equipo de Proyecto & Especialista en Infraestructura & Alejandro Delgado Ledesma \\
\hline RESP_PYP_07 & Equipo de Proyecto & Desarrollador & Daniel Dueñas Zamorano \\
\hline RESP_PYP_08 & Equipo de Proyecto & Administrador de Base de Datos & Raphael Hinostroza Lozada \\
\hline RESP_PYP_09 & Equipo de Proyecto & Jefe de Proyecto & Edgar Díaz \\
\hline
\end{tabular}

Fuente : Elaboración Propia

\section{Anexo 16: Roles - Responsabilidades (1)}


Figure 66: Roles - Responsabilidades (1)

\begin{tabular}{|c|c|c|c|}
\hline \multicolumn{4}{|r|}{ Responsabilidades } \\
\hline ID & Área & Nombre del Rol & Responsabilidad \\
\hline RESP_PYP_01 & $\begin{array}{l}\text { Gerencia de Desarrollo Utbano } \\
\text { Subgerencia de Desarrollo } \\
\text { Económico }\end{array}$ & Asesor CAS & $\begin{array}{l}\text { - Orientar y dirigir las políticas de la gerencia de acuerdo a las Directivas de los órganos de gobierno y la Gerencia Municipal. } \\
\text { - Informar al administrado el desarrollo de las actividades espećícicas de suresponsabilidad. } \\
\text { - Programar, ejecutar y yevaluar actividades conducentes a incentivar la práctica de manifestaciones de carácter comercial. } \\
\text { - Erindar asesoramiento técnico a las unides orgánicas correspondientes en asuntos referidos ala problemática de desarrollo económico. }\end{array}$ \\
\hline RESP_PYP_02 & $\begin{array}{l}\text { Gerencia de Desarrollo Urbano } \\
\text { Subgerencia de Desarrollo } \\
\text { Económico }\end{array}$ & Subgerente & 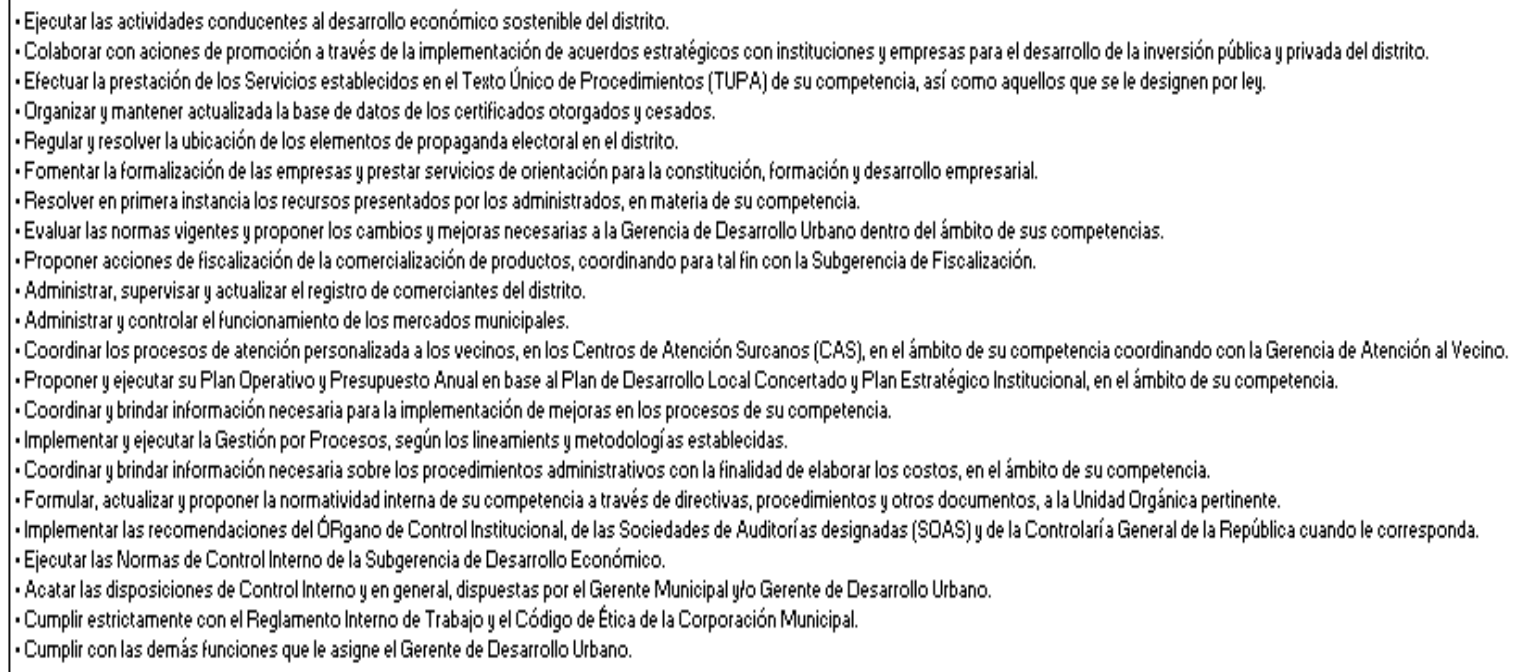 \\
\hline RESP_PYP_03 & $\begin{array}{l}\text { Gerencia de Desarrollo Urbano } \\
\text { Subgerencia de Desarrollo } \\
\text { Económico }\end{array}$ & Ausiliar & 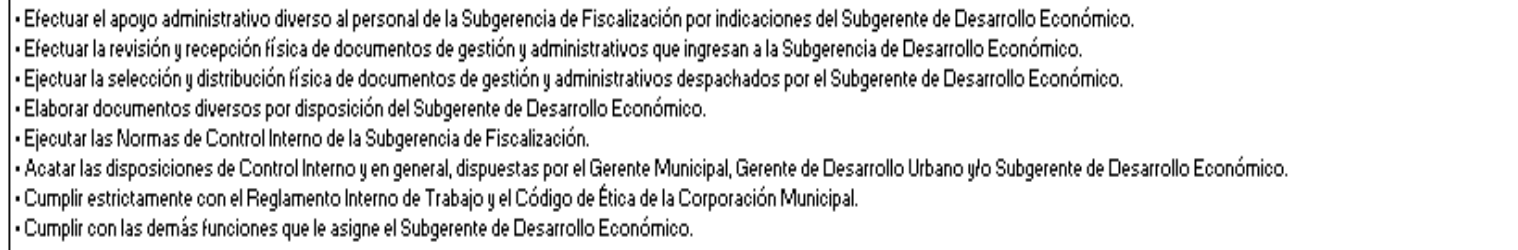 \\
\hline
\end{tabular}

Fuente : Elaboración Propia

\section{Anexo 17: Roles - Responsabilidades (2)}


Figure 67: Roles - Responsabilidades (2)

\begin{tabular}{|c|c|c|c|}
\hline RESP_PYP_04 & Gerencia de Desarrollo Urbano & Asescrlegal & 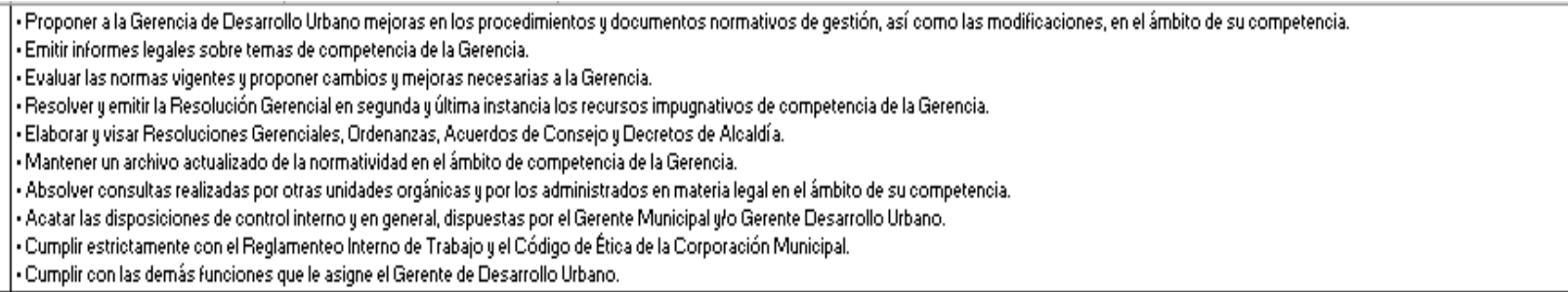 \\
\hline RESP_PYP_ 05 & Equipo de Proyecto & Anabista Funcicnal & $\begin{array}{l}\text { - Comprender yestablecer de manera formal las necesidades del proceso ydel ciudadano. } \\
\text { - Anali zar y documentar procesos integrales, requerimientos técnicos, requerimientos de negocio, etc. } \\
\text { - Establecer un orden de prioridades a las necesidades establecidas y confirmar que las especilicaciones reflejan realmente dichas necesidades. } \\
\text { - Realizar de informes yreportes. } \\
\text { - Entrevistar ausuarios y proveedores. } \\
\text { - Detectar cuáles pueden ser los riesgos potenciales y determinar cuáles serán las acciones preventivas. } \\
\end{array}$ \\
\hline RESP_PYP_ 06 & Equipo de Proyecto & Especialista en minfraestructura & 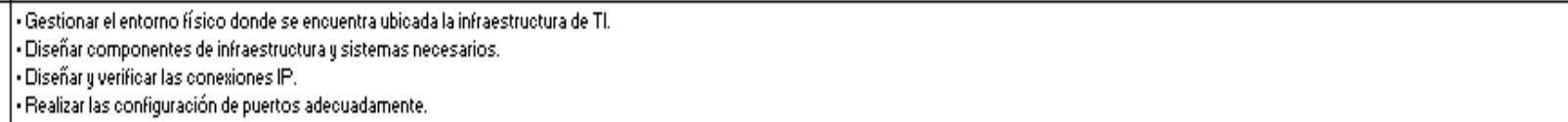 \\
\hline RESP_PYP_ 07 & Equipo de Proyecto & Desamollador & 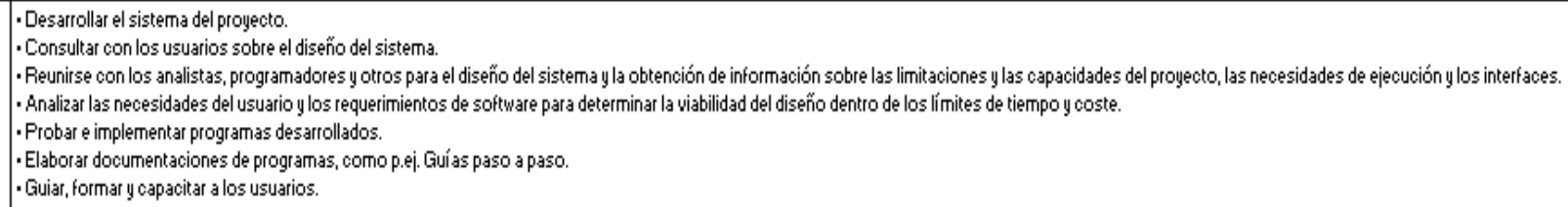 \\
\hline RESP_PYP_ 08 & Equipo de Proyecto & Administrador de Base de Datos & 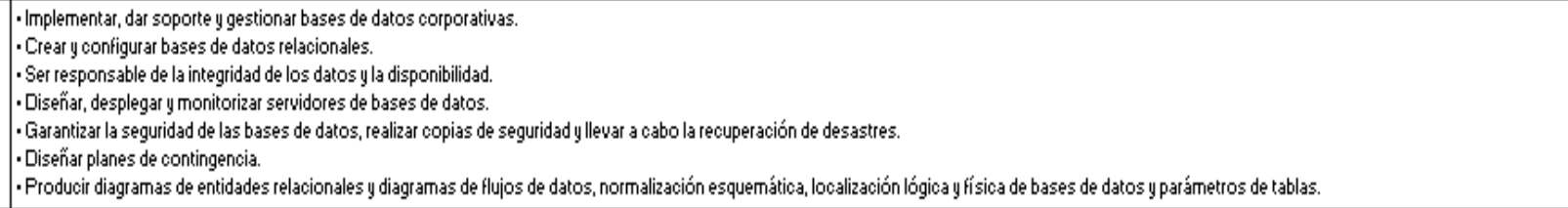 \\
\hline RESP_PYP_ 09 & Equipo de Proyecto & Wefe de Proyecto & 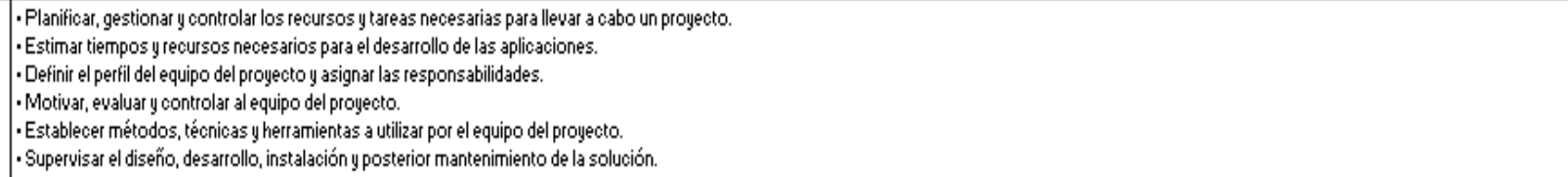 \\
\hline
\end{tabular}

Fuente : Elaboración Propia 


\section{Anexo 18: Cuestionario de Evaluación para TI}

Evaluación del Modelo de Mejora de eServicios Municipales

Nombre:

Municipalidad:

Cargo:

Cuestionario:

Ingrese los números de los documentos en la casilla que considere conveniente.

1. ¿Consideras que el documento ayudaría a su municipalidad a implementar correctamente el Gobierno Electrónico Municipal?

\begin{tabular}{|c|l|l|l|l|l|l|l|l|l|}
\hline $\mathrm{P} / \mathrm{A}$ & 1 & 2 & 3 & 4 & 5 & 6 & 7 & 8 & 9 \\
\hline 5 & & & & & & & & & \\
\hline 4 & & & & & & & & & \\
\hline 3 & & & & & & & & & \\
\hline 2 & & & & & & & & & \\
\hline 1 & & & & & & & & & \\
\hline
\end{tabular}

Comentarios

2. ¿Considera que sería difícil para la municipalidad ingresar la información que solicita el documento?

\begin{tabular}{|c|l|l|l|l|l|l|l|l|l|}
\hline $\mathrm{P} / \mathrm{A}$ & 1 & 2 & 3 & 4 & 5 & 6 & 7 & 8 & 9 \\
\hline 5 & & & & & & & & & \\
\hline 4 & & & & & & & & & \\
\hline 3 & & & & & & & & & \\
\hline 2 & & & & & & & & & \\
\hline 1 & & & & & & & & & \\
\hline
\end{tabular}

Comentarios

3. Si hubiera algún proyecto nuevo para el área ¿El documento aumentaría las posibilidades de una implementación exitosa? 


\begin{tabular}{|c|l|l|l|l|l|l|l|l|l|}
\hline P/A & 1 & 2 & 3 & 4 & 5 & 6 & 7 & 8 & 9 \\
\hline 5 & & & & & & & & & \\
\hline 4 & & & & & & & & & \\
\hline 3 & & & & & & & & & \\
\hline 2 & & & & & & & & & \\
\hline 1 & & & & & & & & & \\
\hline
\end{tabular}

Comentarios

4. Respecto al esquema propuesto. ¿Considera que incentivaría la implementación de del Gobierno Electrónico Municipal en el Perú?
5
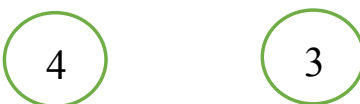
2

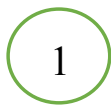

Comentarios

5. ¿Utilizaría el presente esquema en la municipalidad donde trabaja?

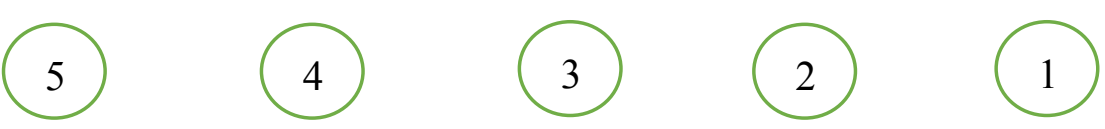

Comentarios

Firma 


\section{Anexo 19: Cuestionario de Evaluación para Funcionario}

Evaluación de la propuesta de emisión de licencias de funcionamiento web

Nombre:

Municipalidad:

Cargo:

1. ¿Considera que la propuesta presentada disminuye la carga procesal de los funcionarios?

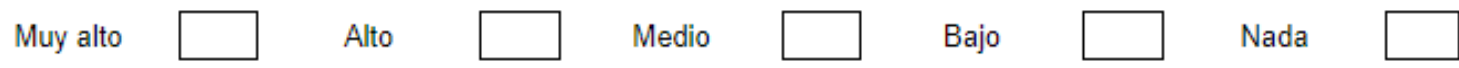

¿Por qué?

2. ¿Considera que la propuesta presentada facilitaría al ciudadano a realizar sus trámites?

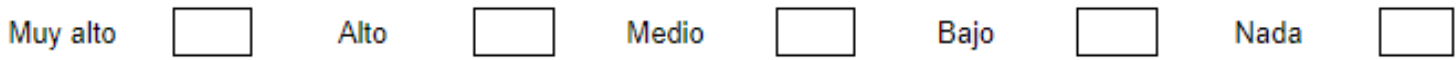

¿Por qué?

3. ¿Considera que la propuesta presentada contribuye a mejorar la relación entre el ciudadano y la municipalidad?

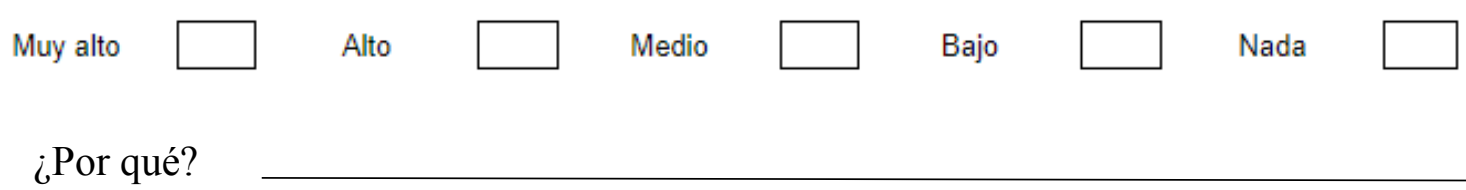

4. ¿Considera que la propuesta presentada contribuye a que los procesos de la municipalidad sean más transparentes para el ciudadano?

Muy alto $\square$ Alto $\square$ Medio $\square$ Bajo $\square$ Nada $\square$
¿Por qué?

5. En general, ¿cómo considera la propuesta?

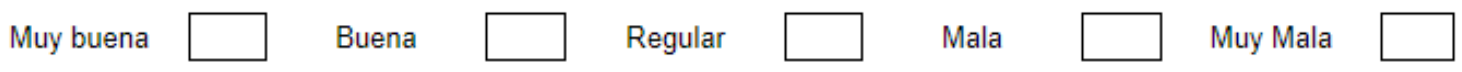


¿Por qué?

Firma 


\section{Anexo 20: Cuestionario de Evaluación para Ciudadano}

Evaluación de la propuesta de emisión de licencias de funcionamiento web

Nombre:

Local:

Dirección:

1. ¿Considera que la propuesta presentada le facilita solicitar una licencia de funcionamiento?

Muy alto $\square$ Alto $\square$ Medio $\square$ Bajo $\square$ Nada

¿Por qué?

2. ¿Considera que la municipalidad debería utilizar una solución como esta?

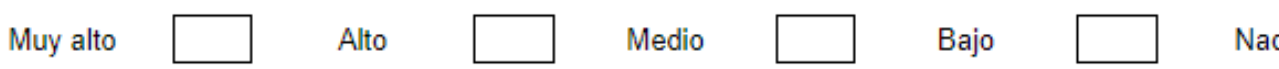

¿Por qué?

3. ¿Considera que la propuesta presentada contribuye a mejorar la relación entre el ciudadano y la municipalidad?

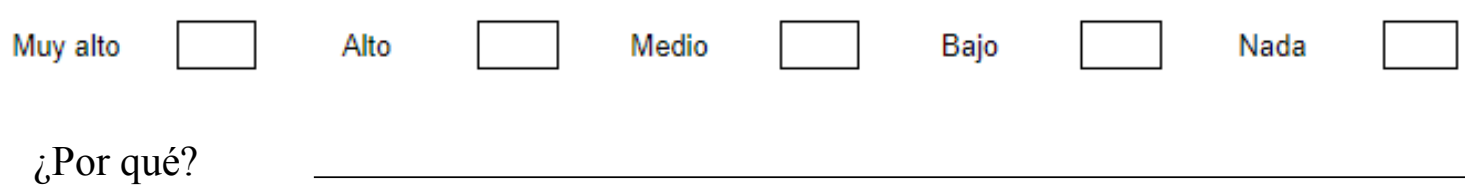

4. ¿Considera que la propuesta beneficiaría los ciudadanos?

Muy alto $\square$ Alto $\square$ Medio $\square$ Bajo $\square$ Nada $\square$
¿Por qué?

5. En general, ¿cómo considera la propuesta?

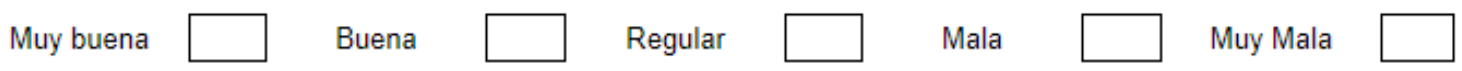


¿Por qué?

Firma 


\section{Anexo 21: Trámite Documentario}

Figure 68: Trámite Dcoumentario

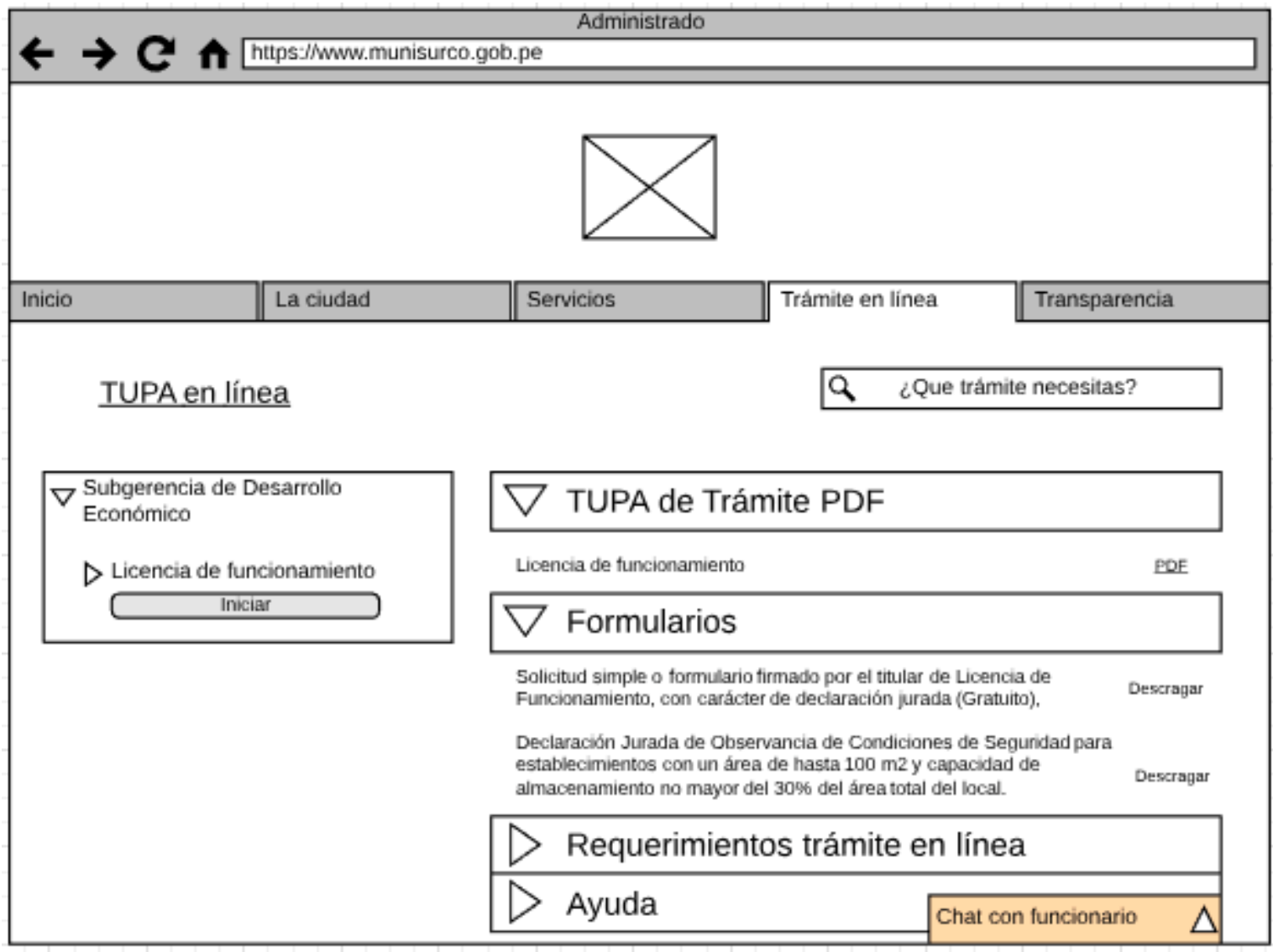

Fuente : Elaboración Propia 


\section{Anexo 22: Licencia de Funcionamiento}

Figure 69: Licencia de Funcionamiento

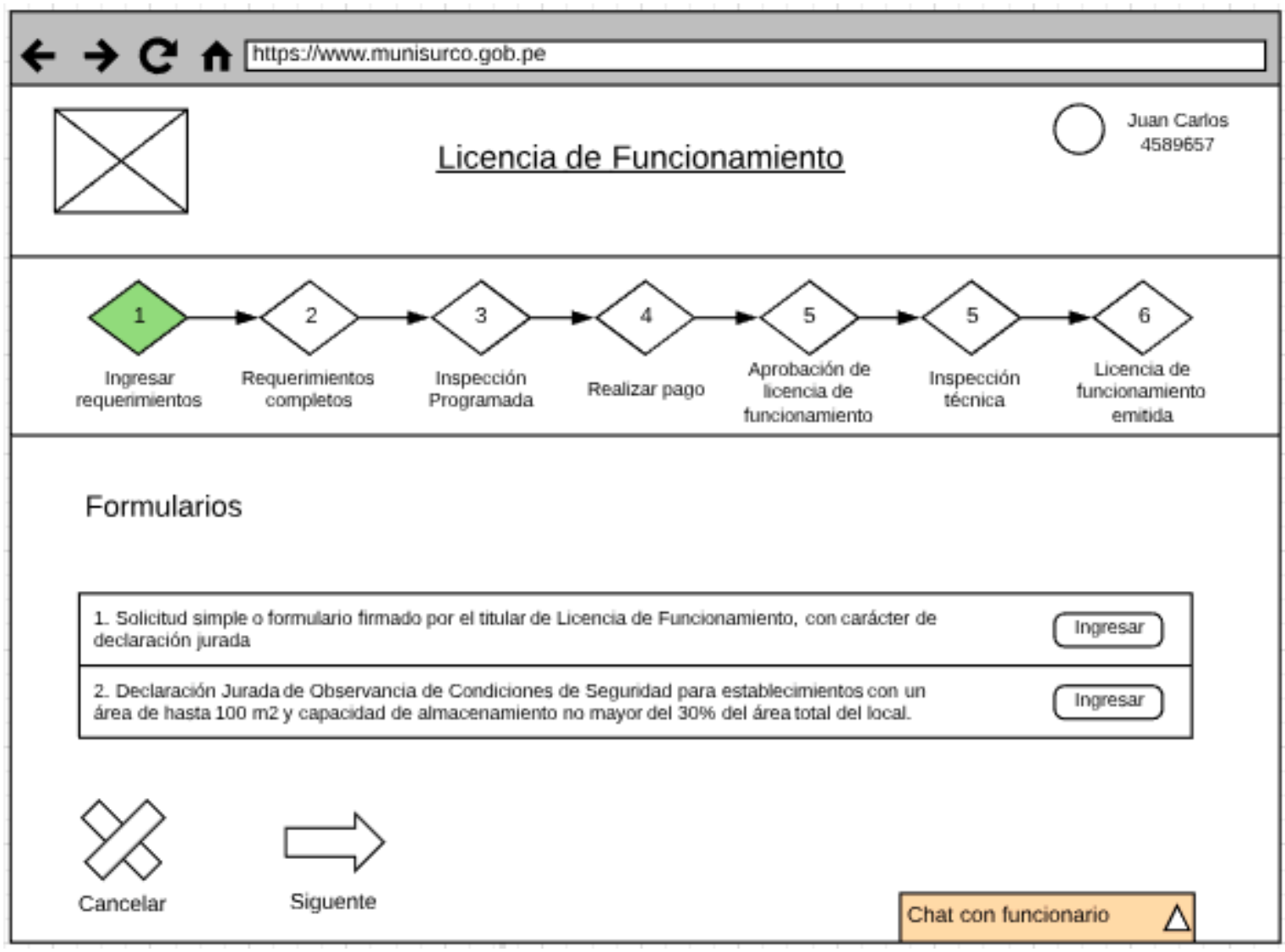

Fuente : Elaboración Propia 


\section{Anexo 22: Declaración Jurada de Observancia de Condiciones de Seguridad - Parte 1}

Figure 70: Declaración Jurada

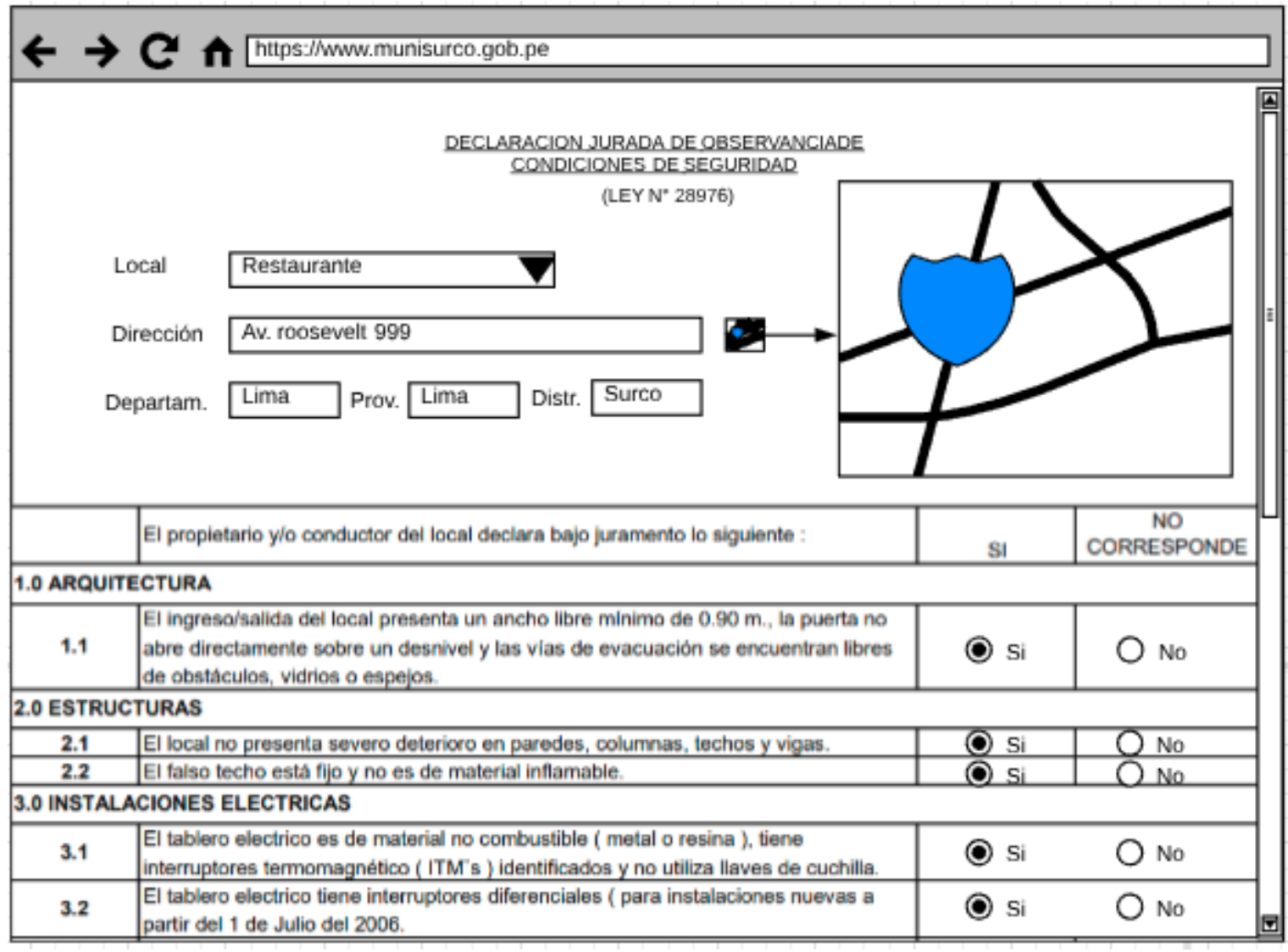

Fuente : Elaboración Propia 


\section{Anexo 23: Declaración Jurada de Observancia de Condiciones de Seguridad - Parte 2}

Figure 71: Declaración Jurada (2)

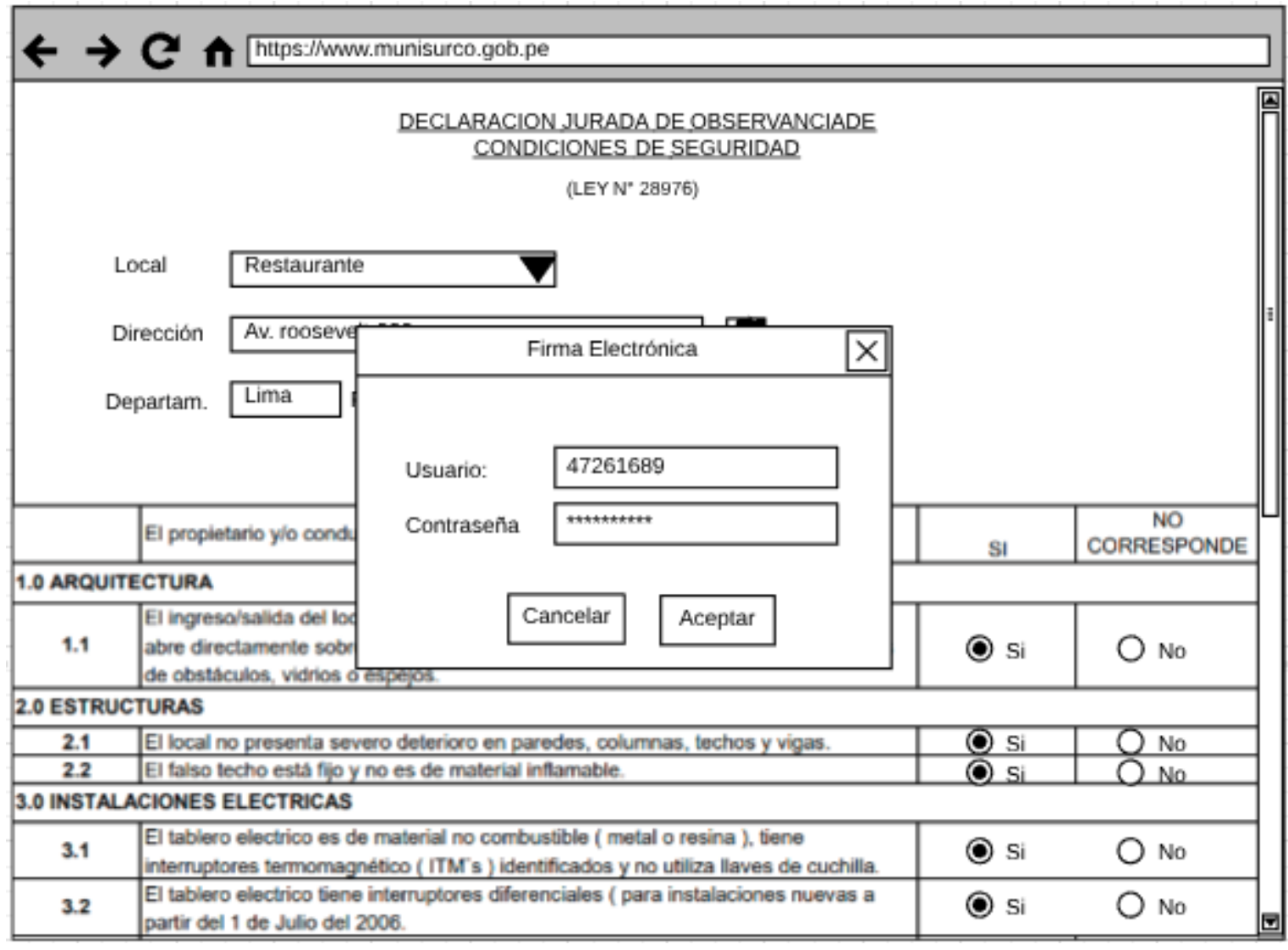

Fuente : Elaboración Propia 


\section{Anexo 23: Solicitud de Declaración Jurada para Obtener Licencia Municipal de Funcionamiento}

Figure 72: Solicitud de Declaración Jurada

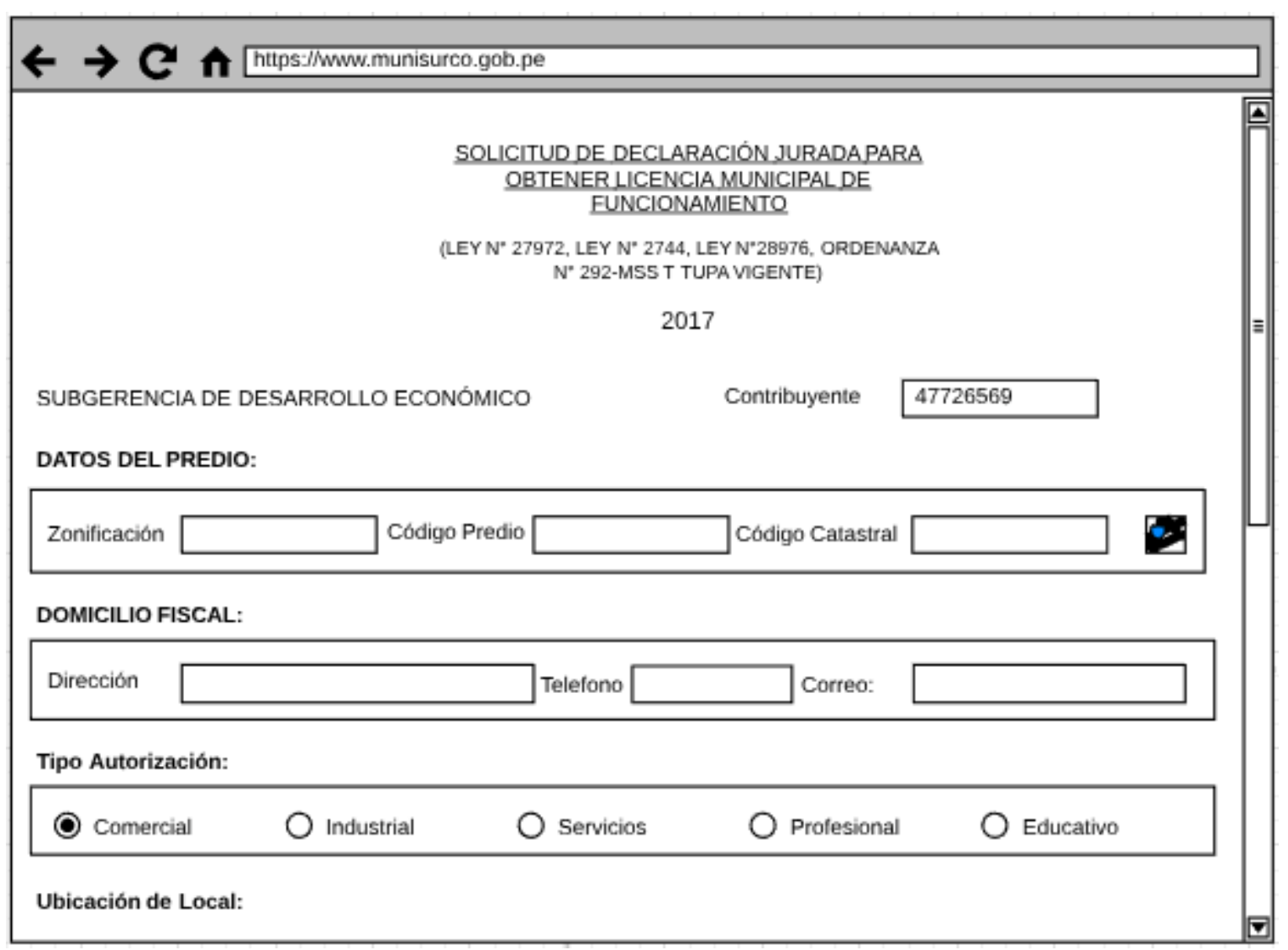

Fuente : Elaboración Propia 


\section{Anexo 23: Licencia de Funcionamiento - Parte 1}

Figure 73: Licencia de Funcionamiento

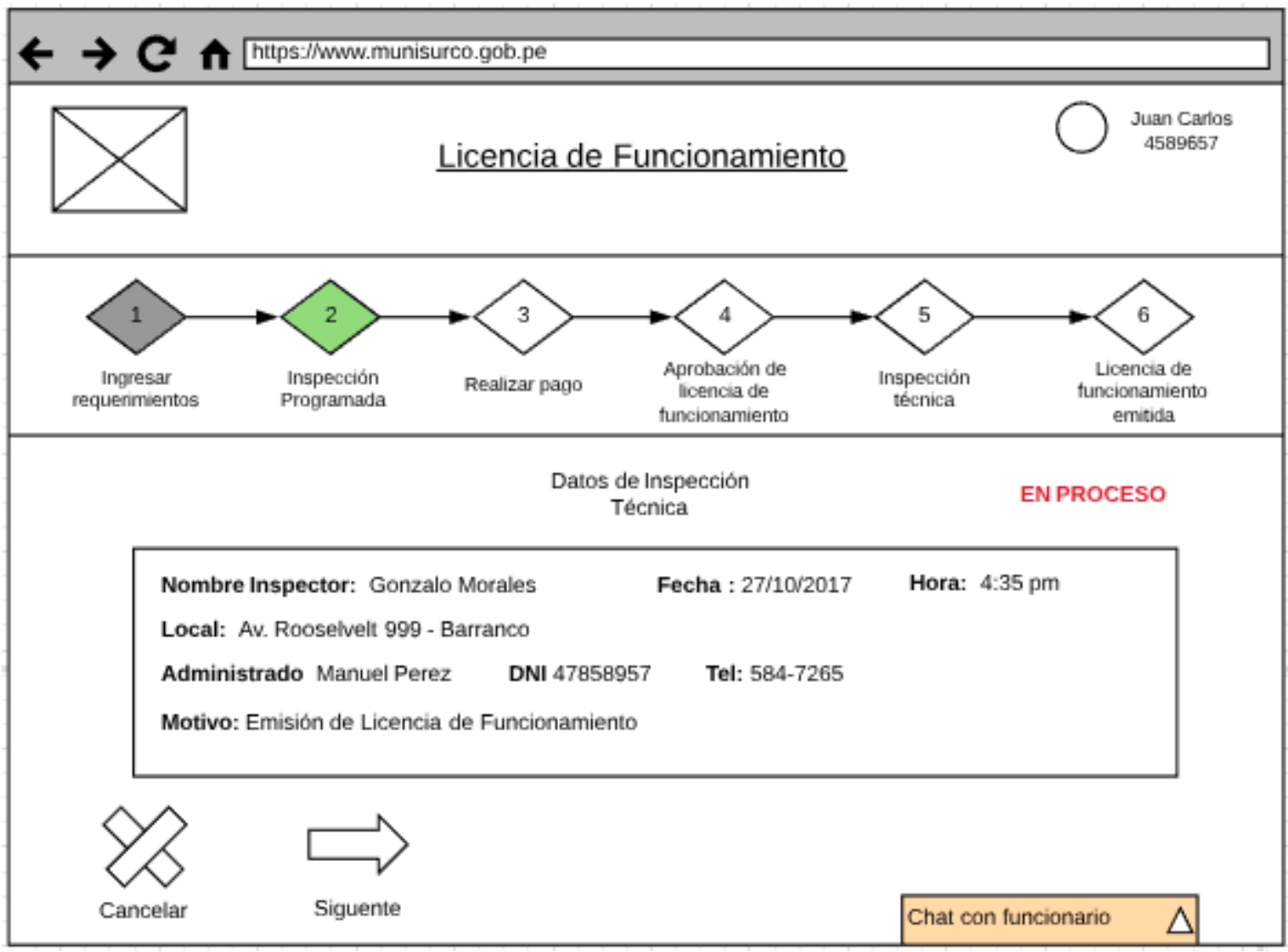

Fuente : Elaboración Propia 


\section{Anexo 24: Licencia de Funcionamiento - Parte 2}

Figure 74: Licencia de Funcionamiento (2)

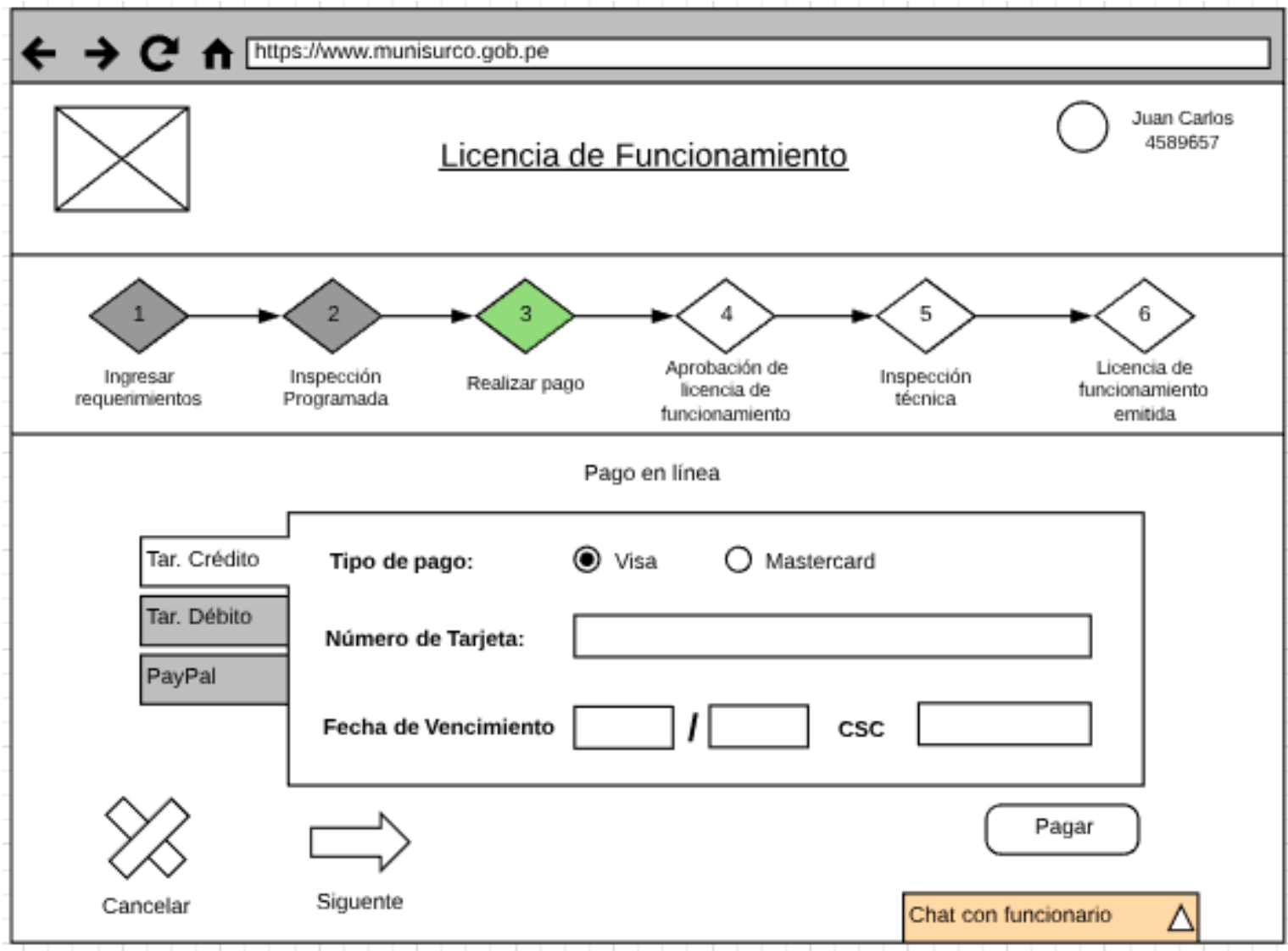

Fuente : Elaboración Propia 


\section{Anexo 24: Licencia de Funcionamiento - Parte 3}

Figure 75: Licencia de Funcionamiento (3)

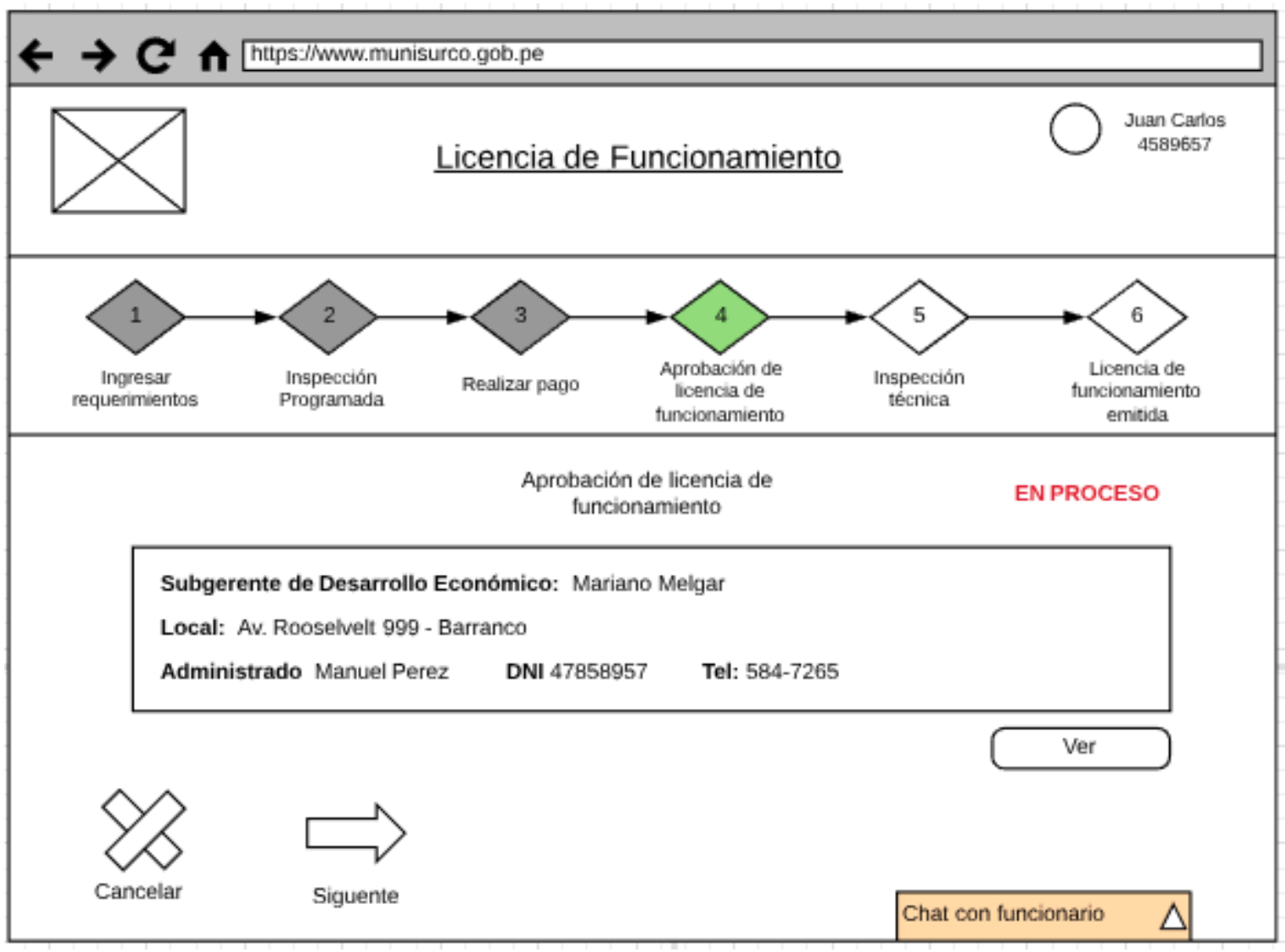

Fuente : Elaboración Propia 


\section{Anexo 24: Licencia de Funcionamiento - Parte 4}

Figure 76: Licencia de Funcionamiento (4)

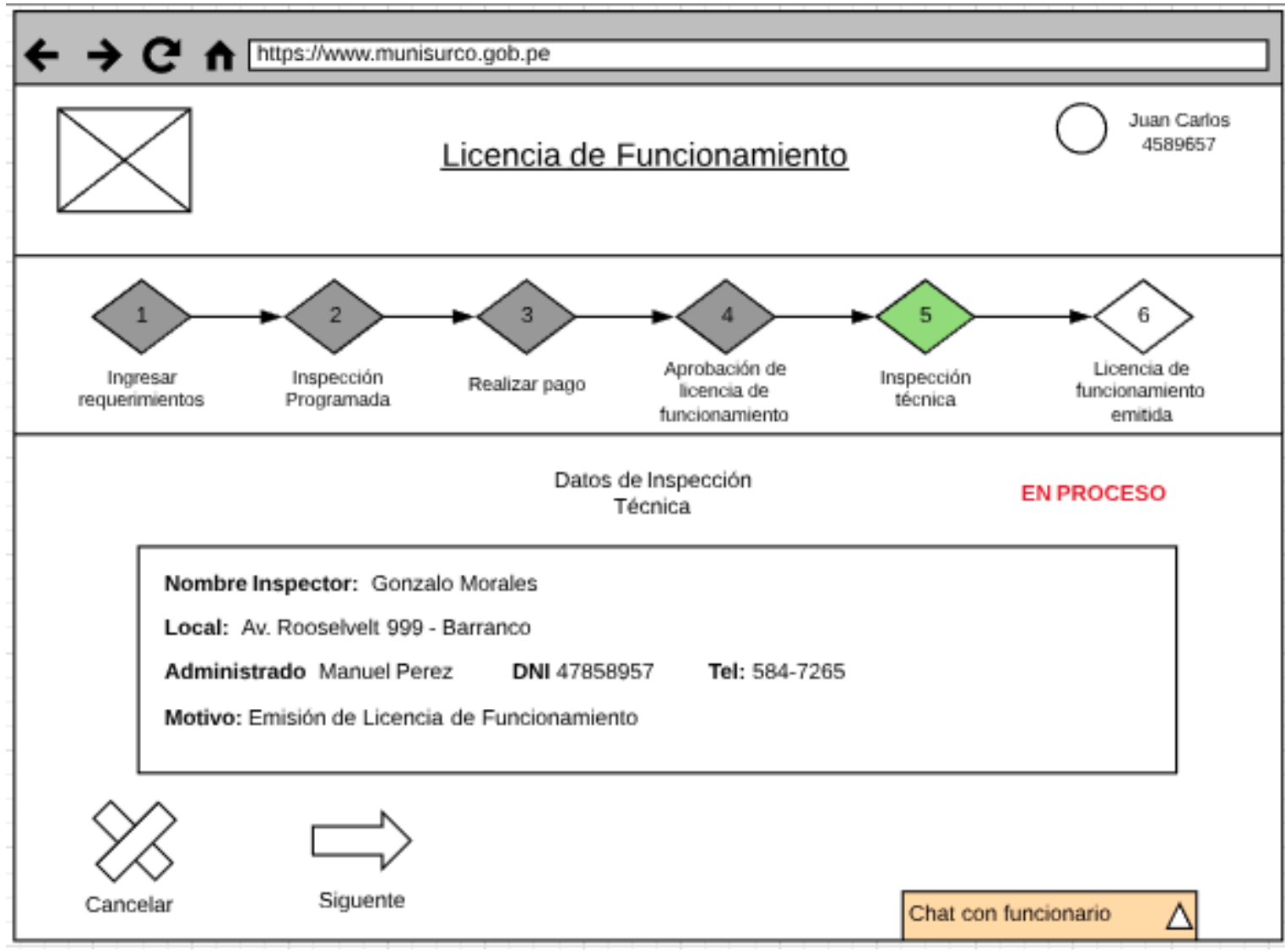

Fuente : Elaboración Propia 


\section{Anexo 24: Licencia de Funcionamiento - Parte 5}

Figure 77: Licencia de Funcionamiento (5)

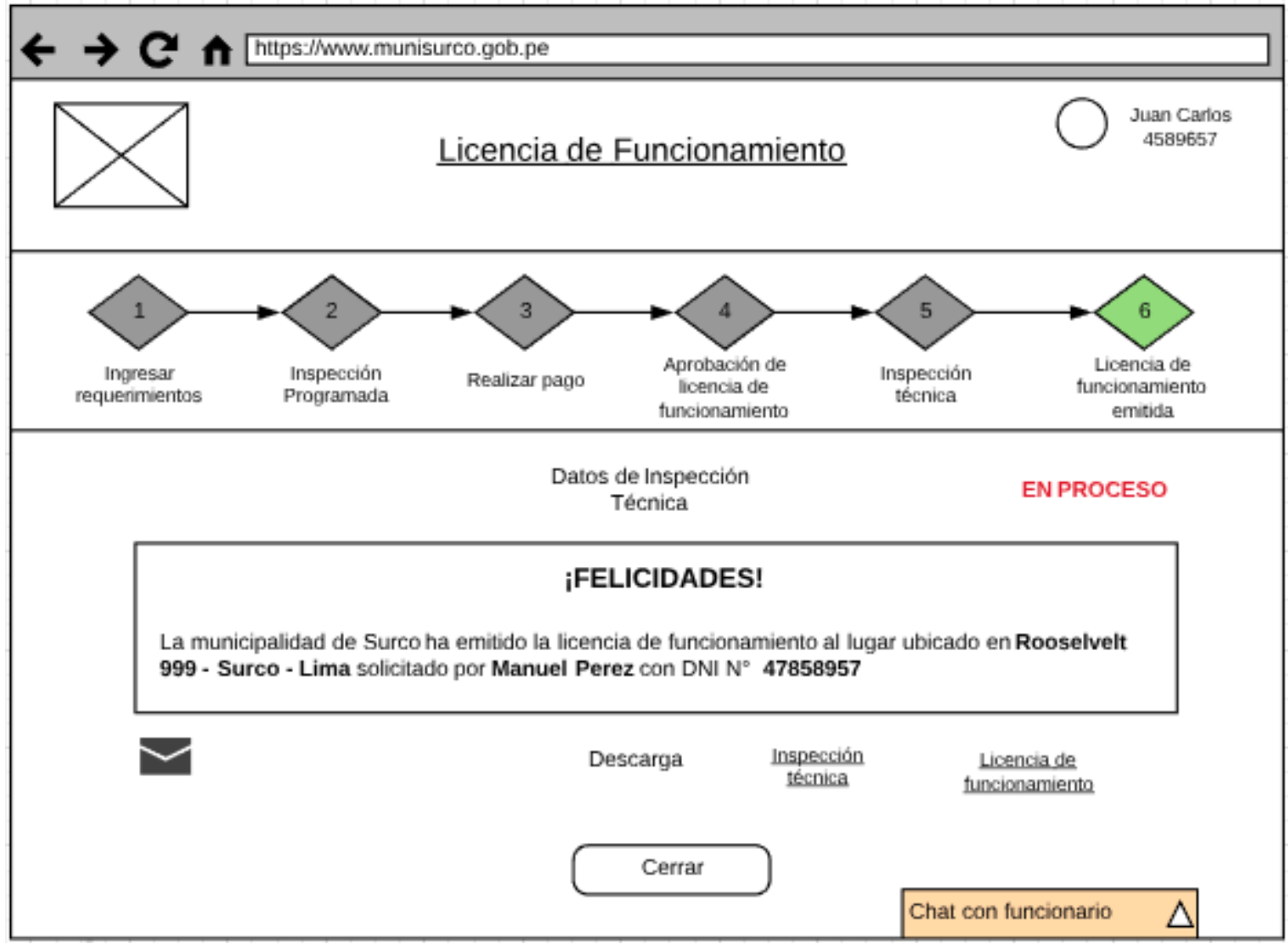

Fuente : Elaboración Propia 


\section{Anexo 24: Chat en Línea - Parte 1}

Figure 78: Chat en Línea

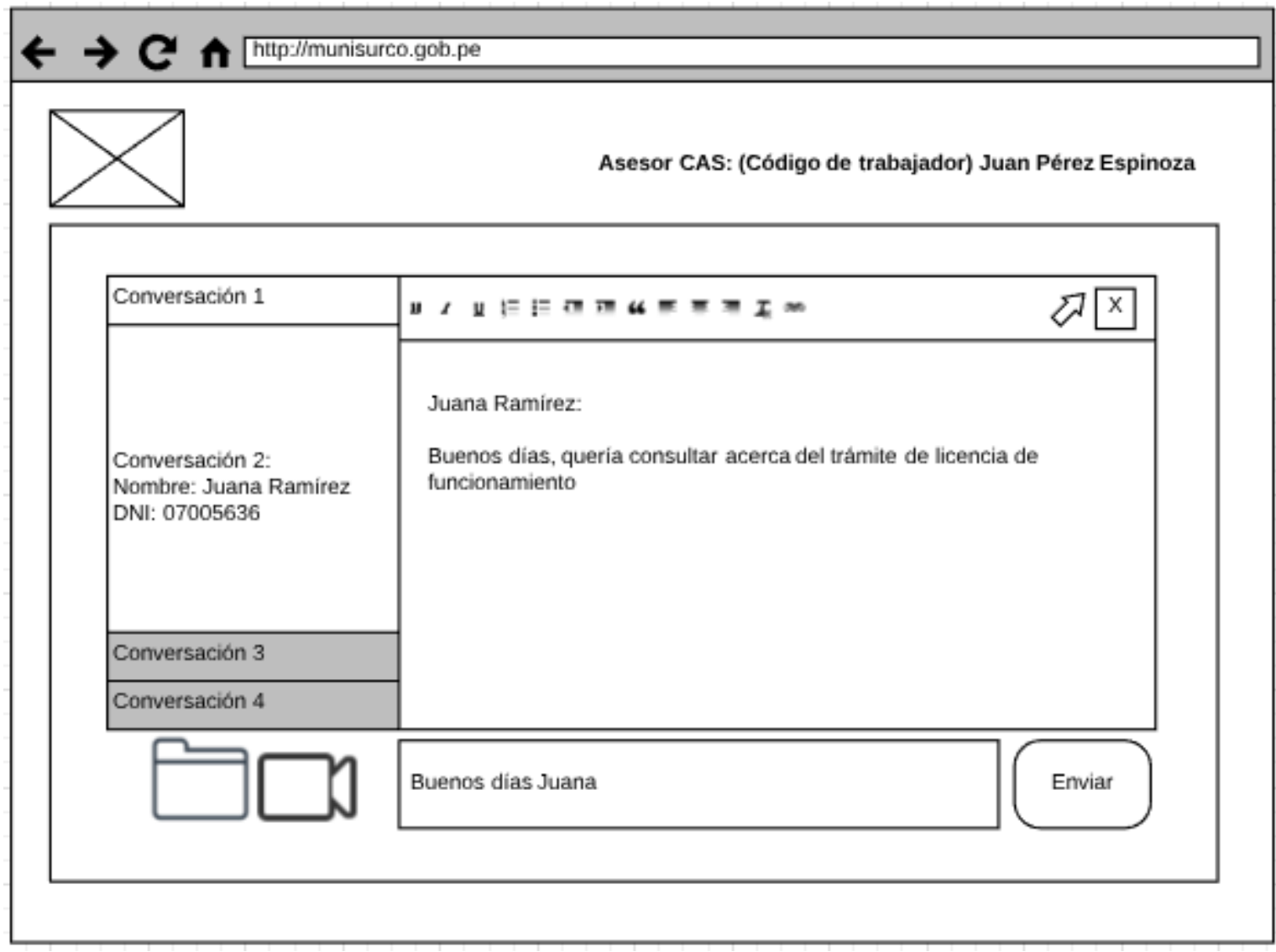

Fuente : Elaboración Propia 


\section{Anexo 24: Chat en Línea - Parte 2}

Figure 79: Chat en Línea (2)

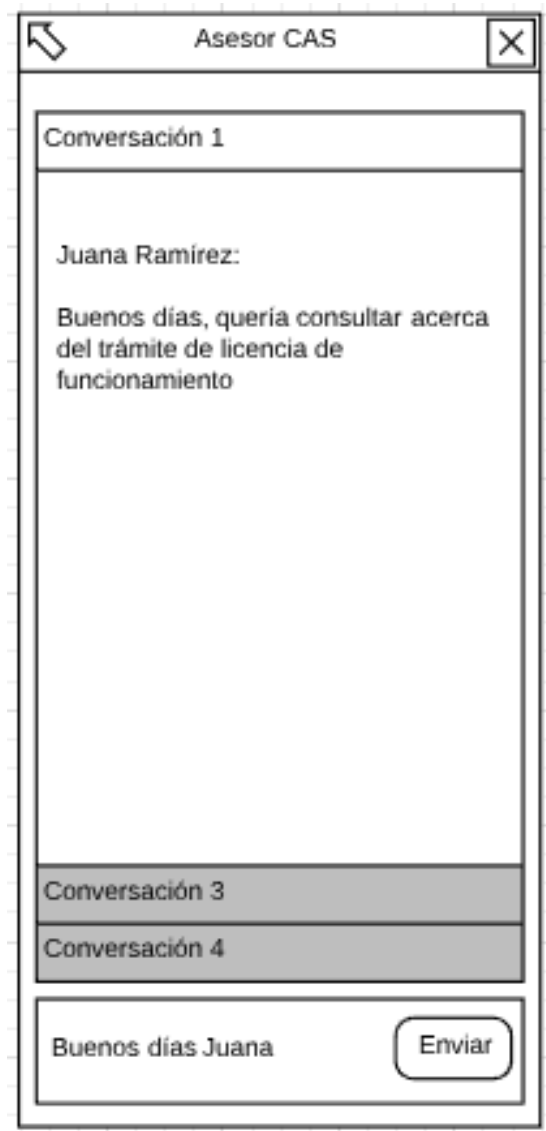

Fuente : Elaboración Propia 


\section{Anexo 24: Firma de Certificado}

Figure 80: Firma de Certificado

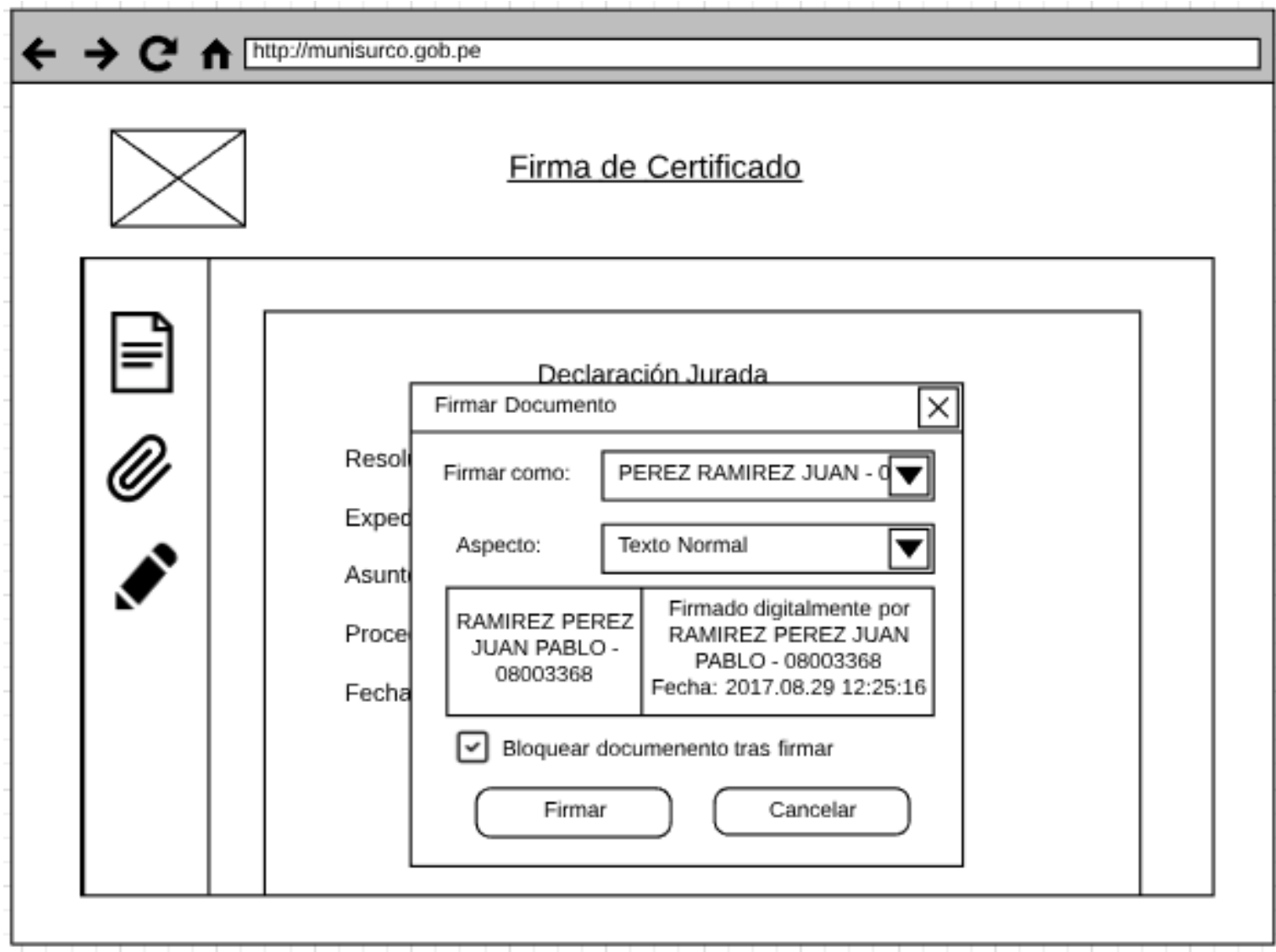

Fuente : Elaboración Propia 


\section{Anexo 24: Memorandum}

Figure 81: Memorandum

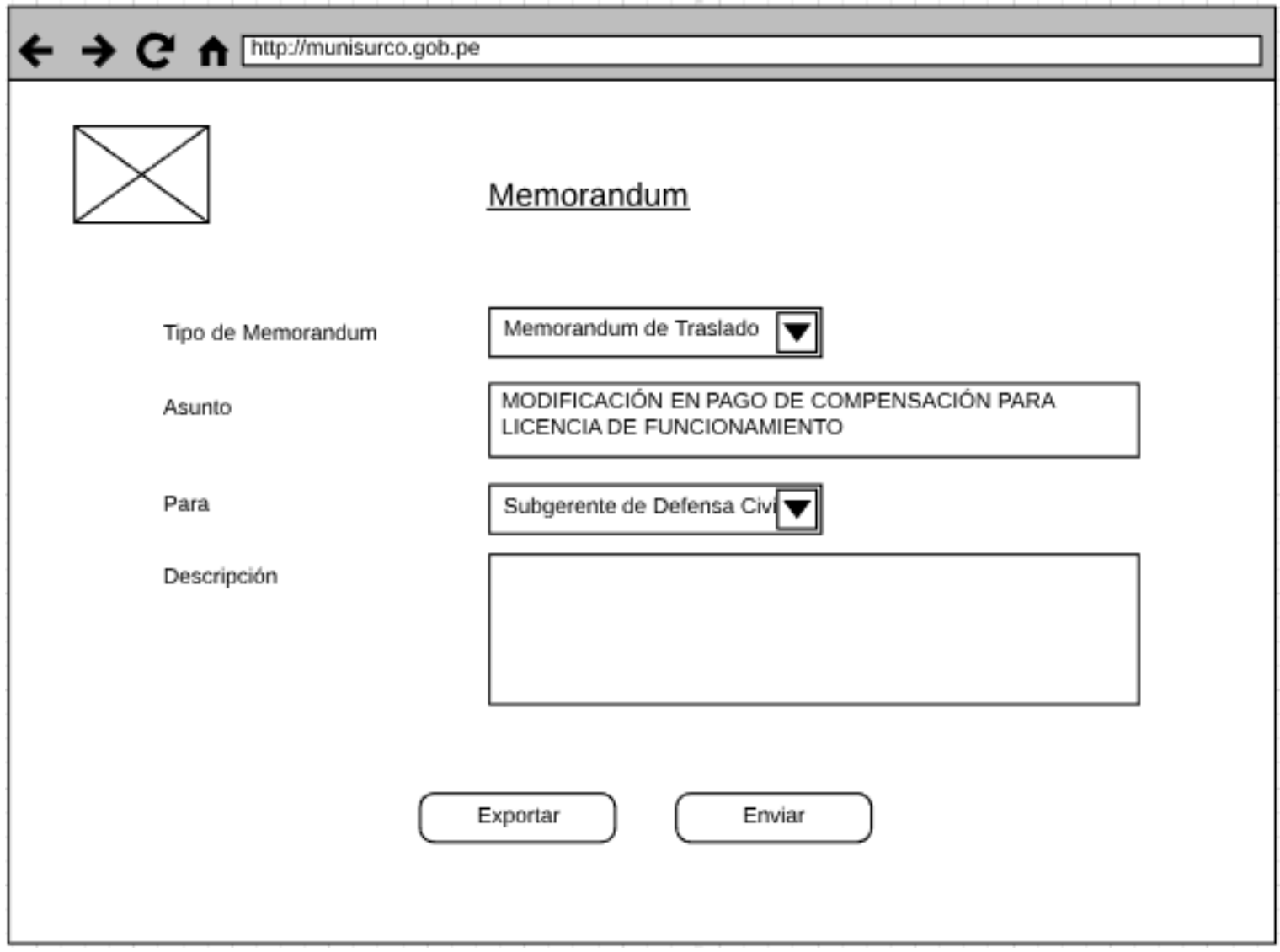

Fuente : Elaboración Propia 


\section{Anexo 24: Elaborar Documento}

Figure 82: Elaborar Documento

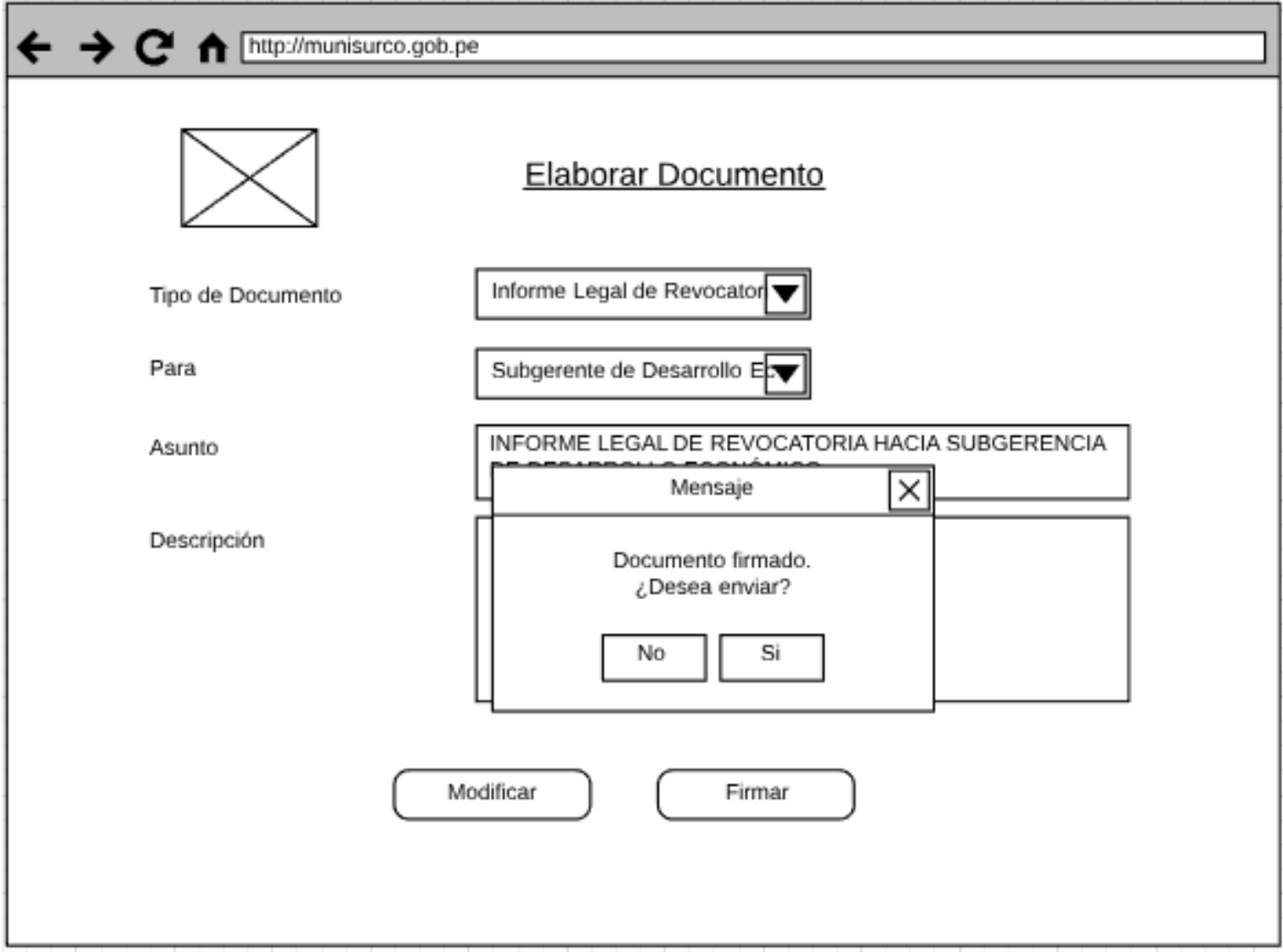

Fuente : Elaboración Propia 


\section{Referencias Bibliográficas}

En esta sección, se describirá la bibliografía usada para el desarrollo del presente documento:

Arango, M., Londoño, J. \& Zapata, J. 2010. Arquitectura Empresarial - Una Visión General. Revista Ingenierías Universidad de Medellín. Colombia.

Areej AlHogail. 2015. Diseño y validación del marco de cultura de seguridad de la información.

CIO@GOV.2016. Arquitectura Empresarial. El camino hacia un gobierno integrado.

Definición ABC. Definición de Municipalidad. 2016. Sitio Web: http://www.definicionabc.com/general/municipalidad.php

Definición de. Definición de municipalidad. 2016. Sitio Web: http://definicion.de/municipalidad/

Es.wikipedia.org. Gobierno local. 2016. Sitio Web: https://es.wikipedia.org/wiki/Gobierno_local

Enrique Bonsón, Sonia Royo, Melinda Ratkai. 2014. Participación de los ciudadanos en los sitios de Facebook de los gobiernos locales. Un análisis empírico: El impacto de los diferentes tipos de medios y contenidos en Europa Occidental.

Filipe Sá, Álvaro Rocha, Joaquim Gonçalves, Manuel Pérez Cota. 2016. Modelo para la Calidad de los Servicios en Línea del Gobierno Local.

Hai Wanga, Shouhong Wang. 2013. Mapa ontológico de la arquitectura orientada a servicios para servicios de administración compartidos.

Jie Lu, Dianshuang Wu, Mingsong Mao, Wei Wang, Guangquan Zhang. 2015. Sistema de recomendación de desarrollos de aplicaciones: una encuesta.

Josey, A., Harrison, R., Homan, P., Rouse, M., Van Sante, T.,Turner, M. \& Van der Merwe, P. 2013. TOGAF Versión 9.1 Guía de Bolsillo. Zaltbommel.

Kaja J. Fietkiewicz, Agnes Mainka, Wolfgang G. Stock. 2016. La administración electrónica en las ciudades de la sociedad del conocimiento. Una investigación empírica de los sitios web gubernamentales de Smart Cities.

Lu, J. 2001. Medición de los costos y beneficios de las aplicaciones de comercio electrónico y la satisfacción del cliente. Actas de la $2^{\mathrm{a}}$ Conferencia Internacional de la Web. 
Molano. 2015 ¿Qué es Arquitectura Empresarial? Sitio Web: https://colombiadigital.net/actualidad/articulos-informativos/item/8123-que-es-arquitecturaempresarial.html

Molano 2015. ¿Qué es Togaf? Sitio Web: https://colombiadigital.net/actualidad/articulosinformativos/item/8163-que-es-togaf.html

Opengroup.org. TOGAF®, an Open Group standard | The Open Group. 2016. Sitio Web: https://www.opengroup.org/togaf/

Petnji Yaya Luc Honore, Marimon Frederic, Casadesus Marti. 2012. Investigando Discrepancias entre E-Services: Implementación o No - Iso 9001: Perspectivas de los Clientes en el Ejemplo de los Servicios Electrónicos en Cataluña (España).

Po-Ling Sun, Cheng-Yuan Ku, Dong-Her Shih. 2013. Un marco de implementación para EGovernment 2.0

Project Management Institute, Inc. 2013. Guía de los Fundamentos para la Dirección de Proyectos (guía del PMBOK).

Slideshare. 2010. e-Gobierno (e-government). Sitio Web: http://es.slideshare.net/hugoces/egobierno-egovernment.

Unesco. Gobernabilidad Electrónica Fortalecimiento de capacidades de la gobernabilidad electrónica. Sitio Web: http://portal.unesco.org/ci/en/files/14896/11412266495egovernance.pdf/e-governance.pdf

Zhao Huang, Morad Benyoucef. 2014. Facilidad de uso y la credibilidad de los sitios web de gobierno electrónico. 